\title{
NANOINDENTATION OF ANNEALED AND AS-SPUTTERED THIN FILMS OF NICKEL TITANIUM SHAPE MEMORY ALLOYS
}

\author{
A Thesis \\ presented to \\ the Faculty of California Polytechnic State University, \\ San Luis Obispo
}

\author{
In Partial Fulfillment \\ of the Requirements for the Degree \\ Master of Science in Engineering, \\ with Specialization in Materials Engineering \\ by \\ Matthew Tyson Lewis \\ October 2010
}


(C) 2010

Matthew Tyson Lewis

ALL RIGHTS RESERVED 


\section{COMMITTEE MEMBERSHIP}

TITLE:

Nanoindentation of Annealed and As-Sputtered Thin Films of Nickel Titanium Shape Memory Alloys
AUTHOR:
Matthew Tyson Lewis

DATE SUBMITTED: October 2010

COMMITTEE CHAIR: Dr. Richard N. Savage

Professor of Materials Engineering

California Polytechnic State University, San Luis Obispo

COMMITTEE MEMBER: Dr. William L. Hughes Assistant Professor of Materials Science \& Engineering Boise State University, Boise, ID

COMMITTEE MEMBER: Dr. Trevor S. Harding

Professor and Chair of Materials Engineering California Polytechnic State University, San Luis Obispo 


\begin{abstract}
Nanoindentation of Annealed and As-Sputtered Thin Films of Nickel Titanium Shape Memory Alloys

Matthew Tyson Lewis
\end{abstract}

The bottom-up processing techniques used for making Microelectromechanical systems (MEMS) devices can produce material properties different from bulk processing. The material properties must be evaluated with the process parameters used and for changes in the process parameters. The mechanical properties are needed to design MEMS devices. A material of interest for MEMS devices is nickel titanium (NiTi) shape memory alloy (SMA) because of the high work output $\left(\sim 10^{7} \mathrm{~J} / \mathrm{m}^{3}\right)$. This thesis will focus on the fabrication of thin film NiTi by DC magnetron sputtering deposition and testing mechanical properties of the fabricated films by nanoindentation. Thin film NiTi SMA was successfully created by DC magnetron sputtering deposition and high vacuum annealing in the Microfabrication Laboratory at California Polytechnic State University San Luis Obispo. Characterization of the thin film by nanoindentation produced an elastic modulus of the thin film NiTi SMA with the developed processing parameters was 67.9 $\mathrm{GPa}$ with a hardness of $2.1 \mathrm{GPa}$. The measured thin film NiTi elastic modulus was greater than bulk NiTi of $40 \mathrm{GPa}$ because of the residual stress from the deposition process. The shape memory effect was evaluated at the nanometer scale by measuring the nanoindents before and after thermally inducing a phase transformation. A maximum indentation depth recovery of 58\% was measured upon the heat induced martensitic phase transformation. The low recovery was attributed to the high strain of $8 \%$ induced by the Berkovich tip. The effects of deposition power on the NiTi as-sputtered film stress, elastic modulus, hardness, and electrical conductivity were evaluated. At the highest 
sputtering deposition power of 450 Watts, an elastic modulus of $186 \mathrm{GPa}$ with a hardness of $8.3 \mathrm{GPa}$ was measured by nanoindentation. An increase in deposition power increased the residual film compressive stress, elastic modulus, and hardness while the electrical resistivity increased. The mechanisms for the measured properties are discussed in this thesis.

Keywords: NiTi, nanoindentation, sputtering deposition, elastic modulus, hardness 


\section{ACKNOWLEDGEMENTS}

I would first like to thank my parents and family for all their unwavering support and encouragement during this process. Their encouragement and support have been more than I could have ever hoped.

My advisors Dr. Savage and Dr. Hughes for their support and advice during this process. They have become my mentors and friends.

To Asylum Research and specifically Alejandro Bonilla without their support this research would have not been possible.

Micro Systems and Technology and the former Hughes research group including but not limited to Drew Felker, Dylan Chesbro, Nic Vickers, Matt Little, Matt Goebel, Aaron Guerrero, Greg Boban, Brian Stahl, and Sean Kaylor. Thank you for helping the research of my project, my personal growth, and/or spent long hours in the lab with me.

The California Polytechnic State University Materials Engineering department for providing the facilities to complete my research. 


\section{TABLE CONTENTS}

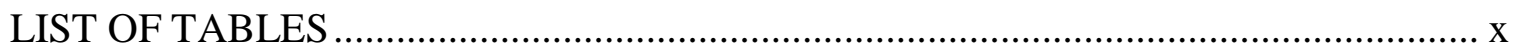

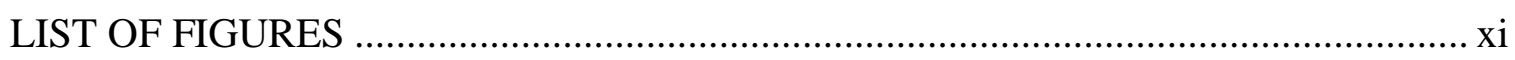

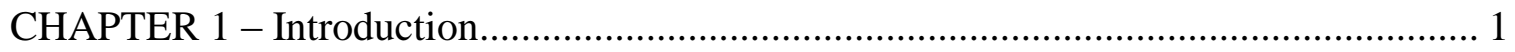

CHAPTER 2 - Background and Literature Review ……………………...................... 5

2.1 Nickel Titanium Shape Memory Alloy ……………................................................ 5

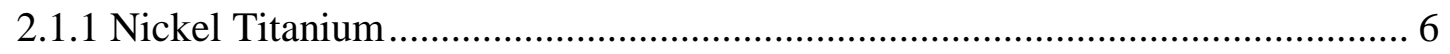

2.1.2 NiTi Transformation Temperature ……………………………………...... 10

2.1.2.1 Impurities Affect on Transitions Temperature ………………………..... 12

2.2 Instrumented Indentation Testing-Nanoindentation................................................ 12

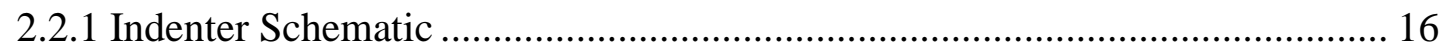

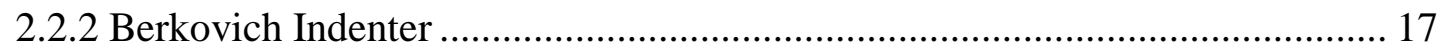

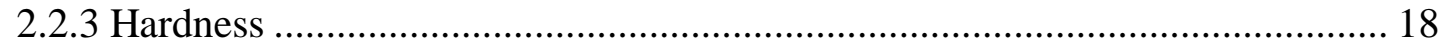

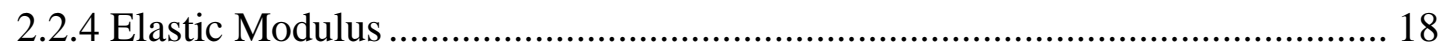

2.2.5 Factors Affecting Nanoindentation Data ....................................................... 19

2.2.5.1 Indentation Material Response ……………....................................... 21

2.2.6 Other Uses of Nanoindenting ................................................................... 24

2.3 Sputtering - Physical Vapor Deposition............................................................. 24

2.3.1 Physical Sputtering Deposition Process ............................................................ 24

2.3.2 Processing Parameters that Affect Material Properties .................................... 27

2.3.2.1 Applied Gun Power........................................................................... 28

2.3.2.2 Chamber Pressure ……………………………................................. 28

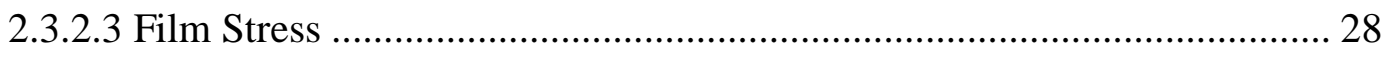

2.3.3 Sputtering Deposition Applications............................................................ 29

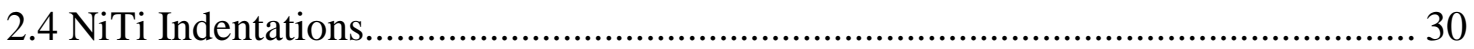

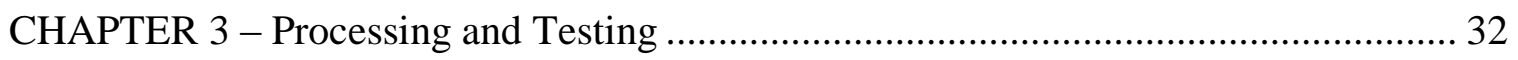

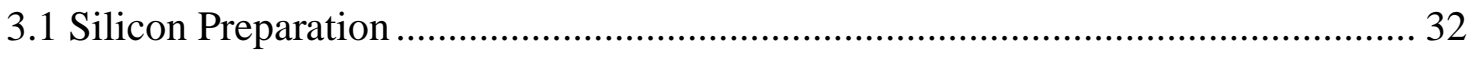

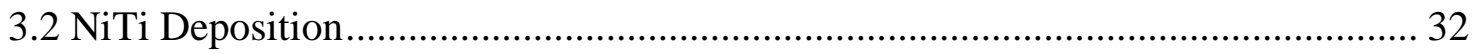

3.2.1 Silicon Dioxide Growth ............................................................................ 32

3.2.2 Film Stress by Radius of Curvature................................................................ 33

3.2.3 Bottom Chrome Adhesion Layer Deposition .................................................... 36 
3.2.4 Nickel Titanium Deposition ....................................................................... 37

3.2.5 Top Chrome Oxidation Protection Layer Deposition........................................ 38

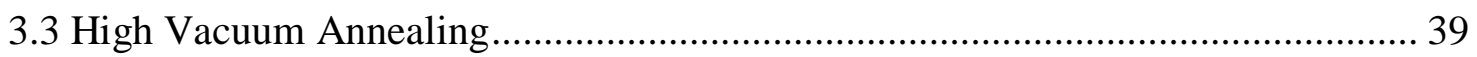

3.4 Etch Top Chromium Layer .............................................................................. 40

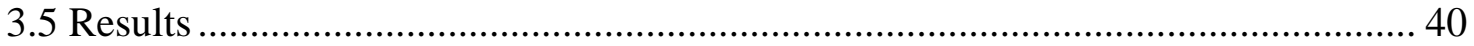

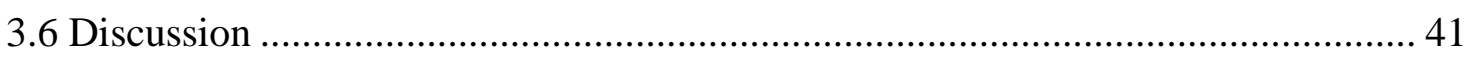

Chapter 4- Process Evaluation: Shape Memory Properties ............................................... 43

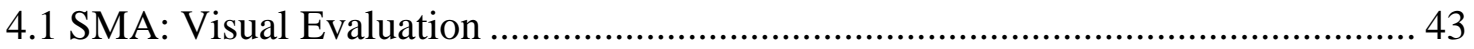

4.2 SMA: Differential Scanning Calorimeter ............................................................. 43

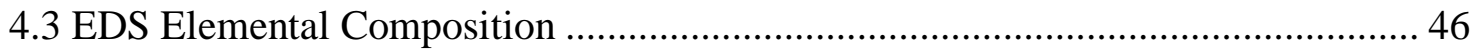

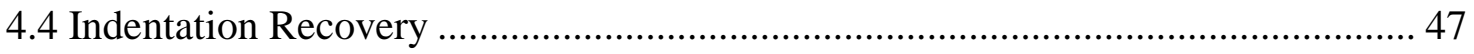

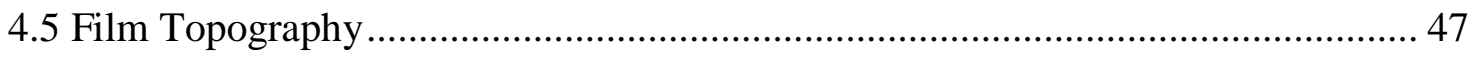

4.5.1 NiTi Film Roughness............................................................................... 50

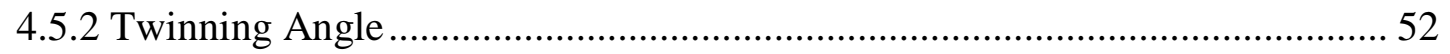

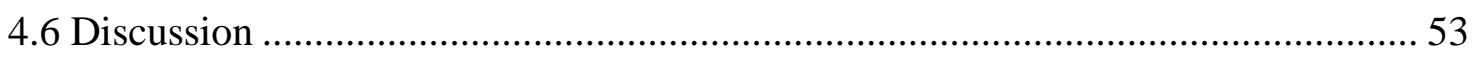

CHAPTER 5 -Thin Film Annealed NiTi Indents......................................................... 54

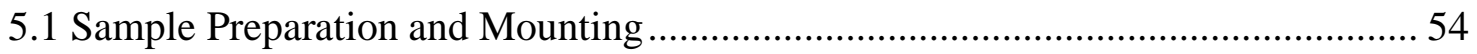

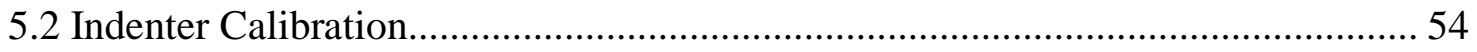

5.3 Indenter Setup ……................................................................................... 57

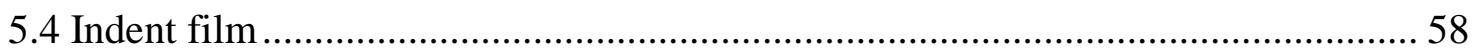

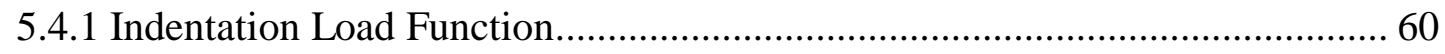

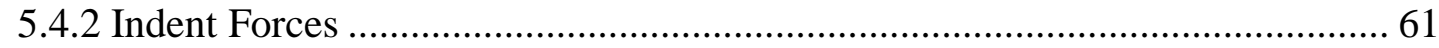

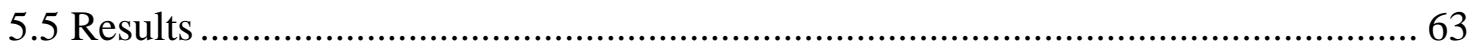

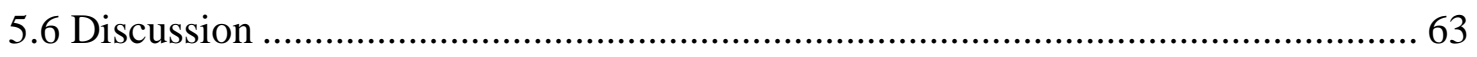

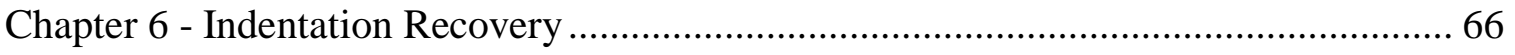

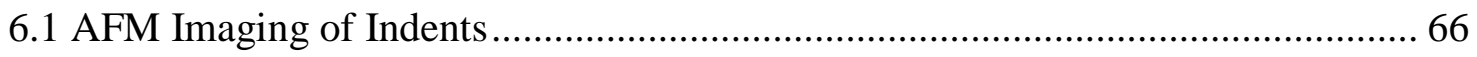

6.1.1 Post Phase Transformation AFM Imaging ………………………………........ 69

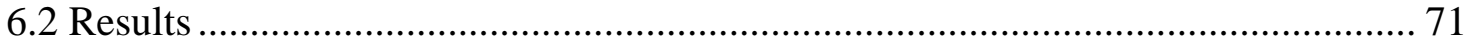

6.2.1 Results: Statistical Analysis of Indentation Recovery..................................... 72

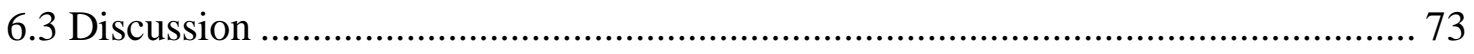

Chapter 7 - As-Sputtered NiTi Properties...................................................................... 77 


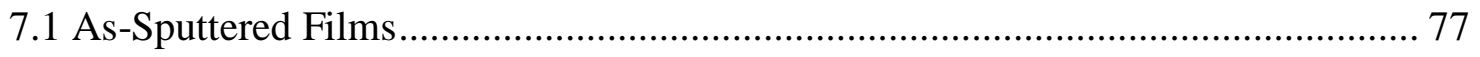

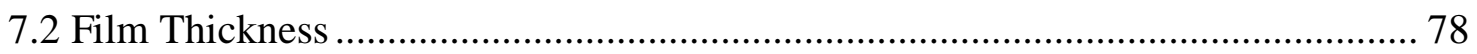

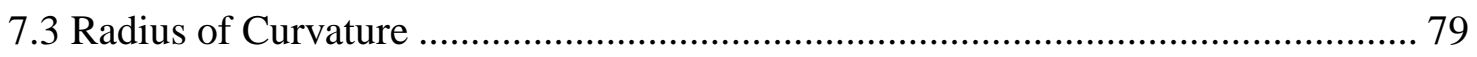

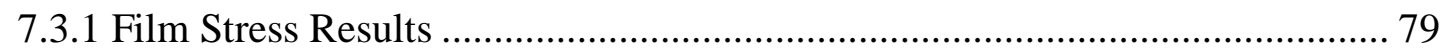

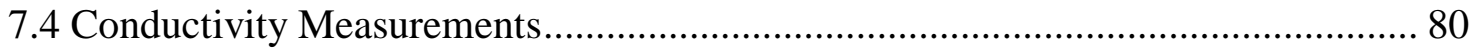

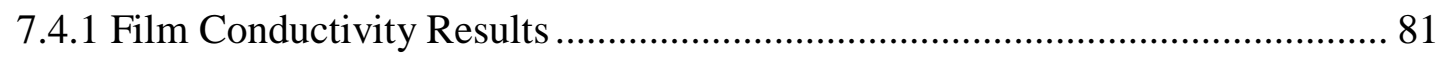

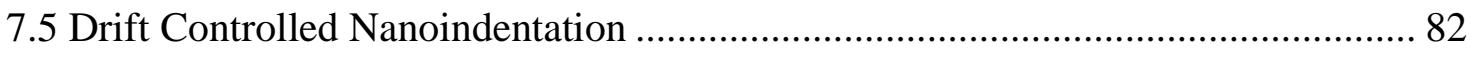

7.5.1 Elastic Modulus and Hardness ..................................................................... 83

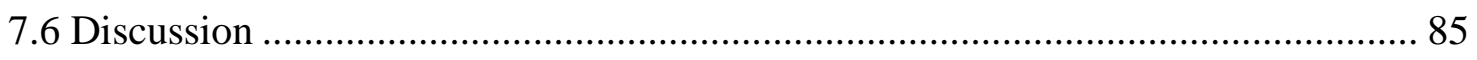

CHAPTER 8 - Conclusions \& Recommendations...................................................... 87

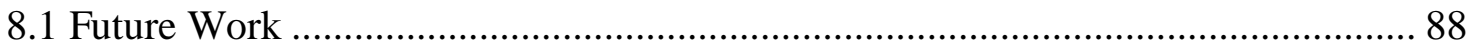

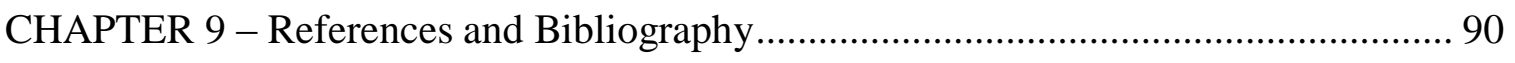

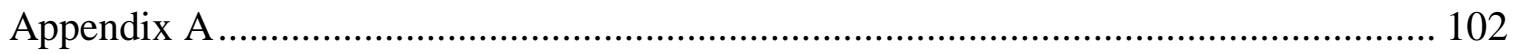




\section{LIST OF TABLES}

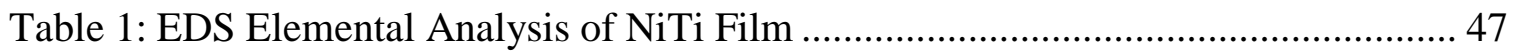

Table 2: Annealed NiTi Thin Film Elastic Modulus and Hardness................................ 63

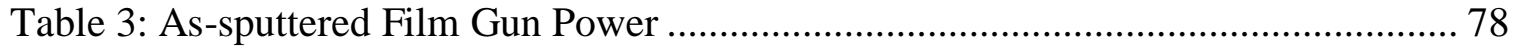




\section{LIST OF FIGURES}

Figure 1: The indentation recovery was evaluated by making the a) thin film of NiTi SMA, nanoindenting, b) measuring the indent, c) heating the NiTi past the phase change temperature, and d) measuring the amount of recovery.

Figure 2: Nickel titanium shape memory alloys have two phases. If the room temperature phase is martensite, the material exhibits the shape memory effect (a). The shape memory effect allows the material to recover large strains when heat is applied to the material. If the room temperature phase is austenite, the material will exhibit pseudoelastic properties (b). Pseudoelastic properties allow the material to recover large strains when the load is removed from the material.

Figure 3: Two crystal structures/phases of Nickel Titanium a) austenite: Parent phase, stable at higher temperatures, cubic crystal structure (B2); b) martensite: daughter phase, stable at lower temperatures, and monoclinic crystal structure (B19'). The twinning angle $(\alpha)$ of the martensite structure is $96.8^{\circ}$

Figure 4: Section of the periodic table of elements that highlights binary shape memory alloys with a B2 parent phase. Two categories classify the SMAs on the periodic table. Category $\mathrm{I}$ is a combination of an element from column four through seven with an element from columns eight through ten. Category II is composed from elements from column eleven and an element from column twelve. The only binary shape memory alloys with a B2 parent phase that does not follow the categories are $\mathrm{NiAl}$ and $\mathrm{CuZr} . . . . .8$

Figure 5: Atomic view of the shape memory effect cycle. An induced load is accommodated by the martensite structure detwinning. Heating the structure above the austenite transition temperature allows the material to recover large stains. Upon cooling, the material will return to the original shape.

Figure 6: Phase Diagram of Ti-Ni alloy. The 50:50 composition of nickel and titanium is the phase that exhibits shape memory properties (image courtesy of Massalski, ASM International). 11

Figure 7: Martensite start temperature as a function of nickel content in NiTi. Data points from different authors and a thermodynamically calculated line (image courtesy of Tang).

Figure 8: Schematic of the contact geometry and the unloading process with residual surface.

Figure 9: Schematic of indentation load and unload curve showing the important parameters: maximum load, maximum depth, final depth, and the elastic unloading stiffness. 15 
Figure 10: Nanoindenter schematic: indenter measures both the indentation depth and applied force by the indenter tip. The Asylum Research MFP-3D Instrumented NanoIndenter uses a piezoelectric stack for actuation and light deflection to detect the applied force and compression of the flexure............................................................... 17

Figure 11: Schematic of the Berkovich indenter tip........................................................ 18

Figure 12: The original nanoindentation method presumes an ideal indenter geometry that is not representative of the actual tip geometry. The indenter tip will have a radius of curvature from manufacturing and further rounding occurs from use. 20

Figure 13: An example of the measured projected area of a new indenter tip at any given depth compared to the ideal tip projected area. The ratio between the two is not constant and changes the most within the radius of curvature of the tip. 21

Figure 14: Three possible material responses that can affect the contact area of the indenter: the ideal condition, sink-in, and pile-up. The Oliver-Pharr method does not account for sink-in or pile-up. AFM imaging of the residual indents can be used to estimate the actual contact area 23

Figure 15: Residual impression of a Berkovich indenter with three different material responses: ideal elastic behavior, pile-up, and sink-in.

Figure 16: Physical sputtering process schematic. Ionized argon atoms bombard a target material and sputter the material out. The sputtered material condenses and creates a thin film of the sputtered material. 26

Figure 17: Cross-sectional view of the sputtering target with the magnets below the target to increase sputtering efficiency. 27

Figure 18: The atomic spacing causes intrinsic stresses of the thin film. Atomic spacing that is smaller than ideal atomic spacing causes compressive stresses. Greater than ideal atomic spacing causes tensile stress. Intrinsic film stress can be measured by the change in the radius of curvature of thin substrates upon the deposition of the film. 29

Figure 19: Affects of stress on the transformation temperature of NiTi. An increase in stress increases the transformation temperature. 35

Figure 20: The layering of sputtering deposition steps to obtain the thin film NiTi....... 38

Figure 21: Differential scanning calorimeter plot. As the temperature of the NiTi is increased, the phase change to austenite started $\left(\mathrm{A}_{\mathrm{s}}\right)$ at $49^{\circ} \mathrm{C}$ and was complete $\left(\mathrm{A}_{\mathrm{f}}\right)$ at $95^{\circ} \mathrm{C}$. When the NiTi sample cooled the phase transformation back to martensite started $\left(\mathrm{M}_{\mathrm{s}}\right)$ at $67^{\circ} \mathrm{C}$ and finished $\left(\mathrm{M}_{\mathrm{f}}\right)$ at $42^{\circ} \mathrm{C}$. 46 
Figure 22: AFM image with a scan size of $\mu \mathrm{m}$ scan of the a) as-sputtered NiTi surface with a b) cross-sectional view. The image reveals the surface features from the deposition

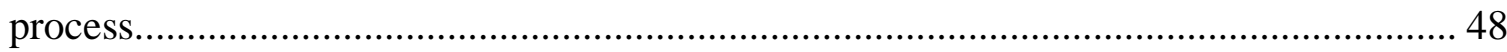

Figure 23: Topography comparison of the as-sputtered (a and c) and the annealed film (b and $\mathrm{d}$ ). The topography of the as-sputtered film remained consistent as the scan size increased while the annealed film showed peaks and valleys resembling twinning with increased scan size.

Figure 24: Comparison of AFM images of annealed thin film NiTi a) from this study and b) from a previous study by Yongqing. The difference between the two is the size and scale of the twinned regions. This difference is attributed to the different annealing temperatures. The Yongqing used an annealing temperature of $450^{\circ} \mathrm{C}$ while this research used $550^{\circ} \mathrm{C}$. The larger twinned features are from the greater temperature, allowing them to grow larger 50

Figure 25: Comparison of roughness between annealed and as-sputtered NiTi by root mean square (RMS) roughness analysis. 51

Figure 26: Cross-section view of one of the twinned structure. An example of a location where an angle of $6.6^{\circ}$ was measured, indicating the twinning angle of martensite....... 52

Figure 27: Sapphire indenter tip approaching the sapphire substrate. .......................... 57

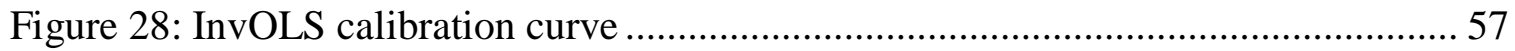

Figure 29: SEM pin mount holder for the MFP-3D base. ......................................... 58

Figure 30: Indentation area and points to be indented .......................................... 59

Figure 31: Indentation loading functions a) testing for rate dependency of the NiTi film, b) typical indentation load and load parameter used for indentations. 61

Figure 32: Force curves of loads ranging from $0.25 \mathrm{mN}$ to $3 \mathrm{mN}$ on annealed nickel titanium. 62

Figure 33: Indentation with asymmetrical contact area. Bottom left corner of the residual indent extends further than the others because of the angular facets of the NiTi surface. 62

Figure 34: Indentation area viewed with the AFM optics. The indentations were located in the center of the 90 by $90 \mu \mathrm{m}$ box that was scratched into the NiTi film.

Figure 35: An a) AFM image of a single indent used to determine if the elastic model for the Oliver and Pharr method was valid. Pile-up or sink-in is not accounted for in the 
Oliver and Pharr method, the b) cross-sectional view assist in determining is pile-up or sink-in had occurred.

Figure 36: Individual indent masked to determine the size of the indent. The indentation size was quantified in four parameters; depth, volume, surface area, and projected area. 68

Figure 37: A 5 by 5 array of indent increasing in depth from the bottom to the top. The bottom row appears like small dimples instead of defined indents. 70

Figure 38: AFM images of a $0.25 \mathrm{mN}$ indent a) after indentation and b) after heating the NiTi past the phase transition temperature. Both AFM images are presented with the same z-scale. 70

Figure 39: Comparison of a $0.25 \mathrm{mN}$ indent before and after heating. The indent appears to recover put did not recover completely.

Figure 40: Average percent recovery for the four measured parameters (depth, surface area, projected area, and volume) verse the indentation force. The overall appearance was a decrease of recovery with an increase in force. However, the $0.25 \mathrm{mN}$ indents appear to have the only significant difference in recovery........................................................ 72

Figure 41: Indentation recovery verse force individually graphed for each parameter. The mean is represented by the crosshair mark. Median is the line in the box. The boxes are the middle $50 \%$ of the data and the lines that extend from the boxes are the upper and lower $25 \%$. 73

Figure 42: Indentation recovery schematic: Indentation depths recovered the least during the martensitic phase transformation while the sidewalls recovered more (Not to scale). 76

Figure 43: Etch line to determine the thickness of the NiTi layer of different deposition powers.

Figure 44: Film stress of the as-sputtered film with different sputtering powers. The increase of power to the sputtering guns made the atoms on the film closer spaced causing an increase in compressive film stress. 80

Figure 45: The electrical conductivity of the as-sputtered films with different sputtering process powers.

Figure 46: Drift correction force curve. Region I is a stress-relax the contact and region II is where the thermal drift is measured.

Figure 47: Nanoindentation forces curve comparison of as-sputtered amorphous NiTi and $\mathrm{NiTi}$ annealed at $550{ }^{\circ} \mathrm{C}$ and transformed into a shape memory alloy. The as-sputtered $\mathrm{NiTi}$ has greater hardness and elastic modulus. 84 
Figure 48: As-sputtered NiTi film properties: both the a) elastic modulus and b) hardness increased with an increase in the deposition power.................................................. 85 


\section{CHAPTER 1 - Introduction}

Decrease in device sizes reduces cost, increases efficiency, fast response time, and produces higher precision devices. Microscopic devices that are often created from traditional microfabrication techniques are known as Microelectromechanical systems (MEMS). A material that has gained much interest for MEMS applications is nickel titanium (NiTi) shape memory alloys (SMAs). NiTi is a useful material for MEMS because of the high work output per unit volume $\left(\sim 10^{7} \mathrm{~J} / \mathrm{m}^{3}\right)$ from the martensitic phase transformation ${ }^{1}$. The martensitic phase transformation allows NiTi to recover strains of 6$8 \%$ by heat or load induced phase transformation ${ }^{2,3}$. Some of the devices that are made with NiTi are micro valves, switches, actuators, pumps, wrappers, and grippers ${ }^{4,5,6,7,8}$. One of the disadvantages of bulk NiTi is the response time and cooling time of the device. As a MEMS device, the high surface area to volume ratio allows the device to have cycle times on the order of milliseconds ${ }^{9}$. The lower thermal conductivity of $10.0 \mathrm{~W} / \mathrm{m}-\mathrm{K}$ makes the heating and cooling cycle slower than most metals and reduce the cycling time of larger devices.

NiTi SMAs are not limited to actuators for MEMS devices. The shape memory effect could be utilized as a data storage medium ${ }^{10}$. Current magnetic hard drives are reaching a fundamental storage density limit ${ }^{10}$. As the magnetic domains reach a size of about 100 atoms, the magnetic anisotropy energy is weak enough that fluctuations in temperature can erase data ${ }^{11}$. The potential maximum storage density of traditional magnetic storage drives is approximately $100 \mathrm{Gbit} / \mathrm{in}^{2}{ }^{2}{ }^{12}$. A potential replacement of traditional hard drives is thin film NiTi as a mechanical storage medium. This would be a 
mechanical type storage device where an indent in the film would represent a one in the binary system and no indent would represent a zero. Indentations could be created by a probe system with a diamond tip. Heating the NiTi induces a martensitic phase transformation that allows the indent to be fully recovered. The heating would be used to erase data. Heating could be done in sections by resistive heating traces under the NiTi or individually heating indents with the indenting probe by resistive heating. A similar technology has been studied called the "Millipede" by IBM which has had storage density in the Tbit/in. ${ }^{2}{ }^{13}$. To create a storage density of 1 Tbit/inch ${ }^{2}$ the bit separation is approximately $24 \mathrm{~nm}$. The Millipede uses polymer thin films as the storage medium, but there are disadvantages due to the high temperatures required to use polymers such as Poly(methyl methacrylate) (PMMA). PMMA devices can reach an operating temperature of $350^{\circ} \mathrm{C}$ because the writing and erasing process both require heat ${ }^{10}$. The $350^{\circ} \mathrm{C}$ operating temperatures to use PMMA can cause degradation and burning of the $\mathrm{PMMA}^{14}$. The operating temperature for PMMA devices is higher because NiTi has higher thermal conductivity and lower heat capacity allowing the erasing operation to be done more rapidly ${ }^{15}$. The erasing temperature for NiTi can be tailored by changing the transition temperature between the martensite and austenite.

Knowing the mechanical properties of a material is necessary for designing devices at any scale. The deposition process for creating the thin film is a bottom-up process where the mechanical properties of the material may not be the same as the bulk material. Different factors become dominant when the scale is reduced. The processing parameters can dramatically change the material properties. Some examples of sputtering deposition parameters affect on material properties include argon pressure on the 
oxidation resistance of $\mathrm{GdTbFeCo}^{16}$, deposition power and gas pressure affect the resistance and optical properties of $\mathrm{ZnO}: \mathrm{Al}^{17}$, and deposition power and substrate temperature on $\mathrm{ZnO}$ film stress and grain size ${ }^{18}$. The material's properties must be known to effectively design MEMS devices ${ }^{19}$.

This thesis will focus on the fabrication and mechanical properties of thin film NiTi. The NiTi thin films were deposited by DC magnetron sputtering and the elastic modulus and hardness of the thin film NiTi was determined by nanoindentation. The elastic modulus was determined for as-sputtered films and films that were annealed to produce a SMA. This provided invaluable information for designing NiTi devices with the equipment in the Microfabrication Laboratory at California Polytechnic State University - San Luis Obispo. The ability for NiTi to recover nanoindentations by martensitic phase transformation upon heating will be studied (Figure 1). This was performed by measuring the topography of the indents (b) before and (d) after undergoing the martensitic phase transformation. The indent recovery at the nanometer scale is one of the fundamental aspects when determining the feasibility of using NiTi as a data storage device. 

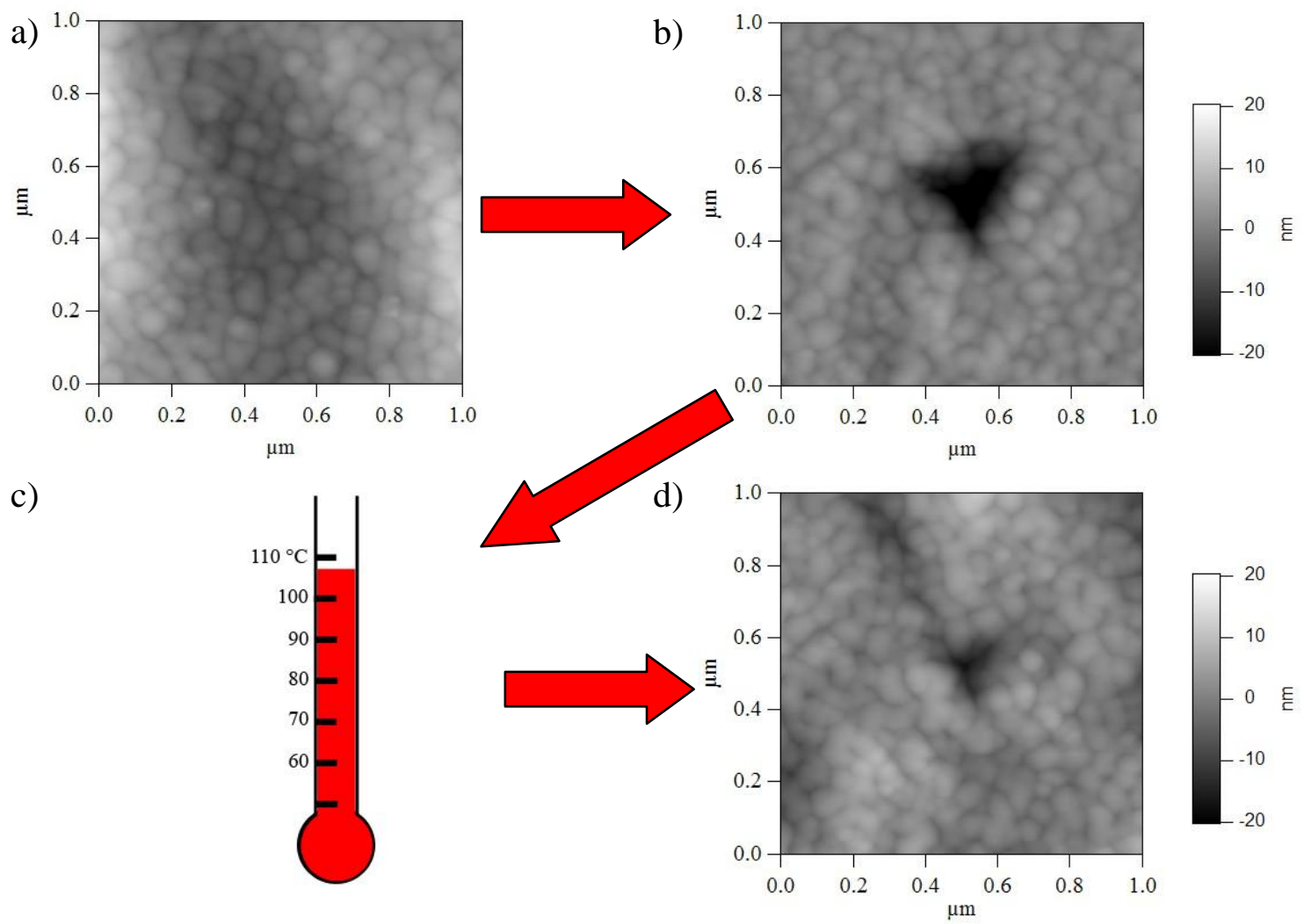

Figure 1: The indentation recovery was evaluated by making the a) thin film of NiTi SMA, nanoindenting, b) measuring the indent, c) heating the NiTi past the phase change temperature, and d) measuring the amount of recovery. 


\section{CHAPTER 2 - Background and Literature Review}

This chapter is provided to frame the research presented in this thesis. The chapter is intended provide a concise synopsis on the topics of nickel titanium shape memory alloy, nanoindentation, sputtering deposition, and a review of previous studies on nanoindenting nickel titanium.

\subsection{Nickel Titanium Shape Memory Alloy}

Shape memory alloys (SMAs) have the ability to recover an original shape after large deformations. Shape memory alloys recover large inelastic deformations by a stress or thermal induced phase change. This solid-state phase change is an atomic level structural change known as a martensitic transformation. The martensitic transformation is a diffusionless transformation from an austenite parent phase to the martensite daughter phase. The phase change is an athermal, displacive transformation that does not require long-range movement or change in the chemical matrix of the material ${ }^{20}$. The transformation is only governed by temperature or stress and the transformation is a displacive shear of the interface that is limited by the speed of sound ${ }^{20}$. The transformation proceeds through the material as a shear wave. The two ways that SMAs recover large deformations are the shape memory effect and pseudoelasticity. The shape memory effect is when the material recovers deformation after heating past the phase transformation temperature (Figure 2). Pseudoelasticity is when the material is deformed and returns to the original shape when the load is released. The shape memory effect is the phenomenon that was studied for this thesis. 
Shape Memory Effect

a)
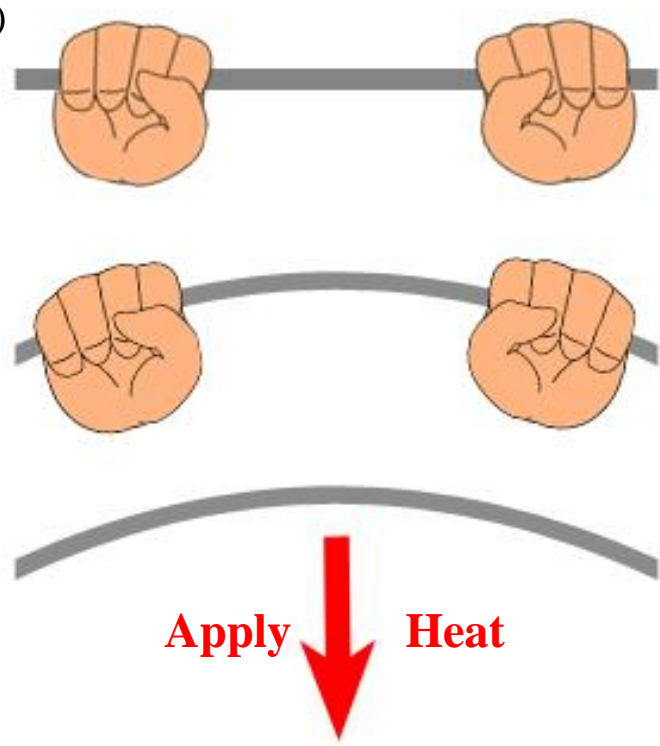

Pseudoelastic

b)
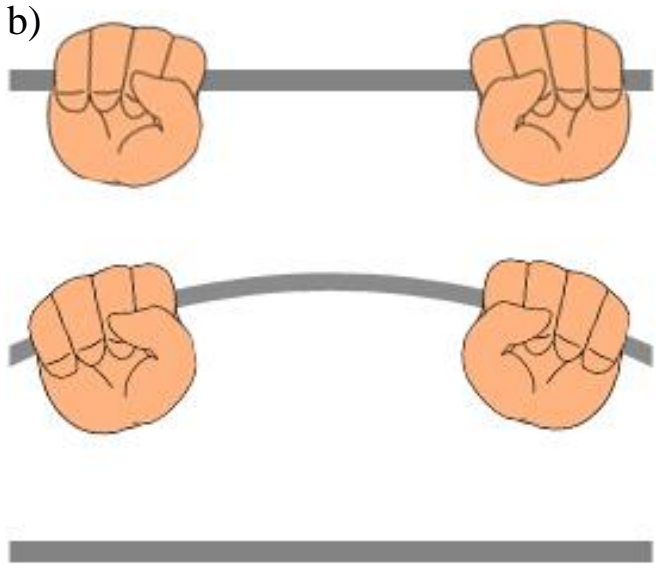

Figure 2: Nickel titanium shape memory alloys have two phases. If the room temperature phase is martensite, the material exhibits the shape memory effect (a). The shape memory effect allows the material to recover large strains when heat is applied to the material. If the room temperature phase is austenite, the material will exhibit pseudoelastic properties (b). Pseudoelastic properties allow the material to recover large strains when the load is removed from the material.

\subsubsection{Nickel Titanium}

The most common SMA is an equiatomic alloy of nickel and titanium. Nickel titanium (NiTi) was discovered by the Naval Ordinance Laboratory in $1962^{21}$. NiTi is the most common SMA because it can exhibit shape memory or pseudoelastic properties with a range of transition temperatures depending on processing ${ }^{22}$. There are copperbased SMAs; but are not preferred over NiTi because they are less stable and more brittle. There are some iron based SMAs, but these have limited recoverable strain and do not have the same level of ductility as $\mathrm{NiTi}^{23}$. NiTi has two different solid phases, austenite and martensite. Austenite is the higher temperature phase and has a $\mathrm{CsCl}$ structure (Figure 3). The lower temperature martensite phase is a complex monoclinic crystal structure. Starting from the lower temperature martensite phase, as the 
temperature increases the material will start to transform to austenite $\left(A_{s}\right)$ and as the temperature increases the NiTi will transform completely to austenite $\left(\mathrm{A}_{\mathrm{f}}\right)$. As the temperature is decreased from the austenite phase, the NiTi will begin to return to martensite $\left(\mathrm{M}_{\mathrm{s}}\right)$ and as cooling continues the phase transformation continues with a complete transformation to martensite $\left(\mathrm{M}_{\mathrm{f}}\right)$.
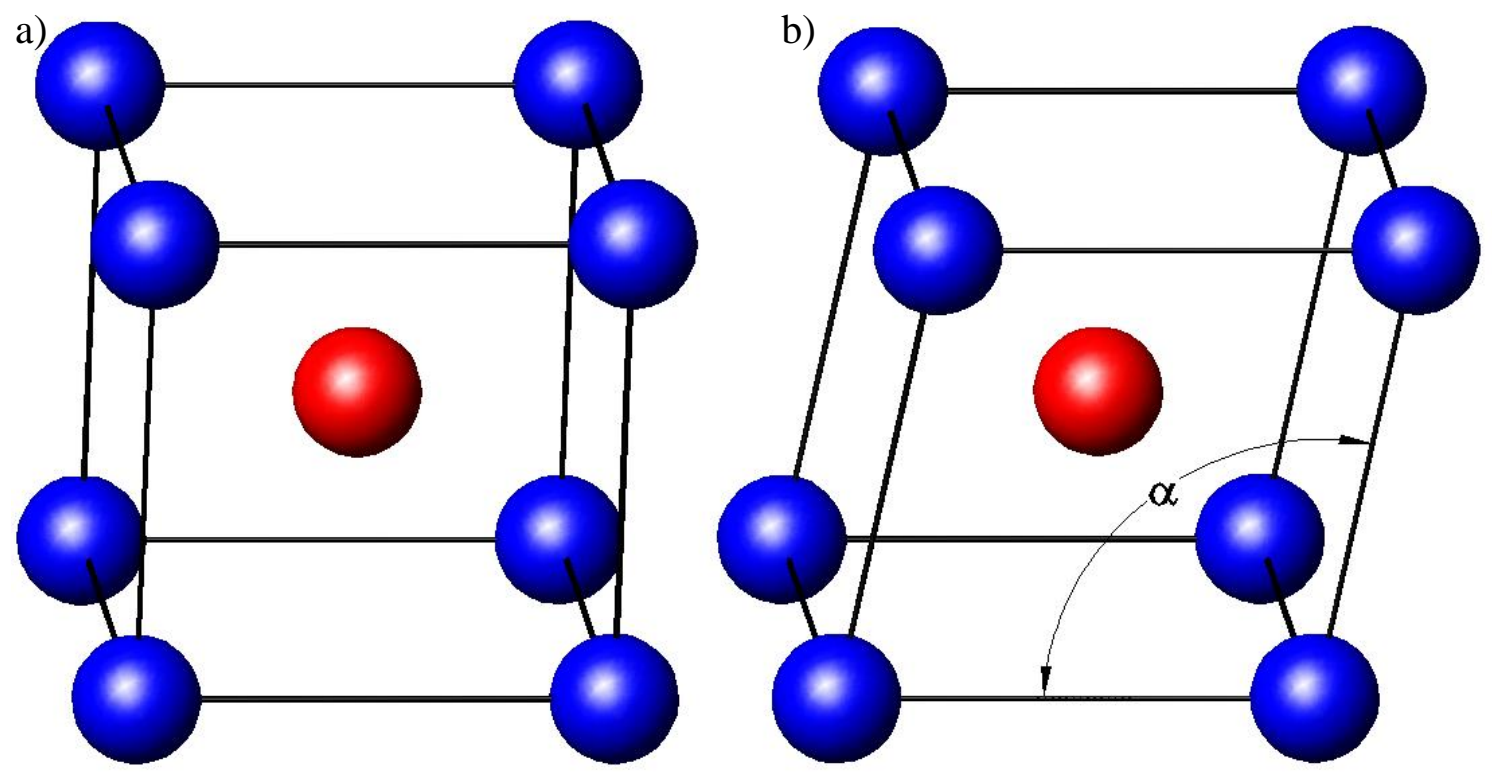

Figure 3: Two crystal structures/phases of Nickel Titanium a) austenite: Parent phase, stable at higher temperatures, cubic crystal structure (B2); b) martensite: daughter phase, stable at lower temperatures, and monoclinic crystal structure (B19'). The twinning angle $(\alpha)$ of the martensite structure is $96.8^{\circ 24}$.

Many shape memory alloys are considered $\beta$-alloys (Au-Cd, Ag-Cd, Cu$\mathrm{Al}-\mathrm{Ni}, \mathrm{Cu}-\mathrm{Zn}-\mathrm{Al}$, etc) and are classified by the valence electron per atom ratio $\left(\mathrm{e}_{\mathrm{v}} / \mathrm{a}\right)$ of approximately $1.5^{26}$. NiTi is often incorrectly referred to as a $\beta$-alloy, but has a valence electron per atom ratio of seven. NiTi does follow a pattern of binary SMAs with a B2 parent phase. The specific category that NiTi fallows is one element is in the periodic table within columns four through seven and the second element is within columns eight through ten (Figure 4) ${ }^{25}$. 


\begin{tabular}{|c|c|c|c|c|c|c|c|c|c|c|}
\hline & $\overline{4}$ & 5 & 6 & 7 & 8 & 9 & 10 & 11 & 12 & 13 \\
\hline \multirow{2}{*}{3} & & & & & & & & & & $\mathrm{Al}_{13}$ \\
\hline & & & & & & & & & & NiAl \\
\hline \multirow{3}{*}{4} & $\mathrm{Ti}_{22}$ & & & $\mathrm{Mn}_{25}$ & & & $\mathrm{Ni}_{28}$ & $\mathrm{Cu}_{29}$ & $\mathrm{Zn}_{30}$ & \\
\hline & $\begin{array}{l}\text { NiTi } \\
\text { TiPd }\end{array}$ & & & NiMn & & & $\begin{array}{l}\mathrm{NiTi} \\
\mathrm{NiMn}\end{array}$ & $\begin{array}{l}\mathrm{CuZn} \\
\mathrm{CuZZ}\end{array}$ & $\begin{array}{l}\mathrm{AgZn} \\
\mathrm{CuZn}\end{array}$ & \\
\hline & & & & & & & TiAl & & $\mathrm{AuZn}$ & \\
\hline \multirow{3}{*}{5} & $\mathrm{Zr}_{40}$ & $\mathrm{Nb}_{41}$ & & & $\mathrm{Ru}_{44}$ & $\mathrm{Rb}_{45}$ & $\mathrm{Pd}_{46}$ & $\mathrm{Ag}_{47}$ & $\mathrm{Cd}_{48}$ & \\
\hline & $\mathrm{ZrRb}$ & $\mathrm{RuNb}$ & & & $\mathrm{RuNb}$ & $\mathrm{ZrRb}$ & TiPd & $\mathrm{AgCd}$ & $\mathrm{AgCd}$ & \\
\hline & $\mathrm{CuZr}$ & & & & $\mathrm{RnTa}$ & & & $\mathrm{AgZn}$ & $\mathrm{AuCd}$ & \\
\hline \multirow{4}{*}{6} & & $\mathrm{Ta}_{73}$ & & & & & & $\mathrm{Au}_{79}$ & & \\
\hline & & RuTa & & & & & & $\mathrm{AuCd}$ & & \\
\hline & & \multicolumn{2}{|c|}{ 1 } & \\
\hline & \multicolumn{7}{|c|}{ Category I } & \multicolumn{2}{|c|}{ Category II } & \\
\hline
\end{tabular}

Figure 4: Section of the periodic table of elements that highlights binary shape memory alloys with a B2 parent phase. Two categories classify the SMAs on the periodic table. Category I is a combination of an element from column four through seven with an element from columns eight through ten. Category II is composed from elements from column eleven and an element from column twelve $\mathrm{e}^{25}$. The only binary shape memory alloys with a B2 parent phase that does not follow the categories are $\mathrm{NiAl}$ and $\mathrm{CuZr}$.

If the room temperature phase is martensite, NiTi will exhibit the shape memory effect. At an atomic level, the martensite structure has a twinned pattern (Figure 5). As a load is placed on the structure, the martensite will detwin to accommodate the load. Once the load is removed, the deformation is still present. Heating the material changes the phase to the austenite crystal structure and the deformation is recovered. Upon cooling, the phase will return to the twinned martensite structure. The deformation and recovery cycle has been measured over millions of cycles and remain reliable ${ }^{26}$. Induced stain of 6 to $8 \%$ can be fully recovered upon heating ${ }^{2,3}$. 


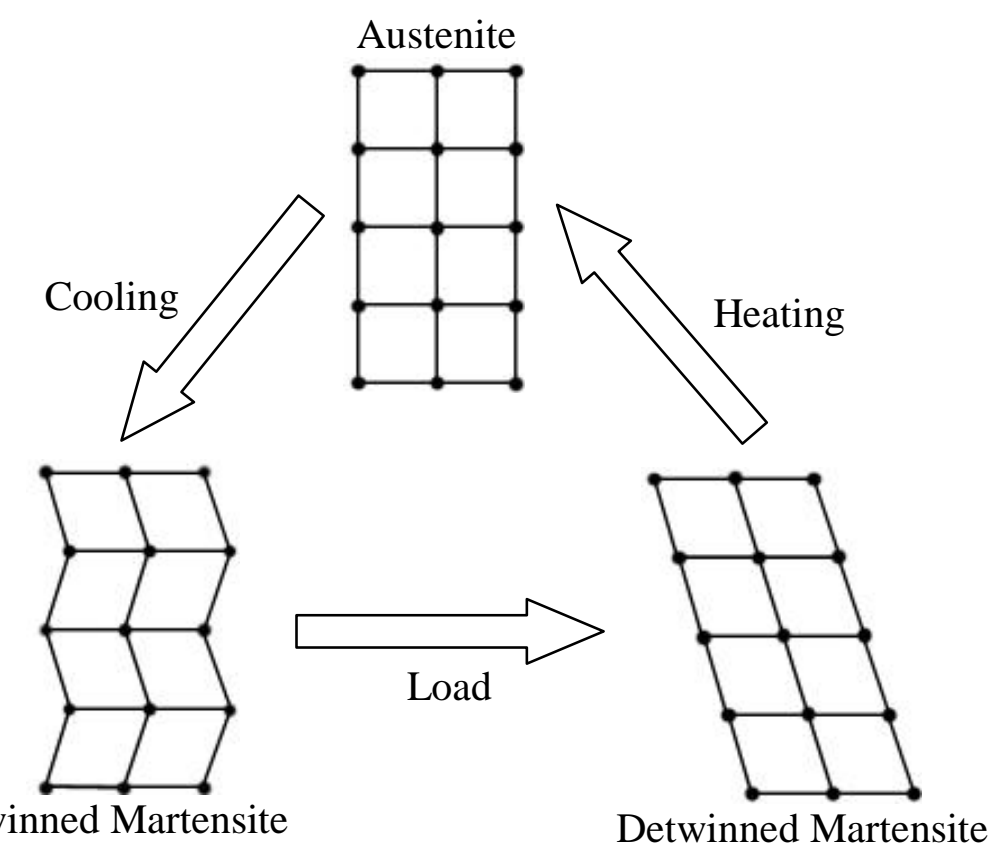

Figure 5: Atomic view of the shape memory effect cycle. An induced load is accommodated by the martensite structure detwinning. Heating the structure above the austenite transition temperature allows the material to recover large stains. Upon cooling, the material will return to the original shape.

The crystallographic transformation for martensite was developed by Wechsler, Lieberman, and Read (WLR theory) ${ }^{27,28}$ The transformation from the symmetrical parent structure to the lower symmetry daughter phase is modeled by three deformations. The three deformations are a Bain distortion, shear deformation, and a rotation of the transformed lattice ${ }^{29}$. The habit plane between the two phases is an invariant plane, which is undistorted and un-rotated. The invariant plane produces the lowest strain energy ${ }^{30}$.

The transformation from one phase to the other is driven Gibbs free energy. The martensite and austenite structures have similar lattice parameters and the atoms nearest neighbor are equivalent. The second nearest neighbors from the two structures are different. The second nearest neighbors are closer with the martensite structure making it energetically favorable at low temperatures. The lower temperature martensite produces a more closed pack plane, which reduces the internal energy. At low temperatures, the 
entropy term in the Gibbs free energy becomes negligible, while the internal energy becomes more of a factor ${ }^{30}$. The change in crystal structure is to maintain the lowest energy of the system. The change in the Gibbs free energy austenite to martensite and vice versa is small, allowing for a metastable reversible phase change.

\subsubsection{NiTi Transformation Temperature}

The transformation temperatures between martensite and austenite mainly depend on the composition of nickel and titanium. The difficulty with creating a NiTi shape memory alloy is the sensitivity to the stoichiometric 50:50 atomic composition of nickel and titanium (Figure 6). A 1\% deviation from the 50:50 composition can change the transformation temperature by $100 \mathrm{C}^{\circ 22}$. An increase of nickel past the stoichiometric composition decreases the transformation temperature (Figure 7$)^{31}$. The decrease in the phase transition temperature with the increase in nickel concentration is due to the increase in valance electrons ${ }^{32}$. Nickel has ten valance electrons while titanium has 4 valence electrons. The average $\mathrm{e}_{\mathrm{v}} / \mathrm{a}$ for the stoichiometric Ti-50Ni is seven. The increase in nickel concentration increases the $\mathrm{e}_{\mathrm{v}} / \mathrm{a}$ to greater than seven. The increase of valance electrons decreases the transition temperature as a result of the higher elastic constraint of the crystal, which increases the resistance against the shear that causes the phase transformation $^{32,33}$. An increase of titanium past the stoichiometric composition has little effect to the transition temperature because excess titanium does not dissolve into NiTi and precipitates in the grain boundaries as $\mathrm{NiTi}_{2}$. The solubility limit of titanium into NiTi is almost vertical making it impossible to create titanium rich NiTi (Figure 6). This makes titanium rich NiTi behavior the same as Ti-50Ni. The maximum $\mathrm{M}_{\mathrm{s}}$ temperature is between $60{ }^{\circ} \mathrm{C}\left(333\right.$ Kelvin) and $67^{\circ} \mathrm{C}(350 \text { Kelvin })^{34}$. 


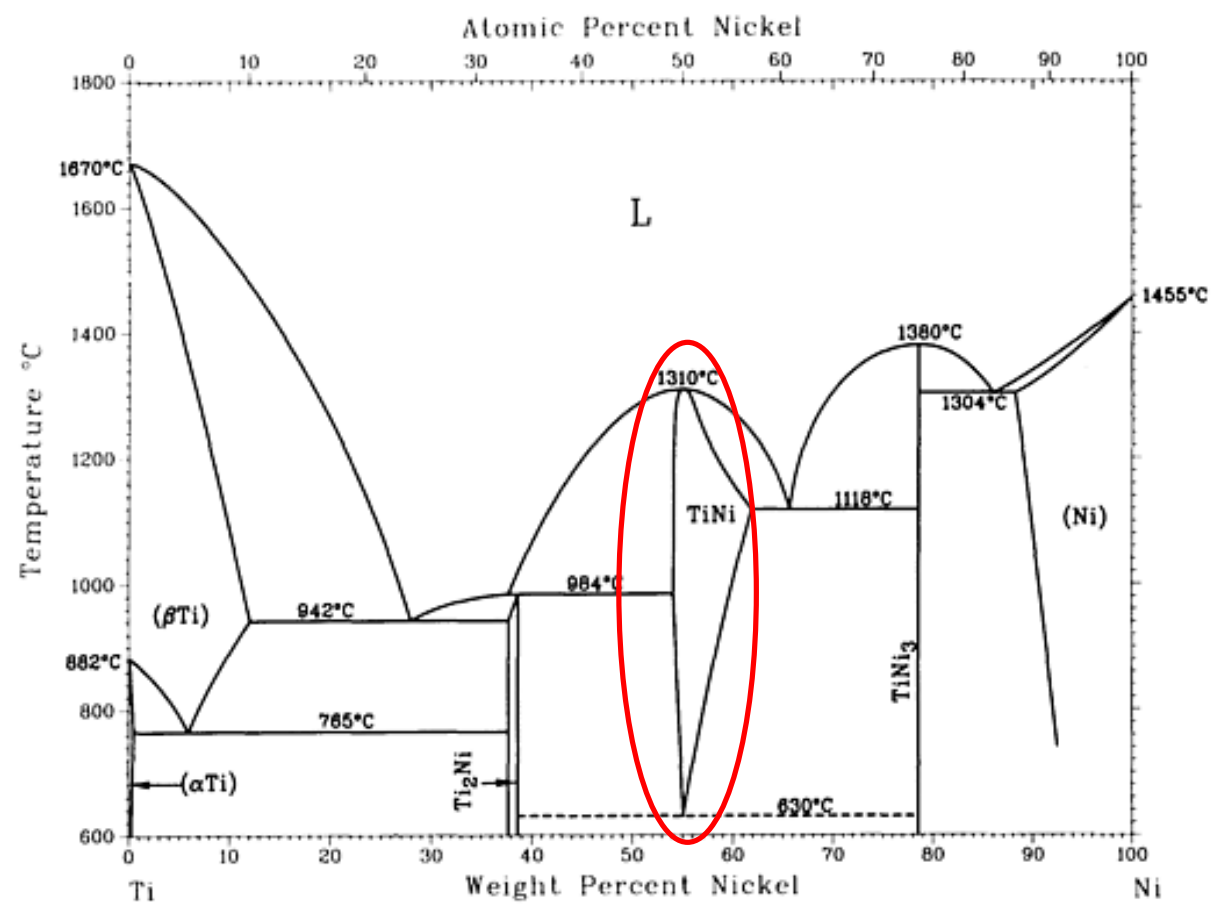

Figure 6: Phase Diagram of Ti-Ni alloy. The 50:50 composition of nickel and titanium is the phase that exhibits shape memory properties (image courtesy of Massalski, ASM International) ${ }^{35}$.

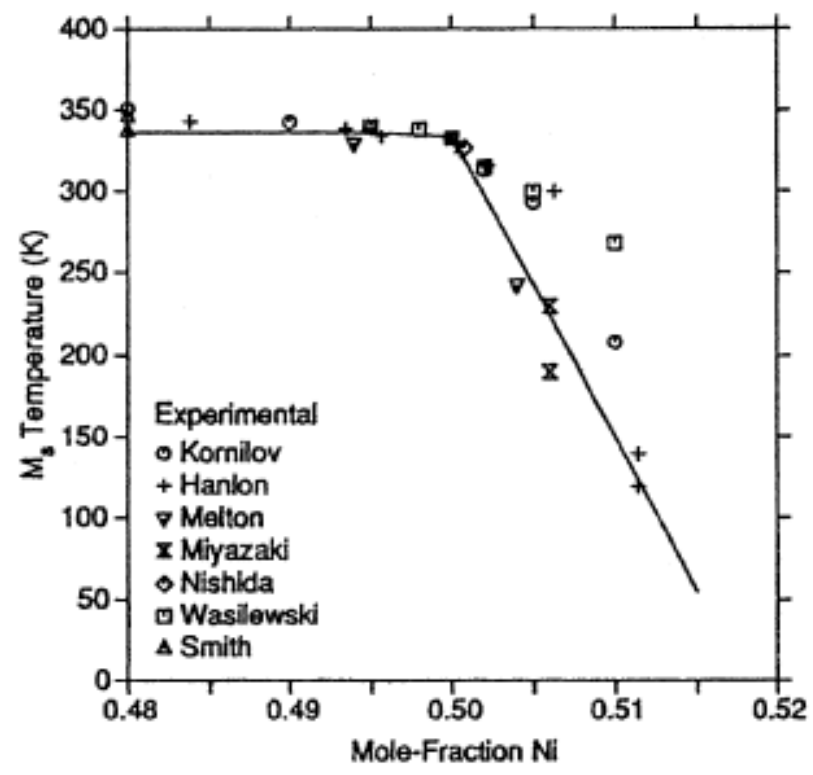

Figure 7: Martensite start temperature as a function of nickel content in NiTi. Data points from different authors and a thermodynamically calculated line (image courtesy of Tang) ${ }^{36}$.

The effective composition can be altered by heat treatments. Heat treatment can be used to change the transition temperatures. Precipitates of different compositions form from the heat treatment, changing the composition of the surrounding material ${ }^{37}$. The 
martensite start temperature can be increased by creating nickel rich precipitates $\left(\mathrm{TiNi}_{3}\right)$ through heat treatment ${ }^{38}$. Precipitation effectively changes the composition of the surrounding material. The change in the effective composition drives the change in transition temperature. The nickel rich precipitates reduce the effective nickel content of the bulk material.

\subsubsection{Impurities Affect on Transitions Temperature}

Impurities in NiTi affect the transition temperature, usually decreasing the

martensite start temperature ${ }^{22}$. Titanium strongly reacts with oxygen, nitrogen, and carbon to form oxides, nitrides, and carbides. Titanium reacting with other elements effectively increases the nickel content of the surrounding material. Chromium, iron, aluminum, cobalt, and vanadium substitute for nickel in the B2 austenite phase and effectively increase the nickel content ${ }^{39}$. These impurities decrease the martensite start temperature, chromium decreases the $\mathrm{M}_{\mathrm{s}}$ the most while cobalt and vanadium have the least affect ${ }^{40}$. Many of these materials are added to suppress the transition temperature and increase stiffness.

\subsection{Instrumented Indentation Testing-Nanoindentation}

Indentation testing is a method of deforming a material of unknown hardness and elastic modulus (E) with a material whose properties are known to determine the unknown properties. Hardness is a material's resistance to permanent deformation at the surface by a harder ideally rigid material. The elastic modulus is a material's stiffness or resistance to elastic strain. Initial work in hardness testing was done by Fredrick Mohs in 1822 where he scratched one material with another. The softer material would scratch and he ordered the materials relatively from one to ten, ten being diamond. Further 
refinements of determining hardness were done by Brinell, Knoop, Vickers, and Rockwell. These refined techniques indent the material with a defined indenter tip with one degree of freedom. The indents are created with a known load and the residual indent was measured with optical microscopy. The penetration depths with these techniques are on the scale of millimeters to micrometers.

Residual indents with depth penetration on the order of nanometer cannot be measured with optical techniques. The field of nanoindentations came from the desire to study thin hard films and surface treatments in the early 1980 's ${ }^{41}$. The microstructure features make thin film and coating properties different from the bulk material because of residual stress, crystallographic orientation, and morphology of the microstructure. Nanoindenting is also considered a nondestructive test method. Microhardness testing was unable to produce low enough forces for testing thin film and the residual indents could not be accurately measured. Doerner and $\mathrm{Nix}^{42}$ were the first to extend indentation into the millinewton range and made a model for measuring hardness and elastic modulus by nanoindentation. The current standard for nanoindentation method was an extension of Doerner and Nix's work by Oliver and Pharr ${ }^{43}$. This brought about a new technique of instrumented indentation testing (IIT) called nanoindenting. Nanoindentation techniques use an indirect method to calculate the contact area. Micro and macro indentations directly measure the residual impression left after indentation whereas; nanoindentations measure both the indentation depth and applied force. The indentation depth combined with the known tip geometry of the indenter provides an indirect measurement of the contact area at full load. 
Much of the work that Oliver and Pharr contributed was modeling the material response to an indention at the nanometer scale. The actual contact area that was previously believed to be the entire depth of the indenter (h) was shown to be inaccurate. The full depth of the indenter was not in contact with the material. The material was shown and modeled to elastically sink-in $\left(\mathrm{h}_{\mathrm{s}}\right)$ around the perimeter of the indenter (Figure 8). This produced a new contact depth $\left(h_{c}\right)$ for the given depth of the indenter.

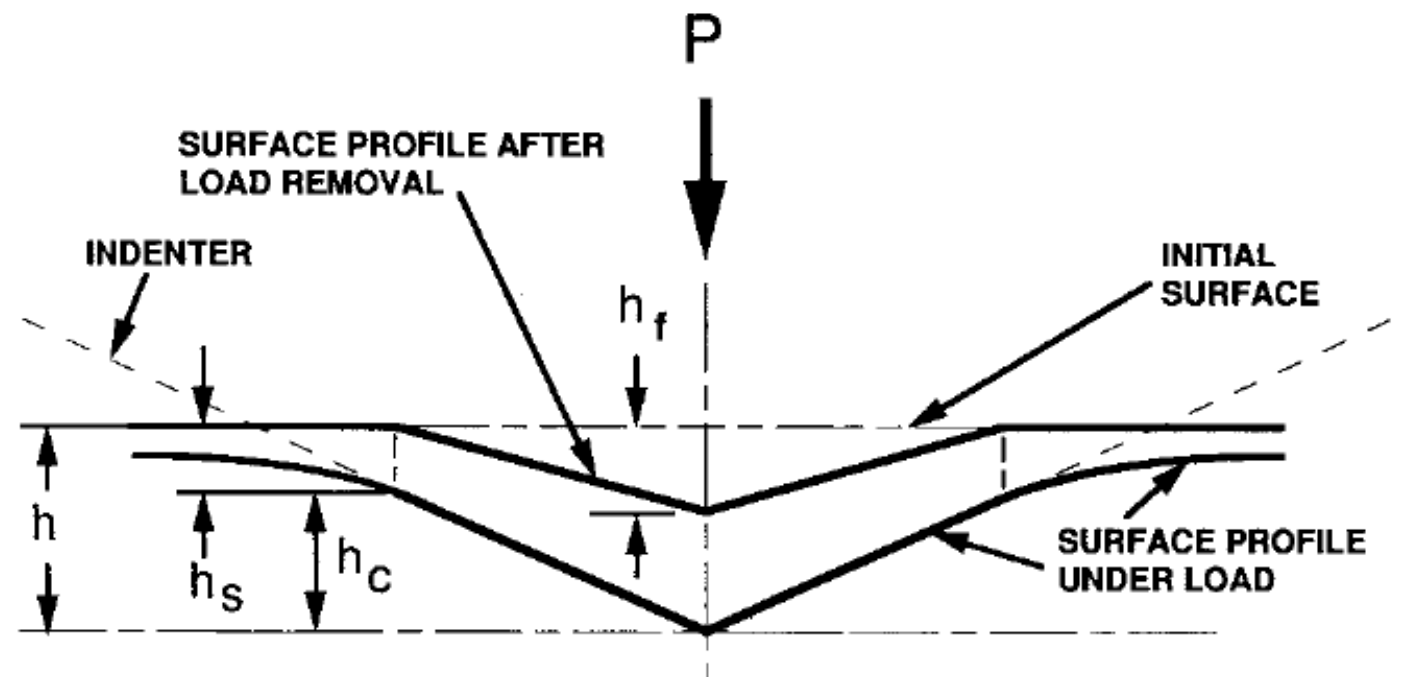

Figure 8: Schematic of the contact geometry and the unloading process with residual surface ${ }^{43}$.

The output from IIT is a force displacement curve (Figure 9). The parameters needed to calculate the mechanical properties are the max load $\left(\mathrm{P}_{\max }\right)$, maximum depth $\left(h_{\max }\right)$, residual depth $\left(h_{f}\right)$, and the slope of the upper section of the unloading curve known as the elastic contact stiffness (S). One of the improvements made by Oliver and 


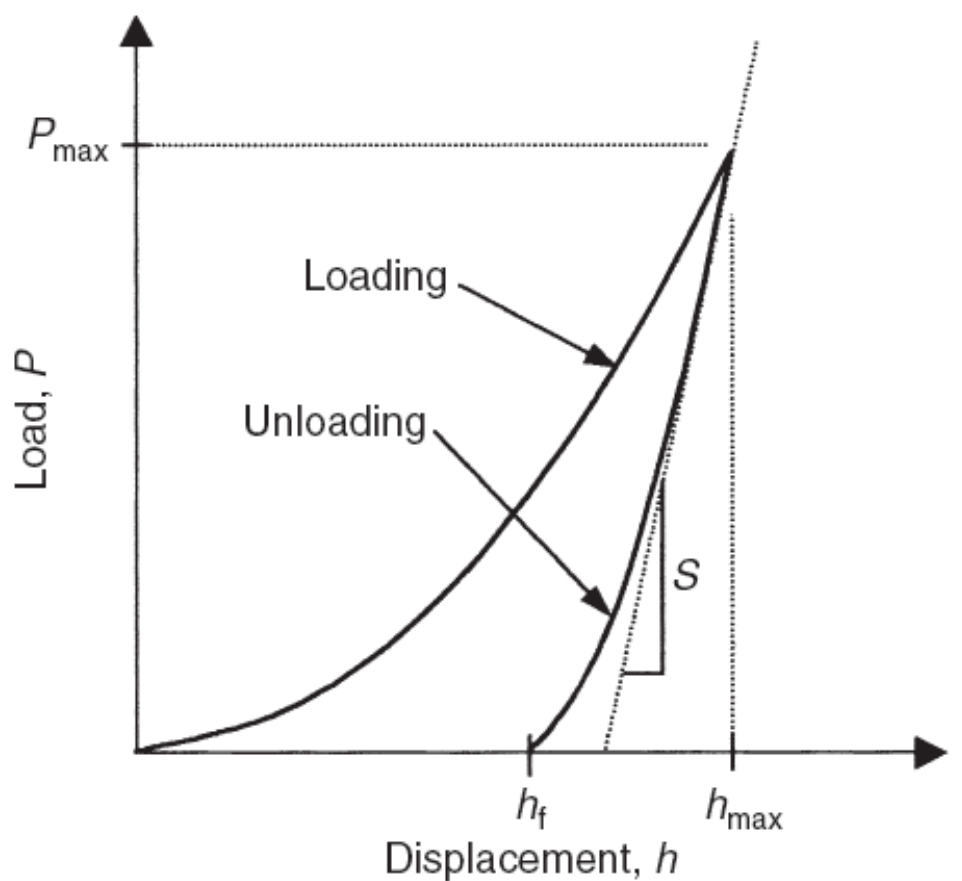

Figure 9: Schematic of indentation load and unload curve showing the important parameters: maximum load, maximum depth, final depth, and the elastic unloading stiffness.

Pharr was modeling the unloading curve ${ }^{43}$. Initial modeling was based on a flat punch indenter by Doerner and Nix and produced a linear unloading curve but was later determined to be inaccurate ${ }^{43}$. The unloading curve was well modeled with a power law relation by Oliver and Pharr (Equation (1). The unloading curve shape is due to the change in effective contact angle and varies with depth because of the elastic recovery of the sample material ${ }^{44}$. Where $\mathrm{P}$ is the load, $\alpha$ and $\mathrm{m}$ are empirically determined to fit the unload curve and $h_{f}$ is the residual indentation depth. The constant $\alpha$ depends on the mechanical properties of the material. The power law exponent $(\mathrm{m})$ is between 1.2 and 1.6, this is different from the original flat punch model where $\mathrm{m}=1$.

$$
P=\alpha\left(h-h_{f}\right)^{m}
$$

The contact depth $\left(h_{c}\right)$ of the indenter is determined from the force curve. The contact depth is determined by the maximum depth of the indenter $\left(\mathrm{h}_{\max }\right)$, max force 
$\left(\mathrm{P}_{\max }\right)$, elastic unloading stiffness $(\mathrm{S})$, and the intercept factor $(\varepsilon)$, which is a constant that depends on the geometry of the indenter tip (Equation(2). For the Berkovich indenter $\varepsilon=0.75$. The contact depth $\left(\mathrm{h}_{\mathrm{c}}\right)$ is used as the depth of the indent for determining both the elastic modulus and the hardness of the sample. The contact depth is different from the maximum depth because of the elastic response of the material.

$$
h_{c}=h_{\max }-\varepsilon \frac{P_{\max }}{S}
$$

\subsubsection{Indenter Schematic}

The instrumented indenter used for this research was an Asylum Research MFP3D Instrumented NanoIndenter. The indenter is engaged with a piezoelectric stack and the distance the piezoelectric stack moves is measured by a nanopositioning system (NPS) (Figure 10). As the indenter tip comes into contact with the surface of the sample, the spring flexure, of known spring constant, deforms while the optical detector deflects from the indenter shaft. Light reflects off the surface of the optical detector to measure the deflection of the optical detector. The deflected light is measured with a position sensitive detector (PSD) to determine the compression of the flexure. The light deflected off the optical detector, calibrated with the spring constant of the spring flexure produces the applied force. 


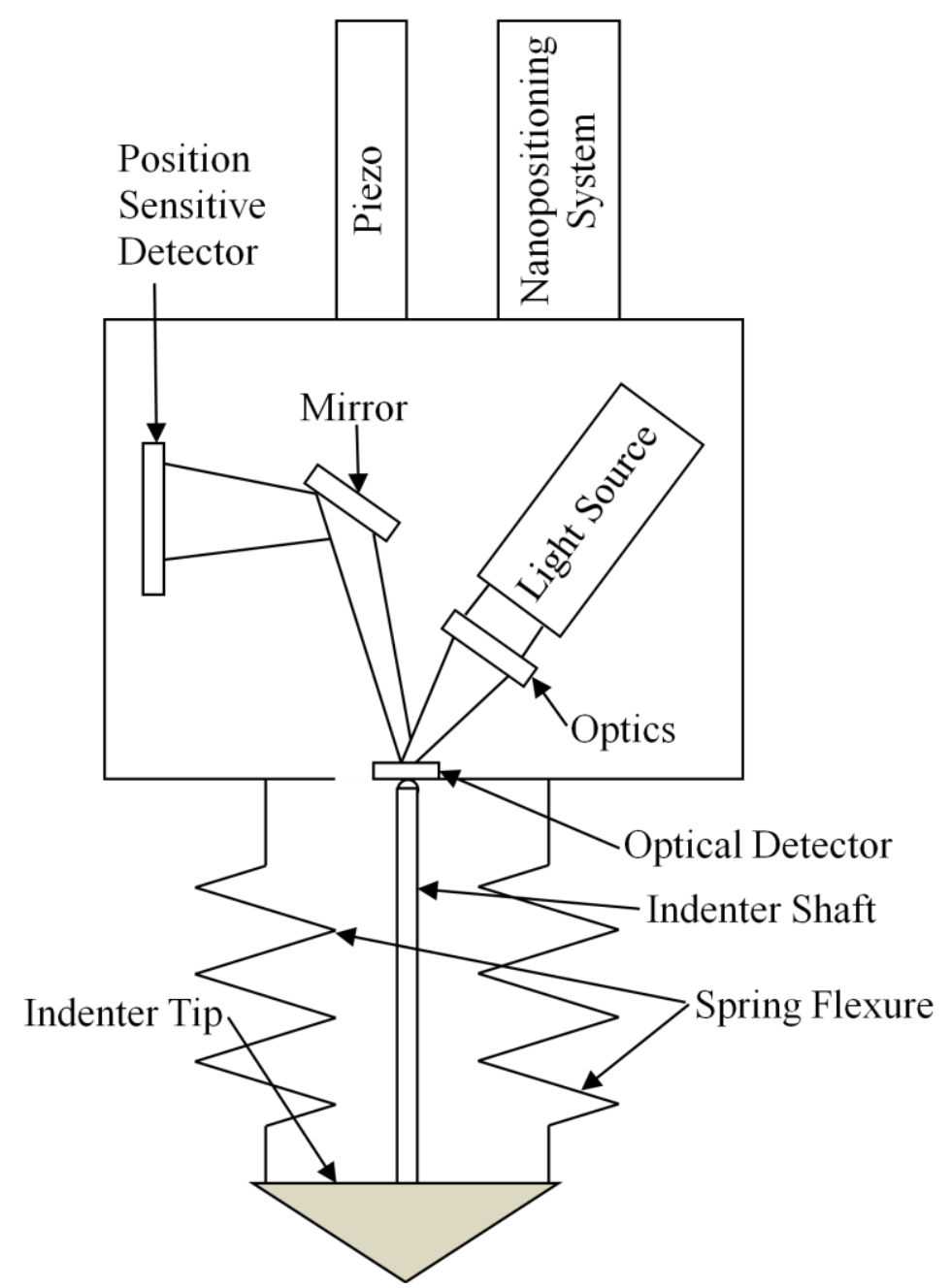

Figure 10: Nanoindenter schematic: indenter measures both the indentation depth and applied force by the indenter tip. The Asylum Research MFP-3D Instrumented NanoIndenter uses a piezoelectric stack for actuation and light deflection to detect the applied force and compression of the flexure.

\subsubsection{Berkovich Indenter}

The Berkovich ${ }^{45}$ indenter is a three-sided pyramid that is the standard for determining the elastic modulus and hardness for nanoindenting. The indenter is three sided because a three-sided pyramid is much easier to make into a sharp point as compared to a four-sided Vickers indenter. The angle of each indenter face is $65.27^{\circ}$ (Figure 11), this produces the same projected area (cross-sectional area) as a Vickers indenter for any given depth. The projected area of a Berkovich indenter for any given depth is $\mathrm{A}=24.5 \mathrm{~h}^{2}$. Where $\mathrm{A}$ is the projected area and $\mathrm{h}$ is the depth of penetration. 


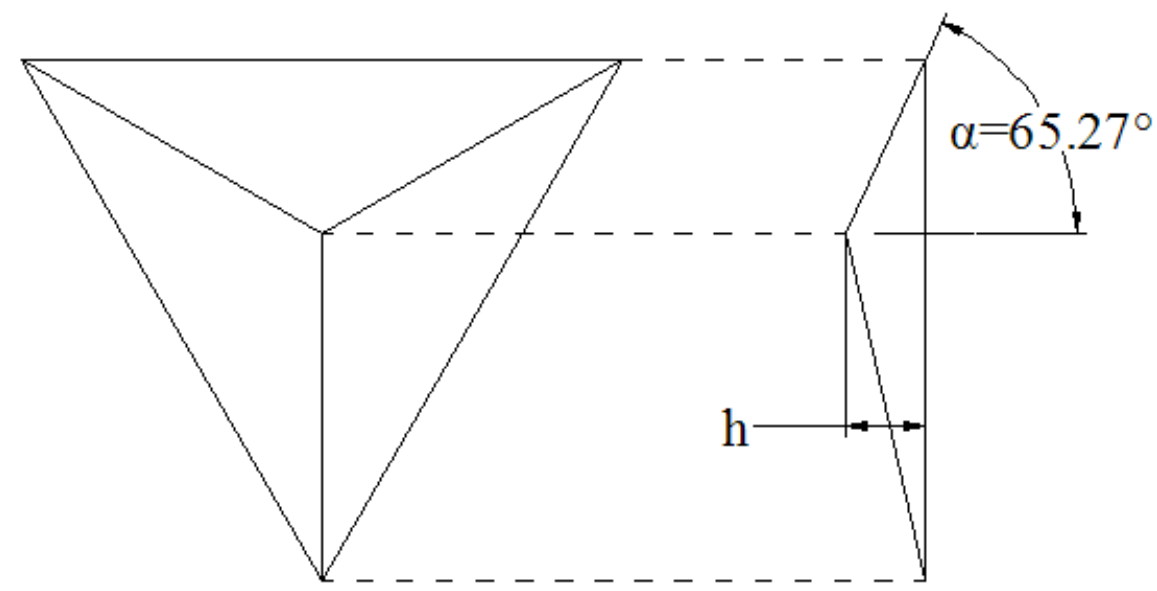

Figure 11: Schematic of the Berkovich indenter tip.

\subsubsection{Hardness}

The hardness of the material is determined with the applied max force and the projected area of the indenter $(\mathrm{H})$ (Equation 3).

$$
\boldsymbol{H}=\frac{\boldsymbol{P}_{\max }}{\boldsymbol{A}}
$$

The projected area of the Berkovich indenter can be placed into the hardness equation (Equation (3) to produce the hardness equation when a Berkovich indenter is used (Equation 4). The depth for determining the projected area is not the maximum depth but the contact depth $\left(\mathrm{h}_{\mathrm{c}}\right)$.

$$
H=\frac{P_{\max }}{24.5 h_{c}{ }^{2}}
$$

\subsubsection{Elastic Modulus}

The elastic modulus was the main work that Oliver and Pharr refined from Doerner and Nix's work. The reduced elastic modulus $\left(\mathrm{E}_{\mathrm{r}}\right)$ is the initial output from the force curve to determine the elastic modulus (Equation 5$)^{43}$. The reduced elastic modulus 
combines the elastic modulus of the indenter and the sample. The indenter geometry shape factor $(\beta)$ is a constant based on the indenter used. For a Berkovich indenter tip, $\beta$ is 1.034 .

$$
E_{r}=\frac{\sqrt{\pi}}{2 \beta} \frac{S}{\sqrt{A}}
$$

The elastic modulus is calculated from the reduced elastic modulus ${ }^{46}$ (Equation 6). The combination of Equation (5 and Equation (6 are used to determine the elastic modulus of the sample. E and $v$ are the elastic modulus and Poisson's ratio of the sample. $\mathrm{E}$ is the elastic modulus to be determined. A Poisson's ratio of the sample must be estimated or known to determine the elastic modulus. An estimation that is \pm 0.1 of the actual Poisson's ratio will produce an uncertainty of the elastic modulus of $5 \%{ }^{47} . E_{i}$ and $v_{i}$ are the elastic modulus and Poisson's ratio of the indenter. The elastic modulus for the synthetic diamond used for this work was 865 GPa with a Poisson's ratio of 0.20 . As a reference, the elastic modulus of real diamond is $1141 \mathrm{GPa}$ with a Poison's ration of $0.07^{48}$

$$
\frac{1}{E_{r}}=\frac{1-v^{2}}{E}+\frac{1-v_{i}^{2}}{E_{i}}
$$

\subsubsection{Factors Affecting Nanoindentation Data}

An assumption in nanoindenting is the ideal indenter tip geometry. The projected area of the indenter tip is calculated with an assumption that the tip is atomically sharp. The assumption of the ideal indenter geometry produces inaccurate results; the indenter area is typically greater than ideal. There are three main reasons the indenter geometry 
can vary from the ideal geometry: manufacturing tolerances, blunting or damage of the tip, and contamination.

Under ISO 14577-22, the angles of the facets on the indenter need to be within a $\pm 0.3^{\circ}$ of the ideal angle. The radius of curvature is required to be less than $200 \mathrm{~nm}$ for nanometer range indentations. Some manufacturers produce Berkovich tips with facet angles deviating $4 \%$ from ideal and deviations of tip radius from $16 \%$ to $97 \%$. However, other manufacturers produce tips with specification better than the ISO requirement ${ }^{50}$.

An indenter tip can blunt with use, causing the radius of the tip to increase with use (Figure 12). The radius of curvature causes the projected area to be greater than expected. The actual projected area of the indenter depends on wear and manufacture specification. The actual projected area of the indenter can differ from the ideal by up to ten times for indents under $10 \mathrm{~nm}$, four times for under $50 \mathrm{~nm}$, and up to double for indents over $100 \mathrm{~nm}^{53}$. If the increase in the projected area is not adjusted for, the elastic modulus and hardness values will be greater than reality.

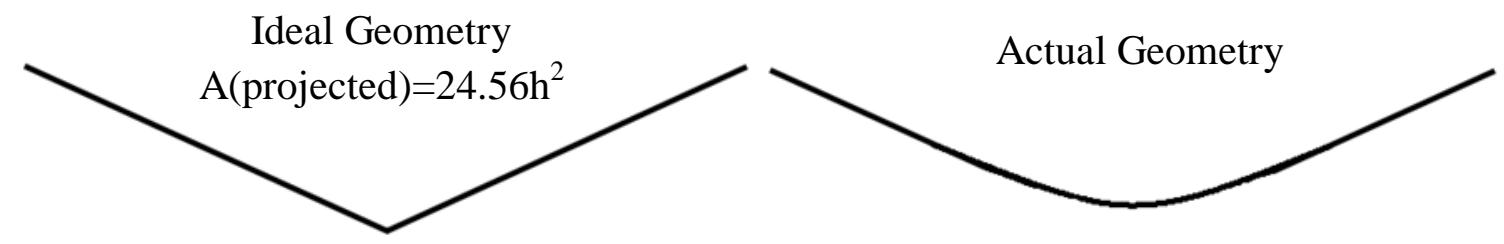

Figure 12: The original nanoindentation method presumes an ideal indenter geometry that is not representative of the actual tip geometry. The indenter tip will have a radius of curvature from manufacturing and further rounding occurs from use.

An atomic force microscope (AFM) can be used to measure the profile of the indenter tip. The AFM scan can be analyzed to produce a projected area of the tip compared to the depth (h) of the indenter (Figure 13). The true projected area of the 
indenter is for the most part greater than the ideal projected area because of the rounded $\operatorname{tip}^{41}$. The ratio of the actual indenter area and the ideal indenter typically changes rapidly for the first 50 to $100 \mathrm{~nm}$ of the indenter depth depending on the radius of curvature of the indenter. Depending on the condition of the indenter tip, the actual indenter area can be up to double that of the ideal tip. The measured projected area of the indenter can be used to replace the ideal area for calculating hardness and elastic modulus, resulting in greater accuracy.

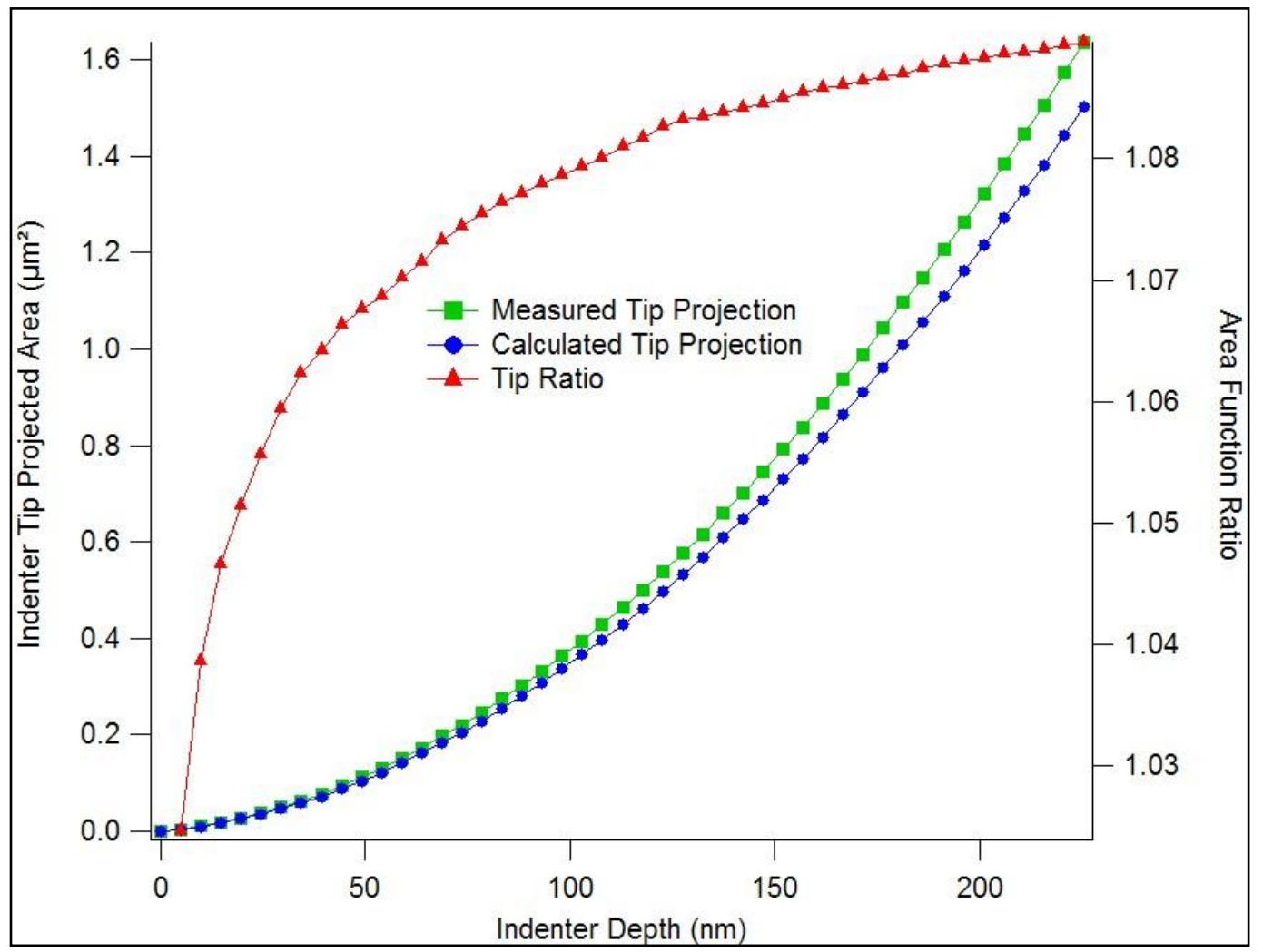

Figure 13: An example of the measured projected area of a new indenter tip at any given depth compared to the ideal tip projected area. The ratio between the two is not constant and changes the most within the radius of curvature of the tip.

\subsubsection{Indentation Material Response}

NiTi stain hardens under compressive deformation ${ }^{51}$. Strain hardening materials often do not respond to indentations in an elastic manner that is assumed by the Oliver and Pharr method ${ }^{43}$. An indentation causes both an elastic and plastic response from the 
sample material. Nanoindentation contact area is modeled after the elastic response of the material. The elastic response model works for the majority of metals. Sometimes the plastic component of the indent creates a response that cannot be modeled using elastic theory. The result of the plastic phenomenon is pile-up or sink-in (Figure 14). Pile-up is the case when the material uplifts around the indenter causing an increase in the contact area of the indenter over the ideal contact area. The other response is when the material sinks-in further than the elastic model predicts. This decreases the contact area from the expected model. Sink-in and pile-up do not occur to all materials. Pile-up usually happens to materials with low yield strength to elastic modulus ratio $\left(\sigma_{y} / E\right)$ and nonstrain-hardening materials ${ }^{47}$. Pile-up occurs because of the more localized plastic zone creating the material uplift ${ }^{52}$. Sink-in usually occurs to materials with a high $\sigma_{\mathrm{y}} / \mathrm{E} \mathrm{ratio}^{53}$. Many stain-hardening materials exhibit sink-in. Sink-in occurs because the yield strength increases with the induced strain. During indentation testing the material under the apex of the tip hardens leaving the surrounding material more susceptible to plastic deformation $^{54}$. The material away from the indenter becomes deformed and the indentation zone sinks-in. The ratios are guidelines of when sink-in or pile-up is more likely to occur but indents must always be inspected for this phenomenon. 

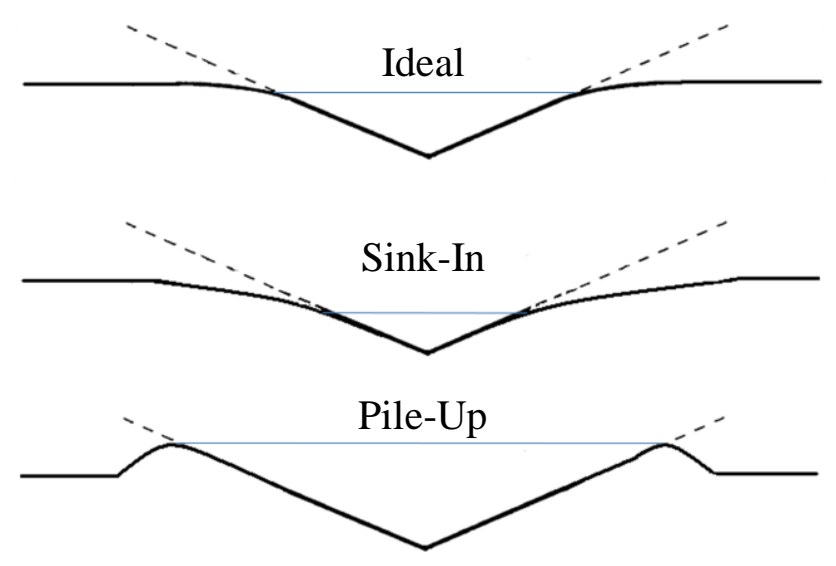

Figure 14: Three possible material responses that can affect the contact area of the indenter: the ideal condition, sink-in, and pile-up. The Oliver-Pharr method does not account for sink-in or pile-up. AFM imaging of the residual indents can be used to estimate the actual contact area.

Pile-up and sink-in affect the accuracy of the indentation results. Pile-up can cause an overestimate of the hardness by as much as $60 \%$ and the elastic modulus up to $30 \%^{54,55}$. The contact area affects hardness more because hardness is proportional to 1/A (Equation (4) while the elastic modulus is $1 / \sqrt{A}$ (Equation (5). If pile-up or sink-in occurs, the residual impression of the indentation varies from the ideal modeling. Pile-up will cause bulging around the perimeter of the indent while with sink-in the residual indent will have an inward arching perimeter (Figure 15). Different techniques have been studied to determine the contact area for samples that exhibit a sink-in or pile-up ${ }^{56}$.
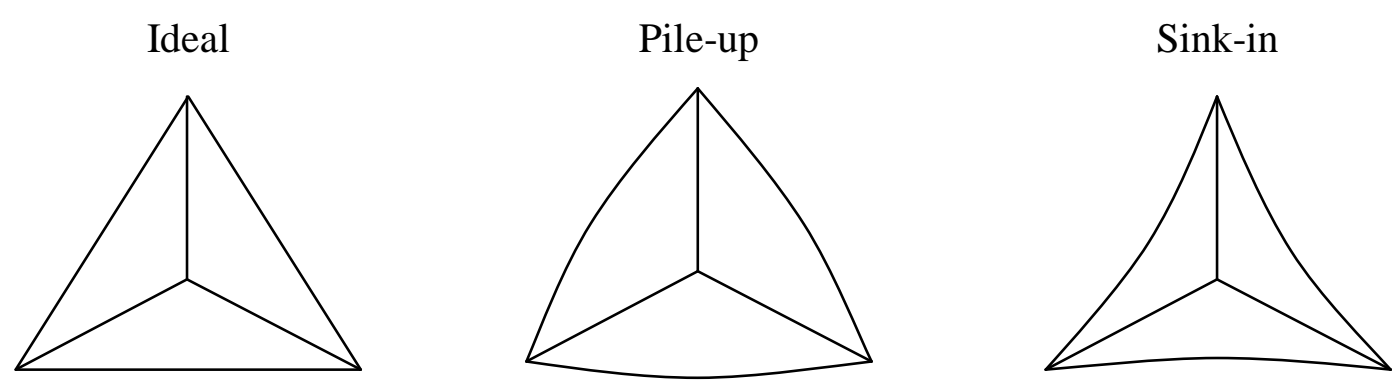

Figure 15: Residual impression of a Berkovich indenter with three different material responses: ideal elastic behavior, pile-up, and sink-in. 


\subsubsection{Other Uses of Nanoindenting}

Nanoindenting is mainly used to determine hardness and elastic modulus of the sample material. The uses of the nanoindenter have expanded beyond hardness and elastic modulus. It can provide information on stain-hardening, cracking, phase transformations, creep, and energy absorption ${ }^{57}$. Some of the properties that can be calculated are stain-hardening exponent, fracture toughness, and viscoelastic properties. Some of the newer and more advanced techniques can study the properties of materials at high temperatures, scratch resistance, acoustic emission testing, and film adhesion. Structures of MEMS devices such as beams, diaphragms, and electrical traces can be also be studied.

\subsection{Sputtering - Physical Vapor Deposition}

Physical vapor deposition (PVD) is a general term to describe a variety of methods to create solid thin films. One of the most common PVD methods is sputtering deposition. In 1852, Grove produced the first thin metal film created by sputtering deposition. The films were created by the deposition of individual atoms on a substrate that condense to produce a thin film by a bottom-up process. PVD is the group of processes in which material is atomized into a vapor from a solid or liquid source, transported in the form of a vapor through a vacuum or low-pressure gaseous environment to the substrate where it condenses into a solid film ${ }^{58}$. The process produces films with a thickness ranging from a few atomic layers to a couple micrometers.

\subsubsection{Physical Sputtering Deposition Process}

Physical sputtering process is a type of PVD that physically vaporizes atoms from a source by transferring momentum from energized particles bombarding the surface. The 
energized particles are typically from ions of a gas created from an electric field accelerated at the material ${ }^{59}$. The ionized gas is known as plasma, which is a gas that contains enough ions and electrons to be a good conductor ${ }^{60}$. The plasma is usually in a vacuum with a low pressure of less than five mTorr for sputtering deposition.

The physical sputtering process occurs in a vacuum chamber that is often reduced to a base pressure of $10^{-6}$ to $10^{-7}$ Torr to create a clean environment for deposition. The pressure is than increased with a gas that can be ionized (typically argon) to a pressure in the low mTorr range. Argon is the most common gas used for sputtering deposition because it is inert with a greater mass than helium and neon and has a fraction of the cost of krypton and xenon. The vacuum chamber has a cathode that is the material to be sputtered, also known as the target (Figure 16). The anode is the substrate that is being coated with the target material. A potential is placed between the anode and cathode causing the gas to ionize. The ionized gas bombards the target and can physically penetrate the surface. The ionized gas bombarding the target creates a cascade of collision inside the target, some of the momentum is transferred back to the surface of the target and atoms can be ejected from the surface (sputtering) ${ }^{58}$. The ejected atoms travel across the chamber and condense on the surface of the substrate. The atoms can also have collisions with particles in the chamber or condense on the walls of the chamber. 


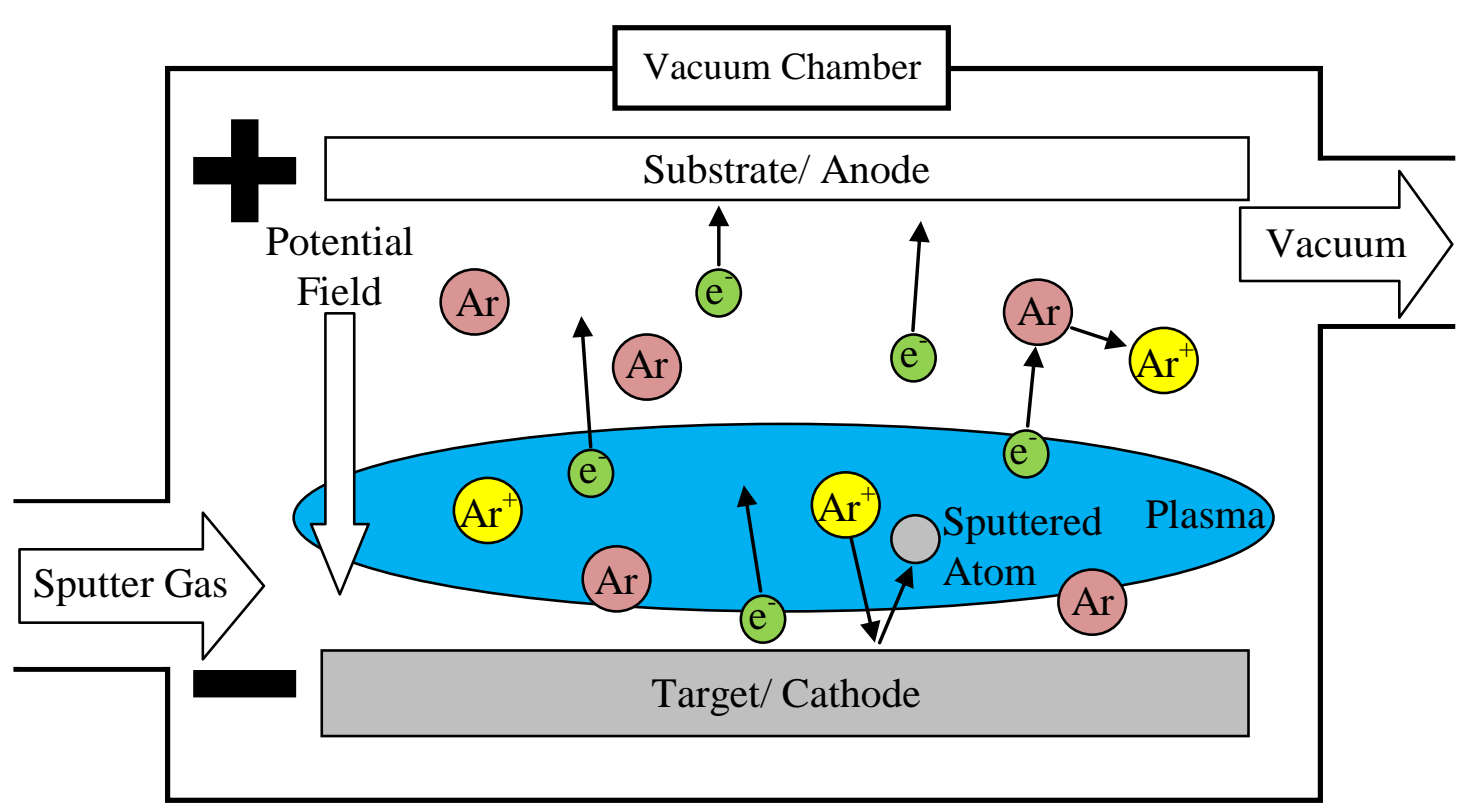

Figure 16: Physical sputtering process schematic. Ionized argon atoms bombard a target material and sputter the material out. The sputtered material condenses and creates a thin film of the sputtered material.

The efficiency of the sputtering process is increased by having magnetic fields over the surface of the target by confining electrons that ionize the argon atoms (Figure 17). The magnetic field is produced from magnets under the target. The magnets are arranged to create a magnetic field that deflects electrons to create a high flux of electrons circulating above the surface of the target. The flux of electrons creates highdensity plasma above the surface of the target producing an increased bombardment of ions into the surface of the target ${ }^{61}$.The magnetic field increases the sputtering rate and allows for decreased chamber pressures. The chamber pressure can be as low as $10^{-5}$ Torr for the sputtering process ${ }^{62}$. Operating pressure without a magnetic field is typically between 10 to $20 \mathrm{mTorr}^{62}$. The lower chamber pressure is necessary for improved film properties. The chamber pressure affects the intrinsic film stress ${ }^{63}$. At low pressure there are few collision between the vapor phase sputtered atoms and the atoms in the gas. The fewer collisions allow the sputtered atoms to reach the substrate with higher energy. As 
the pressure of the gas increases, the momentum of the sputtered atoms is decreased. As the pressure increases the film density decreases and the energy of the atoms are decreased. The decrease in energy reduces the atoms surface mobility and the films will grow in a columnar arrangement. A pressure can be achieved that balances the energy of the sputtered atoms to produce the desired film properties.

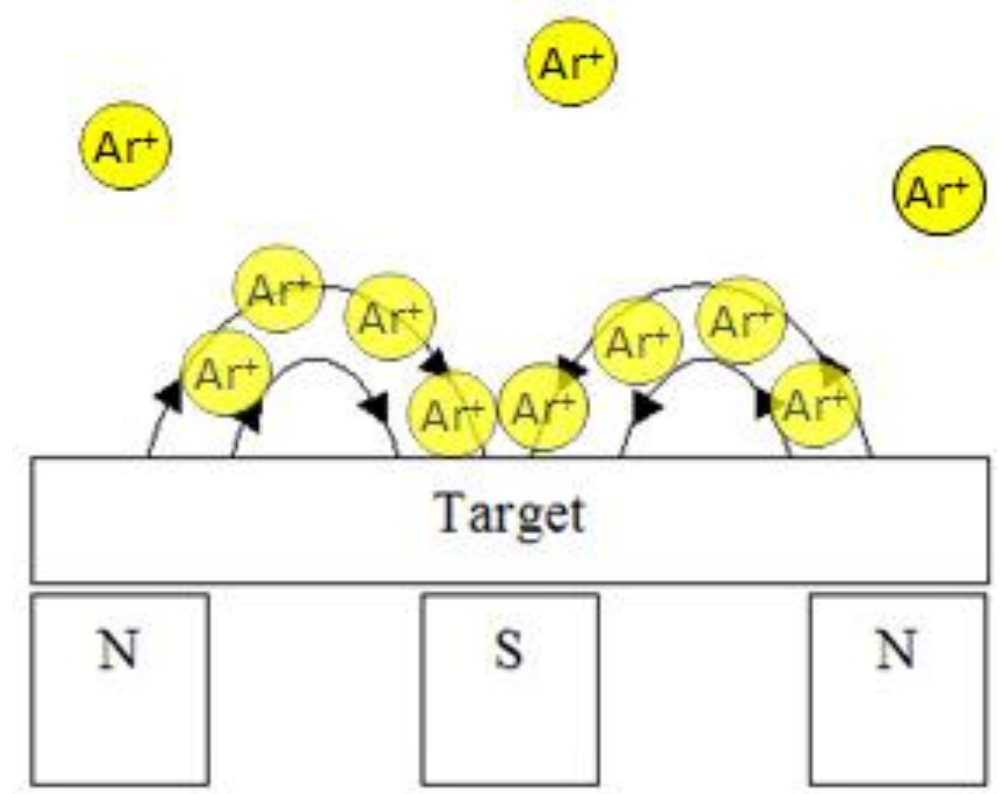

Figure 17: Cross-sectional view of the sputtering target with the magnets below the target to increase sputtering efficiency.

\subsubsection{Processing Parameters that Affect Material Properties}

The material properties of the deposited films are affected by many factors. Some of these factors include substrate surface conditions, design and geometry of the machine, post deposition-processing, temperature of the substrate, pressure, and applied power. The important variable deposition parameter for this study was the chamber pressure and the applied power to the guns. 


\subsubsection{Applied Gun Power}

The applied power to the guns directly affects the sputter rate. An increase in gun power increases the sputter rate. An increased power can also provide increased kinetic energy to the sputtered atoms. Kinetic energy can provide more mobility to the atoms upon condensing on the substrate allowing the atoms to spread and create an increase in film uniformity. The increased kinetic energy can also compress the atoms below the contact point of the bombarding atom. High kinetic energy can lead to atomic peening where the surface atoms are knocked into the interior of the film, increasing the film density ${ }^{63}$. The kinetic energy is transferred into the substrate producing heat and/or deforming the atomic structure below. An increase in substrate heating can cause film stress as the sample is cooled to room temperature from differences in thermal expansion coefficients between the film and the substrate.

\subsubsection{Chamber Pressure}

The chamber pressure affects the energy of the deposited atoms on the substrate. Higher pressures produce lower density films that contain more defects while lower pressure creates denser films with fewer defects ${ }^{64}$. NiTi films deposited at pressures greater than 7.5 mTorr are brittle, have poor adhesion, and crack from tensile stress ${ }^{65}$.

\subsubsection{Film Stress}

Film stress is a result of non-ideal separation of the atoms that create the film. Film stress can be a result of energy of the atoms upon reaching the substrate, differences in thermal expansion, and lattice mismatch. Compressive film stress is caused by atomic spacing smaller than the ideal spacing (Figure 18). The atoms want to spread away from each other but the substrate prevents the atoms from spreading out. The compressive 
stresses bow thin substrates such as silicon wafer. Atoms that have atomic separation greater than the ideal spacing cause tensile stress in the film. Tensile stresses are caused by the atoms pulling together but the substrate keeps the atoms spread out. The cause of residual stress can be from atom mobility upon condensing on the substrate, bonding of atoms to the substrate, different thermal expansion between the film and substrate, and atomic peening ${ }^{66,67}$. The difference in the thermal expansion between NiTi and silicon increases the tensile stresses in the NiTi film by $\sim 1.5 \mathrm{MPa}$ per degree Celsius on cooling from the deposited temperature to room temperature ${ }^{68}$. If the intrinsic film stress becomes greater than the film can withstand, crack, hillocks, delamination, or voids in the film can form.

\section{Compressive Stress}
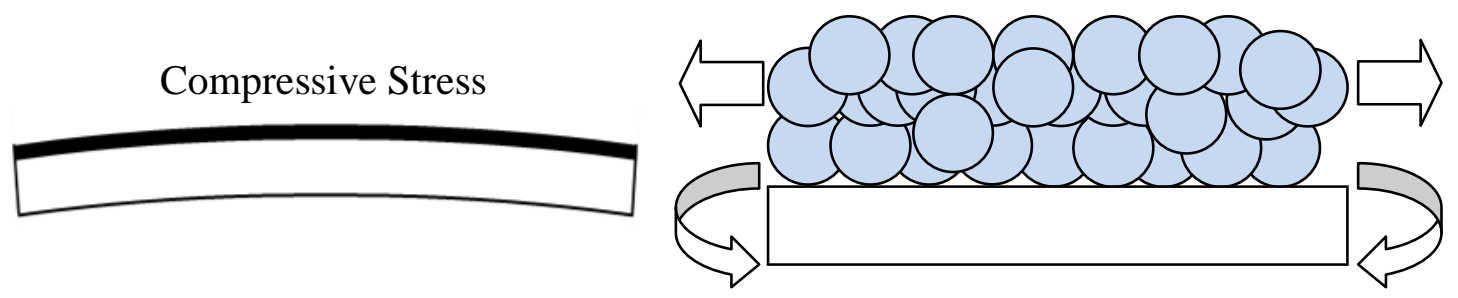

Tensile Stress
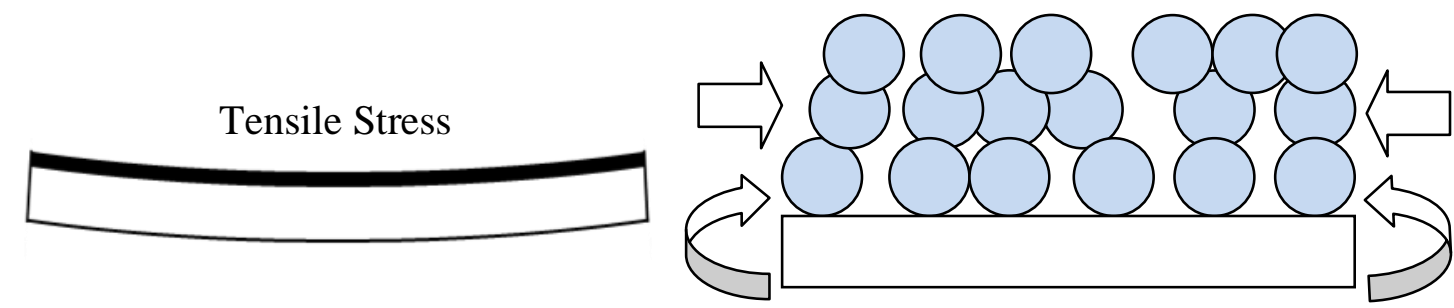

Figure 18: The atomic spacing causes intrinsic stresses of the thin film. Atomic spacing that is smaller than ideal atomic spacing causes compressive stresses. Greater than ideal atomic spacing causes tensile stress. Intrinsic film stress can be measured by the change in the radius of curvature of thin substrates upon the deposition of the film.

\subsubsection{Sputtering Deposition Applications}

The sputtering deposition process utilized for this research was a dc magnetron sputter deposition. Sputtering deposition is typically used for thin metal films on 
semiconductors, architectural glass, compact disc reflective coatings, magnetic films, dry film lubrication, and decorative coatings.

\subsection{NiTi Indentations}

Nanoindentation work of NiTi has received much attention with the increased interest of $\mathrm{NiTi}$ as a MEMS device material. Nanoindentation studies are used to determine the exact properties of NiTi for the processing parameters used to create the thin film. Residual stresses, contamination, composition, and heat treatment are some of the factors that affect the mechanical properties. Thin film NiTi was produced by using DC magnetron sputtering for many nanoindentation studies ${ }^{69,70,71,72}$. Indentations performed with a Berkovich tip leaving residual indent depths of $10 \mathrm{~nm}$ or maximum loads of $100 \mu \mathrm{N}$ have been shown to recover completely upon heating ${ }^{73}$. Larger indents all the way up to the micron scale have about a $40 \%$ depth recovery upon heating ${ }^{74}$. The $40 \%$ recovery was from a fully developed indent from an indenter that induces $8 \%$ strain. As the indentation depths decrease below $100 \mathrm{~nm}$ recovery upon heating can reach $80 \%{ }^{75}$. The higher indentation recovery was due to the lower induced stress from the rounded tip of the indenter. Others observed the increase in indentation recovery at indentation depths of $70 \mathrm{~nm}^{73}$. Indentation recovery increases at lower depths because of the reduced stain from blunted indenter tips. The Berkovich indenter was not atomically sharp, so the stress does not produce the full stain of the Berkovich tip typically until after a $100 \mathrm{~nm}$ indentation depending on the radius of curvature of the tip. The variation of indentation recovery can be a product of how sharp the tip was for each study. Another factor for the recovery of the indentations was the processing of the NiTi thin film. The majority of the publications on nanoindenting NiTi revolve around the indentation 
recovery from the martensitic phase transformation. Little information has been published about the effects of processing parameters on the material properties measured by nanoindentation of NiTi thin films. 


\section{CHAPTER 3 - Processing and Testing}

This chapter covers the process used to create thin films of NiTi SMA on a silicon wafer substrate. A silicon wafer was used because it is the standard substrate for microfabrication. The process started with a bare silicon wafer that was oxidized followed by the sputtering deposition of chromium, NiTi, and chromium. The sample was annealed to crystallize NiTi into a shape memory alloy. The chromium was than etched away leaving a NiTi SMA thin film.

\subsection{Silicon Preparation}

A silicon wafer was used as the substrate for nickel titanium deposition. The wafer type used for this research was a $100 \mathrm{~mm}$ diameter, (100) orientation, $500 \mu \mathrm{m}$ thick, n-type, with a resistivity of $1-20 \mathrm{ohm}-\mathrm{cm}$. Each wafer was scribed with a diamond tip pen on the back for identification purposes. NiTi $001,002 \ldots$ was used to identify each wafer through the processing. The wafers were cleaned in a solution of nine parts sulfuric acid $\left(\mathrm{H}_{2} \mathrm{SO}_{4}\right)$ and one part hydrogen peroxide $\left(\mathrm{H}_{2} \mathrm{O}_{2}\right)$, also known as piranha, at $70^{\circ} \mathrm{C}$ for 15 minutes to remove all organics from the surface. The wafers were rinsed in deionized (DI) water and placed in a solution of buffered oxide etch (BOE) for 30 seconds to remove any native oxide on the surface of the wafer. The wafers were than cleaned in the spin rinse dryer to complete the cleaning process.

\subsection{NiTi Deposition}

\subsubsection{Silicon Dioxide Growth}

An oxide of approximately $500 \mathrm{~nm}$ was grown by wet oxide diffusion. The furnace was pre-heated to $900^{\circ} \mathrm{C}$. While the furnace was reaching temperature, the quartz 
boat was loaded with the freshly cleaned wafers. Two sacrificial wafers were placed in front and behind the row of wafers to be oxidized. The sacrificial wafers were used to reduce turbulence of the steam flowing over the wafers and produce a more uniform oxide layer. The furnace was purged with nitrogen once the temperature reached $900^{\circ} \mathrm{C}$. This was done to prevent any oxidation of the wafers before the furnace had reached the operating temperature. The wafers were loaded into the furnace at a rate less than $30 \mathrm{~cm}$ per minute to prevent thermal shock. Once the wafers were centered in the furnace, the temperature was increased to $1050^{\circ} \mathrm{C}$. When the temperature reached $1050^{\circ} \mathrm{C}$ the nitrogen was turned off and high purity oxygen was bubbled through DI water to create a high purity steam that flowed through the furnace. The steam created a wet oxide that grows at a faster rate than a dry oxide. A wet oxide grows faster than a dry oxide process because an $\mathrm{H}_{2} \mathrm{O}$ molecule is smaller than $\mathrm{O}_{2}$ and diffuses through silicon dioxide more readily ${ }^{76}$. The wet oxidation was used because oxide uniformity was not necessary and wet oxides grow faster. The wafers were left in the furnace for one hour to create a silicon dioxide layer of approximately $500 \mathrm{~nm}$. After an hour, the oxygen was turned off and the nitrogen was turned back on. The furnace was turned off and the wafers were allowed to cool to at least $700^{\circ} \mathrm{C}$ before removing from the furnace. The oxide thickness was measured using the Filmetrics F20 reflectometer.

\subsubsection{Film Stress by Radius of Curvature}

Measurements were made to determine intrinsic film stress of each deposited film. Film stresses were determined by the change in radius of curvature of the substrate from before the film was deposited to after the deposition. Radius of curvature measurements were performed with a contact stylist profilometer. The measurements 
were made with the wafer on a three-point kinematic stress measurement stage provided by Ambios for the XP-1 profilometer. The wafer was placed on the stage with the major flat closest to the operator. The same scan settings were used for all radiuses of curvature measurements. The scan settings were the same for all radius of curvature measurements: speed of $0.1 \mathrm{~mm} / \mathrm{sec}$, the scan length of $10.0 \mathrm{~mm}$, and a z-range of $100 \mu \mathrm{m}$. Once the scan was complete, the Ambios software was used to measure the radius of curvature. A minimum of ten scans were used to determine an average.

The first radius of curvature measurement was performed on the oxide layer. This provided an initial radius. After each deposition, the radius of curvature was measured with the profilometer using the three-point kinematic stress measurement stage. The stresses in each film were approximated by using Stoney’s equation ${ }^{77,78,79}$. Stoney’s equation an accepted method for determining film stress but there are oversimplification and assumption. The five main assumptions include the (1) thickness of the film is much thinner than the substrate and the lateral length of the sample is much larger than the substrate thickness; (2) strains and rotations of the substrate are infinitesimal; (3) the film and substrate are homogeneous, isotropic, and linearly elastic; (4) all film stresses are inplane isotropic while all out-of-plane stress are shear stresses; and (5) all stresses and curvature is uniform over the surface ${ }^{80}$. Some of the assumptions are the properties and thickness layers between the substrate and the film are negligible and effects due to gravity. In Stoney's equation (Equation 7), $\sigma$ is the stress in the film, E is the elastic modulus of the substrate, $v$ is the Poisson's ratio of the substrate, $t_{\mathrm{s}}$ is the thickness of the substrate, $\mathrm{t}_{\mathrm{f}}$ is the thickness of the film, and $\mathrm{R}$ is the change in the radius of curvature measured with the profilometer. The thickness of each film was determined by measuring 
the step height of the film with the Ambios XP-1 profilometer. The measurements were taken along the parameter of the wafer where part of the substrate holder extends over the substrate and acts as a shadow mask at six points around the wafer. The six tabs surrounding the wafer covers a small portion of the wafer so the sputtered atoms could not condense on that portion of the substrate. With the deposition parameters used, the chromium layer had a tensile stress while the NiTi layer had a compressive stress. The deposition of the chromium was at a lower power than what was required to procude a film with minimal stresses. Depending on the application of the deposited film, the stress can be changed by the deposition parameters. Measuring film stress is important because the stresses affect mechanical properties and if the stress is great enough, the result can be delamination, cracking, and buckling of the film. Film stress can increase the phase transformation temperature (Figure 19) ${ }^{34}$. The martensitic transformation is stress induced; the increase of stress changes the free energy in the system and increases the transformation temperature.

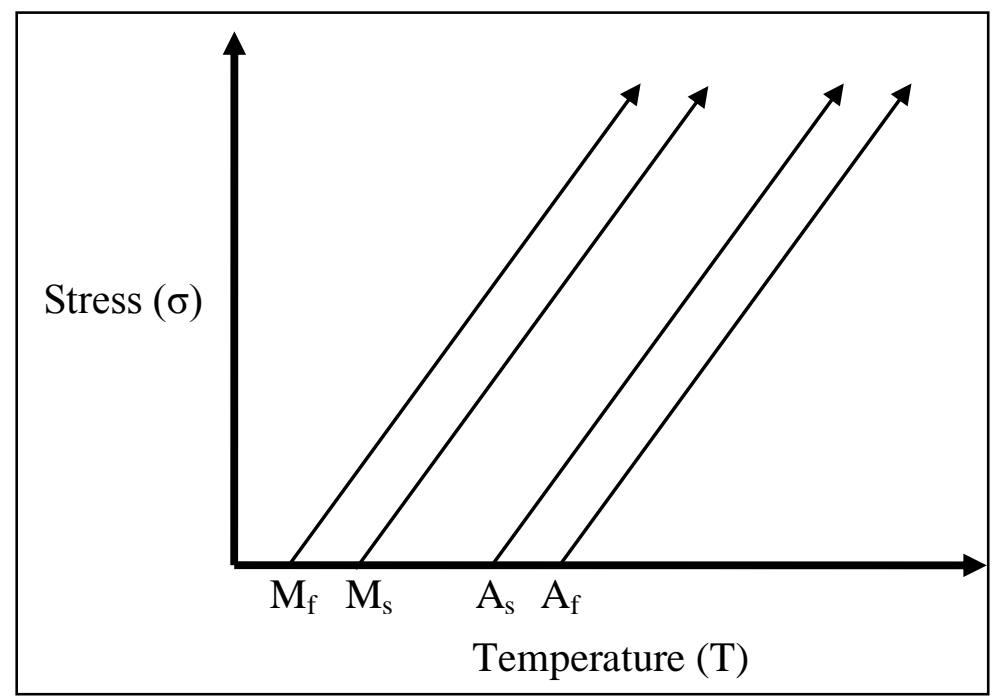

Figure 19: Affects of stress on the transformation temperature of NiTi. An increase in stress increases the transformation temperature. 


$$
\sigma=\left(\frac{E}{1-v}\right)\left(\frac{t_{s}^{2}}{t_{f}}\right)\left(\frac{1}{6 R}\right)
$$

\subsubsection{Bottom Chrome Adhesion Layer Deposition}

Before depositing the NiTi layer, an adhesion layer was deposited on the oxide because NiTi will not adhere well to oxide. An oxygen-active material is necessary as an adhesion layer to allow diffusion between the oxide and the adhesion layer or the film will easily delaminate ${ }^{81}$. Oxygen-active materials include $\mathrm{Ti}, \mathrm{Cr}, \mathrm{Mo}$, and $\mathrm{Zr}^{82}$. Titanium has been experimentally shown to be unsuccessful as an adhesion layer for $\mathrm{NiTi}^{83}$. The formation and intermixing of brittle $\mathrm{TiO}_{2}$ layers cause delamination under scratching ${ }^{84}$. Chromium has been successfully used as an adhesion layer for NiTi; however, chromium has draw back because it reduces the phase transition temperature of $\mathrm{NiTi}^{85}$. Previous work done in the Microfabrication Laboratory at California Polytechnic State University - San Luis Obispo has shown success with using chromium as an adhesion layer and there are not many options for adhesion layers. For this reason, chromium was used as the adhesion layer for this research. The chromium adhesion layer must be less than 50 $\mathrm{nm}$ in thickness ${ }^{58}$. This is the recommended thickness to avoid stress-induced problems such as delaminating and cracking.

The oxidized wafer was cleaned in $70^{\circ} \mathrm{C}$ piranha etchant for 15 minutes. The piranha was rinsed off in DI water and dried with compressed nitrogen. The wafer was placed in the substrate holder chuck of the Rohwedder sputtering system for the deposition of the chromium adhesion layer. Using the standard operating procedures for Rohwedder Sputter Coater (Appendix A), the chrome target was used for Gun B and the titanium target for Gun A. The sputtering deposition chamber was pumped down to a 
base pressure of less than $1 * 10^{-6}$ torr. Pre-sputtering was used to clean the target and lowers the base pressure of the deposition chamber. The pre-sputtering gun powers were 350 watts for Gun B (Cr) and 104 watts for Gun A (Ti). Pre-sputtering was done for 30 minutes with an ultra high purity (UHP) argon pressure of 2.1 mTorr on the dual capacitance monometer. Once pre-sputtering was complete, Gun A was turned off and the shutter was closed. Gun A was not used during the deposition of the chromium adhesion layer but was used during pre-sputtering to decrease the chamber pressure and clean the titanium target. Titanium is a gettering material that absorbs trace amounts of oxygen in the chamber. The deposition of chromium began by opening the main shutter to sputter chromium on the silicon substrate for one minute creating a thin film with a thickness of $50 \mathrm{~nm}$. Upon completion of the sputtering process, the system was turned off and allowed to cool before the chamber was vented to atmospheric pressure. The radius of curvature was determined as previously discussed.

\subsubsection{Nickel Titanium Deposition}

Sputtering deposition is the most common thin film deposition technique that produces NiTi films with the same properties as the bulk material ${ }^{86}$. A one target setup of a $50 \%$ titanium and $50 \%$ nickel will not produce a stoichiometric film because titanium has a lower sputtering yield than nickel ${ }^{87,88,89,90}$. The lower titanium yield is because of the oxide formation of titanium and the difference in angular flux distribution of nickel and titanium ${ }^{91}$. A two target system was used to produce the NiTi film, one target was pure titanium and the other was an alloy of nickel and titanium ${ }^{88,92,93}$. A 48 atomic percent nickel and 52 atomic percent titanium target replaced the chrome target on Gun B. The pure titanium target remained in Gun A. Each gun was supplied different 
deposition powers: $\mathrm{Ti}(\mathrm{Gun} \mathrm{A})$ at 104 watts and $\mathrm{NiTi}(\mathrm{Gun} \mathrm{B})$ at 346 watts during the 30 minute pre-sputter ${ }^{94}$. An argon pressure of 2.1 mTorr on the dual capacitance monometer was used. The argon sputtering deposition was performed with the same parameters as the pre-sputtering for 45 minutes. The deposition parameters yielded a NiTi layer of approximately $2.5 \mu \mathrm{m}$. The radius of curvature was determined with the profilometer allowing the film stress to be calculated. The film stress with the total power of 450 watts was approximately $300 \mathrm{MPa}$. At this point, an as-sputtered amorphous NiTi film was processed on a silicon wafer. Some wafers were used for experimentation at this point in the process to test the as-sputtered properties of NiTi. The rest of the process was used to create SMA NiTi films.

\subsubsection{Top Chrome Oxidation Protection Layer Deposition}

The final layer of chromium prevented oxidation of the titanium during the annealing and crystallization of the NiTi films. All parameters were repeated from the chromium adhesion layer to produce a $50 \mathrm{~nm}$ thick film. The result was a silicon substrate with layers of silicon oxide, chromium, nickel titanium, and chromium (Figure 20).

\begin{tabular}{|cl|}
\hline $\mathrm{Cr}$ & $0.05 \mu \mathrm{m}$ \\
\hline $\mathrm{NiTi}$ & $2.5 \mu \mathrm{m}$ \\
\hline $\mathrm{Cr}$ & $0.05 \mu \mathrm{m}$ \\
\hline $\mathrm{SiO} 2$ & $0.5 \mu \mathrm{m}$ \\
\hline $\mathrm{Si}$ & $500 \mu \mathrm{m}$ \\
\hline
\end{tabular}

Figure 20: The layering of sputtering deposition steps to obtain the thin film NiTi. 


\subsection{High Vacuum Annealing}

The as-sputtered NiTi films were amorphous and not crystallized into a shape memory alloy at this point in the process. Some films of other materials crystallize in the sputtering process from the heat of the deposition; however, NiTi remains amorphous through the process unless heat is added to the substrate. The NiTi films were annealed in a vacuum at the solution treatment/solvus temperature, $550^{\circ} \mathrm{C}$ for an hour to achieve a crystallized shape memory alloy ${ }^{40,94,95}$. Annealing temperatures should be performed at the lowest temperatures and for the minimum annealing time required to reduce the reactions between the substrate and the NiTi film ${ }^{96}$. The Rohwedder deposition system was converted to a high vacuum annealing system. The sputtering guns were removed and a $100 \mathrm{~mm}$ wafer heating chuck was installed so the vacuum chamber could be used to anneal wafers in high vacuum. The Rohwedder SOP was used to convert the system for high vacuum annealing (Appendix A). The wafer was centered on the heating chuck and the system was pumped down to at least $1 \times 10^{-6}$ torr on the hot cathode. Once the vacuum pressure was achieved, the heater was turned on with a set point of $550^{\circ} \mathrm{C}$. Once the temperature reached $500^{\circ} \mathrm{C}$ the timer was started for one hour. After the hour had past, the heater was turned off. The wafer was allowed to cool under vacuum to prevent oxidation. The top chrome layer was a sacrificial layer to prevent oxidation of the titanium in the NiTi layer from trace amounts of oxygen in the vacuum chamber. Once the heater was cooled to less than $300^{\circ} \mathrm{C}$ the venting process was initiated. After the chamber was vented, the wafer was removed from the heating chuck and placed on a piece of aluminum to reach room temperature. 


\subsection{Etch Top Chromium Layer}

At this point in the process, there was a silicon substrate with four layers on top: silicon dioxide, chromium, NiTi, and chromium. It had been annealed so the NiTi was crystallized into a shape memory alloy. The NiTi layer was exposed by etching away the top chromium layer. A commercial chromium etchant was used that has selectivity of etching chromium and the oxide $\mathrm{Cr}_{2} \mathrm{O}_{3}$ without etching NiTi. The commercial etchant used was an acetic acid and ceric ammonium nitric base that was advertised to etch chromium at $32 \AA / \mathrm{sec}$ at room temperature. The wafer was inserted in a Teflon cassette and placed in the etchant. The wafer was agitated in the solution and the complete removal of the chromium was visible to the naked eye because of the reflectivity and color difference between the NiTi and chromium layer. The wafer was left in the chromium etchant longer than the calculated time, by ten percent to insure the chromium was completely removed.

\subsection{Results}

The fabrication process resulted with a silicon substrate with layers of silicon oxide, chromium, and a top layer of nickel titanium. The nickel titanium layer was a 2.5 $\mu \mathrm{m}$ thin film that was annealed into a shape memory alloy. The residual stress in the NiTi film before annealing was $\sim 300 \mathrm{MPa}$ of compressive stress. Measurements of the film stress after the heat treatment process were not consistent or believed to be accurate. The stress relief from heat treatment could not be determined with the available equipment and techniques. 


\subsection{Discussion}

The processing parameters used to create thin film NiTi SMA was a result of previous work done in the Microfabrication Laboratory at California Polytechnic State University - San Luis Obispo ${ }^{94,97,98,99}$. The process used was developed to create shape memory alloy cantilevers for MEMS applications. NiTi adheres well to silicon once annealed ${ }^{85}$ but electrical isolation of devices is needed for most MEMS devices and is provided by the oxide layer. The oxide requires the use of an adhesion layer because NiTi has poor adhesion to silicon dioxide. Chromium as an adhesion layer is not an ideal choice because chromium affects the phase transition temperature by substituting nickel in the B2 structure. According to the Hume-Rothery rule ${ }^{100}$, chromium is only partially soluble in NiTi. A different adhesion layer would be ideal for NiTi. The adhesion of NiTi on $\mathrm{SiO}_{2}$ increases upon annealing. One proposed technique is to break up the NiTi deposition process into two steps: a thin layer of NiTi that is annealed at $700 \mathrm{C}$ to promote interdiffusion with the oxide followed by the deposition process previously described ${ }^{101}$. The adhesion of NiTi on substrates such as $\mathrm{Si}_{3} \mathrm{~N}_{4}$ and poly-silicon are necessary for MEMS devices but have not been well studied ${ }^{5}$. A thin layer of poly-silicon could be deposited on the oxide layer as the adhesion layer for $\mathrm{NiTi}^{83}$. Silicon on insulator (SOI) wafers could be used to provide electrical insulation as another alternative to depositing adhesion layers on the oxide.

The protective chromium layer used to prevent titanium oxidation in the NiTi during the annealing process should be researched for removal. The diffusion of chromium into the top layer of the NiTi film could be occurring during the annealing process. The addition of chromium could change the mechanical properties of the NiTi. 
The transition temperature of NiTi could also be decreased by the addition of the chromium. The oxidation of the titanium in a NiTi film under heating in a vacuum chamber with a pressure of $10^{-7}$ Torr or lower was reported to be negligible ${ }^{96}$.

Duel sputtering targets is the most precise way of controlling the composition of the thin film. A common practice is one target is an alloy of nickel-titanium and the other target is pure titanium. The reason for this is that nickel sputters more readily than titanium. A NiTi target will deposit a film that is 2-4 atomic percent nickel rich over the target $^{87}$. The problem of having a target with one element of lower sputtering yield is the target will become enriched with the material with the lower sputtering yield ${ }^{102}$. As the alloyed target is used, the overall percentage of titanium in the NiTi target will increase and change the composition of the film with increased use because of the different sputtering yields of nickel and titanium. This problem can be eliminated by using the two-target system without an alloyed target: one of pure titanium and the other of pure nickel. Sputtering pure nickel has challenges because it is a magnetic material and distorts the magnetic field above the $\operatorname{target}^{103}$. Certain techniques can overcome this problem such as using a RF-DC coupled unbalanced magnetron sputtering ${ }^{103}$. 


\section{Chapter 4- Process Evaluation: Shape Memory Properties}

Once the processing of the NiTi SMA films was complete, the films were tested to determine if the deposition process and heat treatment produced a SMA. This chapter covers the five different tests that were performed to evaluate the films to insure a SMA was the result of the process.

\subsection{SMA: Visual Evaluation}

The first of these tests was a visual inspection of the film. The as-sputtered film produced a mirror like surface that was highly reflective. Upon annealing, the stable phase at room temperature was martensite. Martensite has a twinned microstructure that causes the film to appear hazy or cloudy at room temperature ${ }^{85}$. The hazy appearance was a result of the twinned martensite structure. The surface appearance was a result of the crystal structure twinning and the volume increase of the martensite structure. As the temperature of the film was increased to the austenitic phase, the twinned structure transforms to a non-twinned structure that is smooth and highly reflective. To test this, the wafer was placed on a hot plate where the films appearance transformed from a hazy surface to a highly reflective surface. Once this transformation was observed, the wafer was removed from the hot plate and placed on an aluminum plate to cool to room temperature. As the wafer cooled, the film was observed to return to the hazy appearance. This experiment was an indication that the sputtering and annealing process produced a SMA.

\subsection{SMA: Differential Scanning Calorimeter}

The sputtering and annealing process was also confirmed by a differential scanning calorimeter (DSC). DSC is the standard for determining the phase 
transformation temperatures of NiTi because most chemical analysis methods are not precise enough to measure subtle differences in the composition ${ }^{104}$. The sample preparation for using the DSC required removing the NiTi from the substrate. This was achieved by following the previously described process of creating the NiTi film with the exception of the chromium adhesion layer. NiTi has poor adhesion to silicon dioxide; therefore, the NiTi layer was sputtered directly onto the silicon dioxide surface to achieve easy removal. The chromium protective top layer was deposited on top of the NiTi. The wafer was then annealed under high vacuum for one hour at $550{ }^{\circ} \mathrm{C}$. The chromium top layer was etched away leaving an annealed NiTi film on silicon dioxide. The NiTi film was delaminated by using a diamond scribe to score the backside of the wafer along the (111) crystal plane and notching the wafer causing the silicon to break along the crystallographic plan. The difference of stiffness between the silicon and the NiTi allows the NiTi to remain intact when the silicon cracked. With the silicon substrate cracked, the NiTi was peeled off the silicon dioxide layer in large sections.

The NiTi film was sectioned and $14 \mathrm{mg}$ were loaded in the DSC for phase transition analysis. The DSC temperature was lowered to $-20^{\circ} \mathrm{C}$ then increased to $150^{\circ} \mathrm{C}$ and back to $-20^{\circ} \mathrm{C}$ at a rate of $5{ }^{\circ} \mathrm{C} / \mathrm{min}$. The resulting data plot revealed phase transformations from the temperature increase and decrease (Figure 21). The transformation to the parent austenitic phase started $\left(\mathrm{A}_{\mathrm{s}}\right)$ at $49^{\circ} \mathrm{C}$ and finished transforming into austenite $\left(\mathrm{A}_{\mathrm{f}}\right)$ at $95^{\circ} \mathrm{C}$. As the temperature decreased, the transformation back to martensite started $\left(\mathrm{M}_{\mathrm{s}}\right)$ at $67^{\circ} \mathrm{C}$ with the phase transformation ending with $100 \%$ martensite $\left(\mathrm{M}_{\mathrm{f}}\right)$ at $42^{\circ} \mathrm{C}$. The DSC plot revealed the transformation to austenite was a two-step transformation. The first step begins at the austenite start $\left(49^{\circ} \mathrm{C}\right)$ 
$\left(\mathrm{A}_{\mathrm{s}}\right)$ and the second step was at $77^{\circ} \mathrm{C}$. The transition temperatures and shape of the DSC plot were as expected from work done by Dequine ${ }^{94}$. The $\mathrm{M}_{\mathrm{s}}$ temperature correlates with the maximum transition temperature ${ }^{34}$. The transition temperature suggests the composition of the NiTi film was at a stoichiometric 50:50 composition of nickel and titanium or the film was titanium rich. The two hypotheses for the two-step transition are a type of R-phase and the presence of precipitates. The first hypothesis is a precursor transition before the austenitic phase. This alternative phase is called R-phase and is a lattice distortion that can occur before a transition. However, R-phase is more commonly found before the transition from austenite to martensite. This led to a second hypothesis; the elongated transition could be from $\mathrm{Ti}_{2} \mathrm{Ni}$ precipitates. These precipitates can elongate the transition temperature as observed from the DSC data and can cause a two-peak transition. The $\mathrm{Ti}_{2} \mathrm{Ni}$ precipitates are also consistent with the overall titanium rich composition. 


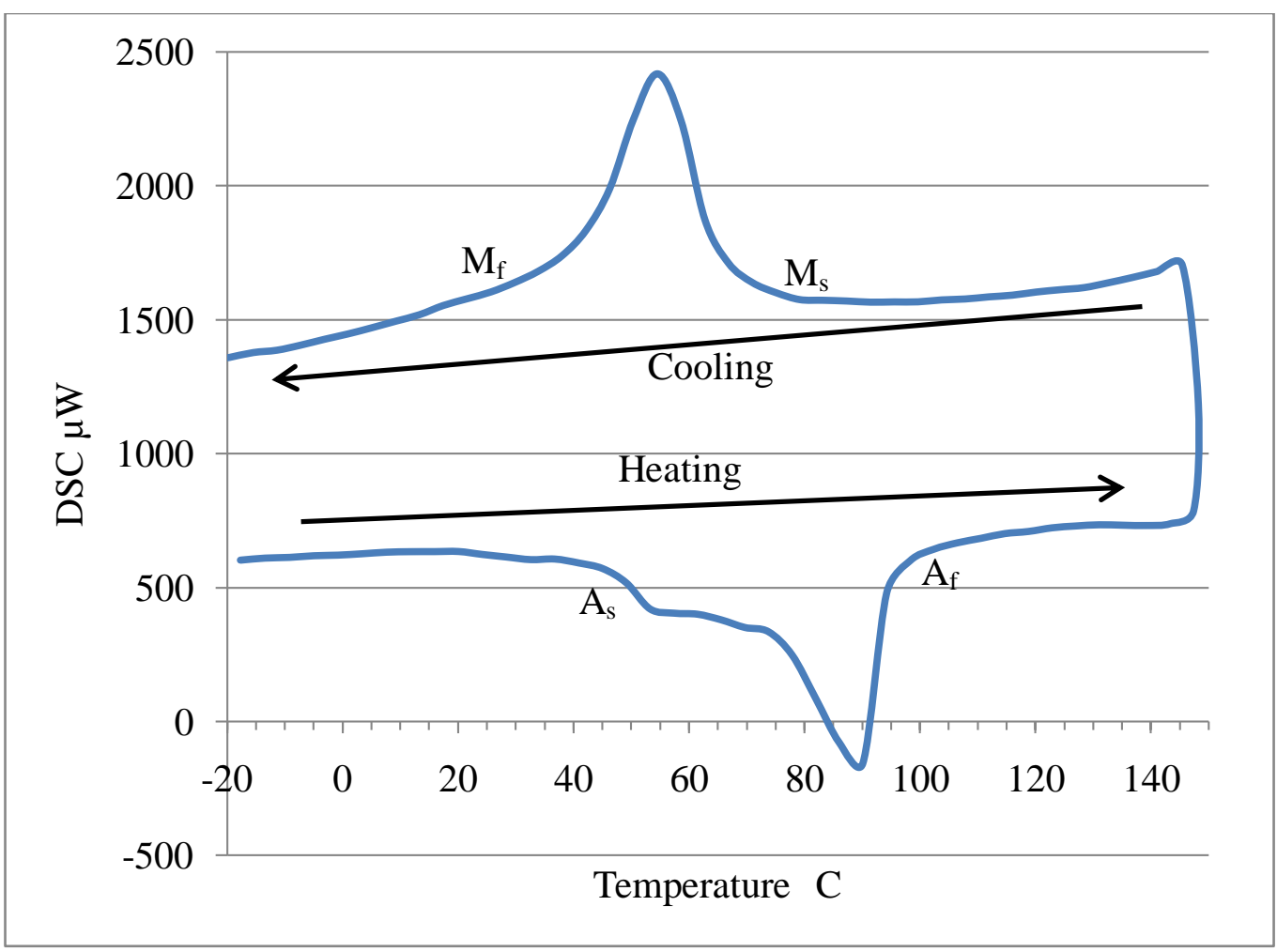

Figure 21: Differential scanning calorimeter plot. As the temperature of the NiTi is increased, the phase change to austenite started $\left(\mathrm{A}_{\mathrm{s}}\right)$ at $49^{\circ} \mathrm{C}$ and was complete $\left(\mathrm{A}_{\mathrm{f}}\right)$ at $95^{\circ} \mathrm{C}$. When the NiTi sample cooled the phase transformation back to martensite started $\left(\mathrm{M}_{\mathrm{s}}\right)$ at $67^{\circ} \mathrm{C}$ and finished $\left(\mathrm{M}_{\mathrm{f}}\right)$ at $42^{\circ} \mathrm{C}$.

\subsection{EDS Elemental Composition}

The atomic percent of nickel and titanium needed to be within a narrow range to obtain a shape memory alloy. The atomic percentage to obtain a shape memory alloy is around an equal amount of nickel and titanium. An increase in nickel decreases the transition temperature of the parent austenite phase. The elemental composition was determined by electron dispersive spectroscopy (EDS). A chromium reference sample was used to calibrate the EDS system. Three NiTi samples were analyzed with three different accelerating voltages, 20, 25, and $30 \mathrm{kV}$. All sampling was done by analyzing an area and not a point composition. The results of the EDS analysis for the NiTi films were 47.98 atomic percent nickel and 52.02 atomic percent titanium (Table 1). The atomic percents of nickel and titanium correlate with the transition temperatures from the 
differential scanning calorimeter ${ }^{31}$. The correlation between the elemental analysis and the transition temperature, strongly suggest that the processing of a SMA film was achieved.

Table 1: EDS Elemental Analysis of NiTi Film

\begin{tabular}{|l|r|r|}
\hline & Weight \% & \multicolumn{1}{|c|}{ Atomic \% } \\
\hline $\mathrm{Ni}$ & 53.07 & 47.98 \\
\hline $\mathrm{Ti}$ & 46.93 & 52.02 \\
\hline
\end{tabular}

\subsection{Indentation Recovery}

Nanoindentations in the annealed NiTi films showed recovery after heating the film over the austenite finish $\left(\mathrm{A}_{\mathrm{f}}\right)$ temperature of $95^{\circ} \mathrm{C}$. This recovery was confirmed to be from the shape memory effect and not by some other phenomenon. This was tested by indenting both the annealed film and the as-sputtered film, measuring the indentations with an atomic force microscope, heat cycling both films with a heat gun, and measuring the indentations on both films post-heating. The annealed films showed indentation recovery while the as-sputtered films did not show indentation recovery. This confirmed recovery was a result of crystallization, which occurred during annealing.

\subsection{Film Topography}

The annealing process crystallized the amorphous film to what is believed to be the monoclinic crystal structure (B19) of martensite. The crystallization created longrange atomic structure and a twinned surface consistent with the martensite crystal structure. The change from the as-sputtered film to the annealed martensite phase changes the topography of the film. The topography was measured and quantified with the use of an Asylum Research MFP-3D Stand Alone atomic force microscope (AFM). Upon imaging the surface of both the as-sputtered and annealed film, it was apparent a 
transformation had occurred. The as-sputtered film had a surface topography that looks like an accumulation of spheres that range from 50 to $100 \mathrm{~nm}$ in diameter along the horizontal plane. The heights of the spheres were approximately a few nanometers (Figure 22). The surface roughness, root mean squared (RMS), of the as-sputtered film with a scan size of $1 \mu \mathrm{m}$ was $1.68 \mathrm{~nm}$. The surface topography is due to the nucleation and growth process of atoms on the substrate during sputtering deposition.

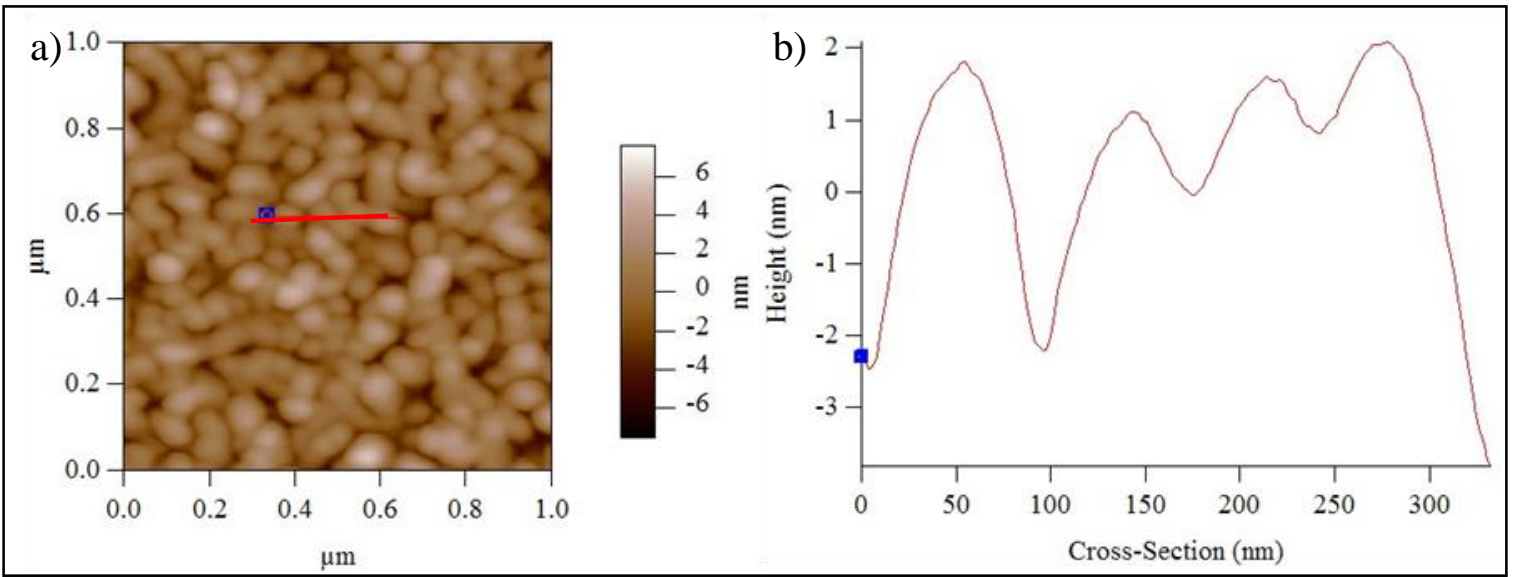

Figure 22: AFM image with a scan size of $\mu \mathrm{m}$ scan of the a) as-sputtered NiTi surface with a b) cross-sectional view. The image reveals the surface features from the deposition process.

The structure of the as-sputtered film was consistent across the wafer. As the scan size was increased, the topography of the film did not change. The spherical structure at the nanometer scale was present on the annealed film as was observed on the as-sputtered film. The annealing temperature was high enough to crystallize the material but hot high enough to eliminate the surface features. The spherical structure of both the as-sputtered and annealed films is a result of the deposition process. The annealed film had larger features that were believed to be from the twinned martensite structure (Figure 23). The twinned surface topography was from the material uplift from the increase in the crystal structure volume of martensite from austenite. The roughness (RMS) of the $2 \mu \mathrm{m}$ scan size for the as-sputtered film a) was $1.77 \mathrm{~nm}$ and the annealed film b) was $12.7 \mathrm{~nm}$. The 
roughness (RMS) of the $20 \mu \mathrm{m}$ scan size for the as-sputtered film c) was $1.37 \mathrm{~nm}$ and the annealed film d) was $27.0 \mathrm{~nm}$. Some of the separation of the features could be separation in grains.
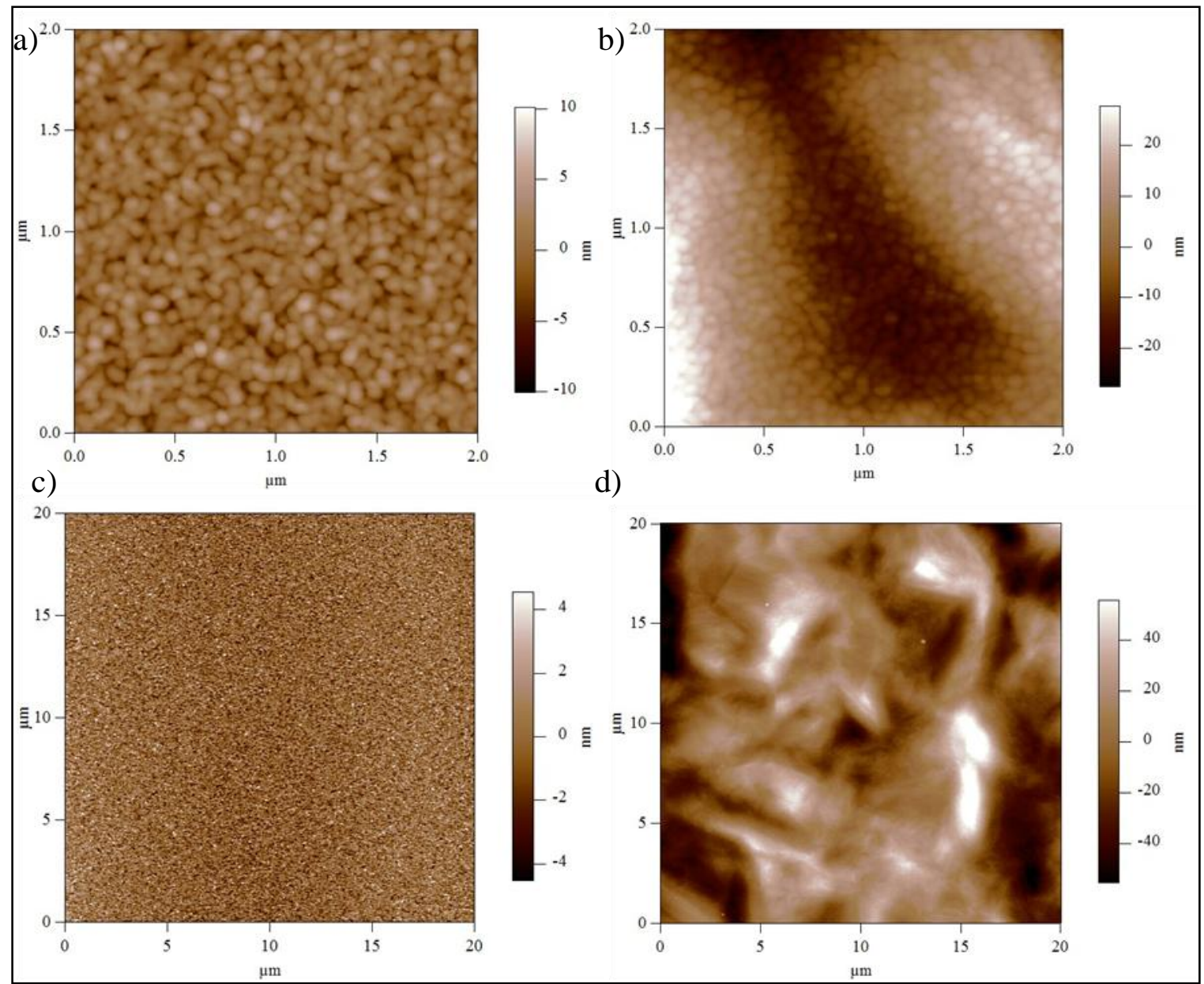

Figure 23: Topography comparison of the as-sputtered (a and c) and the annealed film (b and d). The topography of the as-sputtered film remained consistent as the scan size increased while the annealed film showed peaks and valleys resembling twinning with increased scan size.

The measured topography was similar to the topography of other thin film NiTi in the martensite phase from a study by Yongqing (Figure 24). The as-sputtered film topography remained uniform as the scan size was increased. 

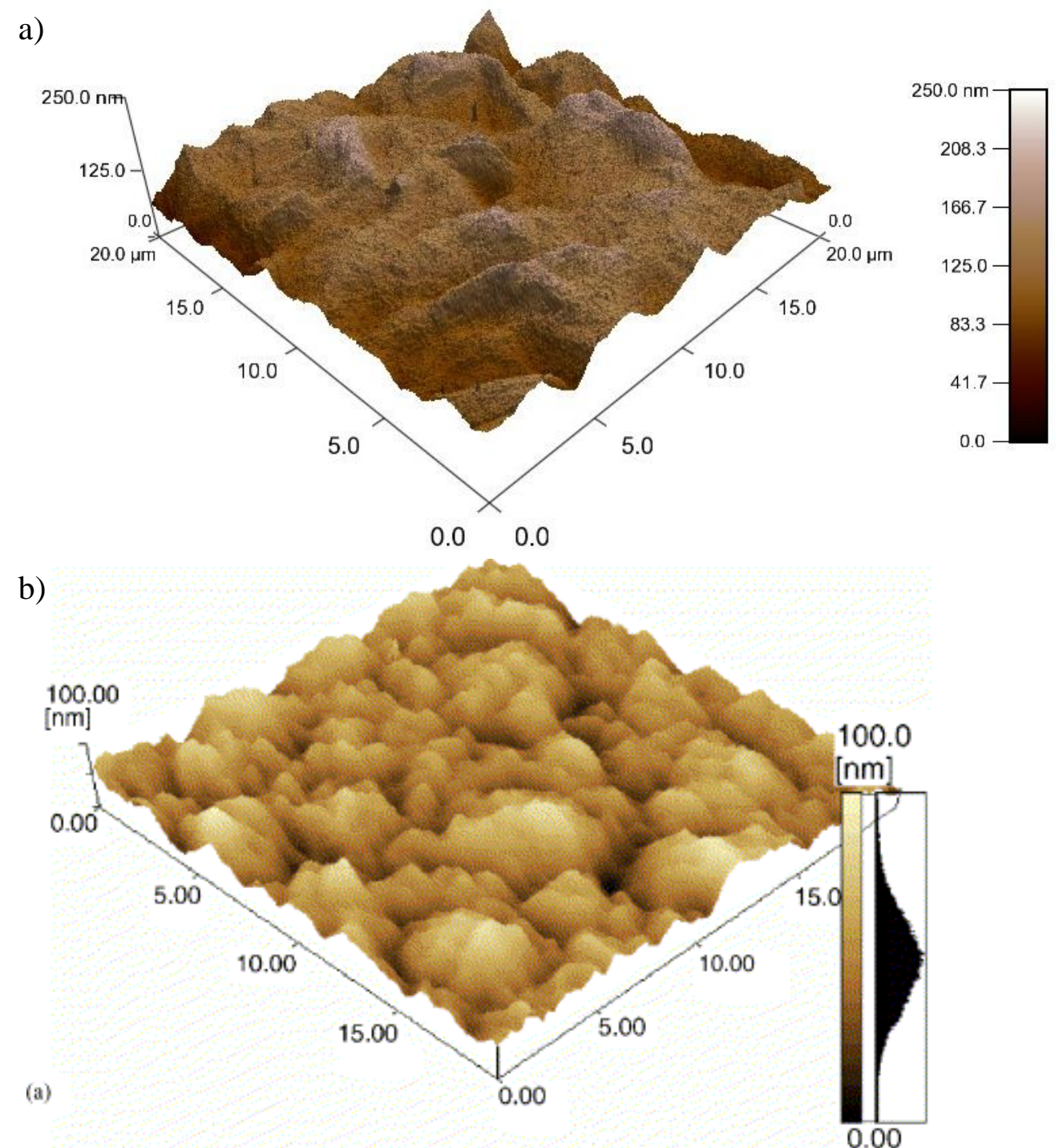

Figure 24: Comparison of AFM images of annealed thin film NiTi a) from this study and b) from a previous study by Yongqing 5 . The difference between the two is the size and scale of the twinned regions. This difference is attributed to the different annealing temperatures. The Yongqing used an annealing temperature of $450^{\circ} \mathrm{C}$ while this research used $550^{\circ} \mathrm{C}$. The larger twinned features are from the greater temperature, allowing them to grow larger.

\subsubsection{NiTi Film Roughness}

The change in the topography was quantified by comparing the root mean square (RMS) roughness of the as-sputtered and the annealed film with increasing scan size (Figure 25). The as-sputtered film roughness did not change much from the small scan size to the larger scan size. The RMS roughness of the as-sputtered films ranged from 1.3 to $1.7 \mathrm{~nm}$. The roughness appeared to decrease a slight amount with an increase in the scan 
size because small defects in the film affect the roughness values less with an increase in scan size. The RMS roughness of the annealed film was $7.4 \mathrm{~nm}$ with a scan size of $1 \mu \mathrm{m}$, over four times greater than the as-sputtered film with the same scan size. The roughness increased rapidly with increasing scan size and leveled out with a maximum RMS roughness of $27.0 \mathrm{~nm}$ at a $40 \mu \mathrm{m}$ scan size. The increase in roughness of the annealed film as the scan size increased was because the twinned structure produced from the annealing process was larger than the as-sputtered features. The twinned structure that caused the increase in the roughness also was the reason for the change in the optical appearance of the film. The cloudy appearance of the film was a result of the twinned martensite. The low surface roughness of the as-sputtered film was the reason for the highly reflective film.

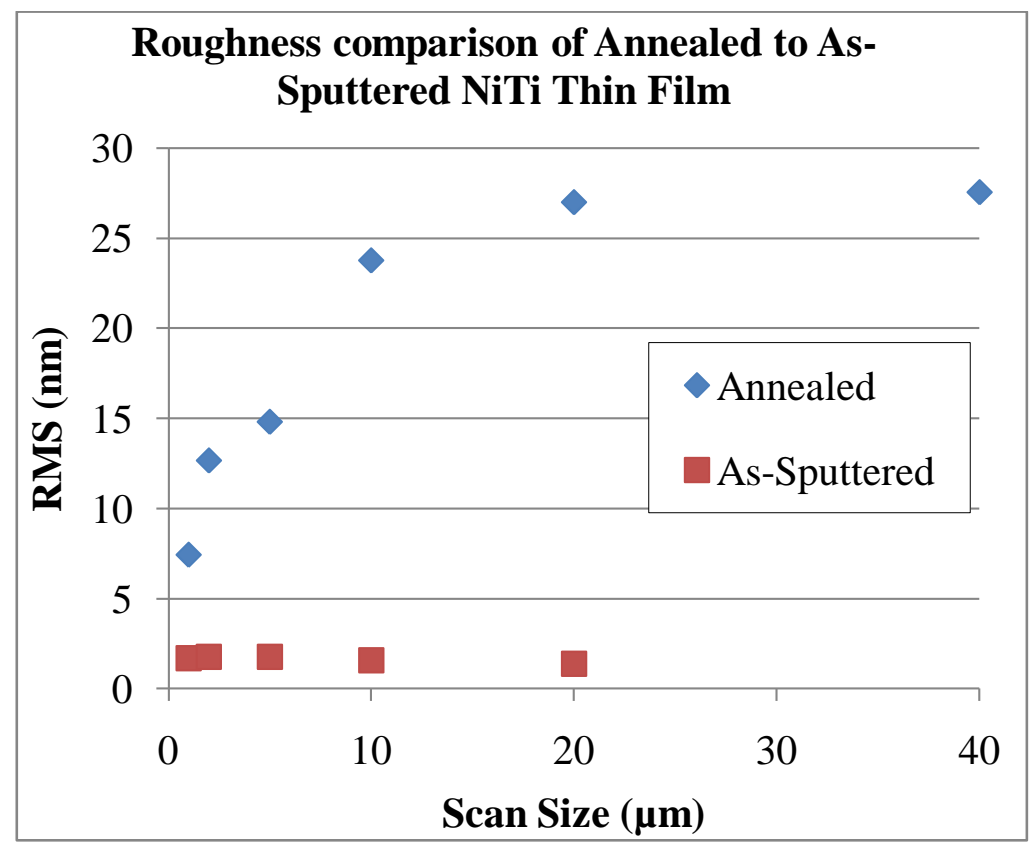

Figure 25: Comparison of roughness between annealed and as-sputtered NiTi by root mean square (RMS) roughness analysis. 


\subsubsection{Twinning Angle}

The twinning angle of NiTi is a specific angle that comes from the martensite monoclinic crystal structure. The angle difference from the austenite and martensite structure is $6.8^{\circ}{ }^{24}$. A common angle that was measured from the surface features of the annealed NiTi film was $6.6^{\circ}$ (Figure 26). These angles were measured from cross-sections of the AFM images. The angles and morphology were the same as the distinctive martensitic twinned structure. This is not conclusive to be the twinning angle of martensite because the crystal orientation was unknown.

The topography angles of the NiTi film do not provide validation of the twinning angles. The angles could be confirmed by imaging the same location at low temperature and at high temperature past the phase transition temperature. The angles difference from the low temperature martensite and the high temperature austenite would provide accurate twinning angles. The crystallographic orientation could also be determined.

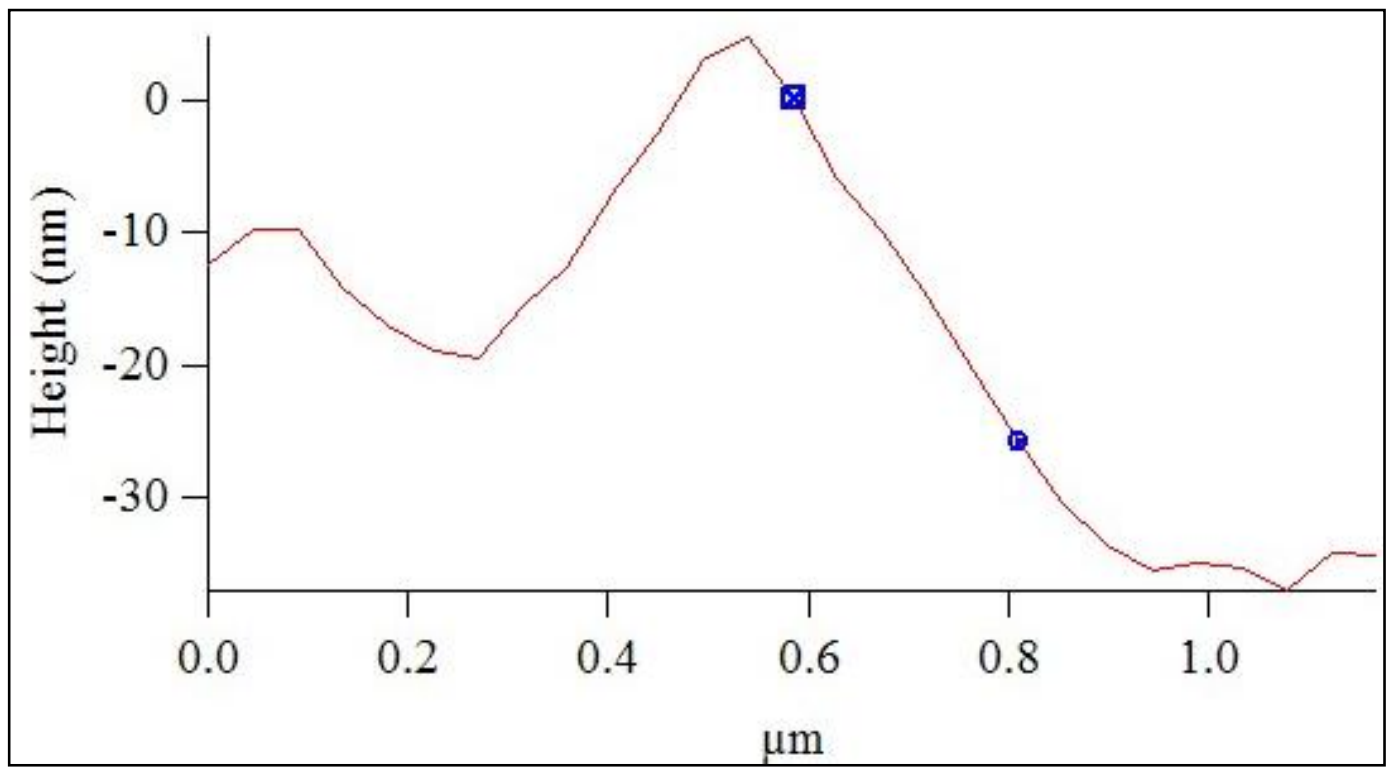

Figure 26: Cross-section view of one of the twinned structure. An example of a location where an angle of $6.6^{\circ}$ was measured, indicating the twinning angle of martensite. 


\subsection{Discussion}

The culmination of all the tests performed led the author to believe a SMA was produced from the sputtering deposition and annealing process. All the data correlated well with each other. The elemental composition was consistent with the observed phase transition temperatures. The surface morphology changed from the smooth as-sputtered film to the film consistent with martensitic twinning from the annealing process. At room temperature, the surface appeared hazy which was consistent with the martensite structure. As the temperature was increased the film changed appearance to a highly reflective surface consistent with the austenite phase. The annealed film was able to recover deformation upon heating while heating indents on the as-sputtered film produced no measureable change. 


\section{CHAPTER 5 -Thin Film Annealed NiTi Indents}

This chapter covers the procedure used to nanoindent the annealed NiTi thin films and the results. The elastic modulus and hardness of the films were the tested parameters. All indentation work was performed with an Asylum Research MFP-3D Instrumented NanoIndenter. The designated NanoIndenter Head was used with a standard flexure module and a Berkovich tip for sample testing.

\subsection{Sample Preparation and Mounting}

Sample preparation began with sectioning the NiTi sample into approximately $1 \mathrm{x}$ $1 \mathrm{~cm}$ sections. A diamond scribe was used to cut through the NiTi film and score the silicon wafer substrate. Sectioning was performed along the (111) plane of silicon which is parallel and perpendicular to the major flat of the wafer. Scoring along the crystallographic plane allowed the silicon to be cleaved and sectioned without a wafer dicer. Once scored, the wafer was turned over and bent on three points, with the single point on the backside of the scored section of the wafer. This provided a clean break through the silicon along the (111) crystal plane. The sections were mounted on scanning

electron microscope (SEM) pin mounts with Master Bond Supreme 11HT: which is a high compliance, low drift, and 24-hour cure epoxy. The samples were mounted to SEM pin mounts for compliance with the indenter sample mount.

\subsection{Indenter Calibration}

The indenter system has many calibrations that need to be performed. The calibrations do not need to be performed prior to every use, but need to be done regularly. The first calibration performed was for the inverted optical lever sensitivity (InvOLS). The InvOLS converts the deflection signal on the photodiode from a voltage to a 
distance. The InvOLS is the conversion from the deflection signal on the position sensitive detector (PSD) to the compression distance of the spring flexure. The InvOLS calibration was performed by indenting a sapphire substrate with a sapphire ball indenter. The hard hertzian contact between the indenter and the substrate produces for a small elastic deformation of approximately 2-3 nanometers with a load of a few millinewton. The displacement depends on the radius of the sapphire ball indenter and the load. Overall, the substrate and indenter do not deform a significant amount and the distance the piezoelectric stack pushes the flexure is proportional to the voltage on the PSD. The small indentation depth was corrected for in the calibration. The calibration provides a conversion for the displacement of the spring flexure into a voltage on the PSD. Highpressure steam was used to clean the sapphire ball and sapphire substrate prior to cleaning.

The sapphire ball was attached to the flexure with a torque wrench to a torque of 3 ounce-force inch (ozf-in). The sapphire sample was mounted on the indenter base. The Indenter head was then placed on the base ensuring the tip did not crash into the substrate. A bubble level was used to level the head on the base as the head was lowered into position. A mechanical coupling of the deflection signal on the PSD with the Z movement was present and must be zeroed. The coupling was a result of the mechanical path not being perfect. The virtual deflection depends on the alignment of the light on the lever or in the case of the indenter system, the optical detector (Figure 10) ${ }^{105}$. The virtual deflection also calibrates the free air portion of the force curve ${ }^{106}$. The virtual deflection was calibrated by driving the $\mathrm{Z}$ piezoelectric stack over the entire range in air. The 
deflection voltage was plotted against the $\mathrm{Z}$ position and the slope of the plot was set to zero. Typical values for the virtual deflection are a few $\mathrm{mV} / \mu \mathrm{m}$.

The indentation settings were changed to an Input Gain of $12 \mathrm{~dB}$ and an integration of 5 . The indenter was engaged with a set point of 0 volts and a deflection offset of $-2 \mathrm{~V}$. This allowed the calibration to be performed over the whole range of the PSD. The head was carefully lowered and leveled with the bubble level until the indenter came into contact with the substrate and the set point was reached (Figure 27). The head was lowered until the $\mathrm{Z}$ voltage reached the midpoint of the range $(70 \mathrm{~V})$. The indenter was withdrawn from the surface using the piezoelectric stack and force curves were performed from approximately -2 to $2 \mathrm{~V}$. These indents were repeated approximately 30 times at a rate of $0.2 \mathrm{~Hz}$. The force curves were displayed Raw LVDT vs deflection (Figure 28). The in-contact portion of the force curve should be linear with the extension and retraction overlapping with no hysteresis. If there were any problems with the force curves, the cause was most likely from contamination. The InvOLS was calibrated from the slope of the curve between the -1 to $1 \mathrm{~V}$ portion of the force curve and an average value was used from all 30 force curves. If there were any patterns in the InvOLS over time for the 30 curves, the calibration was performed again. A common cause for changes in the InvOLS over time was thermal drift or the laser in the head had not warmed up causing drift of the sum on the PSD. 


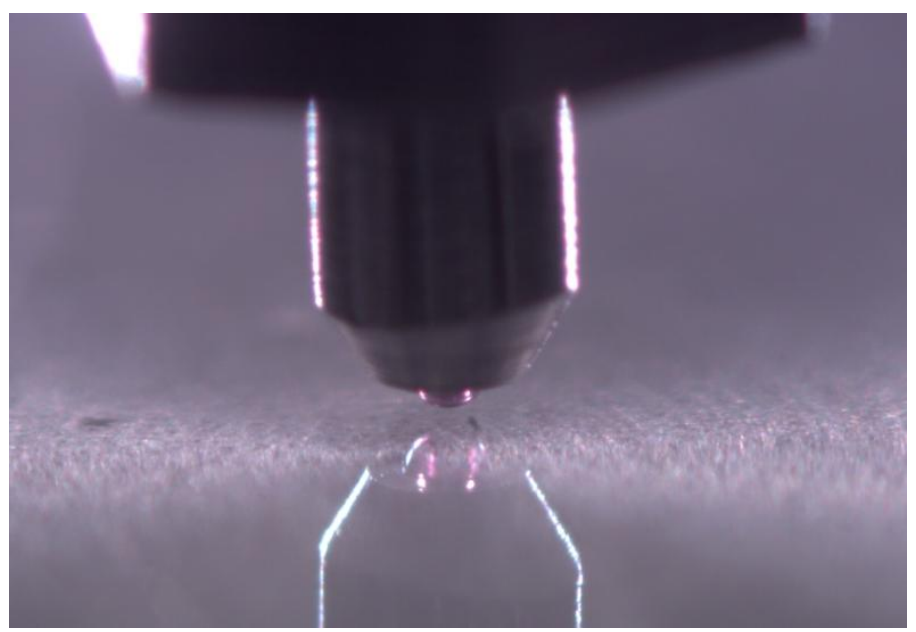

Figure 27: Sapphire indenter tip approaching the sapphire substrate.

Figure 28: InvOLS calibration curve

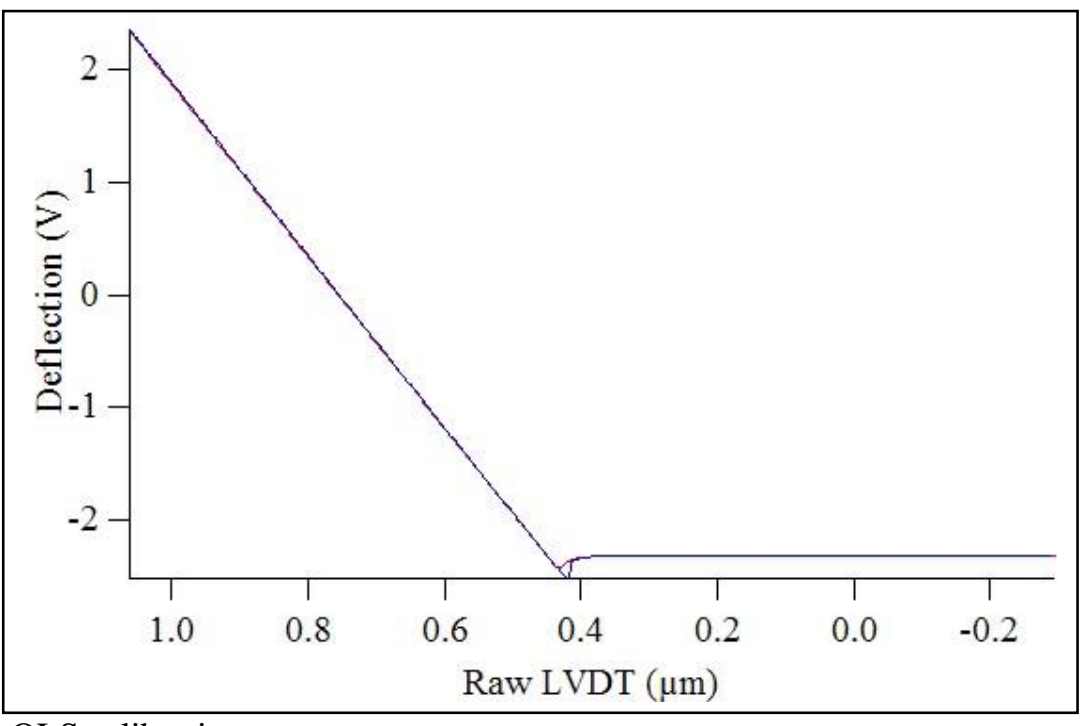

\subsection{Indenter Setup}

Upon completion of the InvOLS calibration, the annealed NiTi films were indented. Before each use of the indenter, the tip was cleaned with a variety of methods. High-pressure steam cleaning, ultra sonic cleaning in isopropyl alcohol and carefully rubbing the tip from the base up with a cotton swab soaked in isopropyl alcohol under a stereoscope. The indenter tip was imaged with an AFM to determine the true projected area of the indenter. The sapphire ball indenter was removed and a Berkovich indenter was placed into the indenter flexure with a torque specification of 3 ozf-in. The mounted 
NiTi films were placed in the SEM pin mount holder and placed on the MFP-3D sample stage (Figure 29). The indenter head was placed on the base insuring the indenter tip did not crash into the sample. A virtual deflection calibration was performed as previously described. A set point of $0.01 \mathrm{~V}$ was used to approach the surface of the NiTi. The indenter was engaged and the head was lowered and leveled until the indenter tip made contact with the surface and the set point was reached. The head was lowered until the $\mathrm{Z}$ voltage was approximately at the midpoint $(70 \mathrm{~V})$. The indenter tip was withdrawn from the surface by the $\mathrm{Z}$ piezoelectric stack.

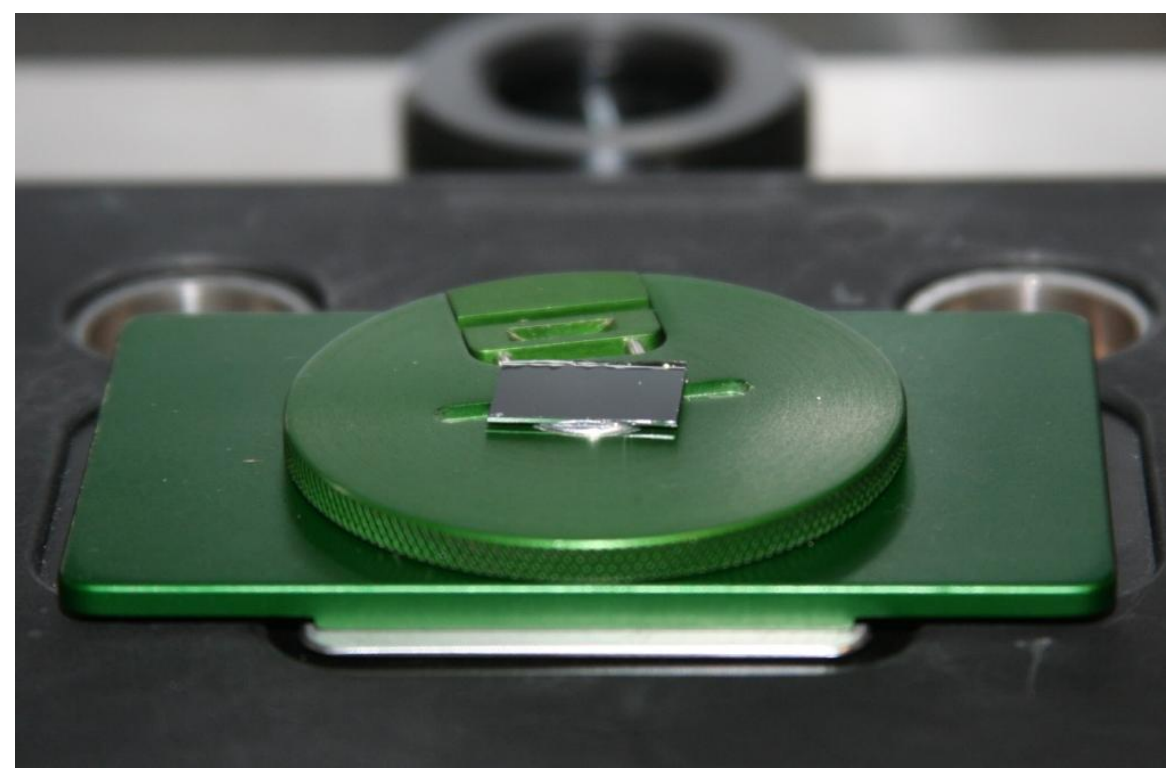

Figure 29: SEM pin mount holder for the MFP-3D base.

\subsection{Indent film}

The area to be indented was defined by hovering the indenter tip over the surface of the film. The indenter was hovered over the NiTi for only a few seconds just to bring up a defined area to indent in the software. A grid was placed over the defined area and the grid points were numbered as desired (Figure 30). The spacing between indentations depends on the depth of the indentations and the stress field that is produced. The rule for 
indentation separation for metals is at least 20 to 30 times the indentation depth for Berkovich and Vickers indenters ${ }^{47}$. The recommended maximum indentation depth, with a $5 \mu \mathrm{m}$ spacing, is between 167 and $250 \mathrm{~nm}$ for the NiTi films. Each indentation point can have completely different parameters or a force map can be done. Most indentation work was performed by individually selecting the force curve parameters for each point. A $5 \mu \mathrm{m}$ spacing would provide a storage density of 24.6 megabit/inch ${ }^{2}$. The system used for indentations could make indents with a maximum indentation depth of $10 \mathrm{~nm}$ or a force of approximately $18 \mu \mathrm{N}$. A maximum indentation depth of $10 \mathrm{~nm}$ would require a spacing of $200 \mathrm{~nm}$. A spacing of $200 \mathrm{~nm}$ allows a storage density of approximately 15,000 megabits/inch ${ }^{2}$.

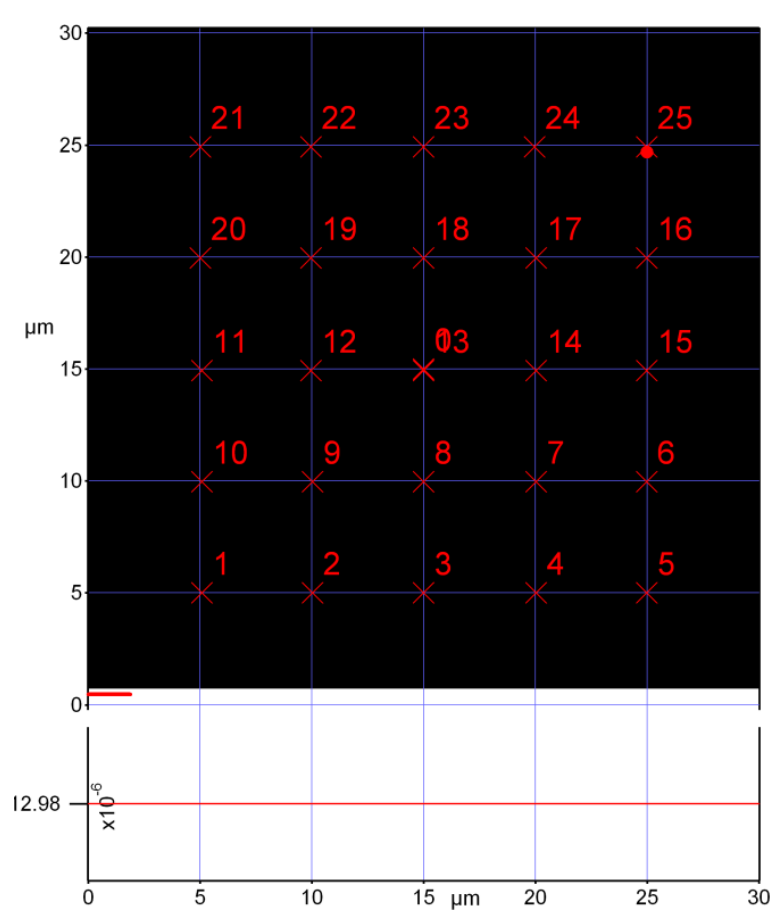

Figure 30: Indentation area and points to be indented

The indentation points were defined and the indentation parameters were set. The point that was considered contact between the tip and the surface was set. It was used as a datum for the indentation loading parameters to engage. The initial contact force mainly 
depends on the noise of the system, if it was set too low the system will false engage. If set too high, it will eliminate a larger portion of the force curve than is acceptable. The point of contact should not be greater than $5 \mu \mathrm{N}$ and was usually 2 to $3 \mu \mathrm{N}$. These parameters are only for the standard indenter flexure and NiTi films indented for this research. The initial contact force depends on the indenter flexure and the material that is being indented. If an indenter flexure with a lower spring constant were being used, than a lower contact force would be necessary. If a soft material was of interest other methods of finding the surface might need to be used.

\subsubsection{Indentation Load Function}

It was necessary to determine if the properties of the NiTi samples were timedependant at the testing temperature. Many polymers have rate dependant properties because of the viscoelastic properties of polymers. Creep can be an issue with metals and ceramics at elevated temperatures, but indium will creep at room temperature. To test for time dependent properties, initial loading parameters were used to test for a viscoelastic response. Indentations were performed at different rates as well as indenting and holding to determine if the NiTi films mechanical properties were rate dependant (Figure 31). Each of the loading parameters produced the same results. The NiTi films were not rate dependant and a simple load and unload force curve could be used. A typical load and unload rate used was $1 / 3 \mathrm{mN} / \mathrm{sec}$. 


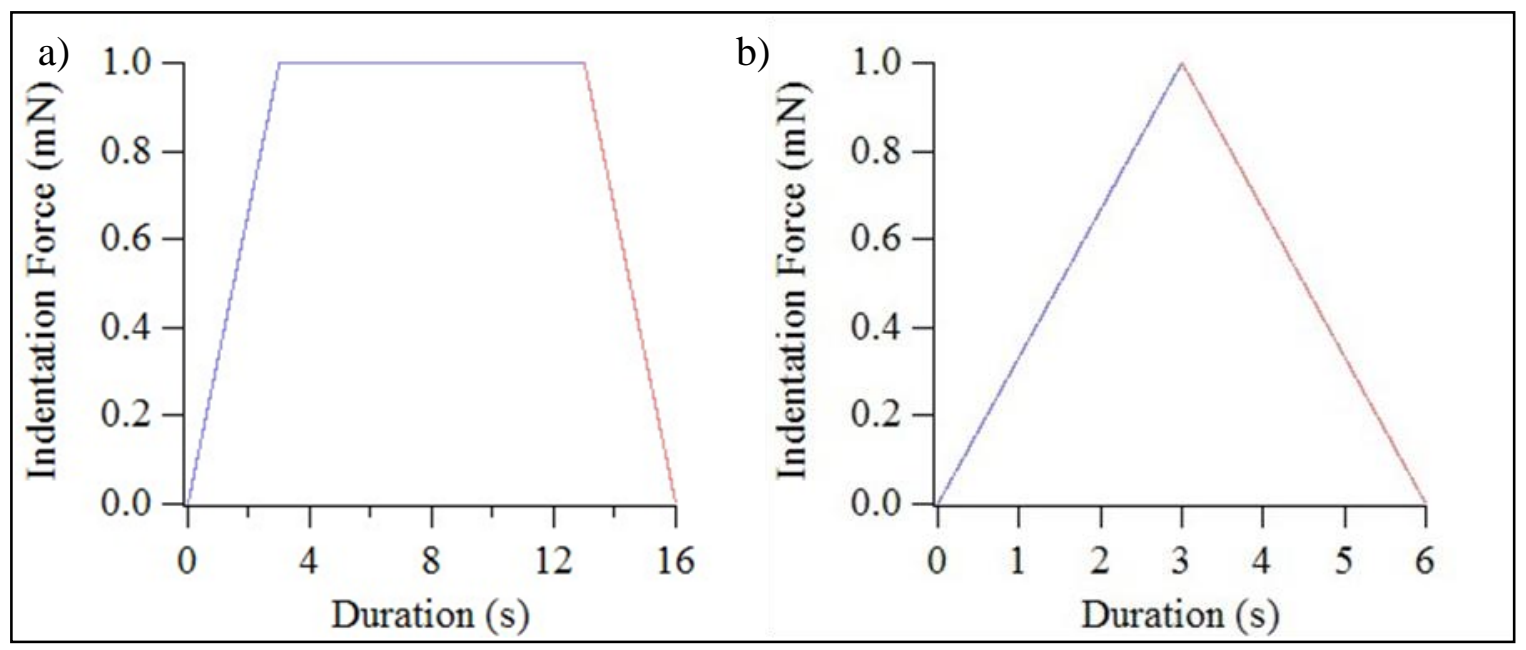

Figure 31: Indentation loading functions a) testing for rate dependency of the NiTi film, b) typical indentation load and load parameter used for indentations.

\subsubsection{Indent Forces}

Indentations were performed on six different annealed NiTi samples with a total of 309 indents ranging in force from 0.25 to $4 \mathrm{mN}$. Indentations over $3 \mathrm{mN}$ were inconsistencies with the mechanical properties from indents under $3 \mathrm{mN}$. This was a result of substrate effects where the results were a coupling of the NiTi and substrate properties. Indentations performed with a load over $3 \mathrm{mN}$ were not used to calculate the films properties. Indents from 0.25 to $3 \mathrm{mN}$ were used to determine the elastic modulus and hardness of the annealed NiTi films (Figure 32). The unloading and loading curves had variations in the slope and inflections in the slope. The variations could have been from different crystallographic orientations, friction affects that change with indentation size, indentation angle from surface topography (Figure 33), and grain boundaries ${ }^{53}$. After indenting a region, a 90 by $90 \mu \mathrm{m}$ box was scratched around the indented area. This box provided a marker to locate the indentations for analysis. The indenter tip was imaged by the AFM to determine the true area of the indenter, providing more accurate results than assuming perfect tip geometry. 


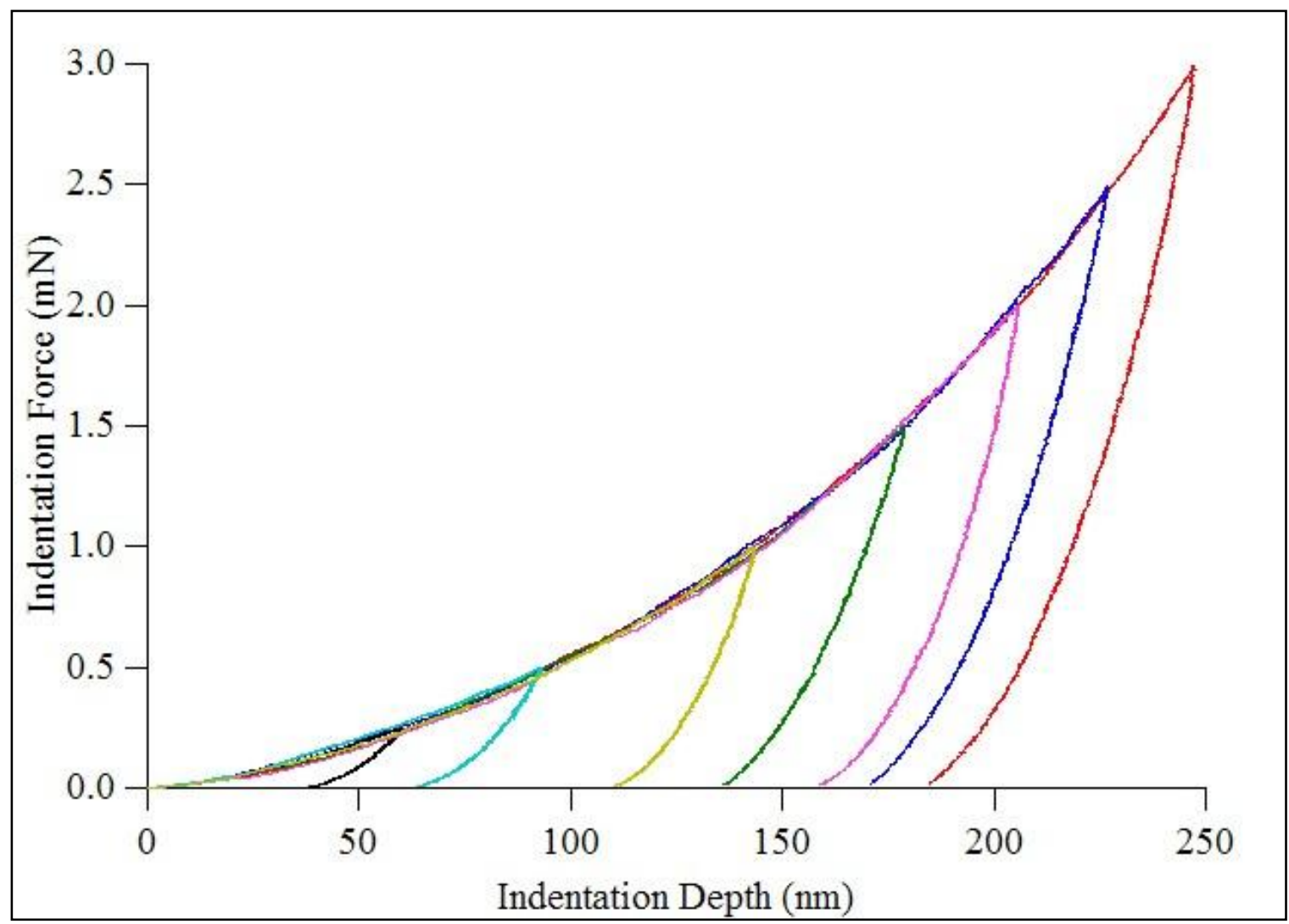

Figure 32: Force curves of loads ranging from $0.25 \mathrm{mN}$ to $3 \mathrm{mN}$ on annealed nickel titanium.

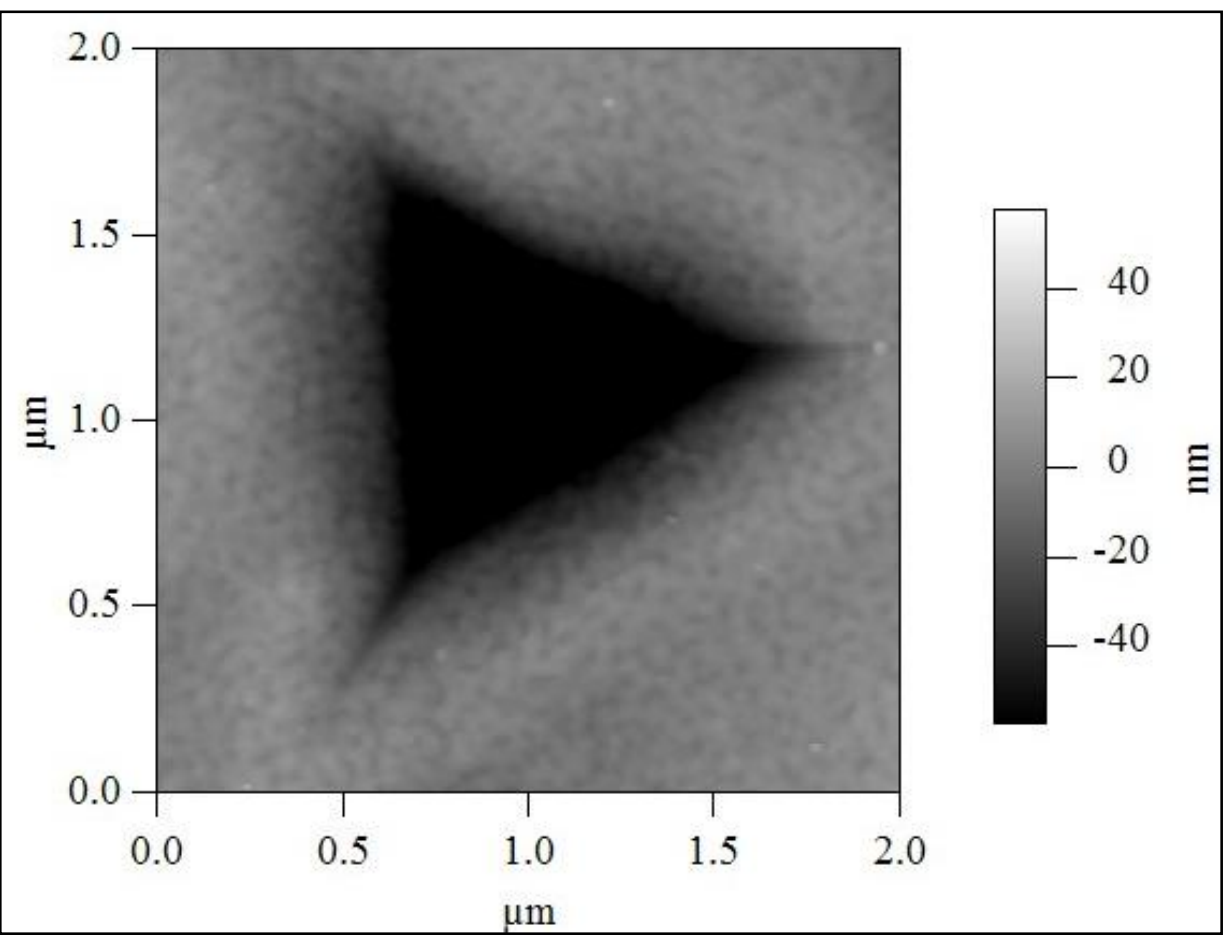

Figure 33: Indentation with asymmetrical contact area. Bottom left corner of the residual indent extends further than the others because of the angular facets of the NiTi surface. 


\subsection{Results}

Each force curve was analyzed using the Oliver-Pharr method to determine the elastic modulus (Equation (6) and hardness (Equation (4) of the films. The Asylum Research software was used to determine the elastic modulus and hardness. A Poisson's ratio of 0.33 was used for the NiTi film in the calculation from the reduced elastic modulus to the elastic modulus of the NiTi sample ${ }^{40}$. The elastic modulus of the annealed NiTi films using ideal indenter geometry was $76.3 \mathrm{GPa}$ with a standard deviation of $7.4 \mathrm{GPa}$ (Table 2). The hardness of the annealed NiTi films was $3.2 \mathrm{GPa}$ with a standard deviation of $0.64 \mathrm{GPa}$. The projected tip area was corrected with the AFM data collected by imaging the indenter tip. The elastic modulus of the NiTi films with the true indenter projected area was determined to be $67.9 \mathrm{GPa}$ with a standard deviation of $3.2 \mathrm{GPa}$. The hardness was $2.1 \mathrm{GPa}$ with a standard deviation of $0.34 \mathrm{GPa}$. The indentation results were the same for all indentations from 0.25 to $3 \mathrm{mN}$. If there were a deviation in the elastic modulus or hardness with respect to depth, the cause would most likely be from substrate effects. If this was the case further testing would be required to determine the properties of the film without substrate influence ${ }^{107,108}$.

Table 2: Annealed NiTi Thin Film Elastic Modulus and Hardness

\begin{tabular}{|c|c|c|c|c|}
\hline & \multicolumn{2}{|c|}{ Elastic Modulus (GPa) } & \multicolumn{2}{c|}{ Hardness (GPa) } \\
\cline { 2 - 5 } & Average & Standard Deviation & Average & Standard Deviation \\
\hline $\begin{array}{c}\text { Ideal Indenter } \\
\text { Area }\end{array}$ & 76.3 & 7.4 & 3.2 & 0.64 \\
\hline $\begin{array}{c}\text { True Indenter } \\
\text { Area }\end{array}$ & 67.9 & 3.2 & 2.1 & 0.34 \\
\hline
\end{tabular}

\subsection{Discussion}

A typical value for the elastic modulus of bulk NiTi in the martensite phase is 40 $\mathrm{GPa}^{40}$. The measured elastic modulus of the NiTi thin film was much greater than the 
reported bulk value of NiTi. The variation in the elastic modulus from the bulk was due to the residual film stress caused by deposition. The residual stress was the largest factor in the variance in elastic modulus. Other sources of the increased elastic modulus include the diffusion of chromium into the surface and different elemental composition from the reported value of bulk NiTi. Chromium is often added to increase the stiffness of NiTi. Chromium was not measured with the EDS elemental analysis but the presence of the chromium could have been below the detection limit of the system or too shallow in the film to be detected. Other techniques such as x-ray photoelectron spectroscopy (XPS) or secondary ion mass spectrometry (SIMS) could be used to determine the chromium concentration as a function of depth. Little research has been done with the diffusion of chromium into NiTi. The concentration profile of chromium in the NiTi would provide the information to determine the diffusion-coefficient. The diffusion-coefficient could be used to calculate the depth of chromium in $\mathrm{NiTi}$ for future work. The presence of chromium could create regions of room temperature austenite at the surface. Regions of austenite would also increase the elastic modulus because the elastic modulus of austenite was greater than martensite at $75 \mathrm{GPa}$.

The tested NiTi films had a compressive stress of approximately $300 \mathrm{MPa}$ before annealing. If the stress levels were much greater there would begin to be cracking and delamination problems. The main cause for the greater elastic modulus than bulk was believed to be from the deposition stress. If the stress were reduced to zero or close to zero the elastic modulus would most likely be close to the bulk value of $40 \mathrm{GPa}$. Other research has reported close to bulk values for the elastic modulus but do not mention the deposition film stress ${ }^{71}$. 
The values of the elastic modulus and hardness were not a function of depth for indents below a load of $3 \mathrm{mN}$. If the values had varied, the source of variation would have most likely been from substrate effects. If the substrate had an effect on the results, different methods have been developed to subtract the substrate effects. 


\section{Chapter 6 - Indentation Recovery}

This chapter covers measuring the indentations with an AFM to determine if any

deformation recovery occurs from a thermally induced phase change. The indentations were imaged with an AFM to determine the topography of the indents. The film was then heated with a heat gun to induce a phase transformation to the austenitic phase of NiTi. The film was cooled and the indentations were imaged again with an AFM to determine the indent recovery by martensitic phase transformation.

\subsection{AFM Imaging of Indents}

Locating the indents on the NiTi film was performed in two parts, first by optics then by AFM imaging. The AFM optics was used to locate the 90 by $90 \mu \mathrm{m}$ box that was scratched around the indents (Figure 34). The AFM cantilever tip was engaged at the center of the scratched box where the indents were located. The AFM cantilevers used for measuring indents were the Olympus AC-240 and Nanosensor PPP-NCLR both are noncontact cantilevers. Large scan size images were taken to find the indents. Once the array of indents was located, the individual indents of interest were imaged. 


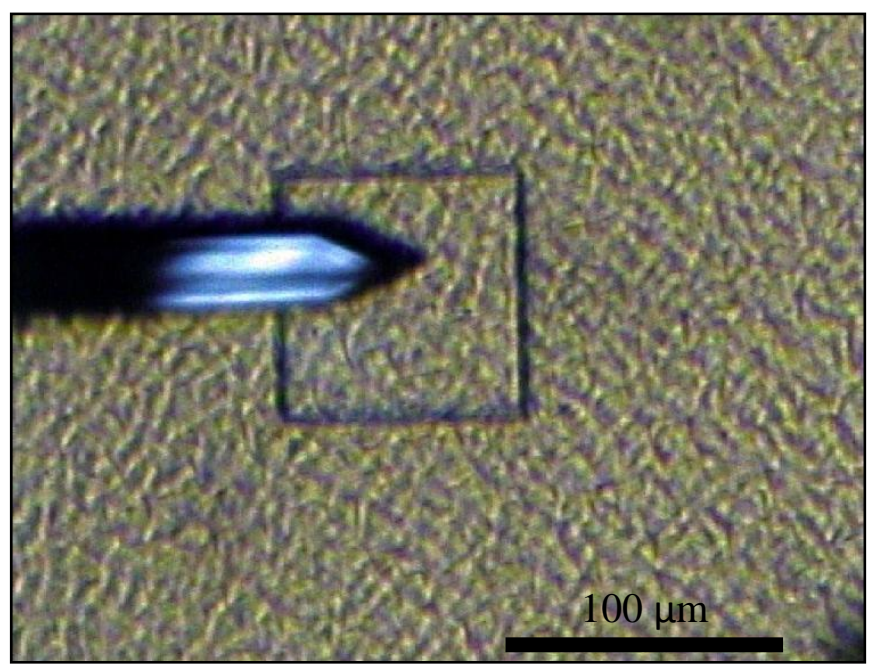

Figure 34: Indentation area viewed with the AFM optics. The indentations were located in the center of the 90 by $90 \mu \mathrm{m}$ box that was scratched into the NiTi film.

All indents were imaged with a minimum resolution of $512 \times 512$ and up to 1024x1024. The indents were inspected for pile-up or sink-in (Figure 35). All indents observed showed no signs of pile-up or sink-in. Since the indents had an ideal contact area, the measured mechanical properties did not need to be adjusted for a different contact area. The AFM images of the indents were analyzed to determine quantitative size measurements to compare the indents before and after phase change. This was achieved using the MFP3D software by Asylum Research. All analysis was performed with the $\mathrm{z}$-sensor that utilizes the linear variable differential transformer (LVDT) and is more accurate than the piezoelectric stacks, which have a hysteresis associated with them. The first step was to mask the indent and flatten the rest of the image surrounding the indent. The flattening process made the surrounding area the zero plane. It also made the indent easier to analyze. The indent remained unmodified but the surrounding area was flattened. A mask was made to analyze the indents. The edge of the indents was determined by looking at a combination of the top view and a cross-sectional view. Once the mask boarder was at the edge of the indent, the size was quantified (Figure 36). The 
dimension output of the Asylum Research software was the depth, area, area percent, and volume. With the area and area percent, the projected area of the indent was also determined. The depth, area, projected area, and volume were used to quantify the indent recovery.

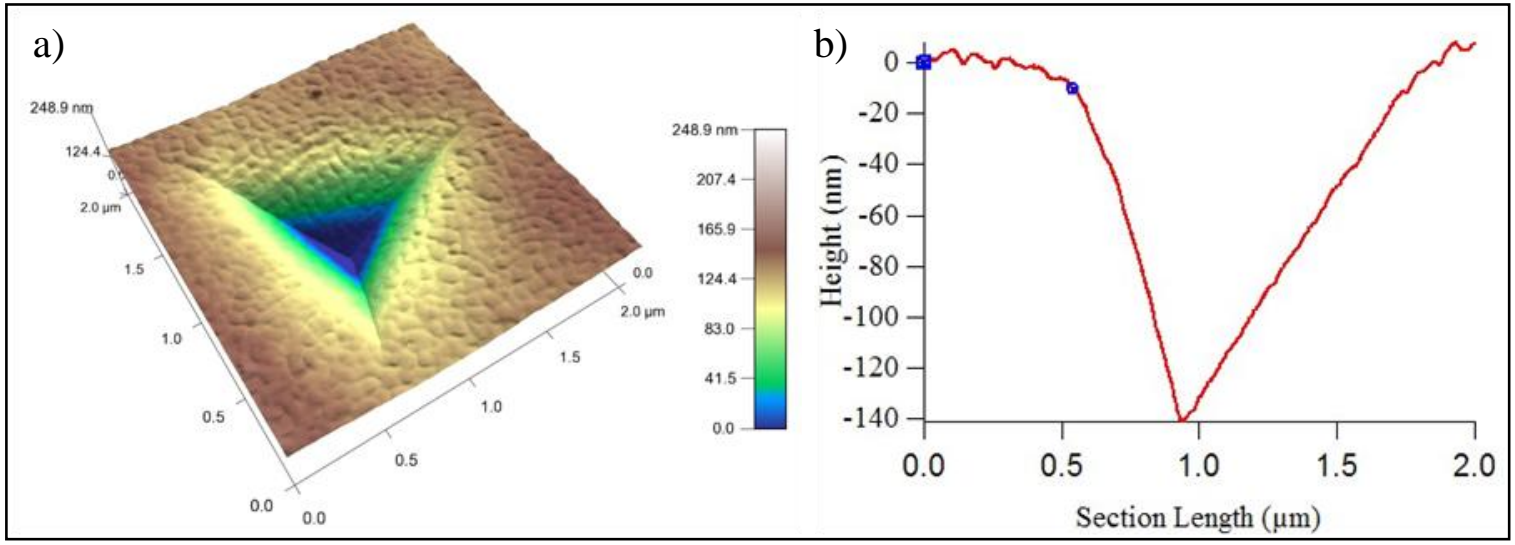

Figure 35: An a) AFM image of a single indent used to determine if the elastic model for the Oliver and Pharr method was valid. Pile-up or sink-in is not accounted for in the Oliver and Pharr method, the b) cross-sectional view assist in determining is pile-up or sink-in had occurred.

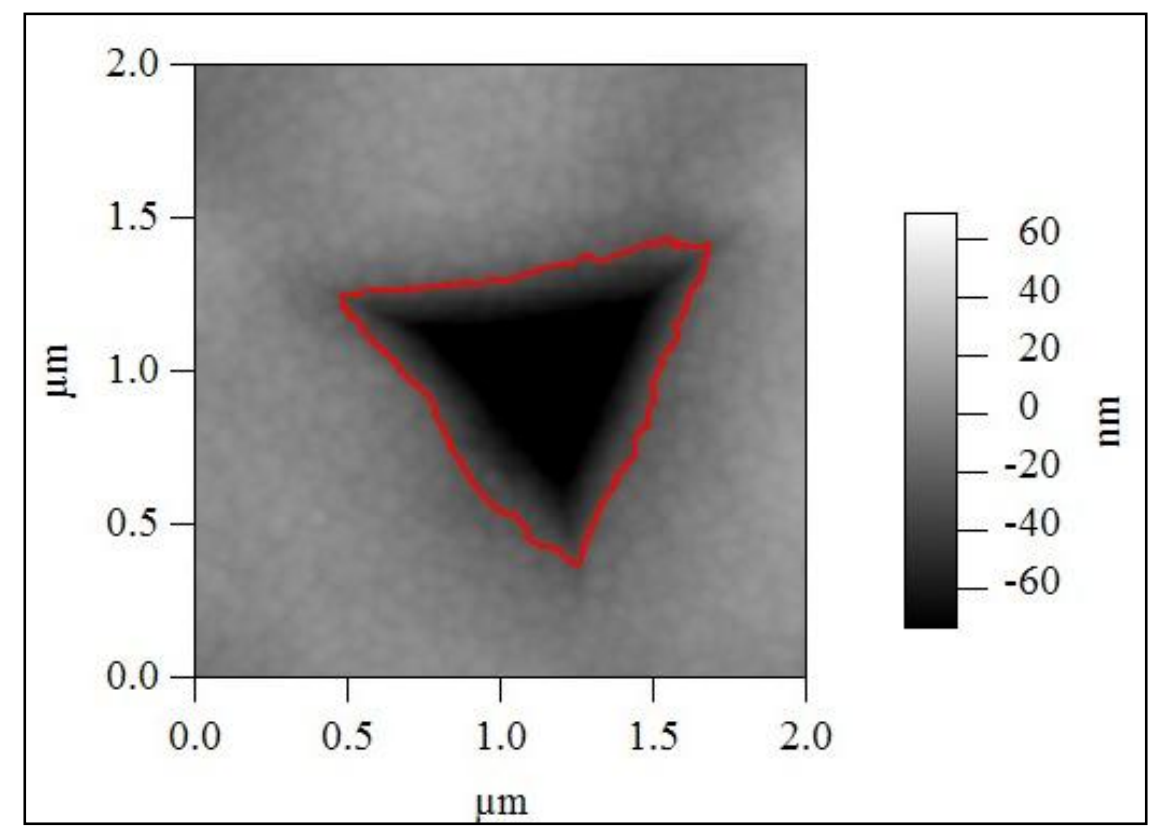

Figure 36: Individual indent masked to determine the size of the indent. The indentation size was quantified in four parameters; depth, volume, surface area, and projected area.

High-resolution images were taken of all indents that would be measured for recovery data. Once all the indents on a sample had been completely imaged, it was 
heated to induce a phase transformation. Heating past the transformation temperature was done with a heat gun. A hot plate was not used because the NiTi samples were mounted to SEM pin mounts. The heat gun was pointed at the sample until the film went from the cloudy martensite structure to the highly reflective austenite structure. The heating was continued for a few more seconds to insure the transformation was complete. The sample was allowed to cool to room temperature. As the sample cooled, the appearance of the film became cloudy indicating the transformation back to the martensite structure.

\subsubsection{Post Phase Transformation AFM Imaging}

After the heat induced phase transformation was complete, the sample was placed back in the AFM to image all the indents again. The 90 by $90 \mu \mathrm{m}$ box was still visible from the AFM optics. The array of indents was located and imaged (Figure 37). None of the indents completely recovered but there did appear to be a reduction in the size of the indents (Figure 38). 


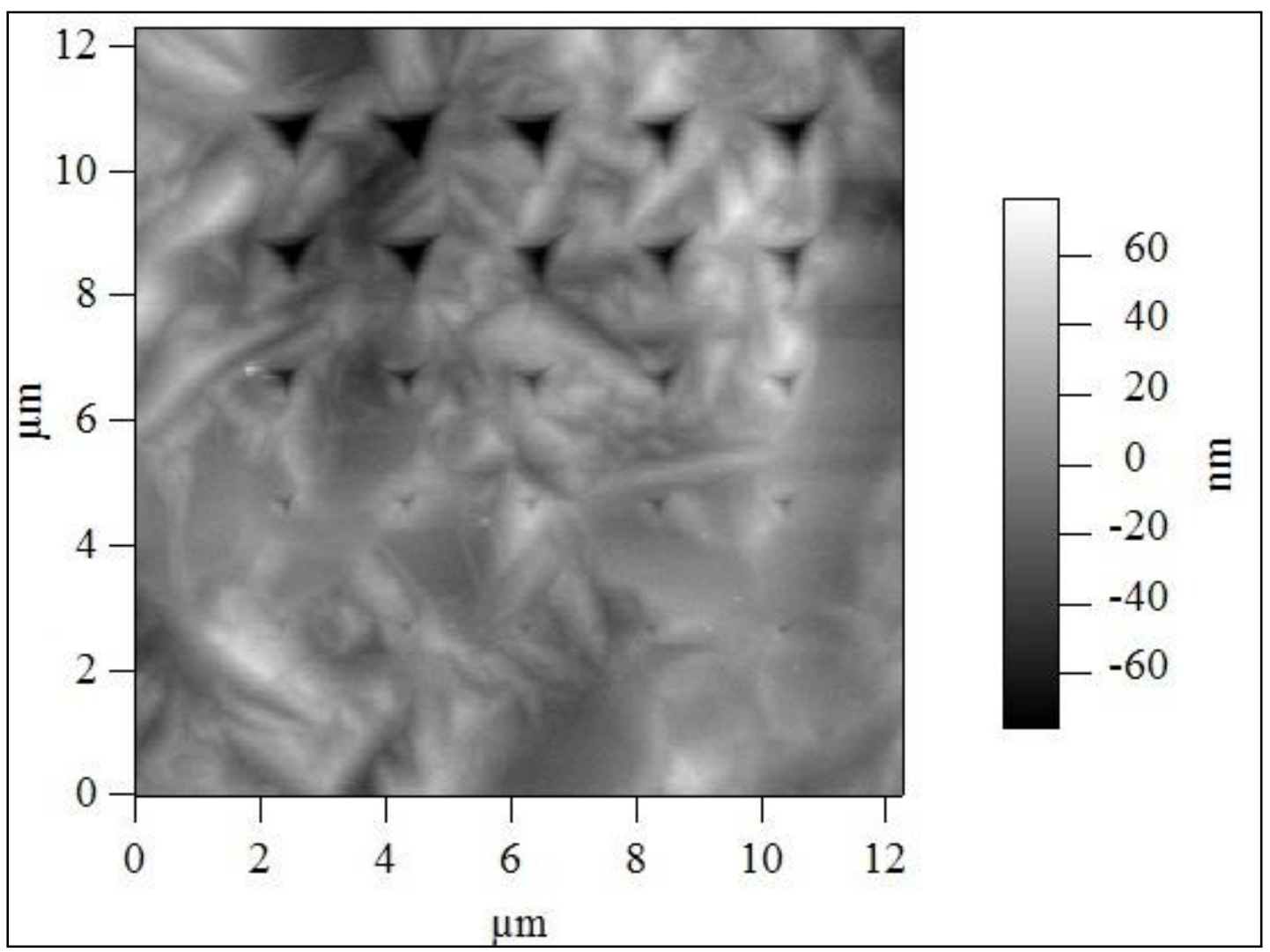

Figure 37: A 5 by 5 array of indent increasing in depth from the bottom to the top. The bottom row appears like small dimples instead of defined indents.

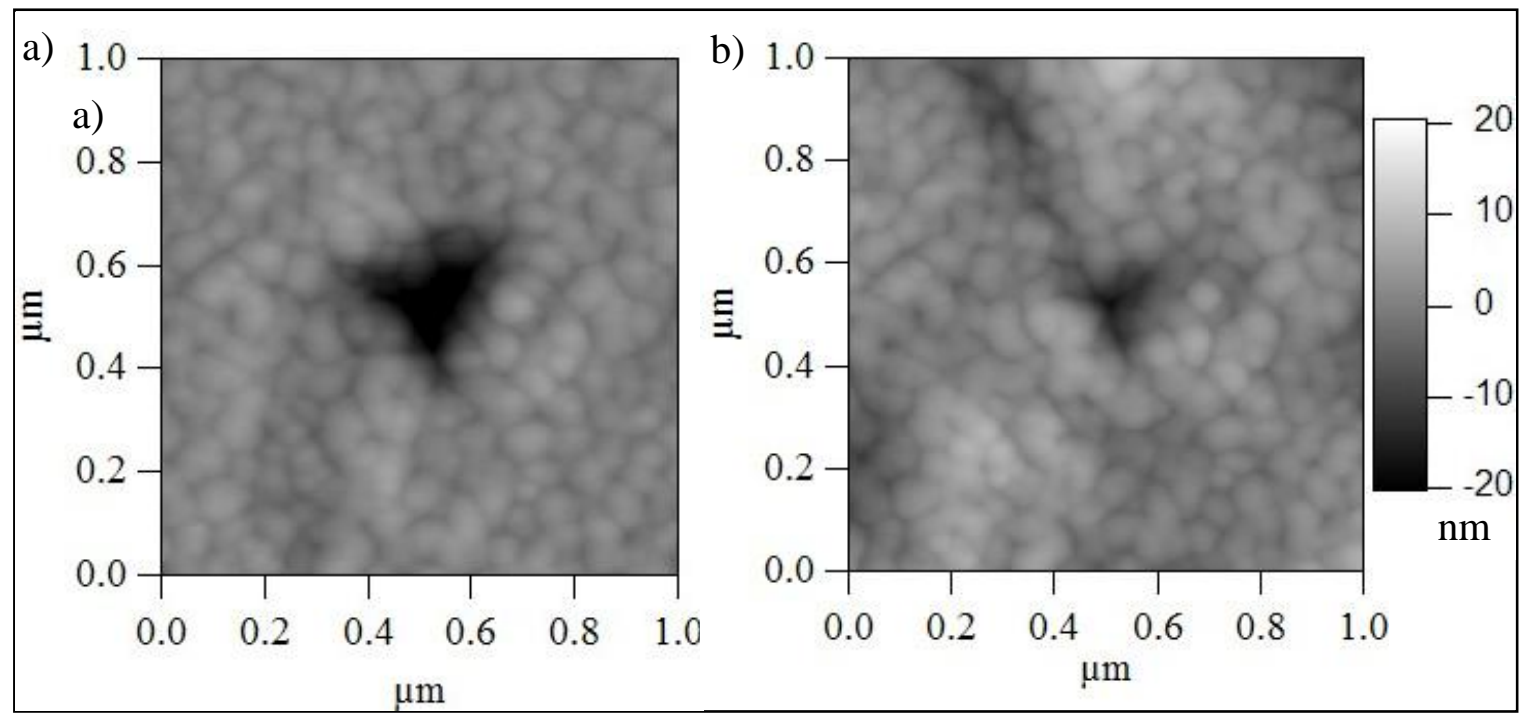

Figure 38: AFM images of a $0.25 \mathrm{mN}$ indent a) after indentation and b) after heating the NiTi past the phase transition temperature. Both AFM images are presented with the same z-scale. 


\subsection{Results}

An initial qualitative examination of the indents was made to investigate if the indents did undergo any recovery. A cross-section view of an indent before and after heating was compared to see if any recovery occurred (Figure 39).

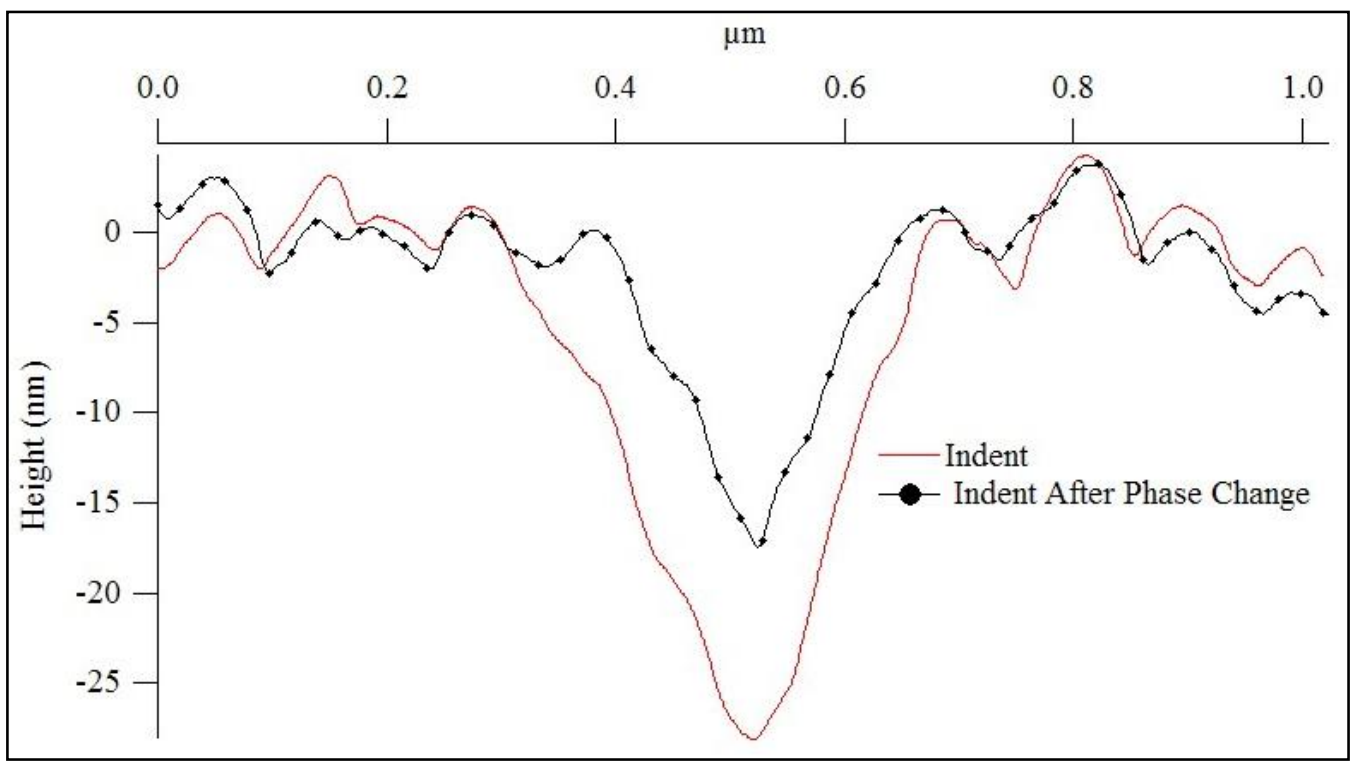

Figure 39: Comparison of a $0.25 \mathrm{mN}$ indent before and after heating. The indent appears to recover put did not recover completely.

The process of determining the indents depth, volume, surface area, and projected area was repeated for all the indents post heating. The data was compared to the indents before heating and a percent recovery was produced for the four recovery parameters. All parameters produced a recovery. On average, the indentations with a force of $0.25 \mathrm{mN}$ recovered more than the other indentation forces (Figure 40). The greatest depth recovery of $58 \%$ was from an indent with a force of $0.25 \mathrm{mN}$. The other indents appeared to have a slight trend to recover less as the indentation force increased. Some recoveries were measured in the ninety percent range for the area, volume, and projected area but were outliers in the data. The volume recovered the most overall of the four parameters. The 
projected area and surface area recovered similar amount. The indent depth recovered the least of the four parameters.

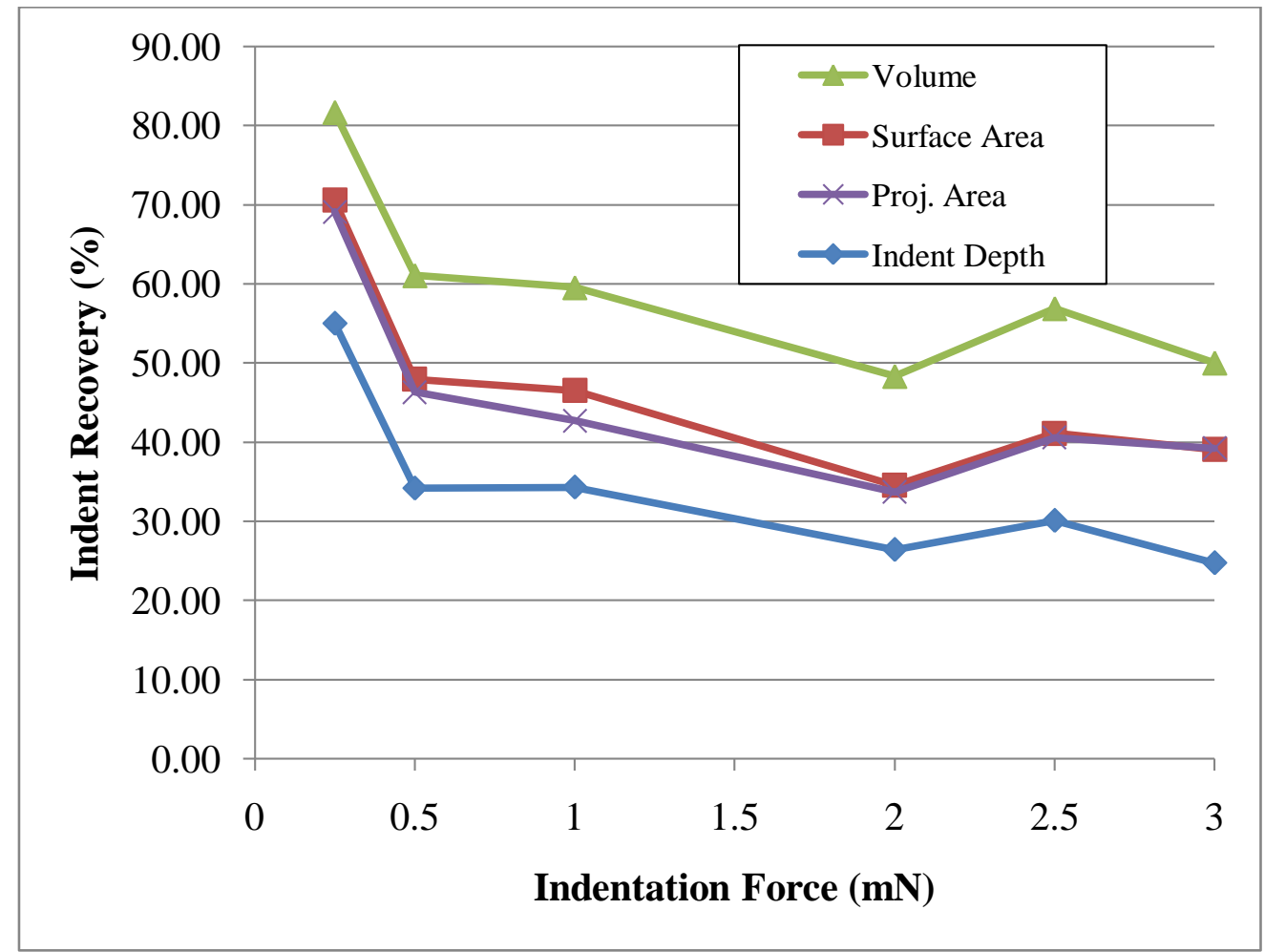

Figure 40: Average percent recovery for the four measured parameters (depth, surface area, projected area, and volume) verse the indentation force. The overall appearance was a decrease of recovery with an increase in force. However, the $0.25 \mathrm{mN}$ indents appear to have the only significant difference in recovery.

\subsubsection{Results: Statistical Analysis of Indentation Recovery}

The indentations appeared to have a slight trend of decreasing recovery with increasing indentation force. A one-way analysis of variance (ANOVA) was performed to determine if there was any significant difference between the amount recovered and the indentation force. A $95 \%$ confidence interval was used and only the $0.25 \mathrm{mN}$ indentation recovery were statistically different from the other indentation forces for the depth, surface area, and projected area. The $0.25 \mathrm{mN}$ volume recovery was significant from the 2 and $3 \mathrm{mN}$ indentations. The confidence level for the recoveries that were significant was $99.54 \%$. The recovery verse indentation force plots for each parameter 
with the data spread reveals the statistical result, that the $0.25 \mathrm{mN}$ indents recovered significantly over the other forces (Figure 41). The indents with forces $0.5 \mathrm{mN}$ and greater all recovered approximately the same amount.
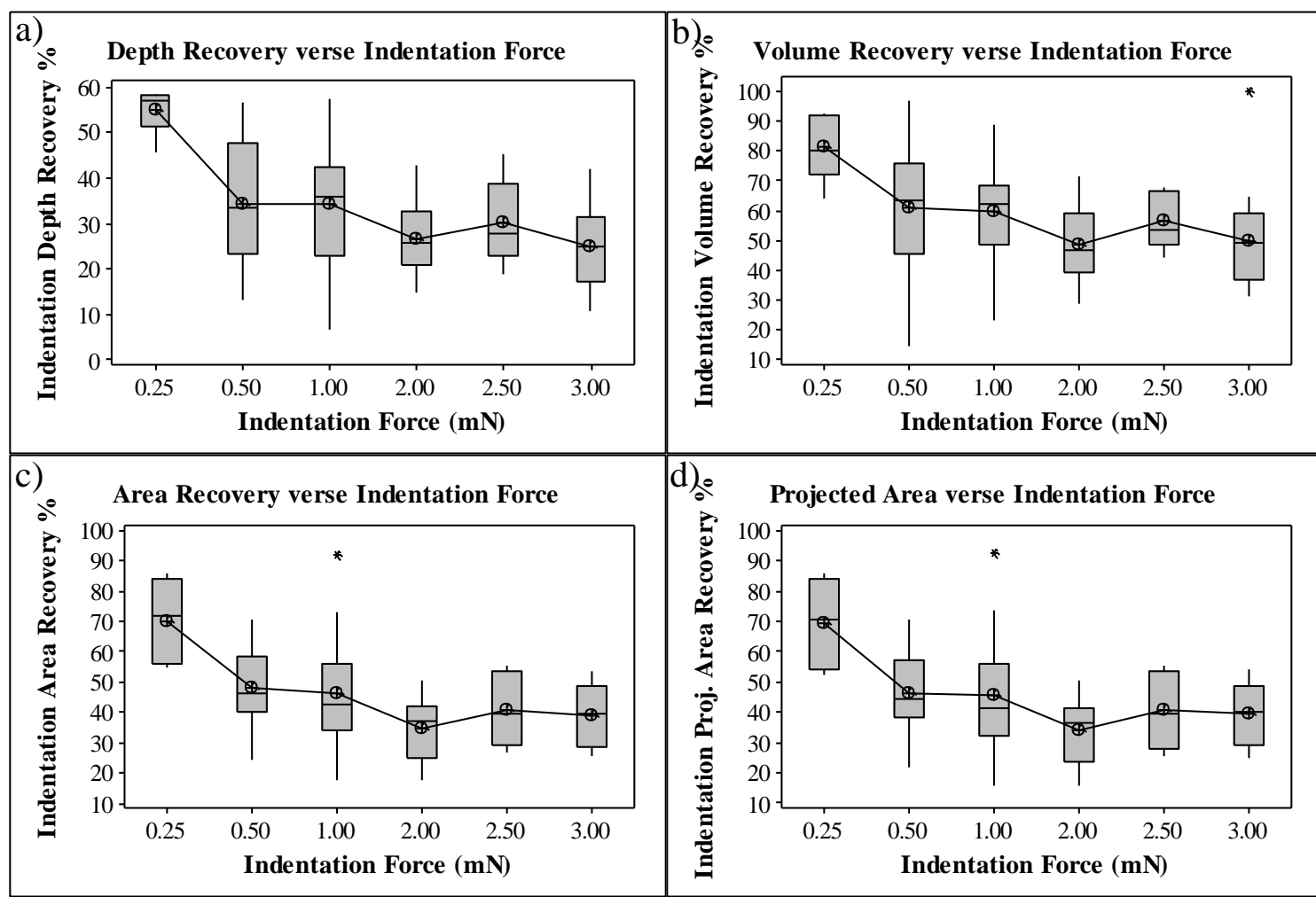

Figure 41: Indentation recovery verse force individually graphed for each parameter. The mean is represented by the crosshair mark. Median is the line in the box. The boxes are the middle $50 \%$ of the data and the lines that extend from the boxes are the upper and lower $25 \%$.

\subsection{Discussion}

Different studies have shown indentation recovery at the nanometer scale for NiTi. Some of the studies reported high recovery upon heating for indents less than 100 nm. Others have shown that shape memory NiTi recovers approximately $40 \%{ }^{74}$ of large indentation depths and up to $80 \%$ recovery for indentations under $100 \mathrm{~nm}$ upon heating ${ }^{75}$. The greatest indentation depth recovery observed from the martensitic phase transformation in this research was $58 \%$. A recovery of the reported $80 \%$ for indents under $100 \mathrm{~nm}$ was not achieved. The indentation recovery decreased as indentation force 
increased because the depth of the indenter increased with greater forces changing the strain in the sample. As the depth increased, the strain leveled off and recovery percents became more constant. This was a result of the rounding of the indenter tip. The radius of the indenter tip changed the induced strain, as the depth increased the strain leveled out to the strain of a Berkovich indenter. The reason the indentation recovery was not as high as previous studies done by done by Frick ${ }^{73}$ and Shaw ${ }^{69,75}$ is believed to be the condition of the indenter. All indenters used for this research had little wear and exceeded the ISO standards for tip tolerances. Numerous indents recovered around the $40 \%$ as reported by another study. The $40 \%$ recovery appears to be the recovery for the fully developed indent with a Berkovich indenter. To achieve full recovery of NiTi upon heating, the strain must be lower than 6 to $8 \%^{2,3}$. The indents in this study were performed with a Berkovich indenter, which induces approximately $8 \%$ stain in the material ${ }^{109}$. The stain induced by a Berkovich indenter was at the upper possible strain limit for shape memory NiTi to recover completely. The recovery appears to be a function of force but the change in recovery at a force of $0.25 \mathrm{mN}$ was because of the radius of curvature of the indenter. If the indenter had an ideal tip geometry the same amount of strain would have been induced at all indenter depth resulting in a relatively constant recovery ${ }^{110}$. The radius of curvature of the tip produced a change in the induced strain with respect to depth until the indenter reached the full $8 \%$ strain of the Berkovich indenter. The Berkovich indenter is the standard for measuring hardness and the elastic modulus with a Nanoindenter. The Berkovich indent is not the ideal indenter for studying the full recovery of NiTi. A major source of recovery variance from study to study with a Berkovich indenter is due to the blunting of the indenter tip. Blunting of the indenter was observed over time with the 
indenters used in this research. An indenter tip will round over time depending on use. If the indenter is worn so the radius of curvature of the indenter is increased the recovery of NiTi will be much greater compared to a new Berkovich indenter. An optimal indenter tip for studying the recovery of NiTi would be a spherical indenter. The stain $(\varepsilon)$ induced by a spherical indenter is related to the radius of the indenter $(\mathrm{R})$ and the radius of the circle of contact (a) (Equation 8) $)^{111,112}$. The induced strain could be tailored and comparison of recovery from study to study would be more accurate. A minimum strain of $\sim 1 \%$ would be needed to induce a strain that is past the elastic recovery and in the shape memory recovery ${ }^{51,113}$.

$$
\varepsilon=0.2 \frac{a}{R}
$$

The maximum force that could have been induced to achieve full recovery from the martensitic phase transformation is $\sim 50 \mu \mathrm{N}$. This is assuming a Berkovich indenter with a radius of curvature of $50 \mathrm{~nm}$. This would produce an indentation depth of $\sim 20 \mathrm{~nm}$.

The depth of the indentations recovered the least of the four measured parameters. This was the result of the greatest stress and deformation at the apex of the indenter as well as the most material constraint. The rest of the indent profile recovered more because of the unequal stress distribution under the indenter tip. The sidewalls of the indentation also recovered more because the material was less constrained at the shallower areas of the indenter. This resulted in less depth recovery and more recovery from the sidewalls of the indents (Figure 42). 


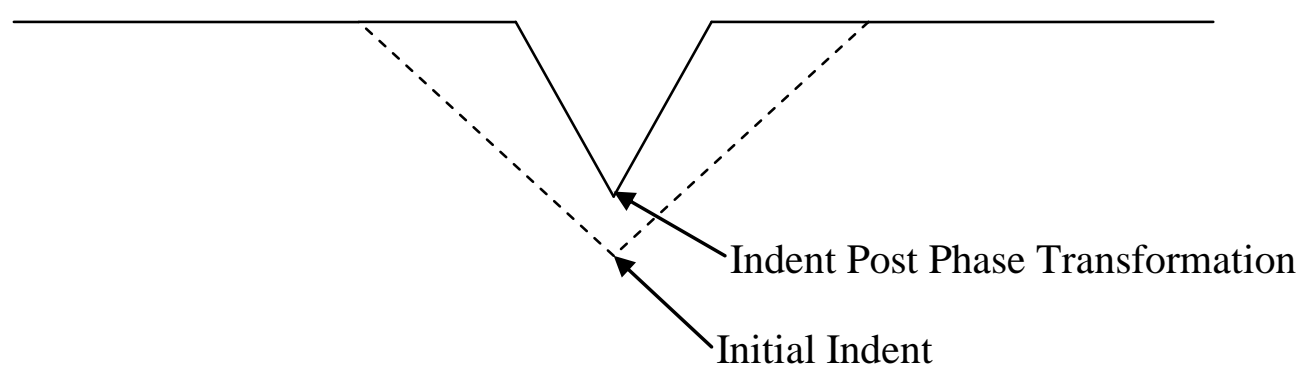

Figure 42: Indentation recovery schematic: Indentation depths recovered the least during the martensitic phase transformation while the sidewalls recovered more (Not to scale). 


\section{Chapter 7 - As-Sputtered NiTi Properties}

The as-sputtered NiTi films were indented to investigate the mechanical properties before annealing to understand the effects of the deposition process. The assputtered film were also indented to confirm the recovery from heat cycling was only associated with the annealing process and not some other thermal process. An investigation of the sputtering deposition parameters on the properties of the films was analyzed.

\subsection{As-Sputtered Films}

The elastic modulus and hardness of the as-sputtered NiTi films was hypothesized to be related to the sputtering deposition parameters. The total power to the sputtering guns was the parameter that would be investigated. The argon pressure in the chamber for the sputtering process was held constant at 2.1 mTorr for all film depositions. The chemical composition of the films remained the same by using the same power ratio to each sputtering gun. The power to the titanium target was $23.1 \%$ of the total power and the total power to the NiTi target was $76.9 \%$ of the total power ${ }^{94}$. Four different sputtering deposition powers were used 300, 350, 400, 450 watts (Table 3). The lowest total wattage the system could still sputter was $\sim 150$ watts. The total deposition power for the films that were annealed into a SMA was 450 watts.

Silicon wafers were processed and cleaned as described previously to produce an oxide layer and a $50 \mathrm{~nm}$ chromium adhesion layer on top of the oxide (Chapter 3). Four different NiTi films were deposited with a total power of 300, 350, 400, and 450 watts. The top chromium layer that was used to prevent oxidation was not necessary because the films were not annealed. 
Table 3: As-sputtered Film Gun Power

\begin{tabular}{|c|c|c|c|}
\hline $\begin{array}{c}\text { As-sputtered } \\
\text { Film }\end{array}$ & $\begin{array}{c}\text { Ti Target Gun A } \\
\text { (Watts) }\end{array}$ & $\begin{array}{c}\text { NiTi Target Gun B } \\
\text { (Watts) }\end{array}$ & $\begin{array}{c}\text { Total } \\
\text { Watts }\end{array}$ \\
\hline 1 & 69 & 231 & 300 \\
\hline 2 & 81 & 269 & 350 \\
\hline 3 & 92 & 308 & 400 \\
\hline 4 & 104 & 346 & 450 \\
\hline
\end{tabular}

\subsection{Film Thickness}

Measuring the thickness of the films was necessary to determine the stress and conductivity of each film. The thickness of the films was measured on the edge of the substrate during processing however; the edge heights were not accurate enough for the desired results. The film thickness was measured by first etching away part of the film with a NiTi etchant. The film was partially etched away by placing the wafer vertically in a room temperature etchant of one part hydrofluoric acid (HF), one part nitric acid $\left(\mathrm{HNO}_{3}\right)$, and twenty parts deionized water. This etched a portion of the film away so the thickness of the film could be determined by measuring the step height of the film with the contact profilometer (Figure 43). Seven locations along the etch line were measured to determine the thickness of the film. Each location was measured three times to determine the average for each location. 


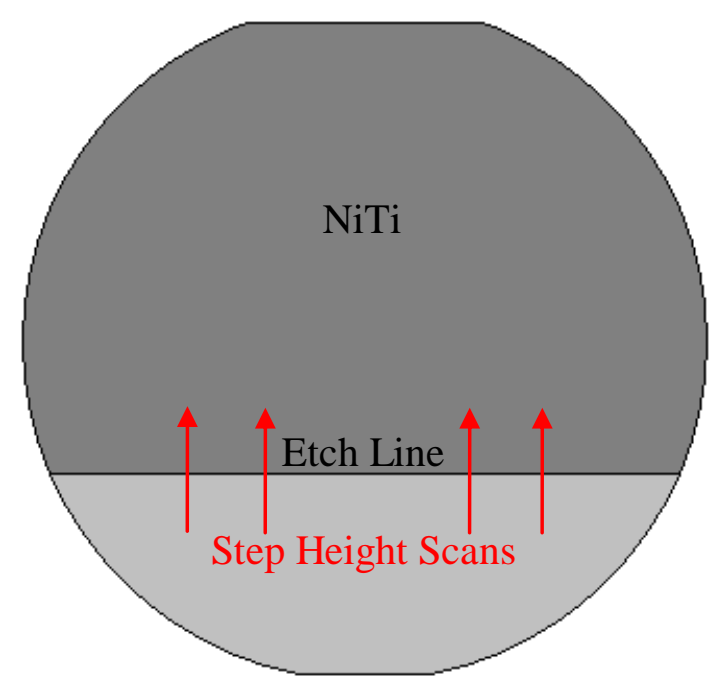

Figure 43: Etch line to determine the thickness of the NiTi layer of different deposition powers.

\subsection{Radius of Curvature}

The radius of curvature was measured with the profilometer after oxidation, chromium deposition, and NiTi deposition to determine the stress in the film. The procedure used to determine the radius of curvature was the same as previously described (Chapter 3). Each films radius of curvature was measured ten times to determine an average radius. Stoney's equation was used to determine the stress in the film (Equation (7).

\subsubsection{Film Stress Results}

The film stress of each as-sputtered NiTi film was determined by measuring the change in radius of curvature of the wafer using Stoney's equation (Figure 44). The stress of the film was a function of the sputtering deposition power. An increase in the sputtering deposition power resulted in an increase in the compressive film stress. At 450 watts, the greatest deposition power used, the compressive film stress was in excess of 
$300 \mathrm{MPa}$. At 300 watts, the lowest deposition power used resulted in a compressive stress of $164 \mathrm{MPa}$.

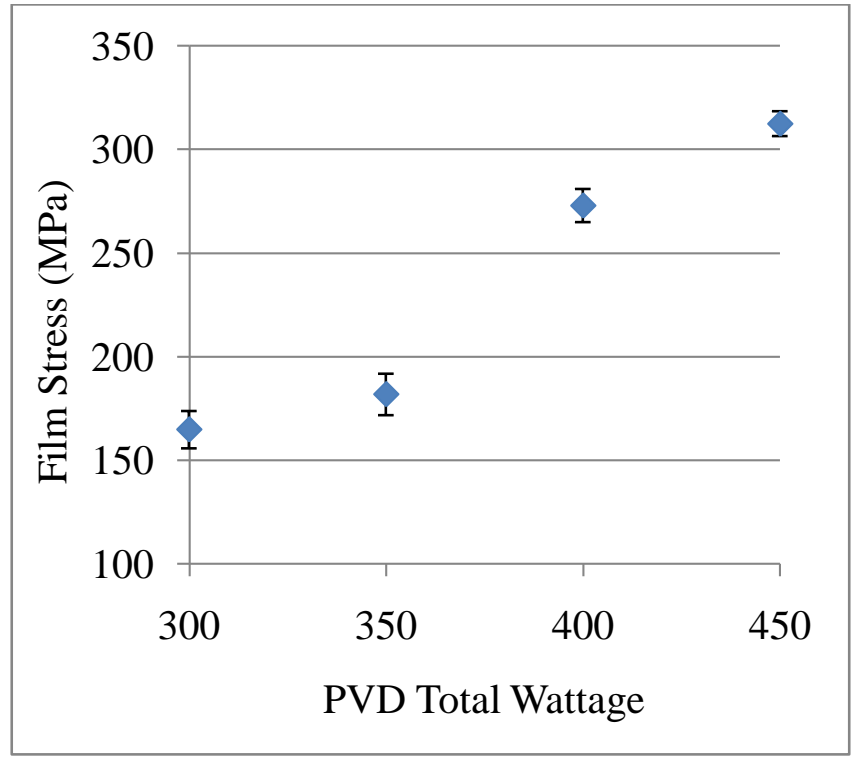

Figure 44: Film stress of the as-sputtered film with different sputtering powers. The increase of power to the sputtering guns made the atoms on the film closer spaced causing an increase in compressive film stress.

\subsection{Conductivity Measurements}

The electrical resistivity of the films was also measured with a four-point probe. The measurements were gathered at five locations on each wafer. This was done to investigate if other film properties were affected by the sputtering deposition power. The resistivity of the annealed films was also measured to investigate the affects of annealing on the resistivity. The sheet resistivity $\left(\mathrm{R}_{\mathrm{s}}\right)$ of the film was determined by applying a current (I) to the outer probes and measuring the voltage (V) of the two inner probes (Equation 9$)^{114}$.

$$
R_{s}=4.53 \frac{V}{I}
$$

The resistance $(\rho)$ of the film is equal to the resistivity $\left(R_{\mathrm{s}}\right)$ times the thickness $(t)$ of the film (Equation 10). 


$$
\rho=R_{s} t
$$

\subsubsection{Film Conductivity Results}

The film that was deposited with a total power of 300 watts produced a film with the lowest resistivity of $6.78 \times 10^{-5} \mathrm{ohm}-\mathrm{cm}$ (Figure 45). An increase in the applied power increased the resistivity of the film. The lowest power had a significantly lower resistivity while the other three as-sputtered films had similar resistivity with averages between $8.32 \times 10^{-5}$ to $8.68 \times 10^{-5}$ ohm-cm. As a reference, the annealed film had a resistivity of $1.47 \times 10^{-2} \mathrm{ohm}-\mathrm{cm}$ at room temperature. The resistivity of the as-sputtered films were greater than the annealed crystallized films because of the increased number of defects in the as-sputtered film perturb the flow of electrons and the crystalline structure creates a longer mean free path for the electrons.

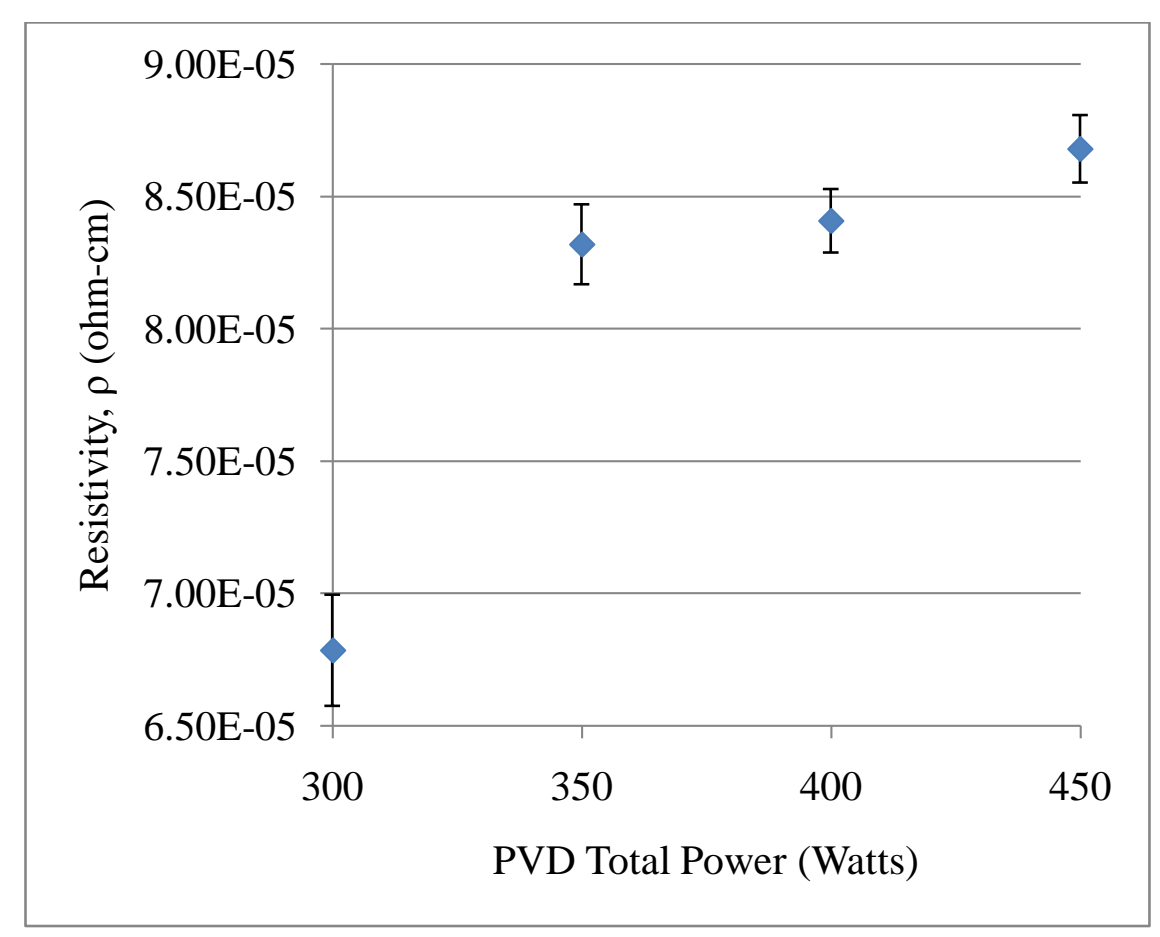

Figure 45: The electrical conductivity of the as-sputtered films with different sputtering process powers. 


\subsection{Drift Controlled Nanoindentation}

Due to the high stiffness and hardness of the as-sputtered films, thermal drift becomes a significant factor. Drift correction was not needed for the annealed films because of the lower hardness and elastic modulus. The as-sputtered film nanoindentation testing was performed in a heated isolation hood and drift correction software was used to correct for any remaining drift. The hood was set to $25^{\circ} \mathrm{C}$ and allowed to reach equilibrium before indentations were performed. Indentation methodology and sample preparation was the same as previously described (Chapter 5). The only change in the procedure was that every ten indentations a different force curve was used for post process thermal drift correction. The drift correction indentation has an initial load and hold at a force of $2 \mathrm{mN}$ for $60 \mathrm{sec}$ to stress-relax the contact ${ }^{115}$. The load was decreased to $10 \%$ of the initial region I part of the force curve. The force was held at $0.2 \mathrm{mN}$ for $100 \mathrm{sec}$ and retracted from the surface (Figure 46). If no thermal drift was present, the output $\mathrm{Z}$ height over the region II time will be level like the input force curve. If there was thermal drift, the plateaus will have a downward slope. From the slope, a drift correction can be made producing a $\Delta \mathrm{Z}_{0} / \Delta \mathrm{t}$. A drift correction indent was performed every ten indents. This provided the amount of drift over time; the drift was linear over time. The force curves were corrected from the drift information during post processing and analysis of the force curves. If the sample was left in the heated hood for several hours, the thermal drift can be at a negligible level to the results and post processing may not be needed. 


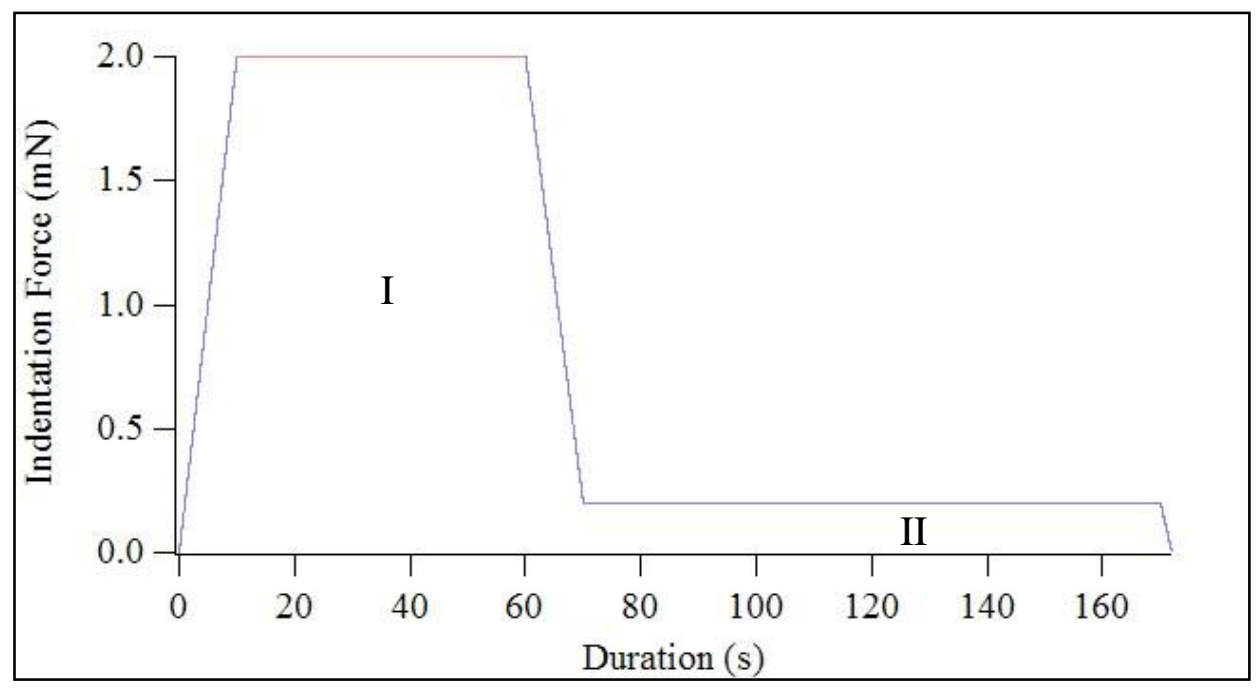

Figure 46: Drift correction force curve. Region I is a stress-relax the contact and region II is where the thermal drift is measured.

\subsubsection{Elastic Modulus and Hardness}

The elastic modulus of the as-sputtered film with an applied power of 450 Watts was $186.8 \mathrm{GPa}$ with a hardness of $8.29 \mathrm{GPa}$. The elastic modulus of the as-sputtered film was measured to be over twice that of the annealed NiTi (Figure 47). The higher elastic modulus for the as-sputtered films is because the impedance to dislocation. The nonperiodic arrangement of atoms in the amorphous film impedes planar slip and dislocation. The impedance makes the slip and dislocation motion harder. Dislocation motion is blocked by the impingement by none periodic atoms. The twinning structure of the NiTi shape memory alloy can also accommodate deformation by detwinning. 


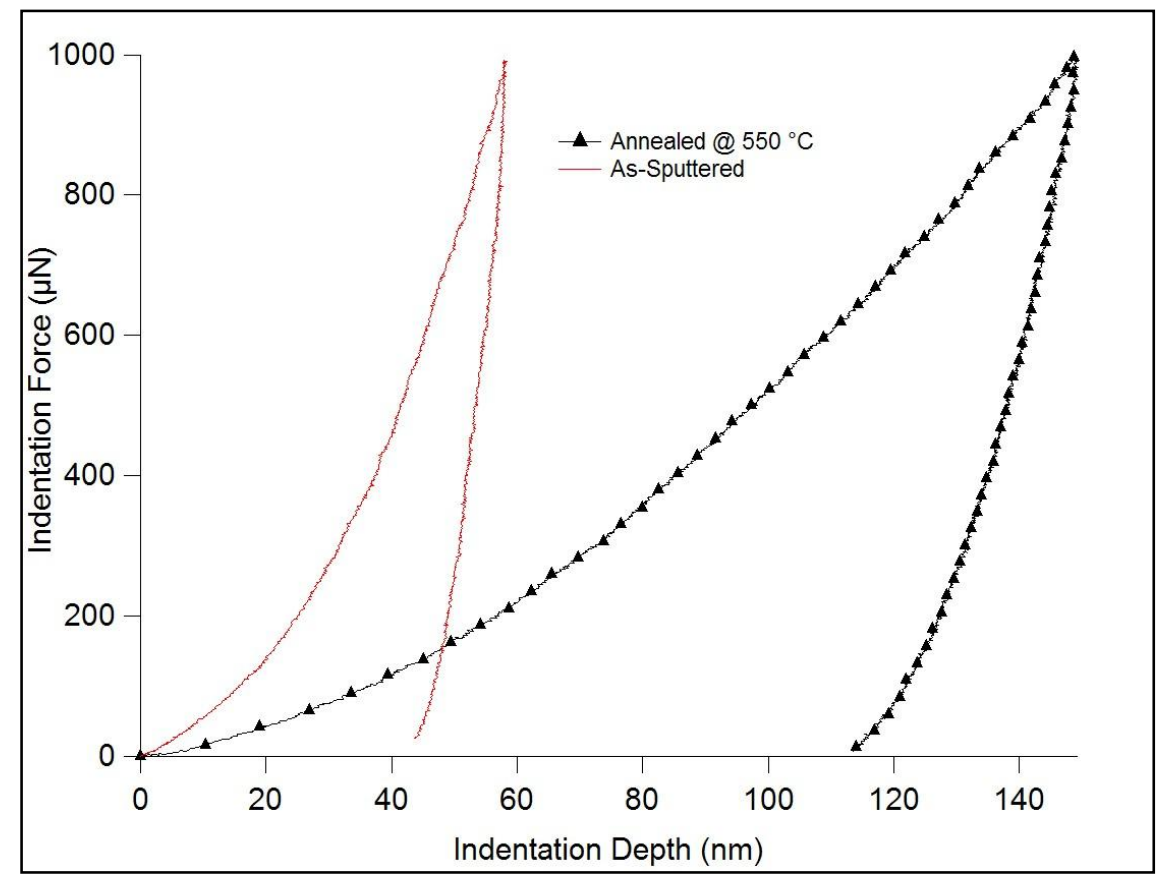

Figure 47: Nanoindentation forces curve comparison of as-sputtered amorphous NiTi and NiTi annealed at $550{ }^{\circ} \mathrm{C}$ and transformed into a shape memory alloy. The as-sputtered NiTi has greater hardness and elastic modulus.

The elastic modulus and hardness of the films increased with an increase of applied sputtering deposition power. The elastic modulus at the lowest sputtering deposition power was $145 \mathrm{GPa}$ and increased to $186 \mathrm{GPa}$ at the deposition power of 450 Watts (Figure 48). The hardness of the films also increased with an increase in deposition power. The hardness started at 7.6 GPa and increased to $8.3 \mathrm{GPa}$ at 450 Watts. All of the properties presented in this section were corrected for the actual indenter tip area. 


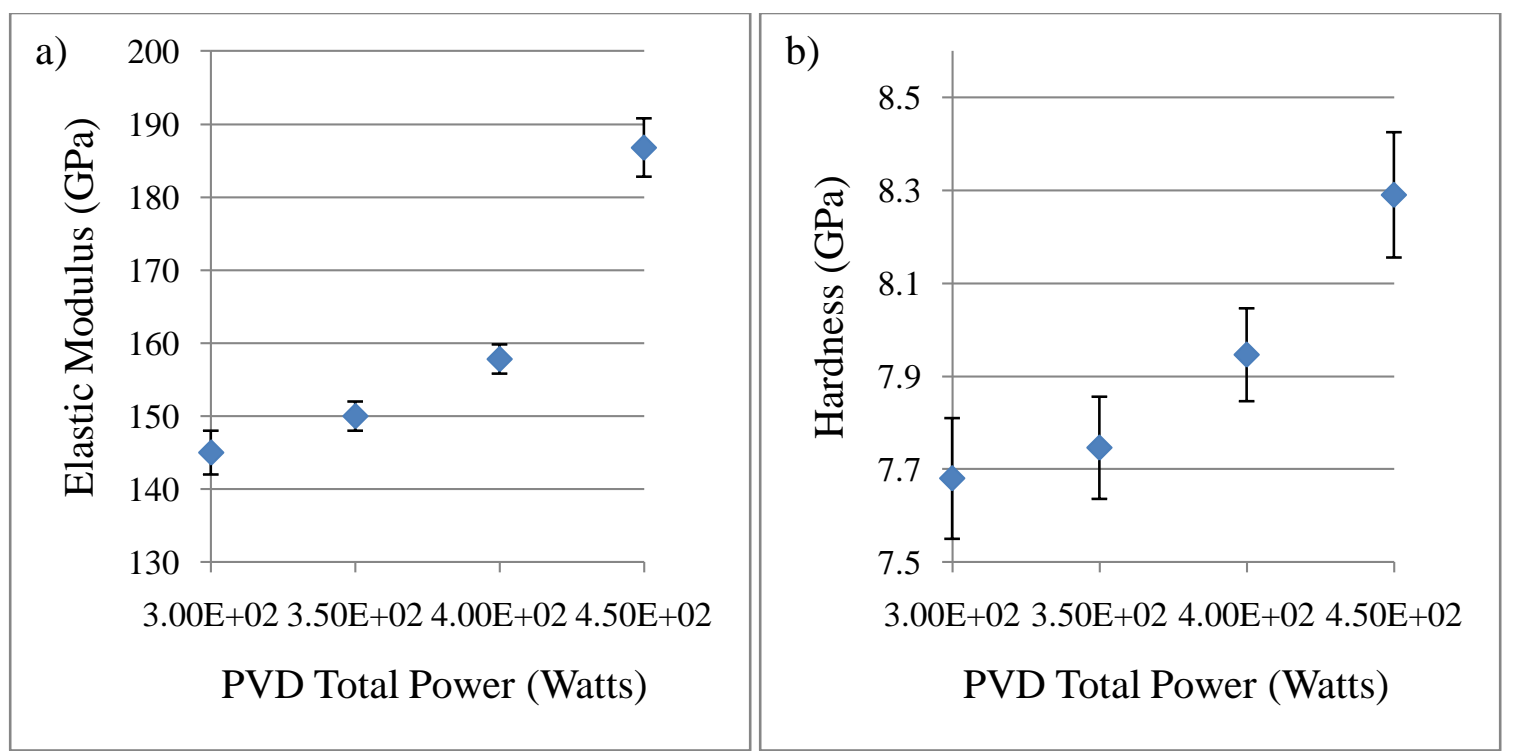

Figure 48: As-sputtered NiTi film properties: both the a) elastic modulus and b) hardness increased with an increase in the deposition power.

\subsection{Discussion}

The sputtering deposition power used for the deposition of thin films affected the atomic spacing, which created stresses in the film. An increase in the applied power between the targets and the substrate increases the electrons that are available to ionize argon atoms. The increase of ionized argon atoms increases the number of atoms sputtered off the target. The increased power also increases the kinetic energy of the sputtered atoms. The high kinetic energy of the atoms creating the film causes atomic peening $^{66,67}$. The increased impact energy of the atoms of the sputtered atoms knocks surface atoms into the film, decreasing the atomic spacing and increases compressive stresses in the film.

As the stress of the film changed, the properties of the film changed as well. The increase in resistivity of the films as the deposition power increased was caused by the separation of the atoms. As the atoms get closer, they impede the flow of electrons. The atomic spacing changes the mean free path of the electrons, decreasing the atom spacing 
decrease the mean free path and increases scattering of the electron flow. The defects in the amorphous film increase electron scattering. In reverse, as the atoms are stained apart the resistivity decreases due to the increased mobility of the electrons. This is similar to stained silicon in transistor manufacturing.

The different stress in the films changed the elastic modulus and hardness of the films. The atoms were closer together than the ideal atomic spacing. The atoms in compressive none ideal space have repulsive forces pushing them apart from each other but don't have the energy to migrate or increase the spacing. The type of mechanical testing used was a compressive load causing the atoms to decrease the atomic spacing that was initially closer than ideal. As a result, the atoms resisted the deformation more than the films with larger atomic spacing. The stress in the film also increases the resistance to slip and dislocation motion. The decreased atomic spacing impedes slip more than larger spacing. The increased compressive stresses in the film increased the elastic modulus and hardness of the NiTi thin film by nanoindentation. 


\section{CHAPTER 8 - Conclusions \& Recommendations}

The focus of this thesis was to produce thin film NiTi by DC magnetron sputtering deposition, determine the film properties, and evaluate the film's ability to recover nanoindentations by the shape memory effect. DC magnetron sputtering deposition was used to create a thin film of NiTi. A heat treatment process was used to anneal to crystallize the as-sputtered film into a shape memory alloy. The deposition and annealing process was confirmed to produce a SMA by DSC, elemental analysis, and topography changes.

The elastic modulus and hardness of the thin film NiTi SMA were determined by nanoindentation. The elastic modulus and hardness were determined to be greater than the bulk values of NiTi. Residual stress in the film from the sputtering deposition process was believed to be the source of the higher than bulk NiTi properties. The mechanical properties of the film provide valuable information for designing MEMS devices with NiTi in the Microfabrication Lab at California Polytechnic State University.

The recovery of nanoindentations by heat induced martensitic phase transformation of NiTi SMA was investigated. The recovery provided insight into the recovery of deformation at the micron and submicron scale. Partial indentation recovery was observed and measure but full recovery was not achieved. Berkovich indenters were used for this study and that type of indenter induces higher strain than NiTi can fully recover through the martensitic phase transformation. This was why full indentation recovery was not measured. 
A DC magnetron sputtering deposition parameter was evaluated to determine the affects the as-sputtered NiTi film properties. The effects of deposition power on assputtered film stress, elastic modulus, hardness, and electrical conductivity were evaluated. As the deposition power increased the residual film compressive stress, elastic modulus, hardness increased, and the electrical resistivity increased. The changes in the films properties were a result of different kinetic energy of the deposited atoms that made the NiTi thin films.

\subsection{Future Work}

Further work can be done to optimize the deposition parameters and quality of the NiTi film. Previous work has been done to optimize the sputtering parameters to create thin film NiTi SMA. Since the optimization, modifications have been done to improve the performance of the Rohwedder DC magnetron sputtering machine used for sputtering deposition of the NiTi. A result of the modifications was the performance of the machine changed from the performance when the optimization occurred. The parameters that need to be optimizations again include the elemental composition and reducing film stress. A SMA was achieved but the elemental composition was not stoichiometric. Compositions that are not stoichiometric produce precipitates such as $\mathrm{NiTi}_{2}$ and $\mathrm{Ni}_{3} \mathrm{Ti}$. The precipitates cause none uniform properties at the micron and submicron scale. Film stress was another parameter that was affected by the system modifications. The stress in the film can cause problems such as warping of the devices structure. The film stress may also affect the mechanical properties after annealing. The effects of initial film stress on the annealed film mechanical properties are of interest. That would provide insight into the high elastic modulus of the NiTi SMA film measured in this research. 
The use of chromium as an adhesion and oxidation protection layer should be removed. Chromium substitutes as nickel in the NiTi structure and rapidly decreases the phase transition temperature because it acts like nickel in the NiTi structure as well as increases the valence electrons per atom. Other adhesion layers like $\mathrm{Si}_{3} \mathrm{~N}_{4}$ could be researched as a replacement. Silicon on insulator (SOI) wafers could be used to provide electrical insulation as another alternative. Different annealing techniques have shown results for improving NiTi adhesion on silicon dioxide. Chromium protective layer could be removed because the annealing process was done in a high vacuum chamber. This could also reduce the potential of chromium diffusion into the NiTi film.

The indentation recovery would be increased by using a spherical indenter that would not induce the high strain that a Berkovich indenter causes. Using a spherical indenter would also provide a standard to compare indentation recovery to other studies. The induced strain could be tailored by changing the radius of the indenter. The spherical indenter would remove the indenter blunting from a factor for indentation recovery. The optimal crystal structure orientation for maximum indentation recovery is a necessary parameter to be characterized. 


\section{CHAPTER 9 - References and Bibliography}

1. Krulevitch, P., A. P. Lee, P. B. Ramsey, J. C. Trevino, J. Hamilton, and M. A. Northrup. "Thin Film Shape Memory Alloy Microactuators." Journal of Microelectromechanical Systems 5 (1996): 270-282.

2. Wayman, C. M. Thermoelastic Martensitic Transfermations and the Nature of the Shape Memory Effect. Proc. of Proceedings Materials Research Society Symposium. Vol. 21. 1984. 657-667.

3. Robertson, S. W., A. Mehta, A. R. Pelton, and R. O. Ritchie. "Evolution of Crack-tip Transformation Zones in Superelastic Nitinol Subjected to in Situ Fatigue: A Fracture Mechanics and Synchrotron X-ray Microdiffraction Analysis." Acta Materialia 55 (2007): 6198-6207.

4. Johnson, A. D., J. D. Busch, C. A. Ray, and C. Sloan. Fabrication of Silicon-based Shape Memory Alloy Micro-actuators. Proc. of Materials Research Society Symp. Proc. Vol. 276. 1992. 151-160.

5. Yongqing, Fu, Hejun Du, Weimin Huang, Sam Zhang, and Min Hu. "NiTi-based Thin Films in MEMS Applications: a Review." Sensors and Actuators A: Physical 112.2-3 (2004): 395-408.

6. Xu, Dong, Li Wang, Guifu Ding, Yong Zhou, Aibing Yu, and Bingchu Cai. "Characteristics and Fabrication of NiTi/Si Diaphragm Micropump." Sensors and Actuators A: Physical 93.1 (2001): 87-92.

7. Gill, J. J., D. T. Chang, L. A. Momoda, and G. P. Carman. "Manufacturing Issues of Thin Film NiTi Microwrapper." Sensors and Actuators A: Physical 93.2 (2001): 148-156.

8. Lee, Abraham P., Dino R. Ciarlo, Peter A. Krulevitch, Stacy Lehew, Jimmy Trevino, and M. A. Northrup. "A Practical Microgripper by Fine Alignment, Eutectic Bonding and SMA Actuation." Sensors and Actuators A: Physical 54.1-3 (1996): 755-759.

9. Jardine, A. P. Cycling times of Thin-film NiTi on Si. Proc. of Materials Research Society Symp. Proc. Vol. 246. 1992. 427-431.

10. Shaw, G. A., J. S. Trethewey, A. D. Johnson, W. J. Drugan, and W. C. Crone. "Thermomechanical High-Density Data Storage in a Metallic Material Via the ShapeMemory Effect." Applied Materials 17.9 (2005): 1123-1127.

11. Chikazumi, Sōchin, and Chad D. Graham. Physics of Ferromagnetism. Oxford, UK: Oxford UP, 1997. 
12. Skumryev, Vassil, Stoyan Stoyanov, Yong Zhang, George Hadjipanayis, Dominique Givord, and Josep Nogués. "Beating the Superparamagnetic Limit with Exchange Bias." Nature 423 (2003): 850-852.

13. Vettiger, P., G. Cross, M. Despont, U. Drechsler, U. Durig, B. Gotsmann, W. Haberle, M. A. Lantz, H. E. Rothuizen, R. Stutz, and G. K. Binning. "The "millipede" Nanotechnology Entering Data Storage." IEEE Transactions on Nanotechnology 1.1 (2002): 39-55.

14. Holland, B. J., and J. N. Hay. "The Kinetics and Mechanisms of the Thermal Degradation of Poly(methyl Methacrylate) Studied by Thermal Analysis-Fourier Transform Infrared Spectroscopy." Polymer 42.11 (2001): 4825-4835.

15. Gall, K., K. Juntunen, H. J. Maier, H. Sehitoglu, and Y. I. Chumlyakov. "Instrumented Micro-indentation of NiTi Shape-memory Alloys." Acta Materialia 49.16 (2001): 3205-3217.

16. Qiu, Ju-Feng. "Magneto-optical Properties and Stability of GdTbFeCo Thin Films Prepared by RF-magnetron Sputtering." Journal of Magnetism and Magnetic Materials 173 (1997): 215-218.

17. Lin, Y. C., M. Z. Chen, C. C. Kuo, and W. T. Yen. "Electrical and Optical Properties of ZnO:Al Film Prepared on Polyethersulfone Substrate by RF Magnetron Sputtering." Colloids and Surfaces A: Physicochemical and Engineering Aspects 337.1-3 (2009): 52-56.

18. Kutepova, V. P., and D. A. Hall. "Effect of the Sputtering Parameters on the Growth and Piezoelectric Properties of Zinc Oxide Thin Films." Ultrasonics Symposium, 1998. Proceedings 1 (1998): 213-216.

19. Frick, Carl P., et al. "Shape Memory at Nanometer Scales." Material Research Society. 2006.

20. Duerig, T. W. "An Introduction to Martensite and Shape Memory." Engineering Aspects of Shape Memory Alloys. London: Butterworth-Heinemann, 1990.

21. Buehler, W. J., J. W. Gilfrich, and R. C. Wiley. "Effect of Low-temperature Phase Changes on the Mechanical Properties of Alloys Near Composition TiNi." Journal of Applied Physics 34 (1963): 1475-1477.

22. Pelton, Alan R., Scott M. Russell, and John DiCello. "The Physical Metallurgy of Nitinol for Medical Applications." Journal of Metals (2003): 33-37.

23. Stoeckel, Dieter. "The Shape Memory Effect - Phenomenon, Alloys and Applications." Shape Memory Alloys for Power Systems EPRI. 1995. 1-13. 
24. Matsumoto, O., S. Miyazaki, K. Otsuka, and H. Tamura. "Crystallography of Martensitic Transformation in Ti-Ni Single Crystals." Acta Metall 35 (1987): 2137-2144.

25. Notomi, Mitsuo, Krystyn J. Van Vliet, and Sidney Yip. "Classification and Characterization of the Shape Memory Binary Alloys." Materials Research Society Symposium Proceedings 980 (2007): 223-228.

26. Otsuka, Kazuhiro, and Clarence Marvin Wayman. Shape Memory Materials. Cambridge, UK: Cambridge UP, 1999.

27. Wechsler, M. S., D. S. Liebermann, and T. A. Read. "On the Theory of the Formation of Martensite." Transactions AIME 197 (1953): 1503-1515.

28. Lieberman, D. S., M. S. Wechsler, and T. A. Read. "Cubic to Orthorhombic Diffusionless Phase Change - Experimental and Theoretical Studies of AuCd." Journal of Applied Physics 26.4 (1955): 473-485.

29. Reed-Hill, Robert E., and Reza Abbaschian. "Chapter 17 Deformation Twinning and Martensite Reactions." Physical Metallurgy Principles. 3rd ed. Boston: PWS-Kent Pub., 1992.

30. Ōtsuka, Kazuhiro, and Clarence Marvin Wayman. Shape Memory Materials. Cambridge: Cambridge UP, 1998.

31. Melton, K. N. "Ni-Ti based shape memory alloys." Engineering aspects of shape memory alloys. London: Butterworth-Heinemann (1990): 21-35.

32. Zarinejad, Mehrdad, and Yong Liu. "Dependence of Transformation Temperatures of NiTi-based Shape-Memory Alloys on the Number and Concentration of Valence Electrons." Advanced Functional Materials 18.18 (2008): 2789-794.

33. Zarinejad, Mehrdad, Yong Liu, and Yunxiang Tong. "Transformation Temperature Changes Due to Second Phase Precipitation in NiTi-based Shape Memory Alloys." Intermetallics 17.11 (2009): 914-19.

34. Otsuka, K., and X. Ren. "Physical Metallurgy of Ti-Ni-based Shape Memory Alloys." Progress in Materials Science 50.5 (2005): 511-678.

35. Massalski, T. B., H. Okamato, P. R. Subramanian, and L. Kacprzak. ASM Handbook. 2nd ed. Vol. 3. Materials Park, OH: ASM International, 1990. 2874. 
36. Tang, Weijia. "Thermodynamic Study of the Low-temperature Phase B19' and the Martensitic Transformation in Near-equiatomic Ti-Ni Shape Memory Alloys." Metallurgical and Materials Transactions A 28.3 (1997): 537-544.

37. Nishida, M., C. M. Wayman, and T. Honma. "Precipitation Processes in Nearequiatomic TiNi Shape Memory Alloys." Metallurgical and Materials Transactions A 17.9 (1986): 1505-1513.

38. Melton, K. N. "Ni-Ti Shape Memory Alloys." Engineering Aspects of Shape Memory Alloys. By T. W. Duerig. London: Butterworth-Heinemann, 1990.

39. Goldstein, D. M., W. J. Buehler, and R. C. Wiley. Effects of Alloying Upon Certain Properties of 55.1 Nitinol. NOL Technical Report. 64-235. 1965.

40. Duerig, T. W., and A. R. Pelton. "TiNi Shape Memory Alloys." Materials Properties Handbook: Titanium Alloys. By Gerhard Welsch, Rodney Boyer, and E. W. Collings. Materials Park, OH: ASM International, 1994. 1035-1048.

41. Fischer-Cripps, Anthony C. "Indentation at the Nanometre Scale." Nanoindentation. 2nd ed. New York: Springer, 2004. 15. Print.

42. Doerner, M. F., and W. D. Nix. "A Method for Interpreting the Data from a Depthsensing Indentation Instrument." Journal of Material Research 1.4 (1986): 601-609.

43. Oliver, W. C. and G. M. Pharr. "An improved technique for determining hardness and elastic modulus using load and displacement sensing indentation experiments." Journal of Materials Research 7.6 (1992): 1564-1583.

44. Bolshakov, A., G. M. Pharr. "Understanding nanoindentation unloading curves." Journal of Material Research 17.10 (2002): 2660-2671.

45. Berkovich, E. S., "Three faceted diamond pyramid for micro hardness testing." Industrial Diamond Review, 11, \#127, June 1951.

46. Oliver, W. C. and G. M. Pharr. "Measurement of hardness and elastic modulus by instrumented indentation: Advances in understanding and refinements to methodology." Journal of Materials Research 19.1 (2003): 3-20.

47. Hay, J. L., and G. M. Pharr. "Instrumented indentation testing." ASM Handbook, Materials Testing and Evaluation 8 (2000): 232-243.

48. Simmons, Gene, and Herbert Wang. Single Crystal Elastic Constants and Calculated Aggregate Properties a Handbook. Cambridge Mass. [etc.: M.I.T., 1971. 
49. VanLandingham, M. R., T. F. Juliano, and M. J. Hagon. "Measuring Tip Shape for Instrumented Indentation Using Atomic Force Microscopy." Meas. Sci Tech 16 (2005): 2173-2185.

50. "NANO INDENTERS FROM MICRO STAR TECHNOLOGIES." Micro Star Technologies. Web. 10 Oct. 2010. <http://www.microstartech.com>.

51. Liu, Yong, Z. Xie, J. Van Humbeeck, and L. Delaey. "Asymmetry of Stress-strain Curves under Tenstion and Compression for NiTi Shape Memory Alloys." Acta Materialia 46.12 (1998): 4325-4338

52. Wang, Y., D. Raabe, C. Klüber, and F. Roters. "Orientation Dependence of Nanoindentation Pile-up Patterns and of Nanoindentation Microtextures in Copper Single Crystals." Acta Materialia 52.8 (2004): 2229-2238.

53. Fischer-Cripps, Anthony C. "Factors Affecting Nanoindentation Test Data." Nanoindentation. 2nd ed. New York: Springer, 2004. 81. Print.

54. Bolshakov, A., and G. M. Pharr. "Influences of pileup on the measurement of mechanical properties by load and depth sensing indentation techniques." Journal of materials research 13.4 (1998): 1049-1058.

55. Cheng, Y. T, and C. M. Cheng. "Scaling approach to conical indentation in elasticplastic solids with work hardening." Journal of Applied Physics 84 (1998): 1284.

56. McElhancy, K. W., J. J. Vlassak, and W. D. Nix. "Determination of Indenter Tip Geometry and Indentation Contact Area for Depth-sensing Indentation Experiments." Journal of Material Research 13.5 (1998): 1300-360.

57. Fischer-Cripps, Anthony C. "Application of Nanoindentation." Nanoindentation. New York: Springer, 2004. 195-212.

58. Mattox, D. M. Handbook of Physical Vapor Deposition (PVD) Processing: Film Formation, Adhesion, Surface Preparation and Contamination Control. Westwood, N.J.: Noyes Publications, 1998. Print.

59. Mattox, D. M., " The historical development of controlled ion-assisted and plasmaassisted PVD process." Proceedings of the $40^{\text {th }}$ Annual Technical conference, Society of Vacuum Coaters (1997): 109.

60. Chapman, Brian N. Glow Discharge Processes: Sputtering and Plasma Etching. New York: Wiley, 1980. Print. 
61. Penfols, A. S., "Magnetron Sputtering." Handbook of Thin Film Process Technology. Sec. A3.2.Institution of Physics Publishing (1995)

62. Wasa, Kiyotaka, and Shigeru Hayakawa. Handbook of Sputter Deposition Technology: Principles, Technology, and Applications. Park Ridge, N.J., U.S.A.: Noyes Publications, 1992. Print.

63. Windischmann, Henry. "Intrinsic Stress in Sputter-deposited Thin Films." Critical Reviews in Solid State and Materials Sciences 17.6 (1992): 547-596.

64. Thornton, John A. "The Microstructure of Sputter-deposited Coatings." Journal of Vacuum Science and Technology 6th ser. 4 (1986): 3059-3065.

65. Sanjabi, Sohrab, Sayed K. Sadrnezhaad, Karen A. Yates, and Zoe H. Barber. "Growth and Characterization of $\mathrm{Ti}_{\mathrm{x}} \mathrm{Ni}_{1-\mathrm{x}}$ Shape Memory Thin Films Using Simultaneous Sputter Deposition from Seperate Elemental Targets." Thin Solid Films 491 (2005): 190-196.

66. Kijima, Y., and T. Hanada. "Effect of the Pressure of Sputtering Atmosphere on the Physical Properties of Amorphous Aluminum Oxide Films." Journal of Materials Science 35 (2000): 2193-199.

67. Hippler, Rainer, Holger Kersten, and Martin Schmidt. Low Temperature Plasmas Fundamentals, Technologies and Techniques. Weinheim: Wiley-VCH, 2008.

68. Grummon, David S., Jinping Zhang, and Thomas J. Pence. "Relaxation and Recovery of Extrinsic Stress in Sputtered Titanium-nickel Thin Films on (100)-Si." Materials Science and Engineering A 273-275 (1999): 722-726.

69. Shaw, G. A., D. S. Stone, A. D. Johnson, A. B. Ellis, and W. C. Crone. "Shape Memory Effect in Nanoindentation of Nickel-titanium Thin Films." Applied Physics Letters 83.2 (2003): 257-259.

70. Moyne, S., C. Poilane, K. Kitamura, S. Miyazaki, P. Delobelle, and C. Lexcellent. "Analysis of the Thermomechanical Behavior of Ni-Ti Shape Memory Alloy Thin Films by Bulging and Nanoindentation Procedures." Materials Science and Engineering (1999): 727-732.

71. Ni, Wangyang, and David S. Grummon. "Nanoindentation and Wear Behavior of Nickel-titanium Alloys and Thin Films." Materials Research Society Symp. Proc. 697 (2002).

72. Crone, W. C., G. A. Shaw, D. S. Stone, A. D. Johnson, and A. B. Ellis. "Shape Recovery after Nanoindentation of NiTi Thin Films." Proc. of 2002 SEM Annual Conference Proceedings. Carlotte, 2003. 
73. Frick, Carl P., Travis W. Lang, Kevin Spark, and Ken Gall. "Stress-induced Martensitic Transformations and Shape Memory at Nanometer Scales." Acta Matarialia 54 (2006): 2223-234.

74. Ni, Wangyang, Yang-Tse Cheng, and David S. Grummon. "Microscopic Shape Memory and Superelastic Effects under Complex Loading Conditions." Surface and Coatings Technology (2004): 512-17.

75. Shaw, G. A., J. S. Trethewey, A. D. Johnson, W. J. Drugan, and W. C. Crone. "Thermomechanical High-Density Data Storage in a Metallic Material Via the ShapeMemory Effect." Applied Materials 17.9 (2005): 1123-1127.

76. Deal, B., and A. Grove. "General relationship for thermal oxidation of silicon." Journal of Applied Physics 36 (1965): 3770

77. Stoney, G. G. "The tension of metallic films deposited by electrolysis." Proceedings of the Royal Society of London. Series A, Containing Papers of a Mathematical and Physical Character 82.553 (1909): 172-175.

78. Preissig, V. "Applicability of the Classical Curvature-Stress Relation for Thin Films on Plate Substrates." Journal of Applied Physics 66.9 (1989): 4262-4268.

79. Hodge, T., S. Bidstrup-Allen, and P. Kohl. "Stresses in Thin Film Metallization." IEEE Transactions on Components, Packaging, and Manufacturing Technology - Part A 20.2 (1997): 241-250.

80. Huang, Shusen, and Xin Zhang. "Extension of Stoney's Formula to Non-uniform Temperature Distributions in Thin Film/substrate Systems. The Case of Radial Symmetry." Journal of the Mechanics and Physics of Solids 53.11 (2005): 2483-2500.

81. Fu, Yongqing, Hejun Du, and Sam Zhang. "Adhesion and Interfacial Structure of Magnetron Sputtered TiNi Films on Si/SiO2 Substrate." Thin Solid Films 444.1-2 (2003): 85-90.

82. Mattox, D. M. "Thin Film Metalization of Oxides in Microelectronics." Thin Solid Films 18.2 (1973): 173-86.

83. Wolf, Richard H., and Arthur H. Heuer. "NiTi (Shape Memory) Films on Silicon for MEMS Applications." Journal of Microelectromechanical Systems 4.4 (1995): 206-12.

84. Fu, Yongqing, Hejun Du, and Sam Zhang. "Adhesion and Interfacial Structure of Magnetron Sputtered TiNi Films on Si/SiO2 Substrate." Thin Solid Films 444.1-2 (2003): 85-90. 
85. Johnson, A. D., and J. D. Busch, "Development of a digital storage medium using thin film shape memory alloy.” NASA SBIR Phase II Final Report, 1992.

86. Miyazaki, S. and A. Ishida. "Martensitic transformation and shape memory behavior in sputter-deposited TiNi-base thin films", Mater. Sci. Eng., A Struct. Mater.: Prop. Microstruct. Process., 106, (1999): 273-275

87. Grummon, D. S., L. Hou, Z. Zhao, T. J. Pence. "Progress on sputter-deposited thermoactive titanium-nickel films." J. Physique Coll. IV 5 (1995):665-670.

88. Shih, C., B. K. Lai, H. Kahn, S. M. Phillips, A. H. Heuer. A Robust Co-Sputtering Fabrication Procedure for TiNi Shape Memory Alloys for MEMS. Journal of Microelectromechanical Systems, 2001. 10(1): 69 - 80.

89. Ho, K., Carman, G., Sputter Deposition of NiTi Thin Film Shape Memory Alloy Using a Heated Target. Thin Solid Films, 2000. 370: p. 18 - 29.

90. Grummon, D. S., L. Hou, Z. Zhao, and T. J. Pence. "Progress on Sputter Deposited Thermoreactive Titanium-nickel Films." J. Phys. IV, 5 (1995): 665-670.

91. Ho, Ken K., and Gregory P. Carman. "Sputter Deposition of NiTi Thin Film Shape Memory Alloy Using a Heated Target." Thin Solid Films 370.1-2 (2000): 18-29.

92. Chen-Luen Shih, Bo-Kuai Lai, Harold Kahn, Stephen M. Phillips, Arthur H. Heuer, A Robust Co-Sputtering Fabrication Procedure for TiNi Shape Memory Alloys for MEMS, Journal of Microelectromechanical Systems, vol. 10, no. 1, (2001): 69-80.

93. Huang, X., Liu, Y., Ling, S., Zhang, H., Huang, W., "Effect of SiO2 Buffer Layer on Properties of Sputter-Deposited NiTi Shape Memory Alloy Thin Films." Surface and Coatings Technology. 167 (2003): 148 - 153.

94. Dequine, Dustin Michael. Process Development And Characterization To Manufacture Nickel Titanium Shape Memory Cantilever Micro-Electro-Mechanical Systems. Master's Thesis. San Luis Obispo, 2007.

95. Miyazaki, S., and K. Nomura. "Development of perfect shape memory effect in sputter-depositedTi-Ni thin films." IEEE Workshop on Micro Electro Mechanical Systems, 1994, MEMS'94, Proceedings. (1994): 176-181.

96. Fu, Yongqing, Hejun Du, Weimin Huang, Sam Zhang, and Min Hu. "TiNi-based Thin Films in MEMS Applications: a Review." Sensors and Actuators A: Physical 112.23 (2004): 395-408.

97. Getchel, D., Processing of Freestanding NiTi Shape Memory Thin Film Cantilevers. 
2007, California Polytechnic State University, San Luis Obispo.

98. Getchel, D., Savage, R. Characterization of Structural and Mechanical Properties of NiTi Shape Memory Thin-films for Micro Actuators. in Materials Research Society Spring 2005 Conference. April, 2005.

99. Acton, O., Developing Micro System Actuators: Residual Stress and Composition in Co-Sputtered Amorphous NiTi Thin Films. 2005, California Polytechnic State University: San Luis Obispo, CA.

100. Shackelford, James F. "Chapter 4: Crystal Defects and Noncrystalline Structureimperfection." Introduction to Materials Science for Engineers. Upper Saddle River, N.J.: Pearson/Prentice Hall, 2005.

101. Wolf, R. H., and A. H. Heuer. "TiNi (shape Memory) Films Silicon for MEMS Applications." Journal of Microelectromechanical Systems 4.4 (1995): 206-212.

102. Betz, G., and G. K. Wehner. "Chapter 2: Sputtering of Multicomponent Materials." Sputtering by Particle Bombardment II. By Rainer Behrisch and Gerhard Betz. Berlin: Springer-Verlag, 1983.

103. Mikami, Y., K. Yamada, A. Ohnari, T. Degawa, T. Migita, T. Tanaka, K. Kawabata, and H. Kajioka. "Effect of DC Bias Voltage on the Deposition Rate for Ni Thin Films by RF-DC Coupled Unbalanced-magnetron Sputtering." Surface and Coatings Technology 134 (2000): 295-300.

104. ASTM F 2004-00 Test Method for transition Temperature of Nickel-Titanium Alloys by Thermal Analysis (Wert Conshohocken, PA: ASTM, 2002).

105. Bemis, Jason. "Virtual Deflection." Asylum Research. Asylum Research, 03 Nov. 2006. Web. 30 Sept. 2010.

$<$ https://support.asylumresearch.com/forum/attachment.php?attachmentid=42\&d=116258 6742>.

106. Fuierer, Ryan. "Ryan's MFP-3D Procedural Operation 'manualette' Version 10." Asylum Research, May 1, 2008.

107. Gao, H., C. H. Chiu, and J. Lee. "Elastic contact verse indentation modeling of multi-layered materials." Int. J. Solids Structures 29.20 (1992): 2471-2492.

108. Stone, D. S. "Elastic rebound between an indenter and a layered specimen: Part I. Model." J. Mater. Res 13.11 (1998): 3207-3213. 
109. Fischer-Cripps, Anthony C. "Berkovich Indenter." Nanoindentation. 2nd ed. New York: Springer, 2004. 27.

110. Fischer-Cripps, Anthony C. "Other Techniques in Nanoindentation." Nanoindentation. 2nd ed. New York: Springer, 2004. 144-158.

111. Fischer-Cripps, Anthony C. "Nanoindentation Testing." Nanoindentation. 2nd ed. New York: Springer, 2004. 35. Print.

112. Tabor, David. The Hardness of Metals. Oxford: Clarendon, 1951.

113. Robertson, S. W., V. Imbeni, E. Notkina, H. E. Wenk, and R. O. Ritchie. "Texture in Tubes and Plates of Nitinol." Proceedings of the International Conference on Shape Memory and Superelastic Technologies (2003): 341-47.

114. Smits, F. M., "Measurements of Sheet Resistivity with the Four-Point Probe," BSTJ, 37 (1958): 711-718.

115. Bonilla, F. A. and R. S. Bonilla. "The MFP-3D NanoIndenter Technical Note: ZThermal Drift Correction.” Asylum Research, United States, March 5, 2009.

\section{Bibliography}

Bining, G. and C. Quate. "Atomic force microscope." Physics Review Letters (1986): 930-933.

Bonilla, Alejandro. NanoIndenter Getting Started Guide. Tech Note 11. Asylum Research. Santa Barbara, 2009.

Crone, Wendy C. and Gordon A. Shaw. "Applying NiTi Shape-Memory Thin Films to Thermomechanical Data Storage Technology." Materials Research Society. 2005.

Dequine, Dustin Michael. PROCESS DEVELOPMENT AND CHARACTERIZATION TO MANUFACTURE NICKEL TITANIUM SHAPE MEMORY CANTILEVER MICRO-ELECTRO-MECHANICAL SYSTEMS. Master's Thesis. San Luis Obispo, 2007.

Duerig, T. W. and A. R. Pelton. "Ti-Ni Shape Memory Alloys." Welsch, Gerhard, Rodney Boyer and E. W. Collings. Materials Properties Handbook Titanium Alloys. Materials Park, OH: ASM International, 1994. 1035-1048.

Duerig, T. W. Engineering aspects of shape memory alloys. London: ButterworthHeinemann, 1990. 
Fischer-Cripps, Anthony C. Nanoindentation. 2. New York: Springer, 2004.

Frick, Carl P., et al. "Shape Memory at Nanometer Scales." Material Research Society. 2006.

Frick, Carl P., et al. "Stress-induced martensitic transformations and shape memory at the nanometer scales." Acta Materialia 54 (2006): 2223-2234.

Hay, Jack C., A. Bolshakov and G. M. Pharr. "A critical examination of the fundamental relations used in the analysis of nanoindentation data." Journal of materials Research (1999): 2296-2305.

Hughes, William L. "Synthesis and characterization of zinc oxide nanostructures for piezoelectric applications." Georgia Institute of Technology, August 2006.

Mattox, Donald M. Handbook of physical vapor deposition (PVD) processing: film formation, adhesion, surface preparation and contamination control. Westwood, N.J.: Noyes Publications, 1998.

Meyer, Ernst, Hans Josef Hug and Roland Bennewitz. Scanning probe microscopy the lab on a tip. Berlin: Springer, 2004.

Müllner, P., et al. "Nanomechanics and magnetic structure of orthorhombic Ni-Mn-Ga martensite." Materials Science and Engineering A (2008): 66-72.

Oliver, W. C. and G. M. Pharr. "Measurement of hardness and elastic modulus by instrumented indentation: Advances in understanding and refinements to methodology." Journal of Materials Research 19.1 (2003): 3-20.

Oliver, W. C. and G. M. Pharr. "An improved technique for determining hardness and elastic modulus using load and displacement sensing indentation experiments." Journal of Materials Research t.6 (1992): 1564-1583.

Qu, Jianmin and Mohammed Cherkaoui. "Micromechanics of martensitic transformation in solids." Fundamentals of Micromechanics of Solids. Hoboken, New Jersey: John Wiley \& Sons, Inc., 2006. 347-380.

Reed-Hill, Robert E. and Resa Abbaschian. "Deformation twinning and martersite reactions." Physical metallurgy principles. Boston: PWS Publishing Company, 1991. $561-585$. 
Sanjabi, S., et al. "Growth and Characterization of TixNi1-x Shape Memory Thin Films Using Simultaneous Sputter Deposition from Separate Elemental Targets." Thin Solid Films (2005): 190-196.

Sanjabi, Sohrab, et al. "Growth and characterization of TixNi1-x shape memory thin films using simultaneous sputter deposition from seperate elemental targets." Thin Solid Films 491 (2005): 190-196.

Shaw, G. A, et al. "Shape Memory Effect in Nanoindentation of Nickel-Titanium Thin Films." Applied Physics Letter (2003): 83.

Shaw, Gordon A., et al. "Thermomechanical high-density data storage in a metallic material via the shape-memory effect." Advanced Materials 17 (2005): 1123-1127.

T., W. Duerig. Engineering Aspects of Shape Memory Alloys. London: ButterworthHeinemann, 1990.

VanLandingham, M. R., T. F. Juliano and M. J Hagon. "Measuring tip shape for instrumented indentation using atomic force microscopy." Measurement Science and Technology (2005): 2173-2185.

Wasa, Kiyotaka and Shigeru Hayakawa. Handbook of sputter deposition technology: principles, technology, and applications. Park Ridge, N.J., U.S.A.: Noyes Publications, 1992.

Wibowo, E. and C. Y. Kwok. "Fabrication and Characterization of Sputtered NiTi Shape Memory Thin Films." Journal of Micromechanics and Microengineering (2005): 101108.

Wolf, Richard H. and Arthur H. Heuer. "NiTi (Shape Memory) Films on Silicon for MEMS Applications." Journal of Microelectromechanical Systems (1995): 206-212.

Ye, Jia, et al. "Direct observation of the NiTi martensitic phase transformation in nanoscale volumes." Acta Materialia (2009). 


\section{Appendix A \\ Standard Operating Procedures:}

Rohwedder PVD Sputtering

\section{System Components}

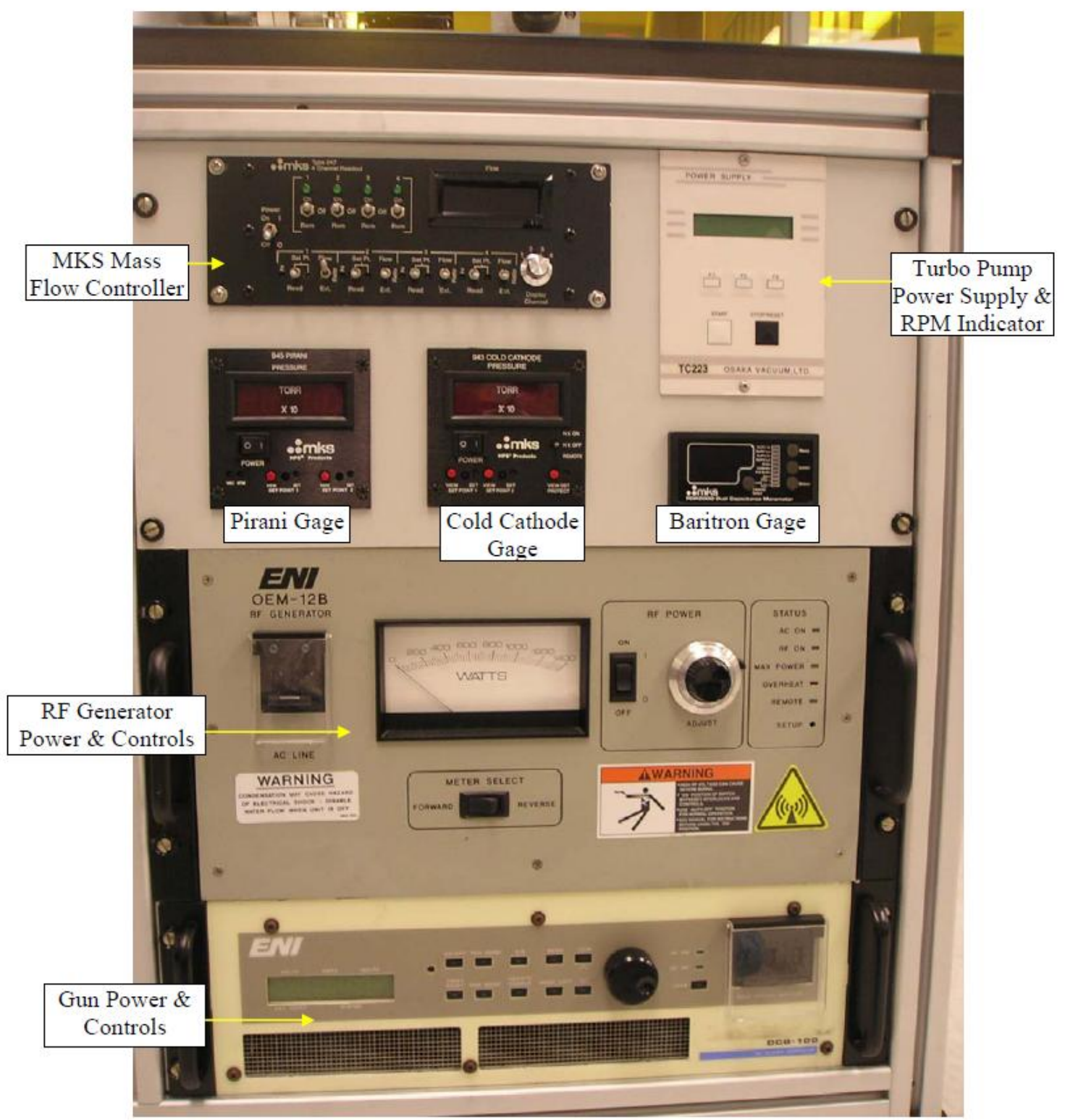



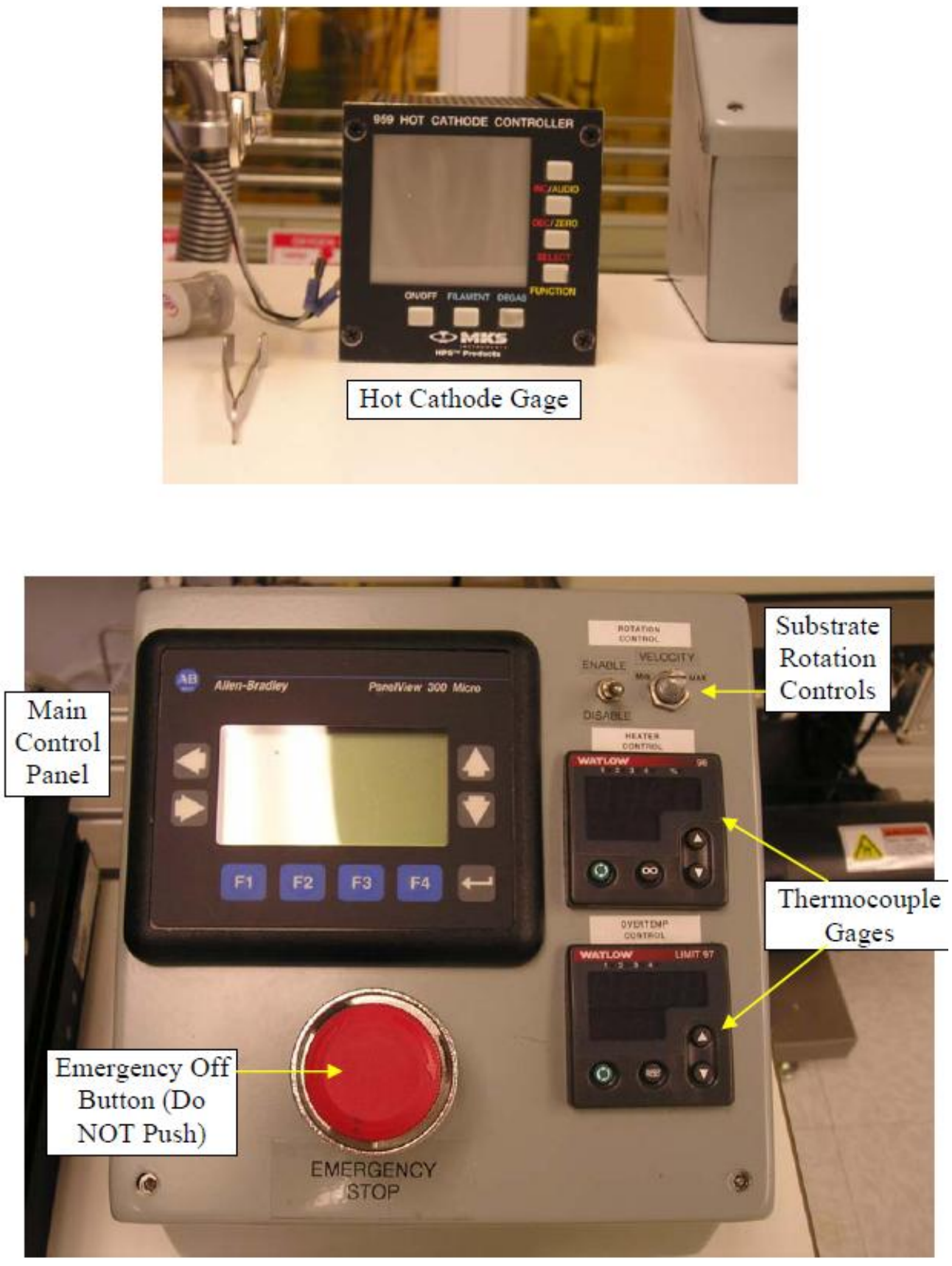


\section{Log Book}

This is Not an Exhaustive List

Name Date Wafer Label Deposition Material

Hot Cathode Pressure

Cold Cathode Pressure

Gun A Water Flow

Gun B Water Flow

MKS Argon Flow

MKS DCM Argon Pressure

\begin{tabular}{llll} 
Presputter & Time & \multicolumn{2}{l}{ Gun A Material Gun B Material } \\
Gun A Parameter & Voltage & Amperage Power \\
Gun B Parameter & Voltage & Amperage Power & \\
& & & \\
Sputter & Time & Gun A Material Gun B Material \\
Gun A Parameter & Voltage & Amperage Power & Power
\end{tabular}

Comments:

Other good things to record: Roughing pump time, pump down time, 


\section{System Preparation}

1. Turn on power supplies on wall at the entrance of the clean room. (Should always be on unless repairs are being done.)

2. Make sure the cold cathode pressure and hot cathode pressure gages are off.
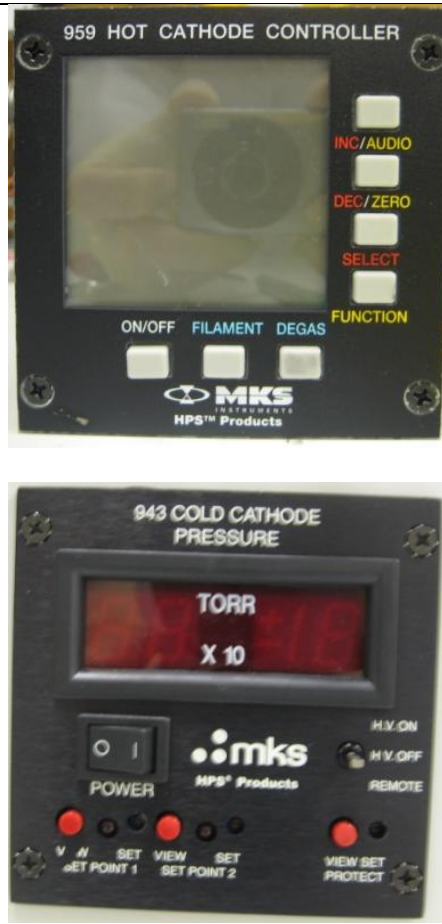
3. Ensure that both chillers are on and flow for each gun is at least 0.8 GPM and the TMP and chamber flow is at max on the gauge.

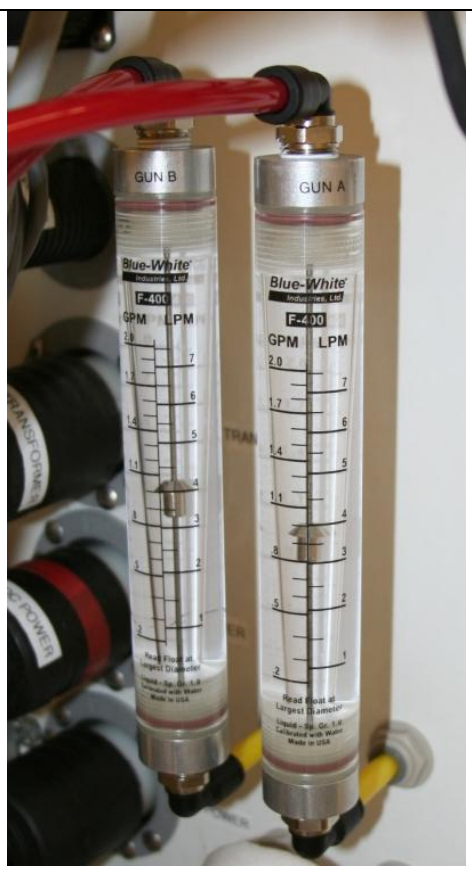

4. Set both chillers to $20^{\circ} \mathrm{C}$ when guns are not in use. TMP and chamber chiller always stays at $20^{\circ} \mathrm{C}$.

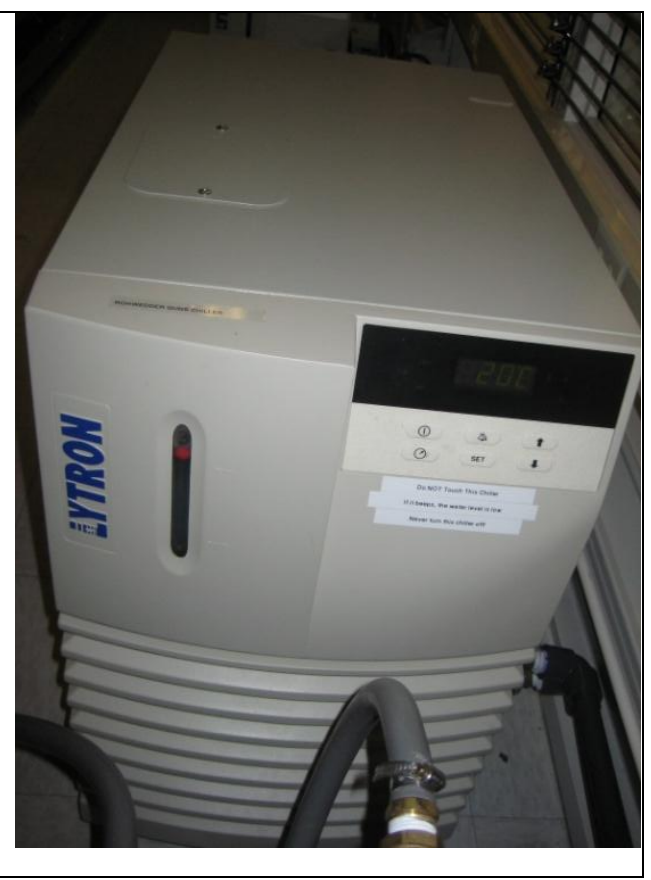

5. The compressed air, and argon supplies should be on:

Check to make sure the compressed air is set to $90 \mathrm{psi}$ at pressure regulator behind sputtering system. 
6. Open the argon valve on rear of sputtering system and make sure the bottle in the chase is open. (argon is needed to vent the chamber)

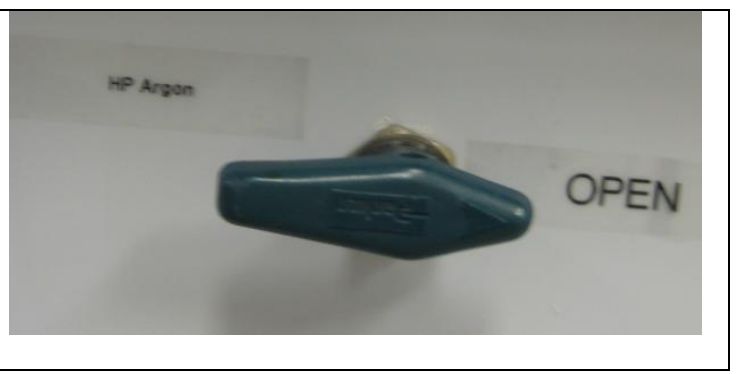

7. Make sure the Pirani gage is on

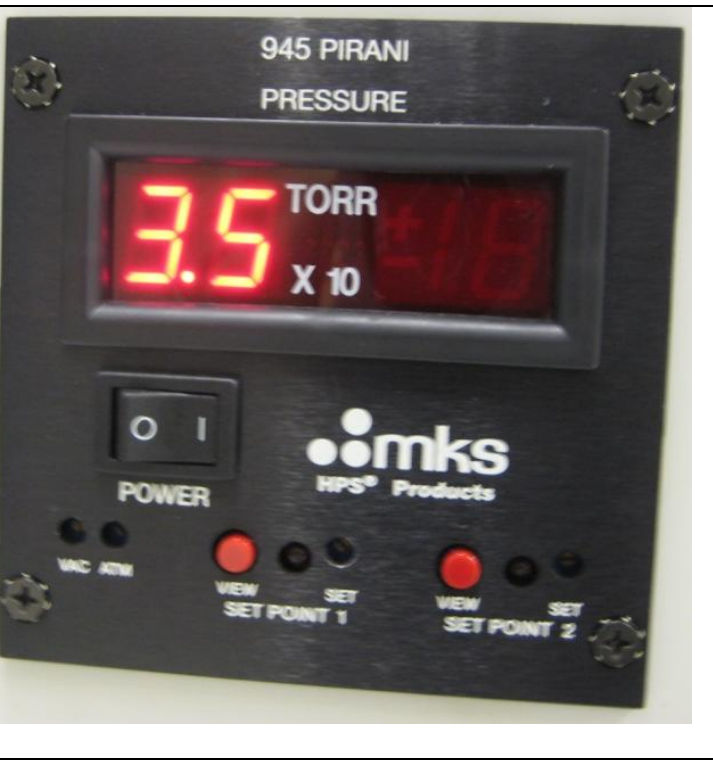




\section{PVD Preparation}

1. With chamber vented, unclamp and lift lid to sputtering chamber

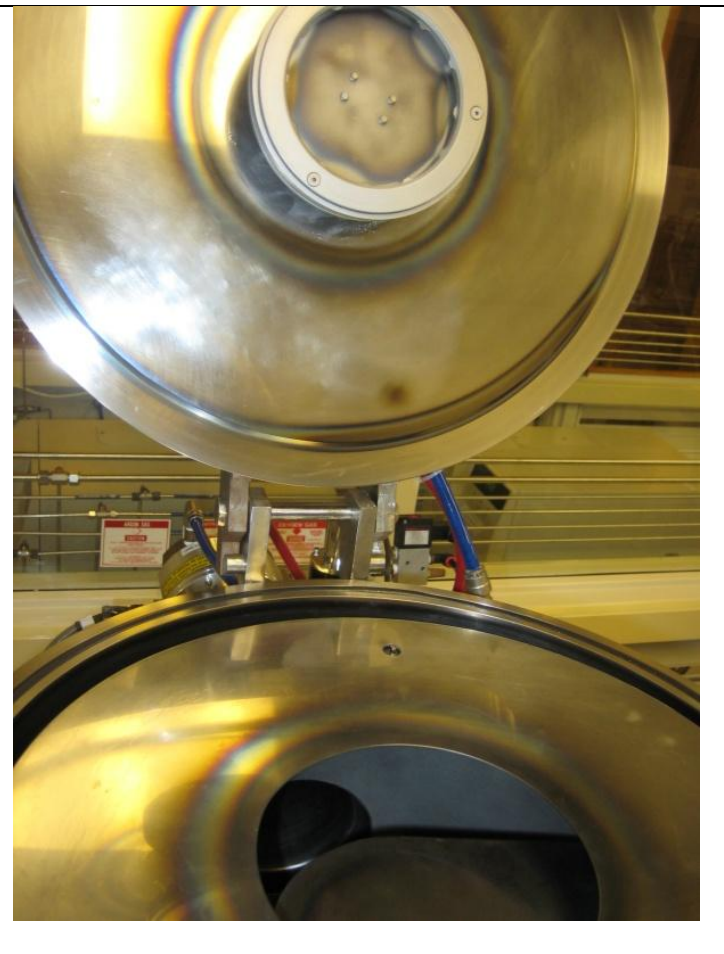

2. Remove the shroud lid

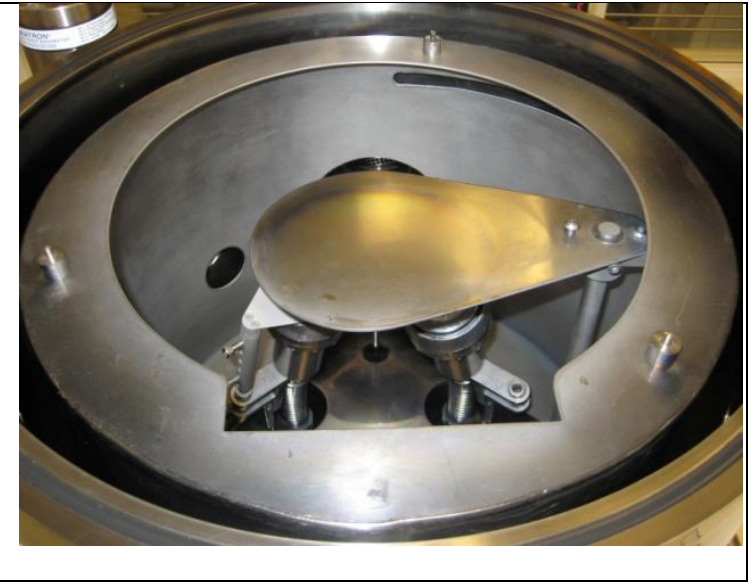


3. Check targets and change if necessary to appropriate material. (If target need to be changed refer to the target replacement SOP)

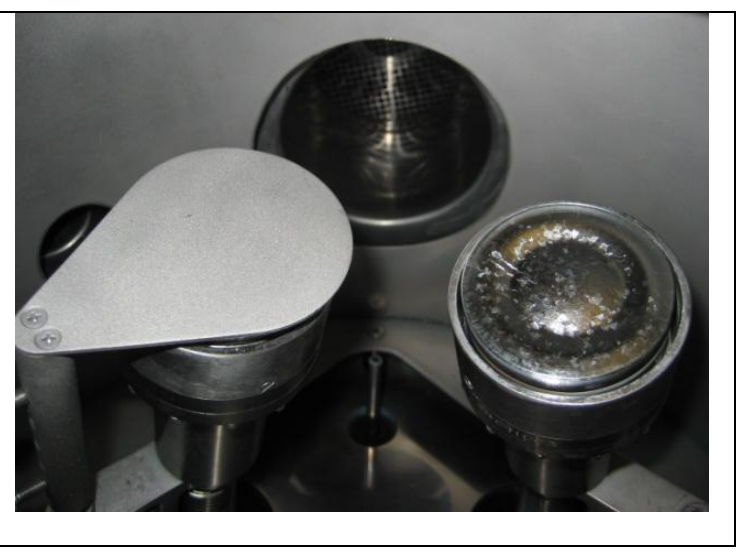

4. On the underside of the chamber lid, remove the substrate holder by gently spinning counter-clockwise. Support mounting bracket to not torque the rest of the assembly.
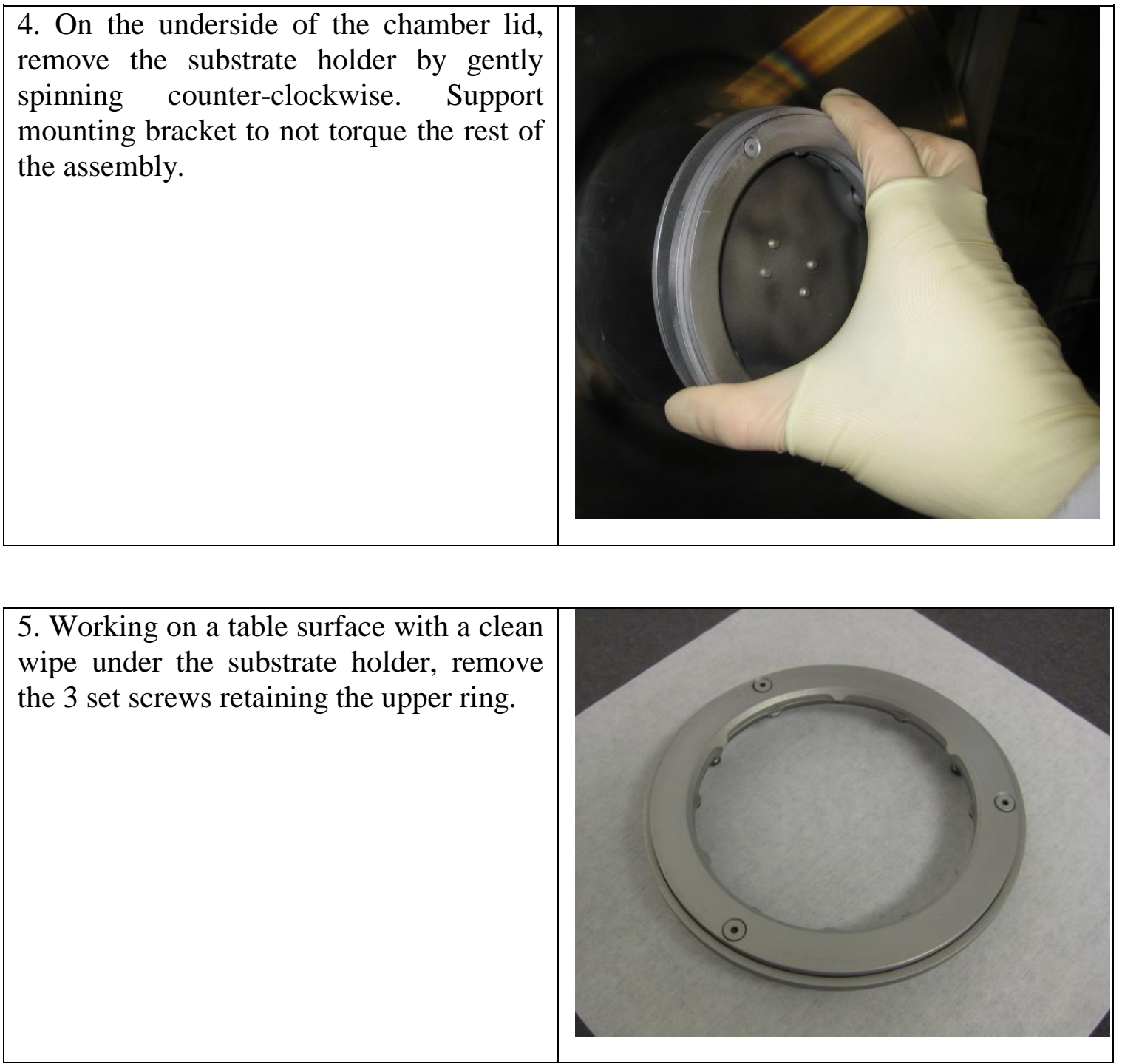
6. Place wafer in bottom ring with polished side of wafer facing out

7. Place retaining ring back on top of wafer and replace 3 set screws

8. Replace substrate holder to underside of chamber lid, align 3 retaining pegs with 3 holes in rotation plate and rotate the substrate holder clockwise to lock in place

*Note: While rotating assembly, hold rotation plate so substrate holder does not torque on center peg

9. Make sure the large hole in the side of the shroud is in line with the turbo pump

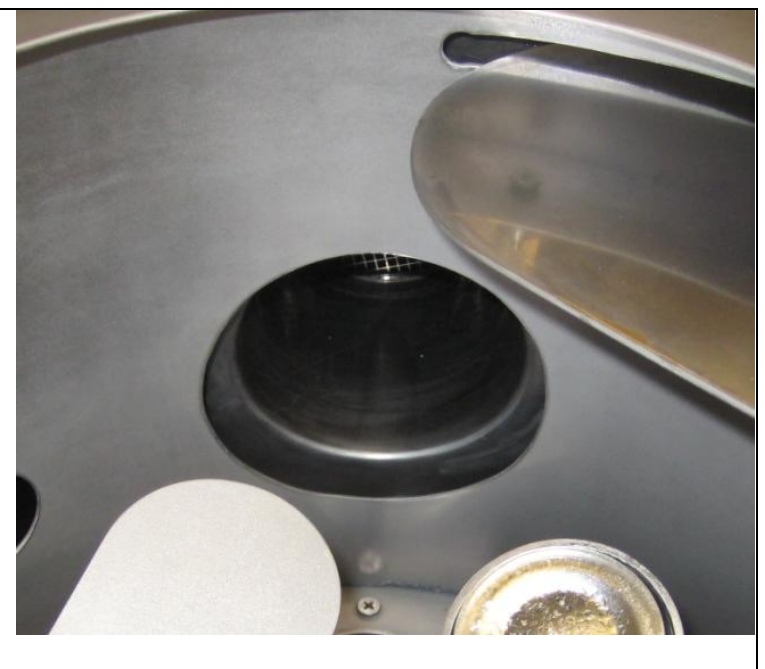

10. Place top shroud lid back in place

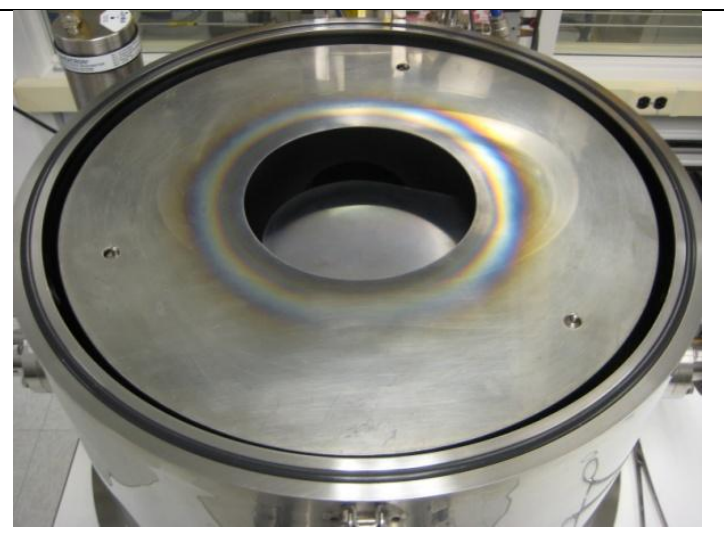


11. Rotate substrate shutter to the closed position so it is centered under the substrate

12. Try to remove all flakes for better vacuum.

13. Clean vacuum chamber o-ring and matting surface with isopropanol. Slowly close the lid and check for substrate holder clearance. (Do not spray directly on parts. Spray on clean room wipe and wipe down surfaces) 


\section{Pump Down}

1. With chamber lid open, clean mating surface of the o-ring and the lid with isopropanol and clean wipes. Try to remove all flakes for better vacuum. (Do not spray directly on parts. Spray on clean room wipe and wipe down surfaces)

2. Align chamber lid to center it on the back hinge for proper sealing. Lower lid slowly insuring the rotation stage does not hit the inner casing.

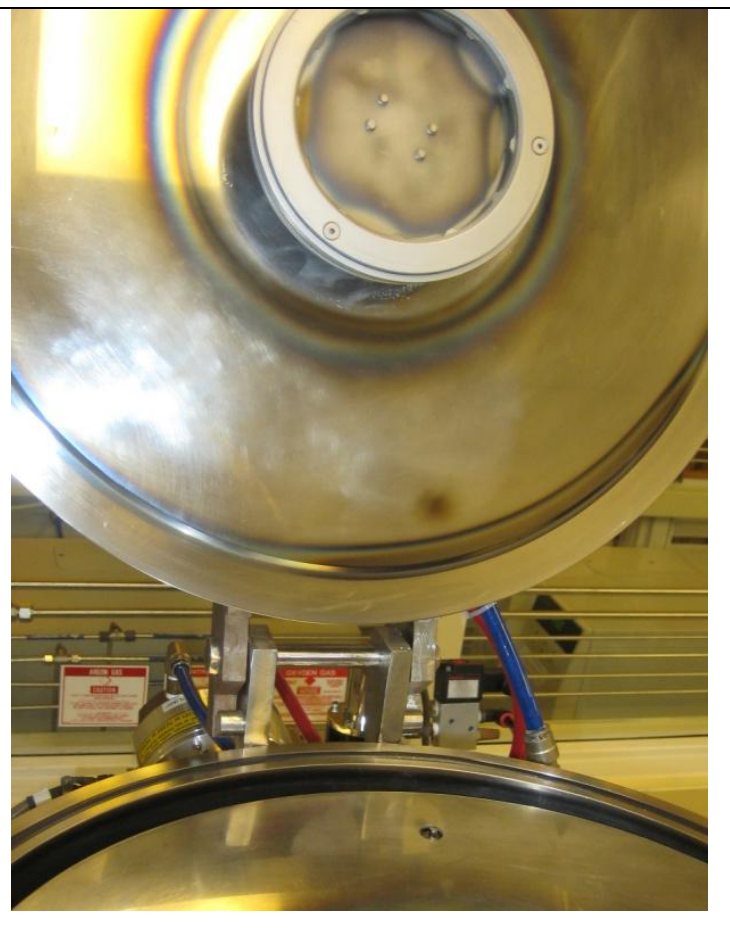




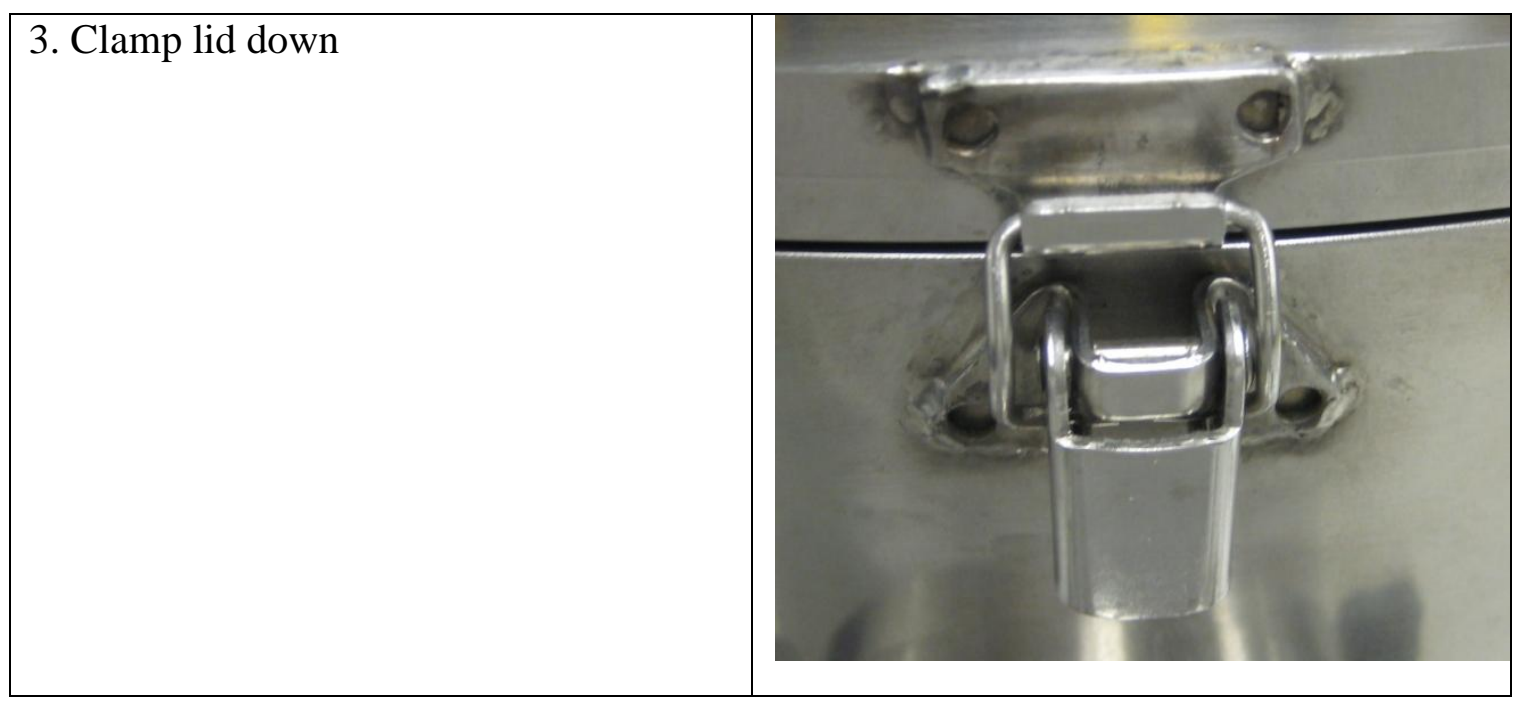

4. Initiate computer controlled pump down procedure at main control panel:

a. Press "F1 Process"

b. Press "F1 Pump Down”

c. Press "Start"

*Note: Pressure may need to be applied to chamber lid at first to ensure proper seal for vacuum

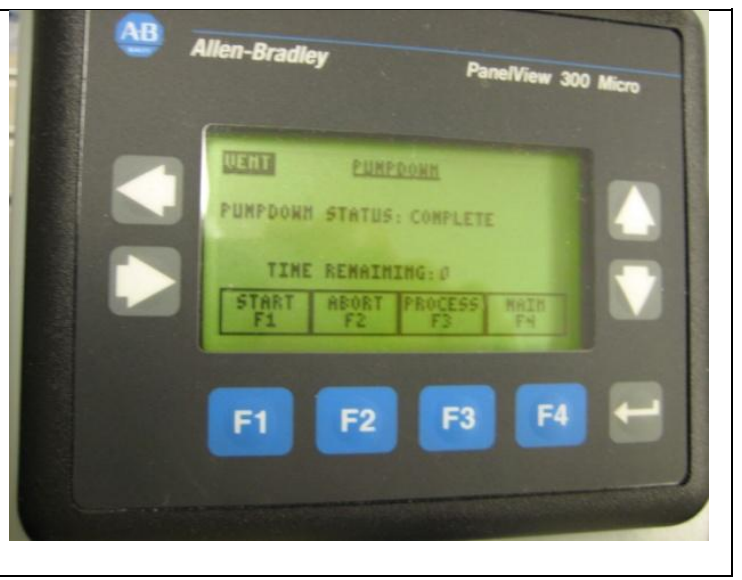

5. When pressure reading reaches 1 torr, the turbo pump will automatically turn on causing pressure reading to decrease quickly 
6. When the turbo pump power supply gage indicates 48,000 RPM and the Pirani gage has reached at least $10^{-3}$ torr, it is ok to turn on the hot and cold cathode pressure gages

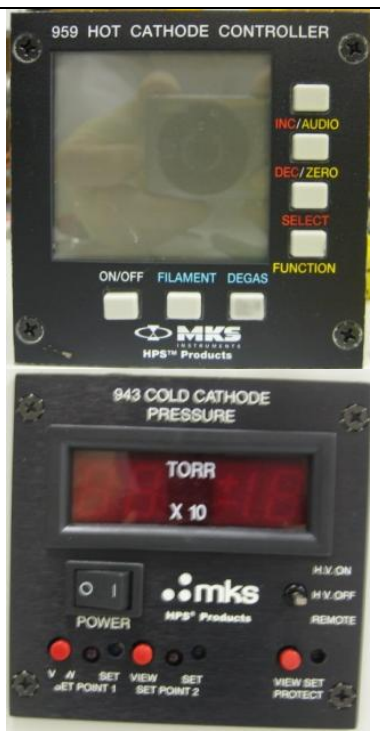

7. It is usually best to let it pump down over night 


\section{Deposition Procedure}

1. Make sure the power cables are connected in the back of the system

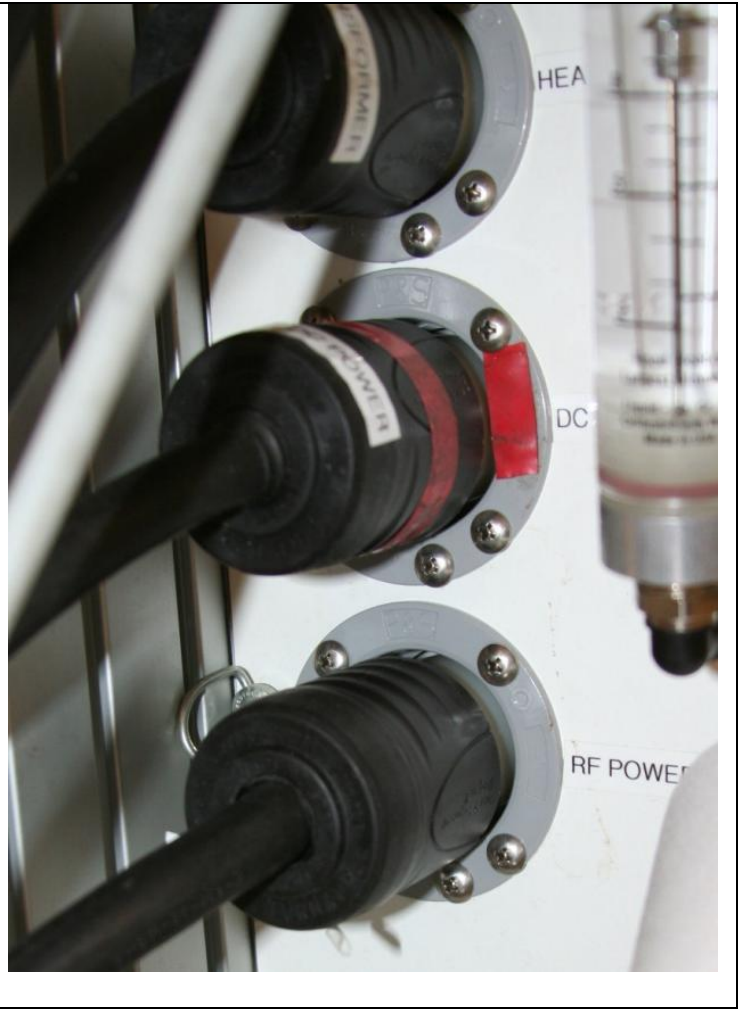

2. Check hot and cold cathode pressure and record in logbook.

\section{RESEARCH} NOTEBOOK 
3. Check water flow to guns and record flow rate in logbook (flow should be at least $0.8 \mathrm{GPM}$ )

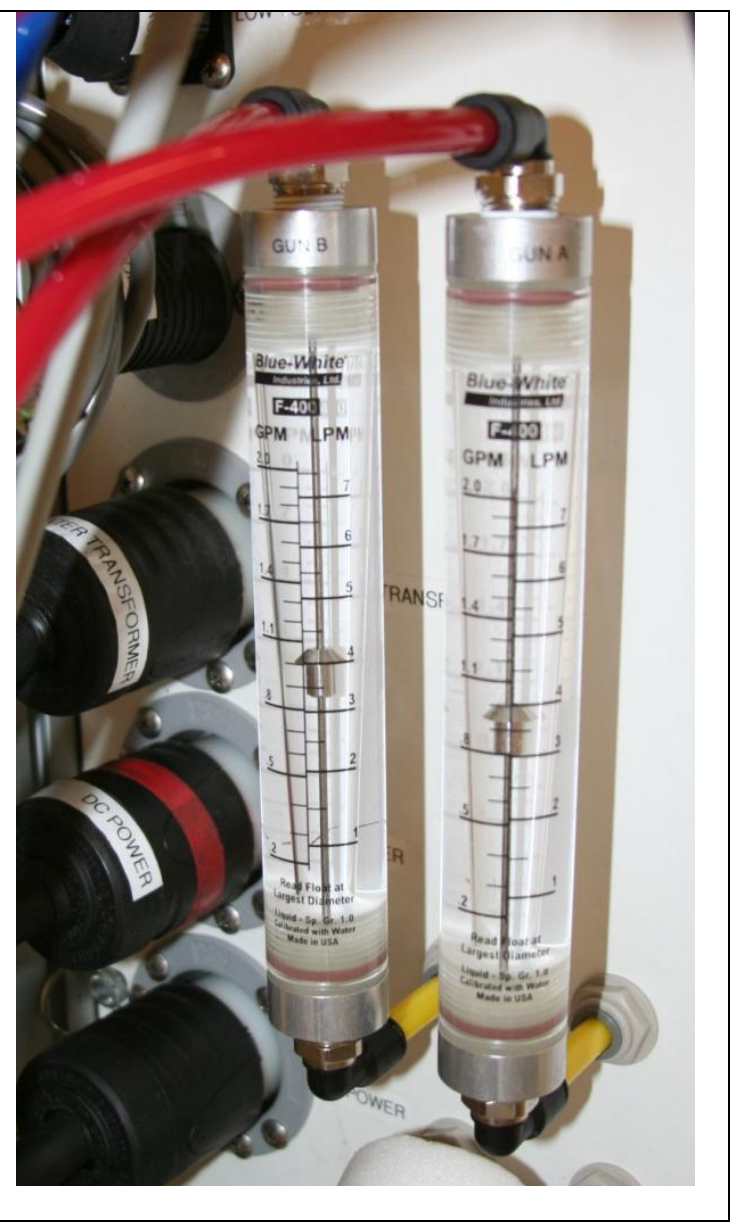

4. Turn off both hot and cold cathodes (cathodes can only be on at low pressures)
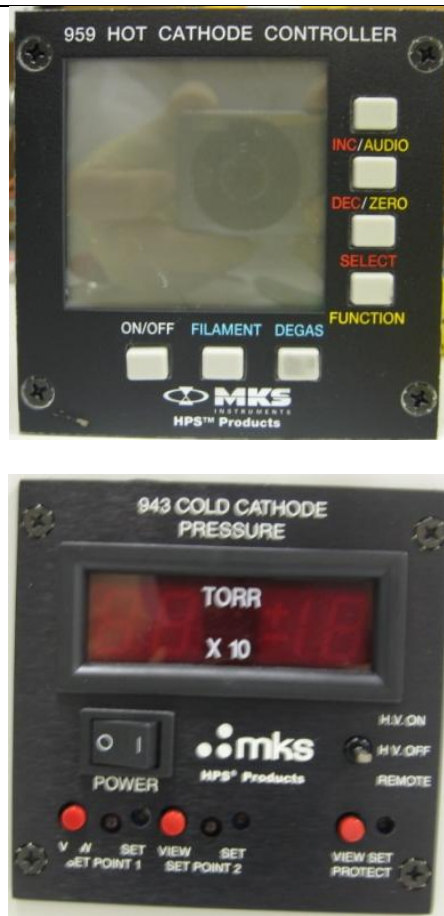
5. Reduce set temperature on gun chiller to $10^{\circ} \mathrm{C}$

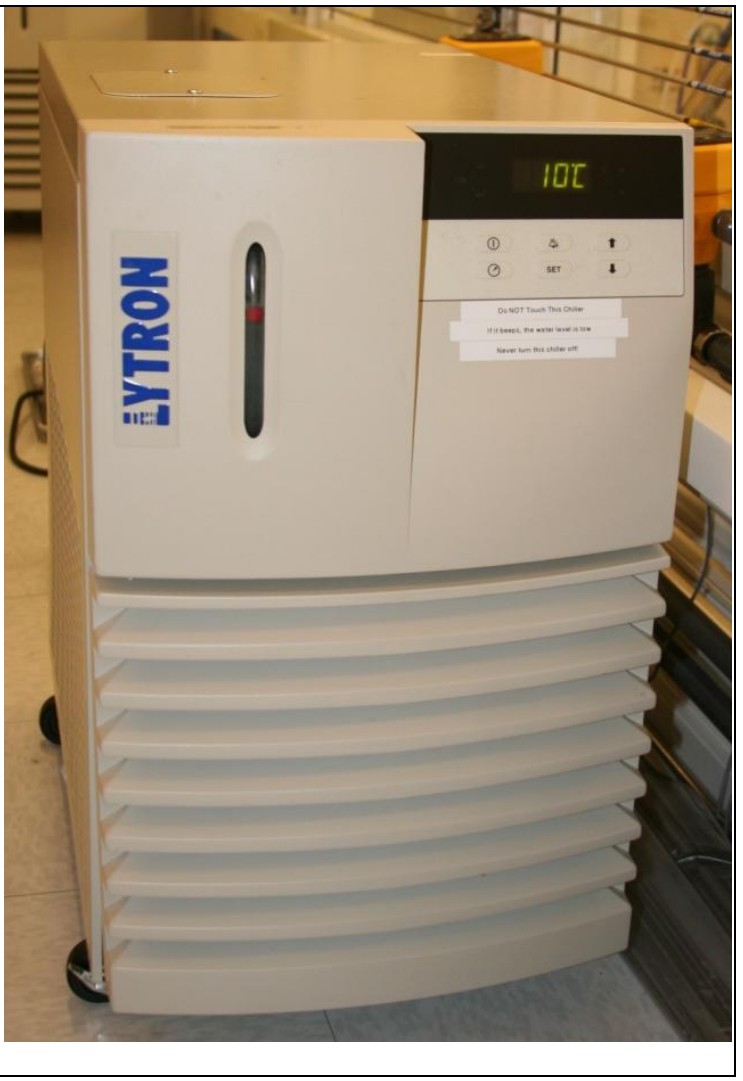


6. Open high purity argon in the chase and at the wall behind the Rohwedder

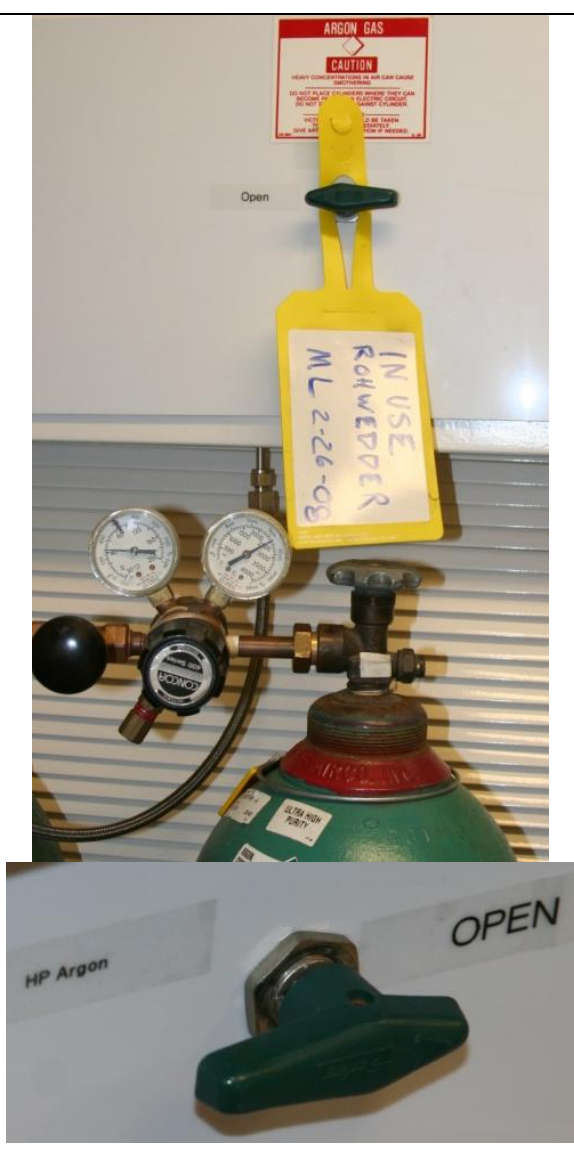

7. Turn on main sputtering gun power supply

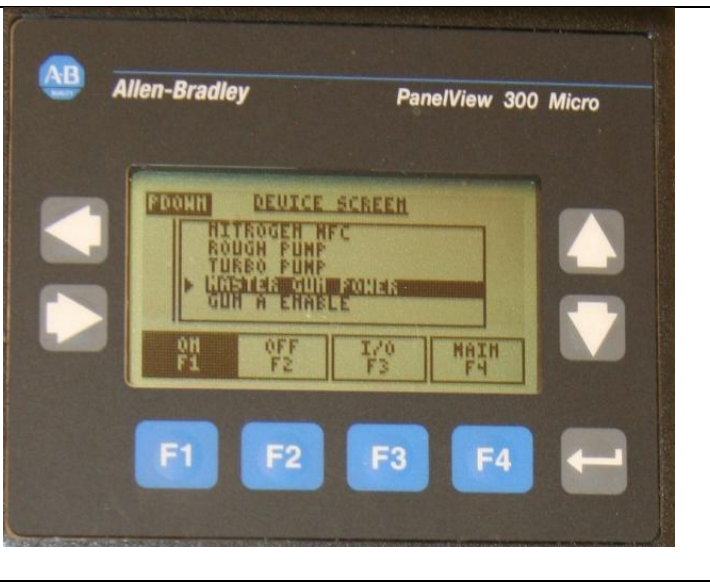


8. Turn on Argon MFC

a. Press "F3 Devices"

b. Scroll down to Argon MFC

c. Press "On"

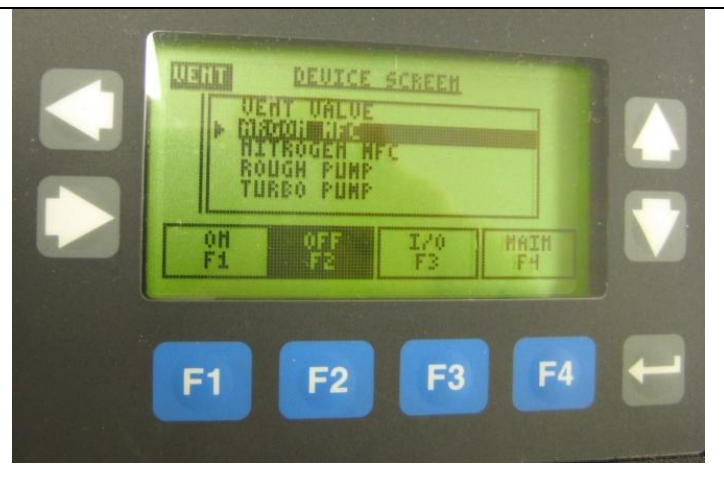

9. Turn on Gun Power Supply Main Breaker on Gun Power panel at right side

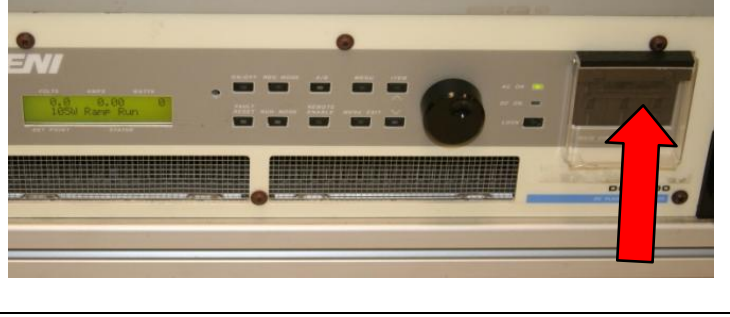

10. Set wattages per gun to the desired number on the Gun Power Supply on bottom

a. Press the "A/B" button once to set Gun A

b. Press the "A/B" button again to set Gun B

c. The power is adjusted by the dial to the right

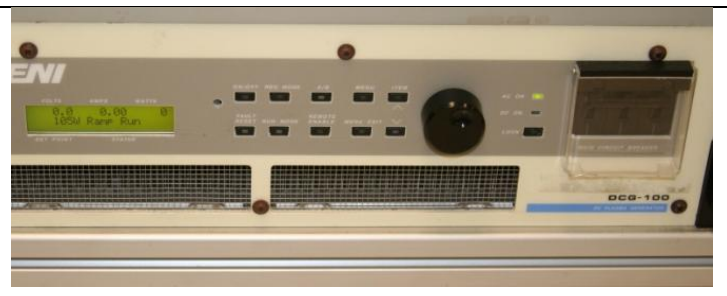

11. Turn on the MKS mass flow control and Turn on Ch. 1 (argon)

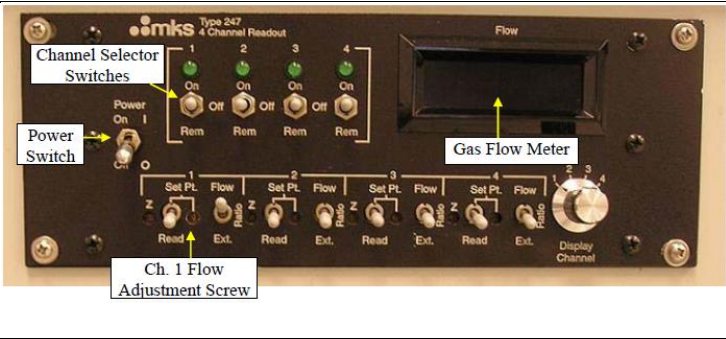


12. You can adjust flow rate with the set screw on Ch. 1 to get the correct pressure on the Baritron gage
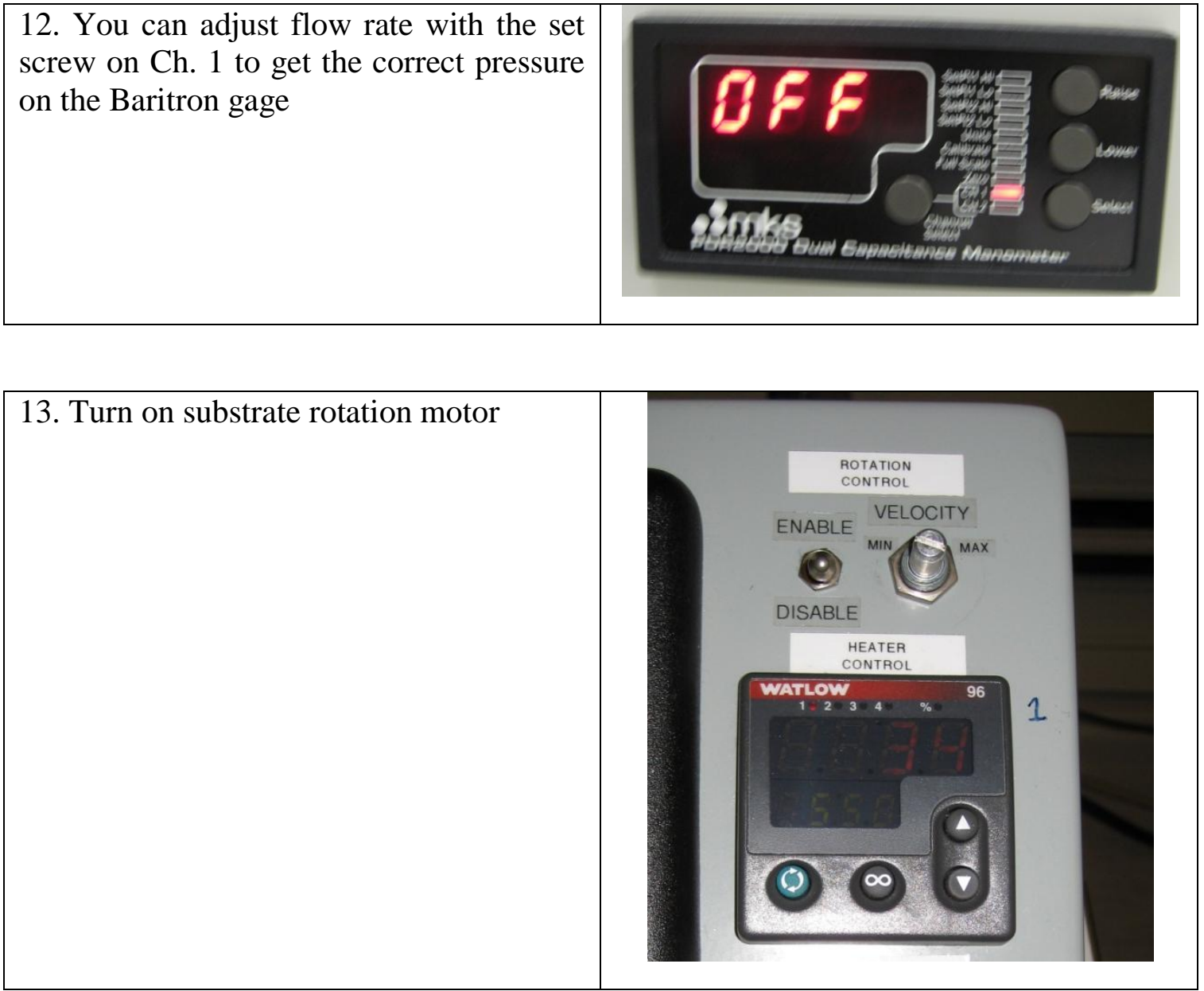


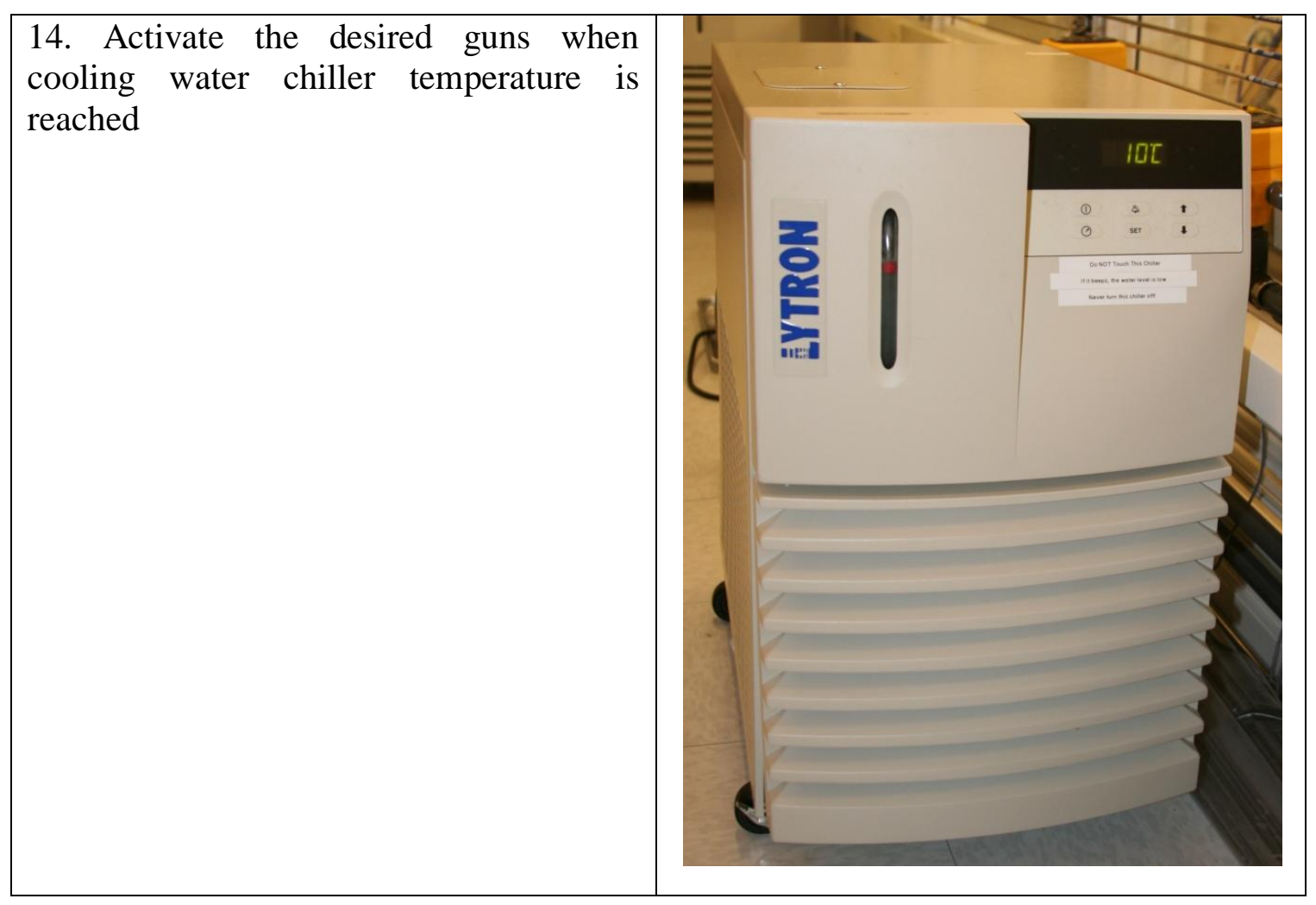

15. Make sure the power is ramping up to desired wattage and a plasma is present

*Note: Look through the porthole window on front of chamber to see the blue-purple plasma

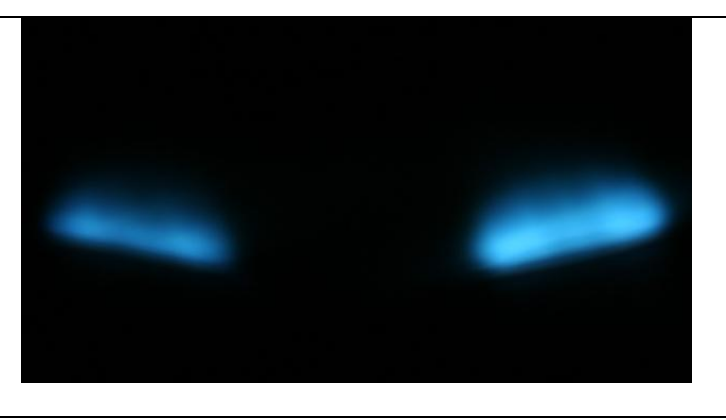

16. Pre-sputter for desired time

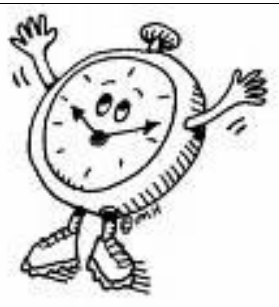


17. Open substrate shutter and start timer

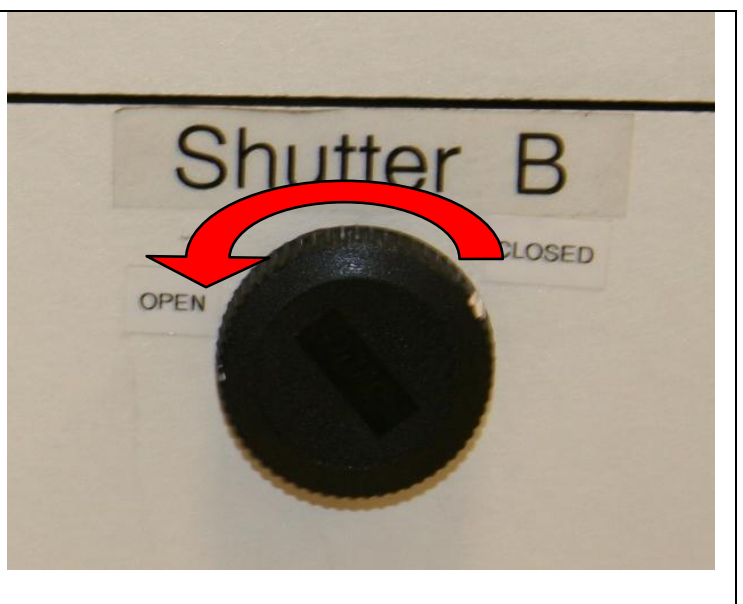

18. Sputter for desired time

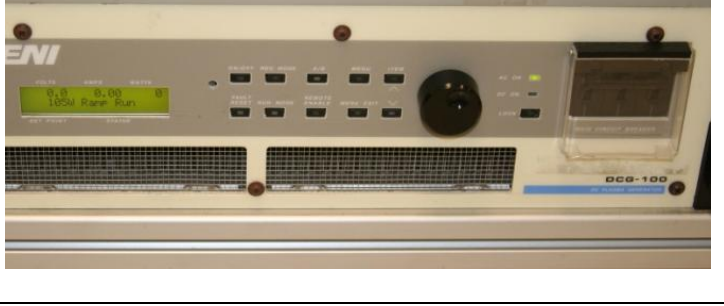

19. Close shutter
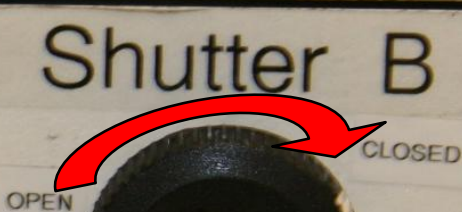
20. Turn off gun power and substrate rotation

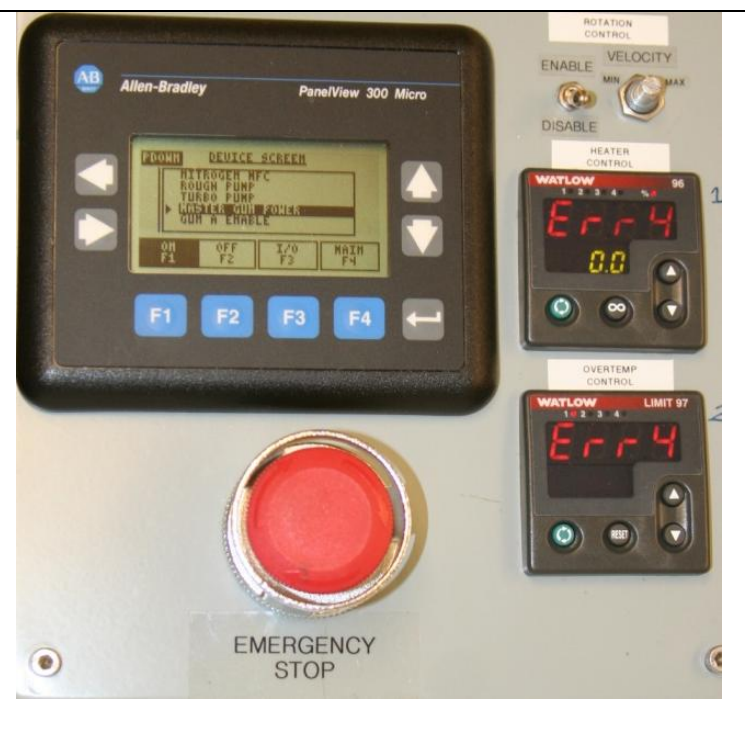

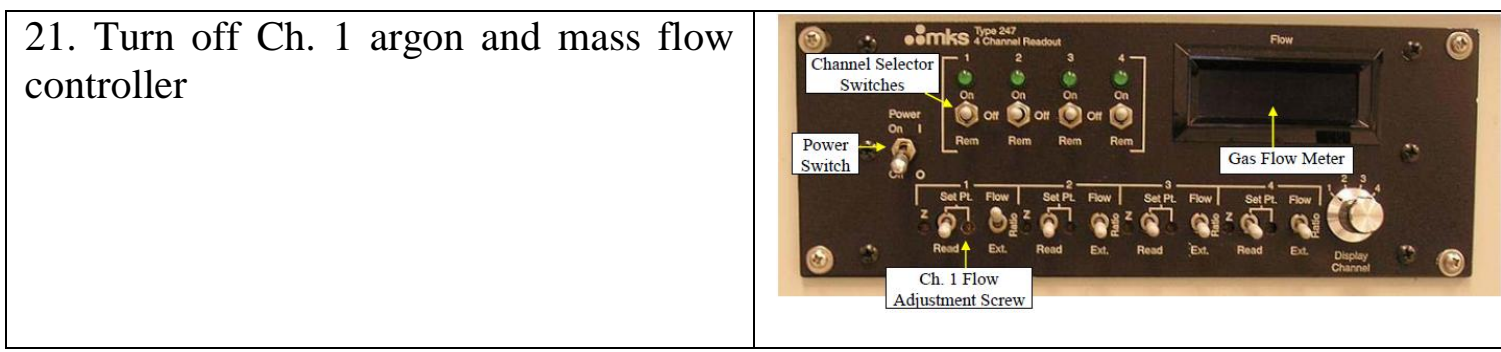

22. Turn off main circuit breaker on DC panel

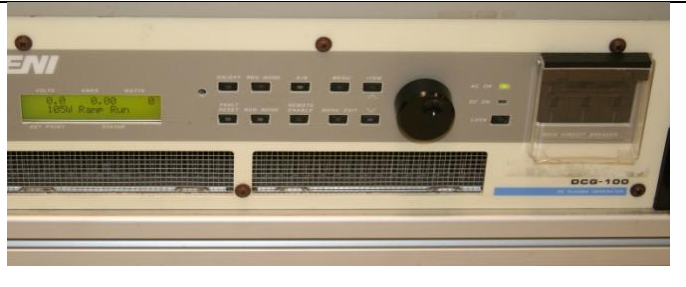




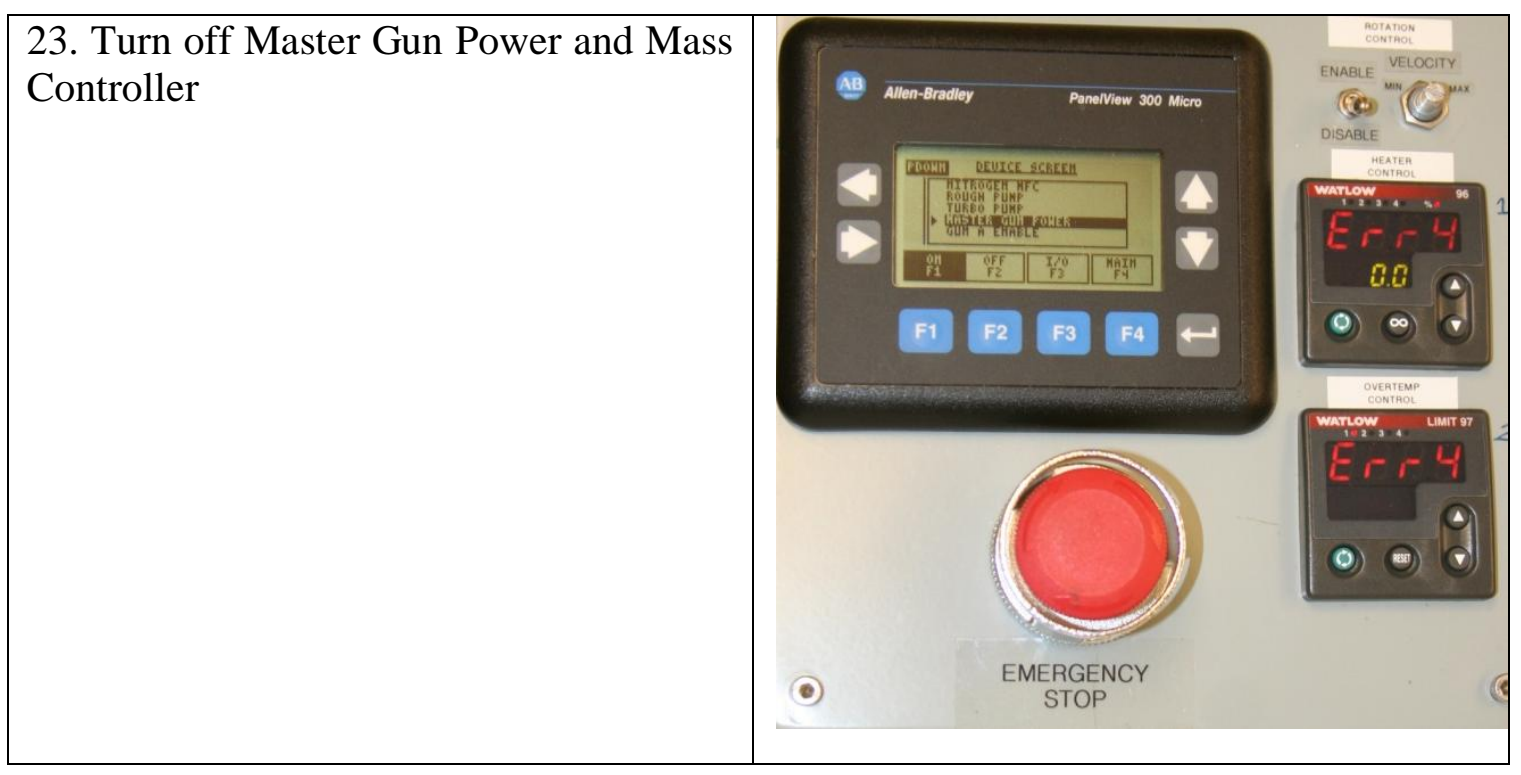

24. Increase set temperature on gun chiller to $20^{\circ} \mathrm{C}$ 
25. Allow time to cool. Initiate vent procedure

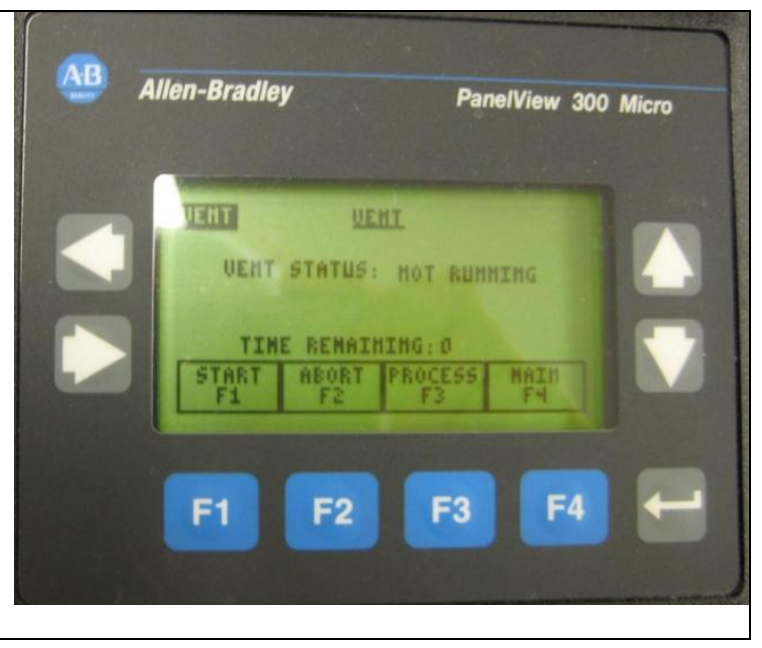




\section{Venting Procedure}

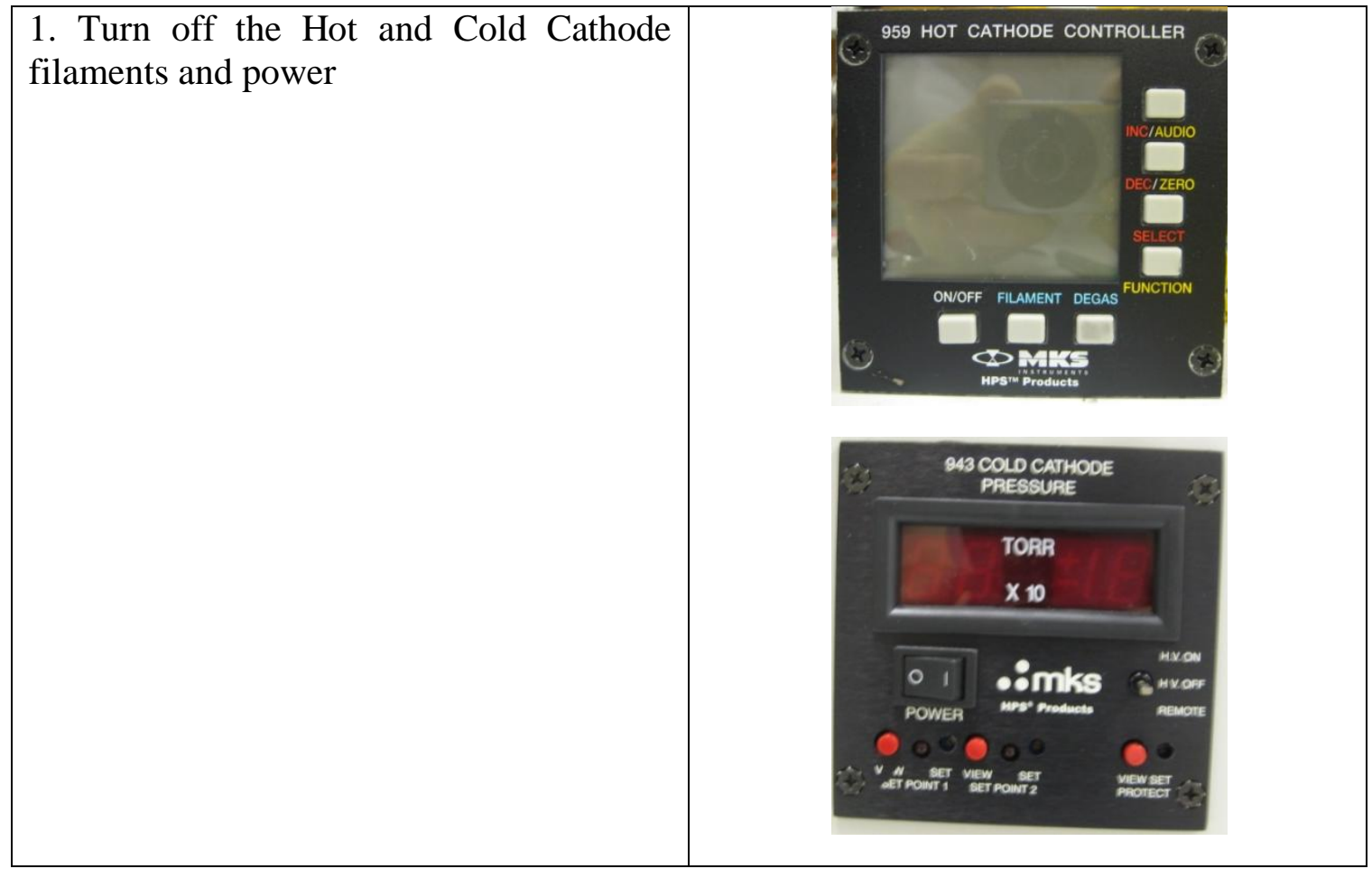

2. Set the chiller temperature for the guns to $\sim 20^{\circ} \mathrm{C}$ (If changing the temperature wait for about 15 minutes for the temperature to be achieved)

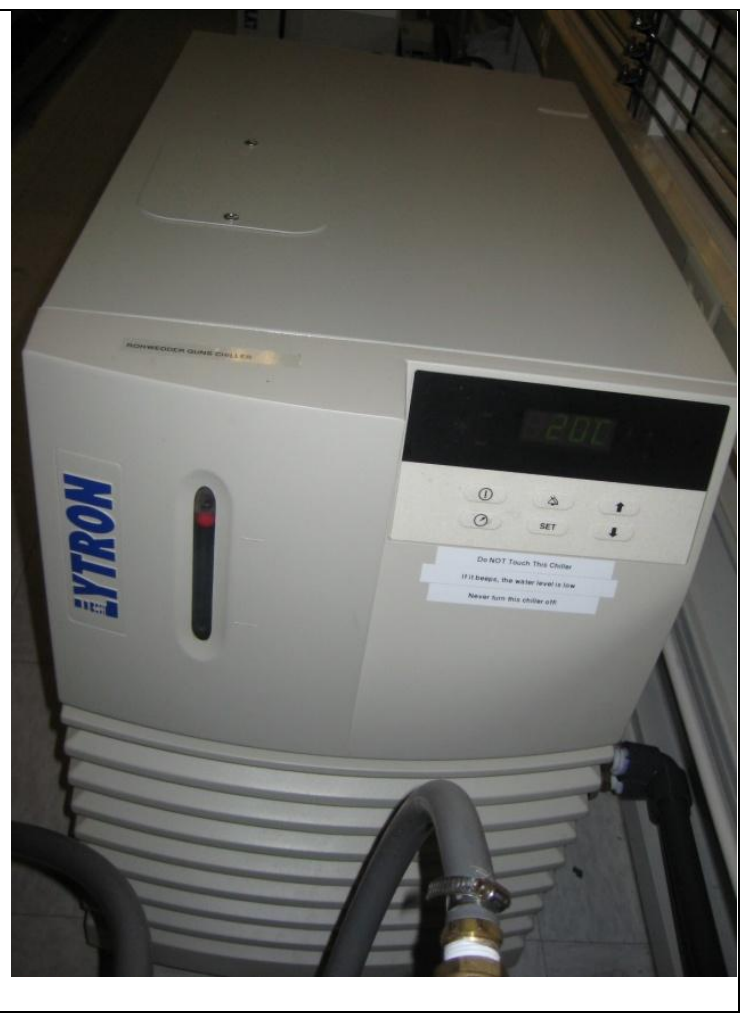


3. Argon must be on. The Chamber is vented with argon

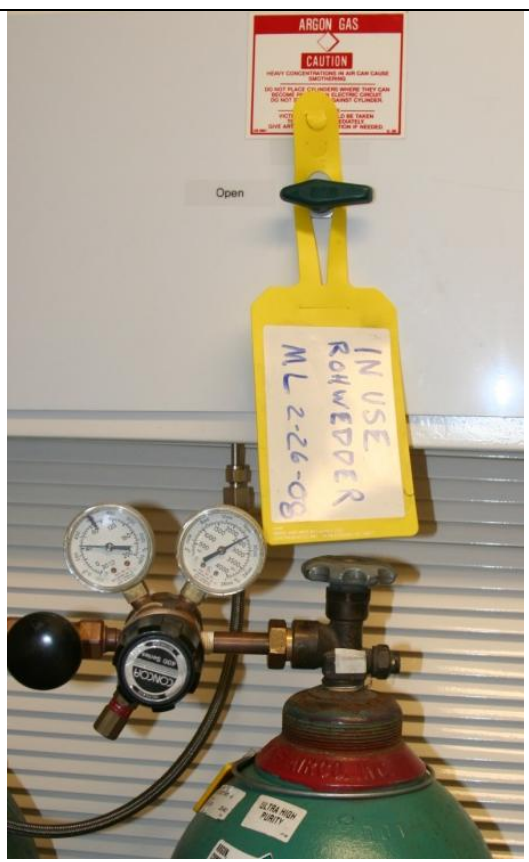

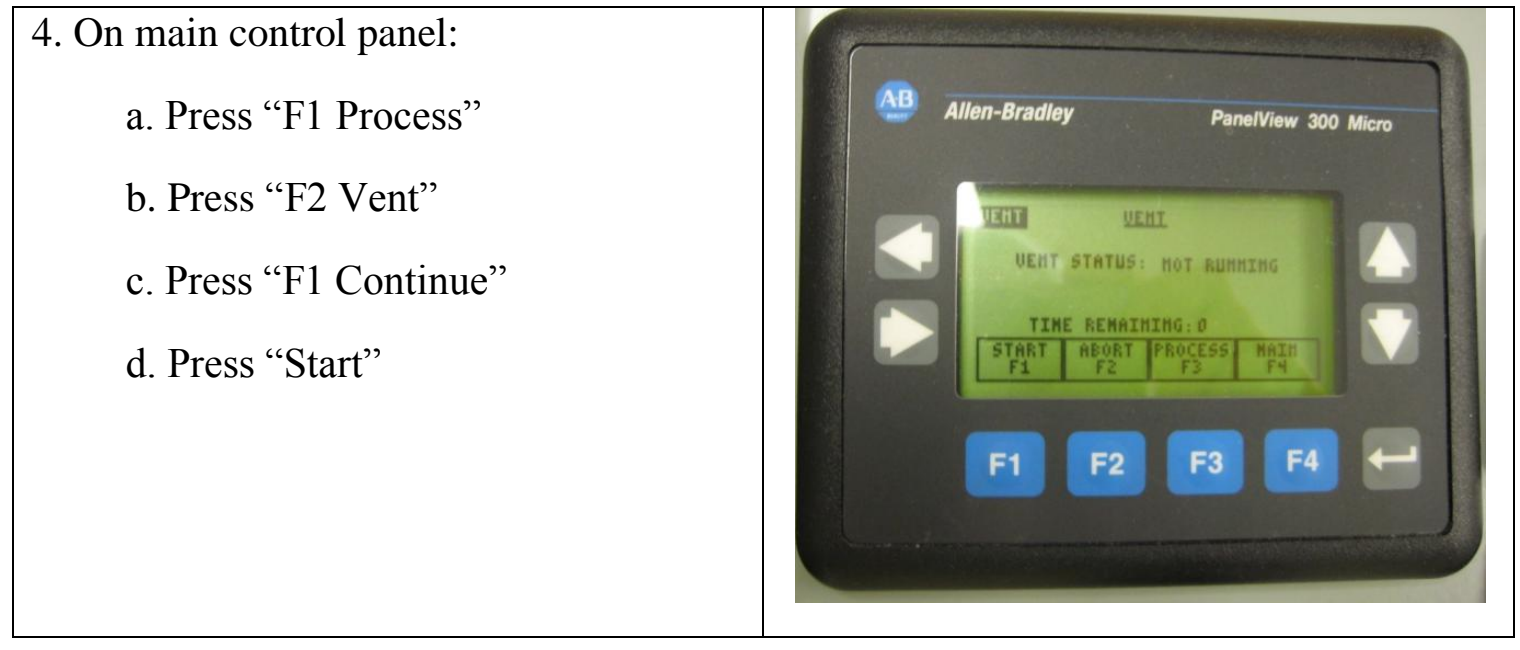

5. Pump down process takes approximately 4 minutes. 
6. Return to "Main" menu and make sure gun power and mass controller are off.

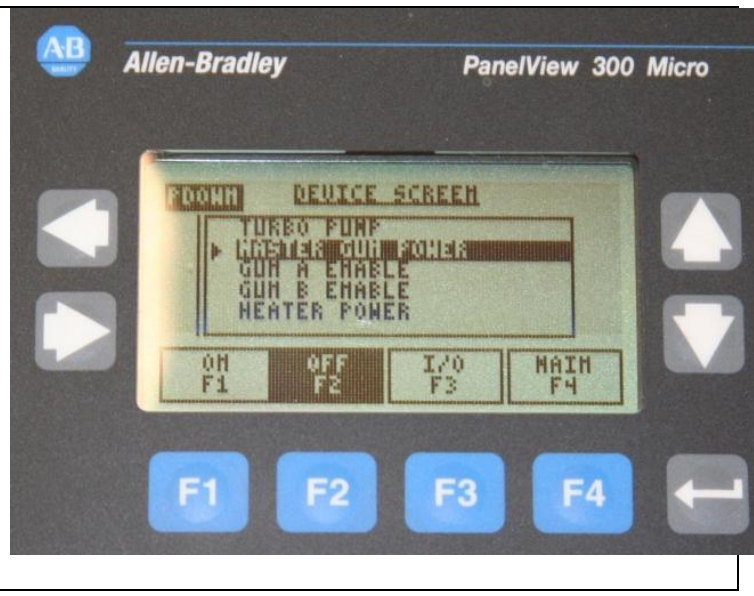

7. The Pirani gage, Baritron gage, Rough Pump, and Turbo Pump power may remain on. 


\section{Target Replacement}

1. Remove old targets with the red Thandle flat screwdriver tool

2. Clean new targets with isopropanol and clean wipe or 600 grit sand paper if necessary

3. Clean grease from target mounting surface with small amount of isopropanol and clean wipe

4. Apply a very small amount of US Inc. Grease to copper target mount and smear with gloved finger for even distribution

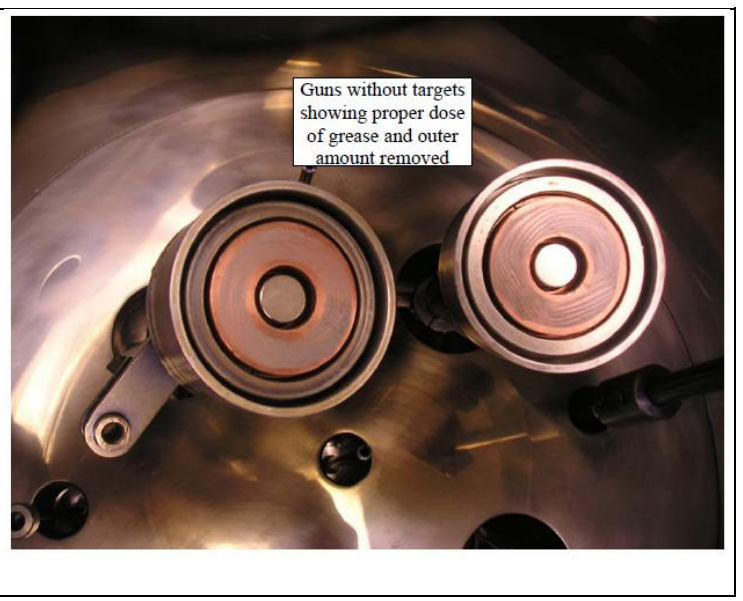


5. Use edge of a folded clean wipe to remove excess grease near edge of copper ring so it doesn't melt and drip down gun

6. Gently place new target in place and rotate for even grease coverage

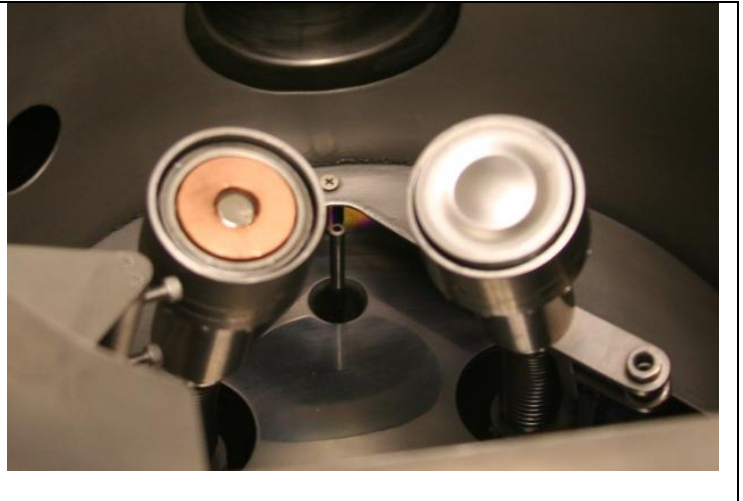




\section{High Vacuum Annealing}

1. Divert chilling water from the Rohwedder guns to circulate in the chiller. This is done turning the bypass valve so the water goes from the supply to the return (the flow to the two guns should drop very low). Then turn off the supply and return valves to and from the guns.

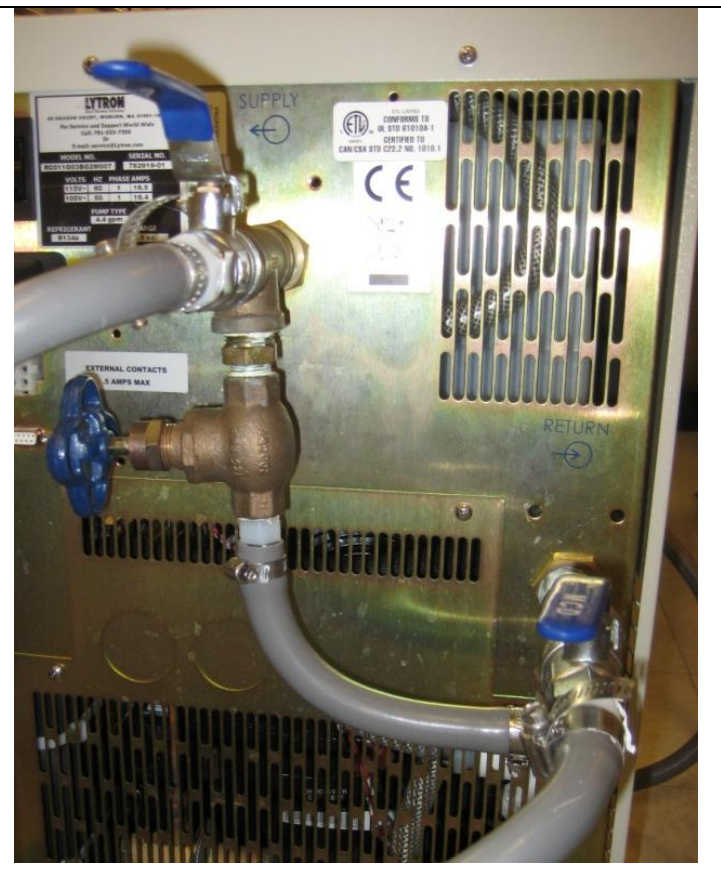

2. In the chase with a bucket in hand disconnect the lines that connect the pvc tubes to the wall. Blow out the lines with LP $\mathrm{N}_{2}$ (this removes all the water in the guns).

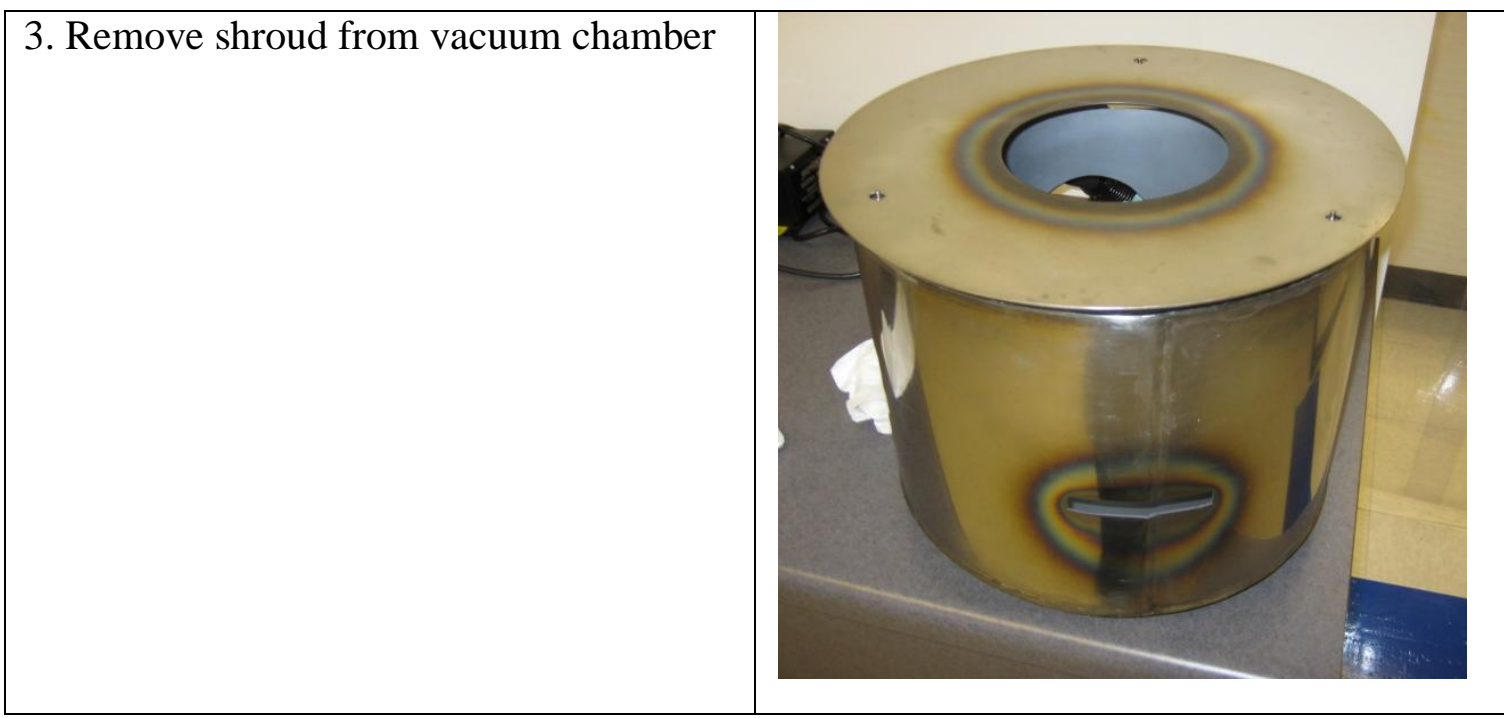


4. Make sure master gun power is off. Disconnect DC power cables from both guns.

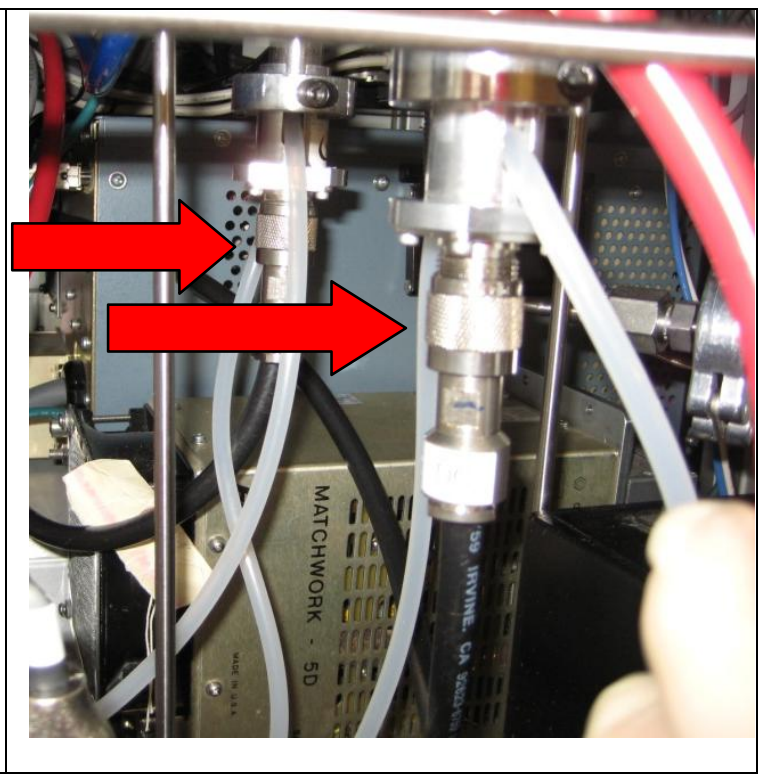

5. Inside the Rohwedder disconnect the lines to the guns (figure1). There are press fits that the clear water lines connect to the rest of the cooling system (that is where they are disconnected). That will fully disconnect the cooling system to the guns.

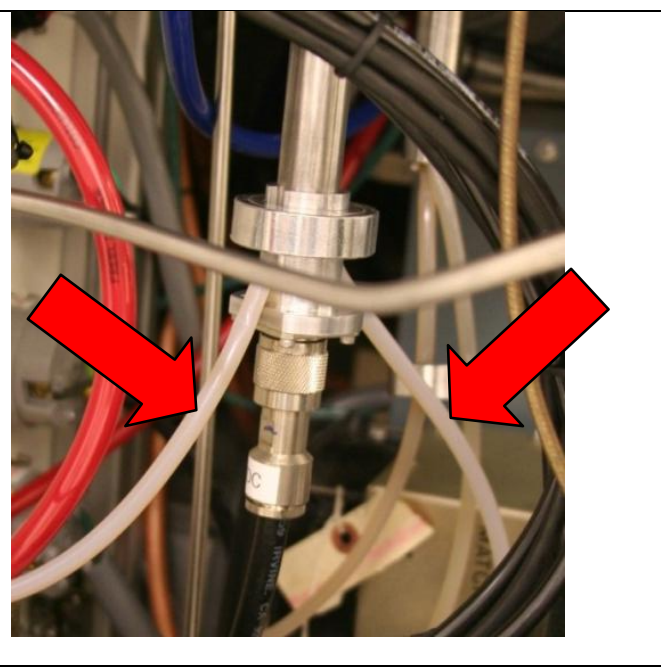

6. Remove the ring that holds the DC power adapter on and the adapter slides right off. 
7. Unscrew gun collars making sure the oring comes off too.
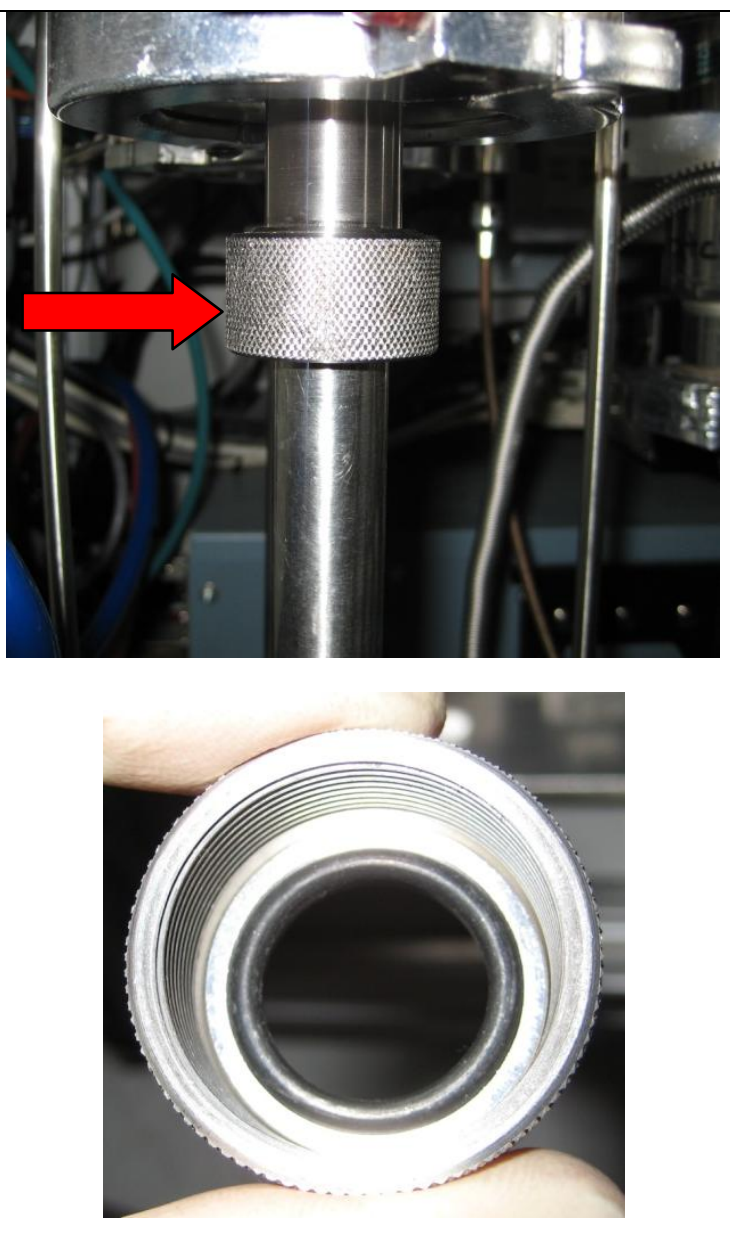

8. Remove gun collar.

9. Remove both shutters. The main shutter is removed at the base. Gun A shutter is removed by loosening all four allen screws and removing the cable from the bottom.

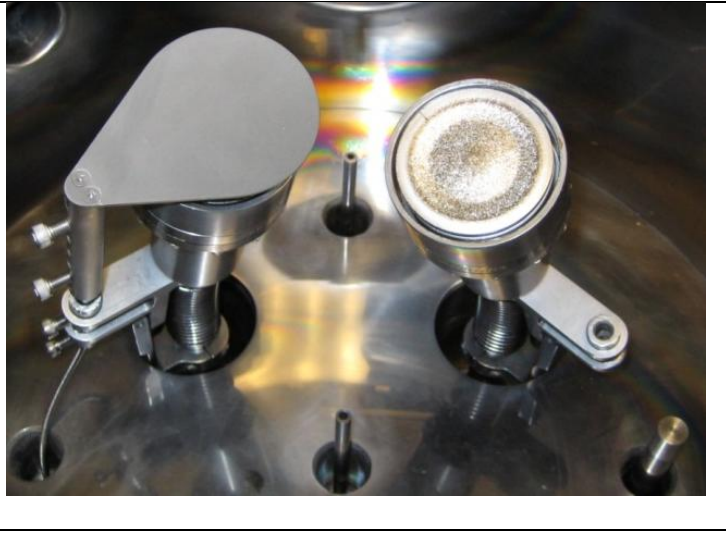


10. Gently pull the two guns out. There should be no resistance getting them out.

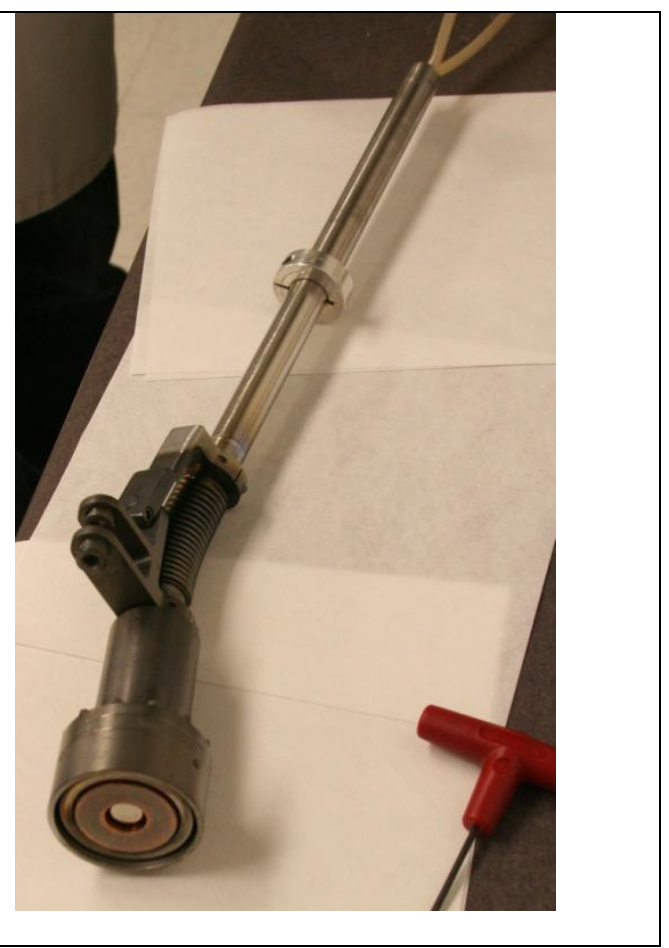

11. Place the vacuum seal cap in place of the gun collar. Make sure to clean all mating surfaces and o-rings.

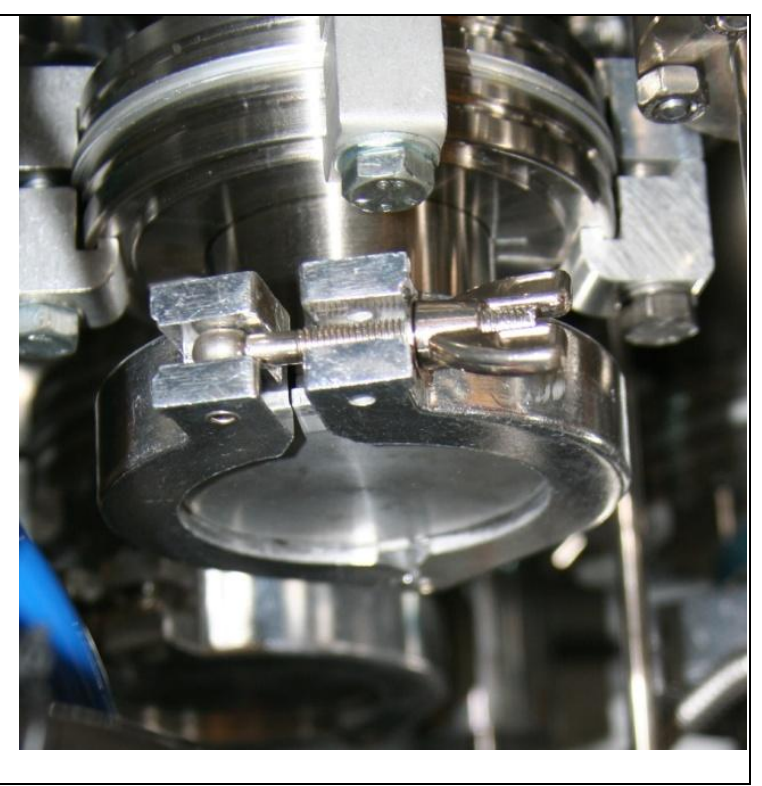




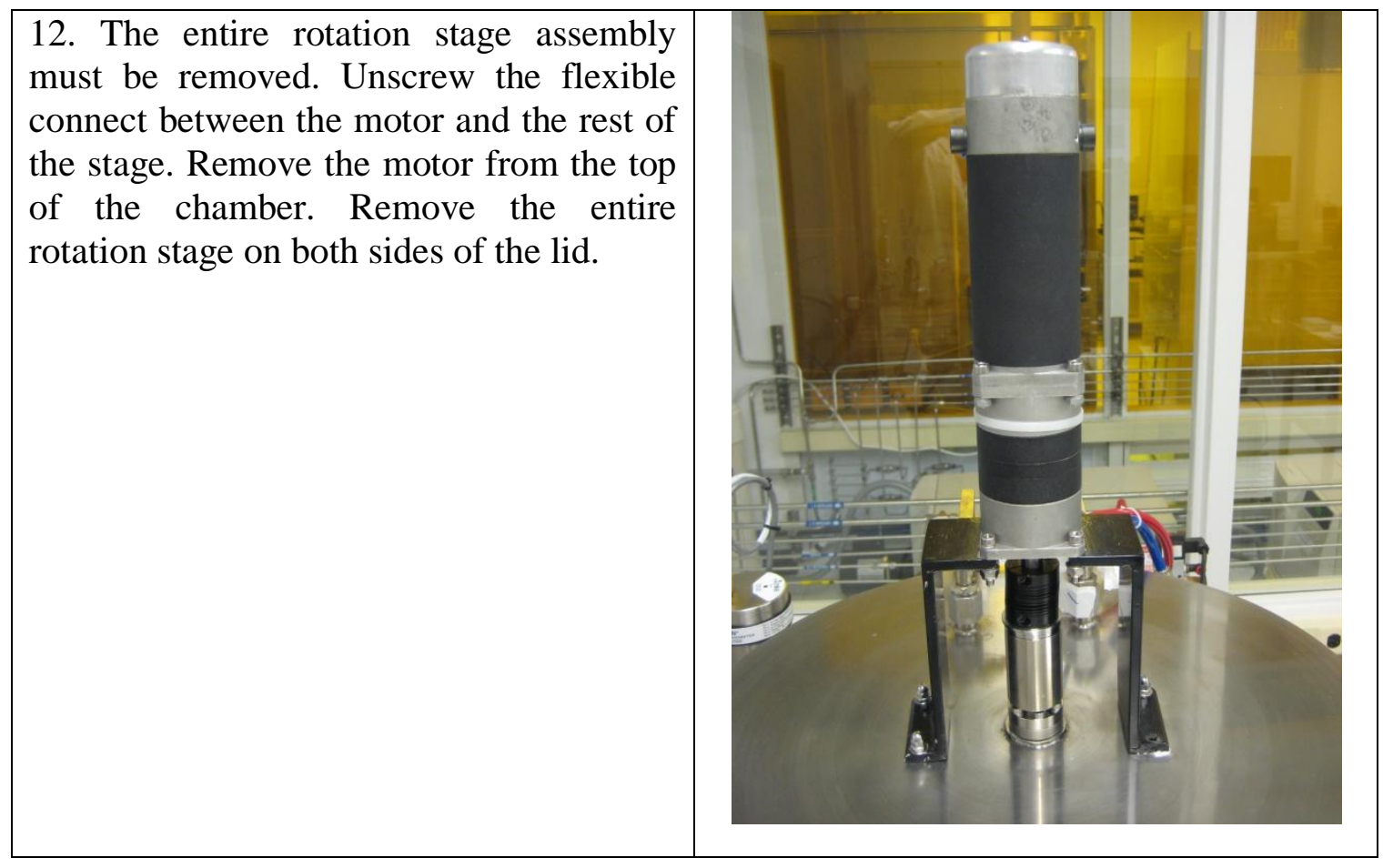

13. Replace copper gasket mini flange with a 0.836 "OD $0.640 " I D$. These gaskets are one time use.

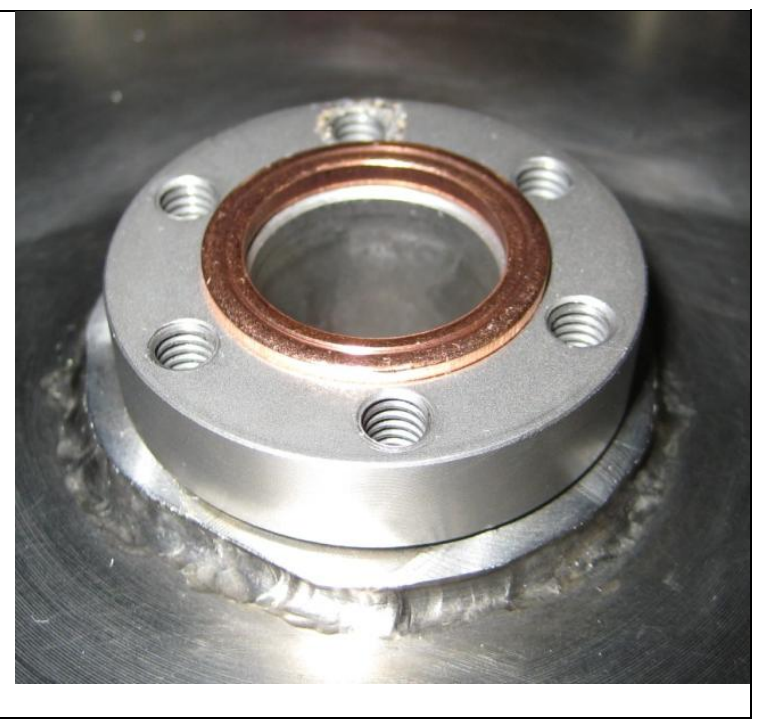


14. The vacuum seal is secured with 6 cap screw \#8-32 x 1/2". Tighten them in a star pattern. Do not tighten it all the way at once, go through the tightening pattern a few times. Warning: the allen heads are easy to strip or damage.

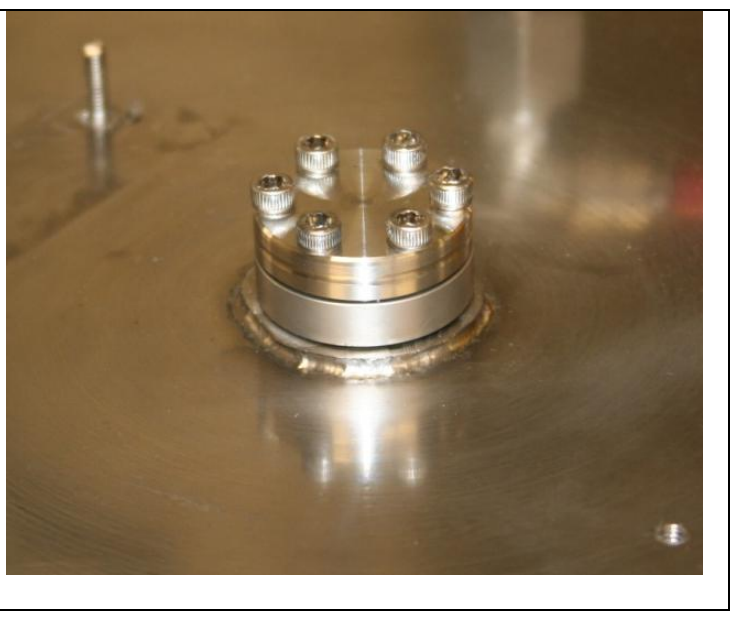

15. Place the heating element upside down on a clean wipe

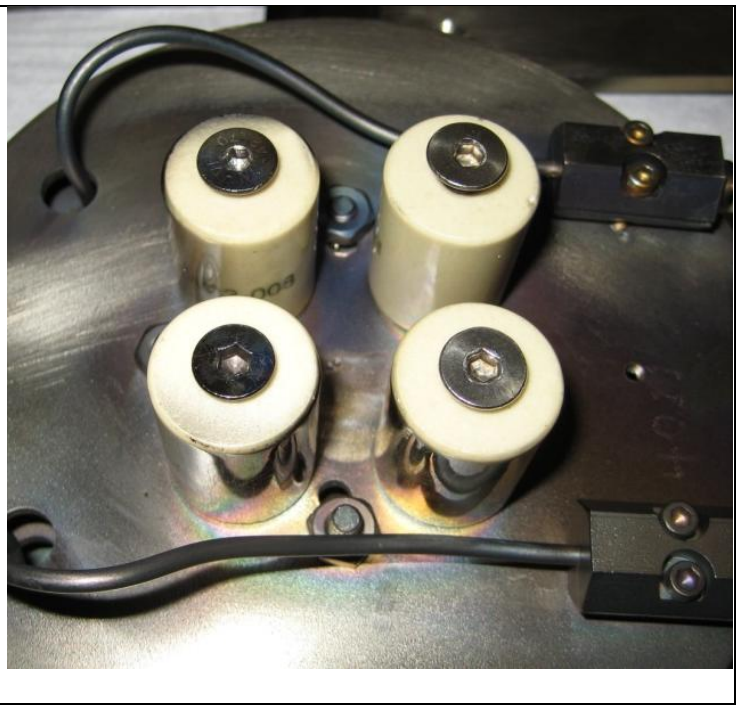


16. Screw the mounting bracket on. *Use extreme caution and do not over tighten any screws. The screw threads are made of alumina ceramic. Do NOT break the ceramic parts.

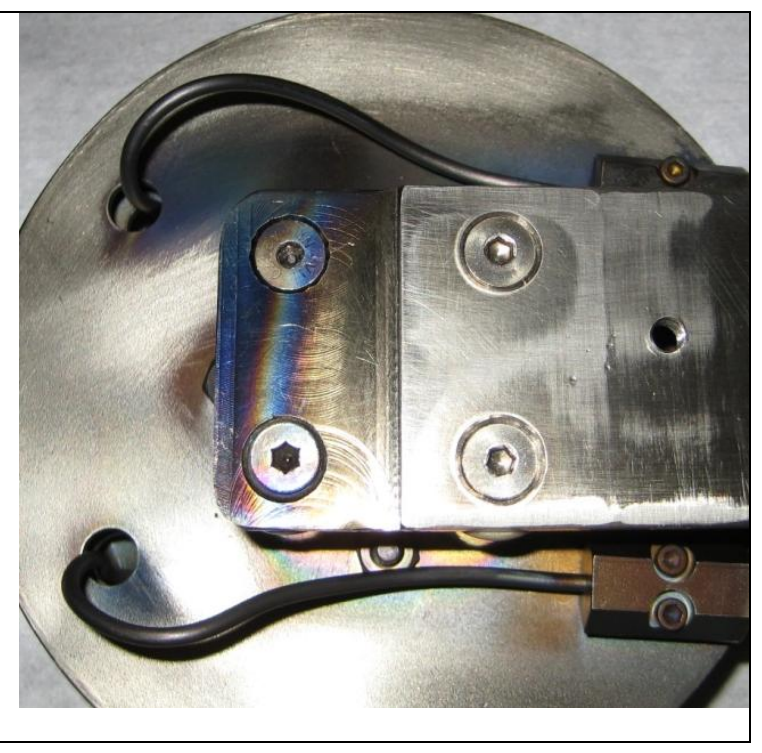

17. Gently place the mounting bracket over the stub in the bottom of the sputter chamber closest to the site window in the front.

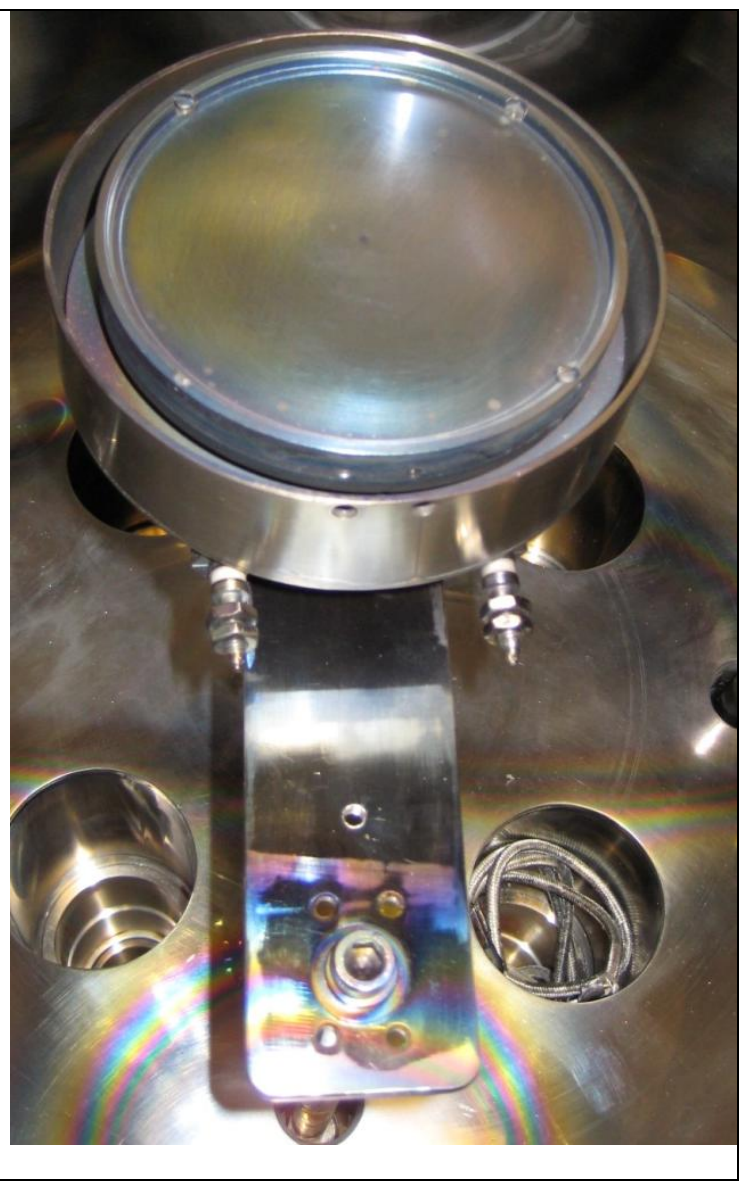


18. Remove the vacuum seal and cap on the right side of the chamber nearest the computer.

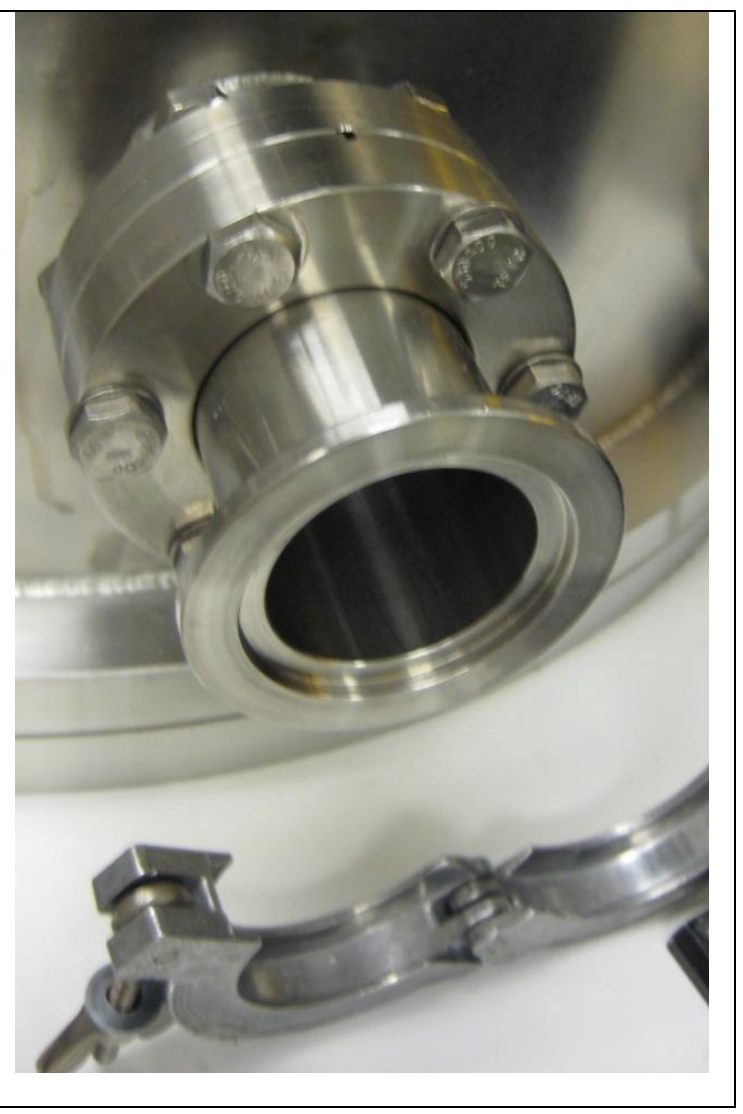

19. Pass the thermocouple assembly through this port and reattach the seal clamp. Make sure all the wires are clamped in and any part of the exposed wire is isolated.

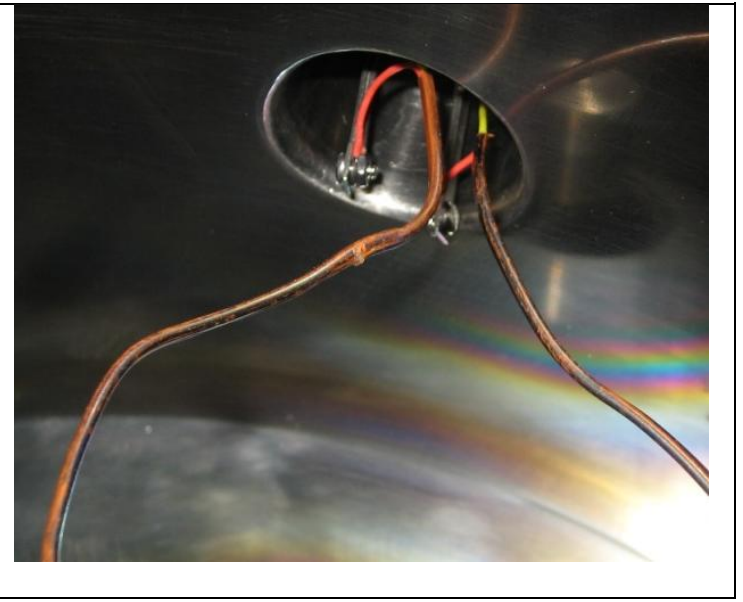


20. Attach the corresponding thermocouple lead to the computer such that the leads marked \#1 are together and the leads marked \#2 are together.

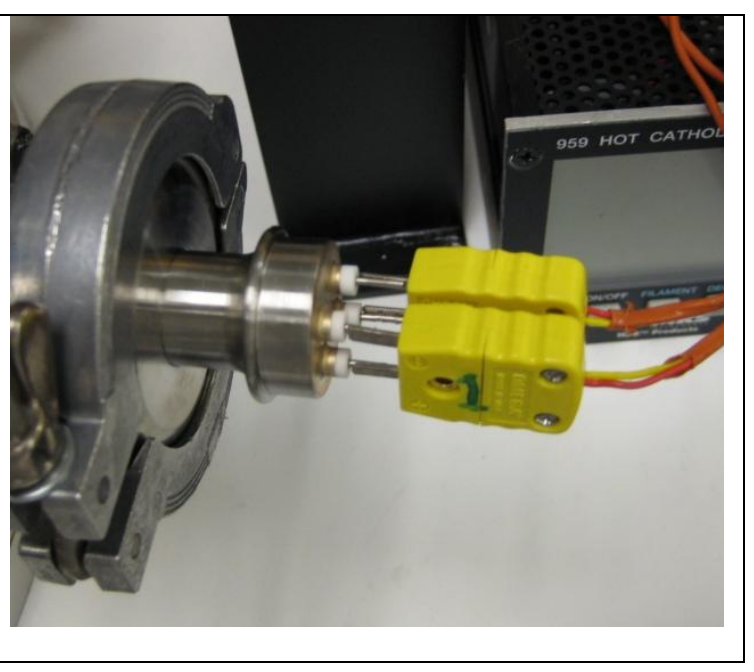

21. Gently attach and secure the power cables to the heating element. These are generally tucked into the bottom of the sputter chamber.

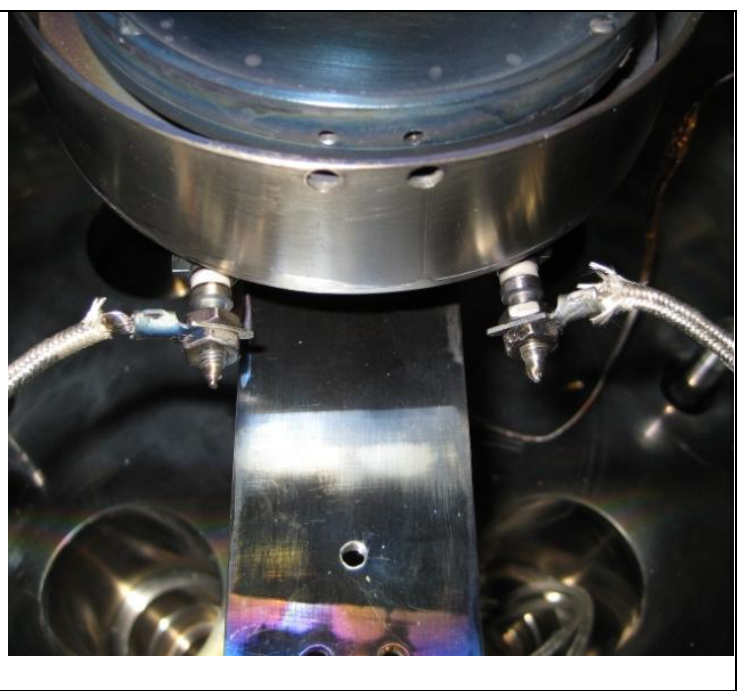


22. Place the thermocouple leads into the heater chuck such that one is located approximately in the center of the wafer and the other measures the edge. Thermocouple \#1 should measure the center, and thermocouple \#2 measures the edge. All exposed wires must be isolated.

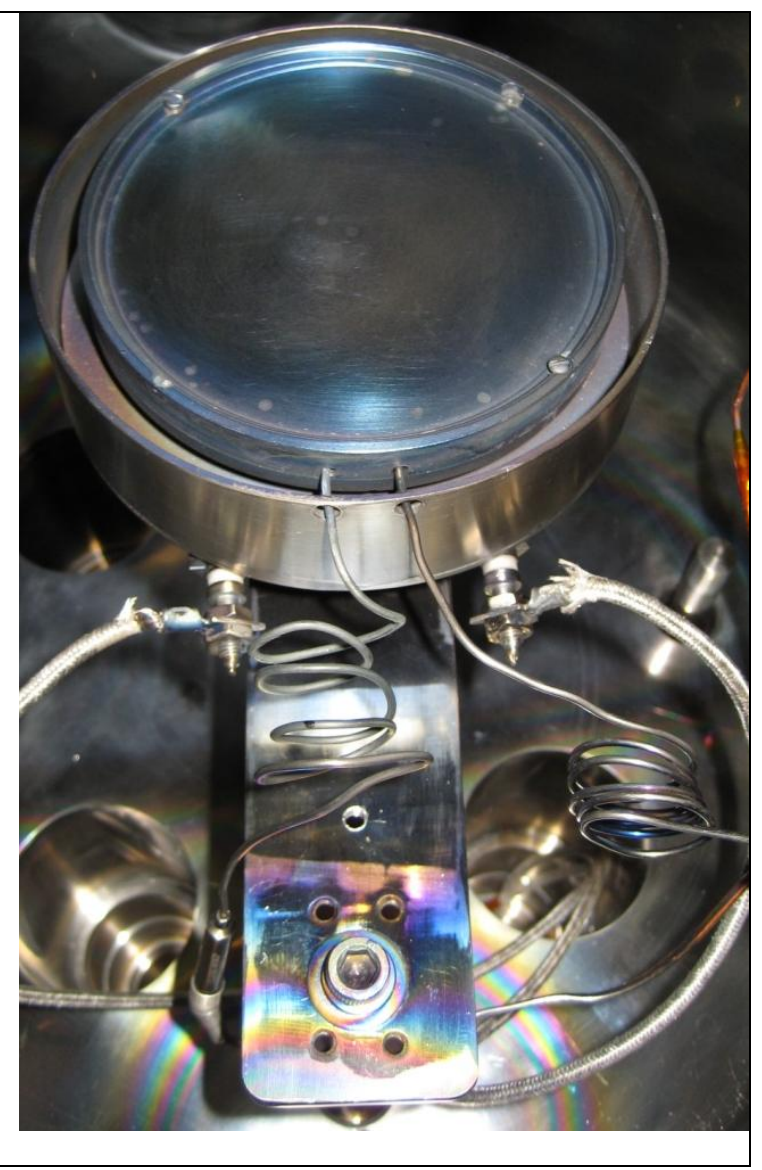




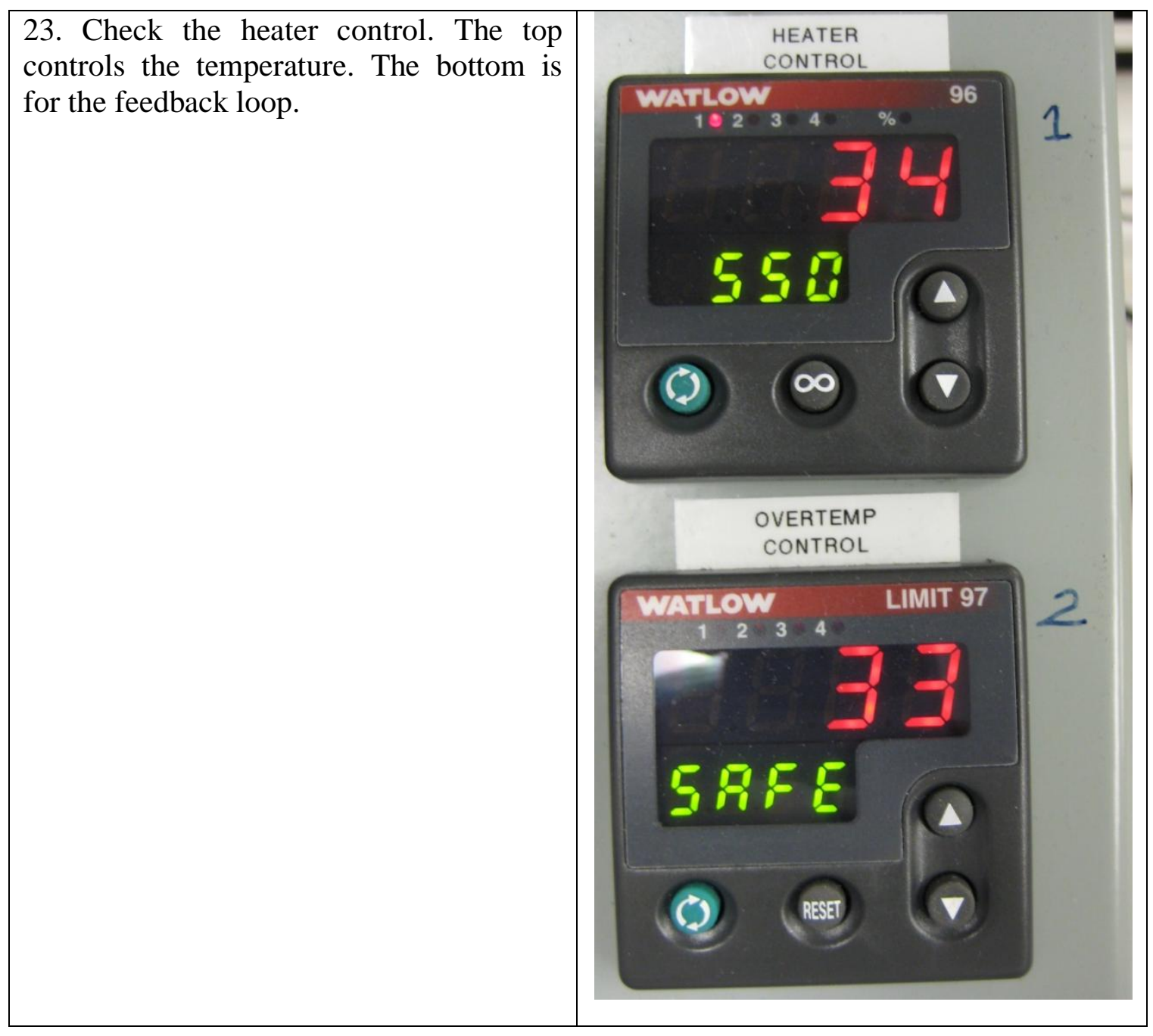

24. Place the wafer on the heater chuck such that it is approximately centered on the lip around the edge of the chuck. This allows a volume between the heater surface and the wafer thus improving temperature uniformity. 
25. Pump down the system. Follow Pump down procedure

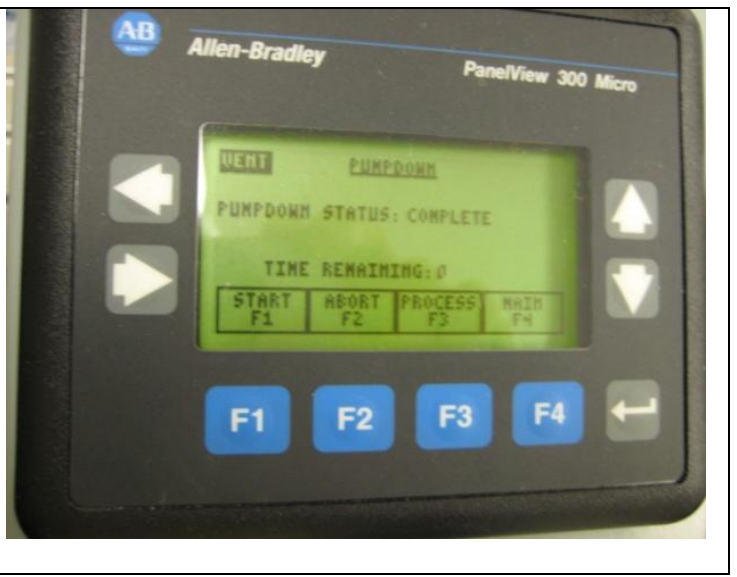

26. To turn on the heater, go to the Devices screen and turn on the Heater Power. Temperature can be changed with the heater control.

27. When done annealing wafers reassemble system. Just reverse assemble to reassemble. When reassembling the guns make sure the DC adapter at the bottom of the guns is assembled correctly or this could happen. 


\section{Magnet Replacement}

1. Follow the High Vacuum annealing instructions to remove the gun that needs the magnet replaced.

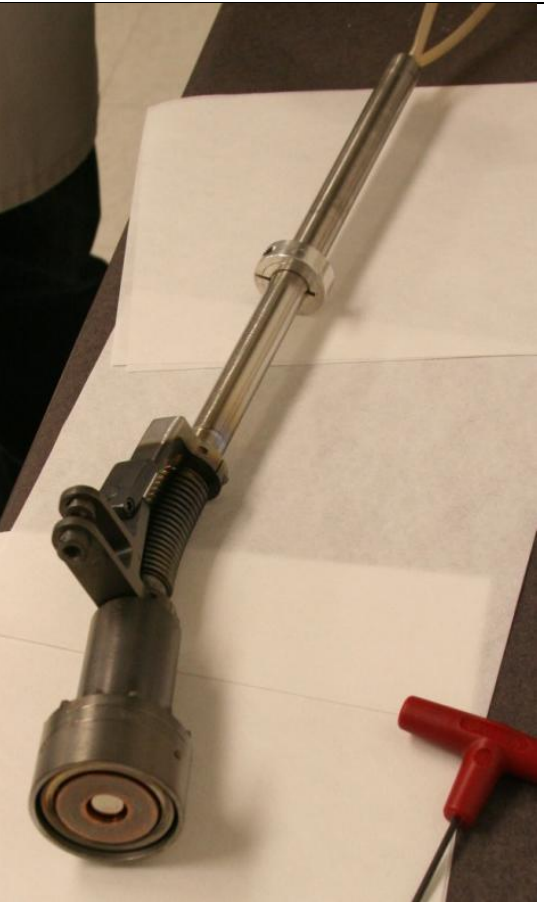

2. Remove the collar around the magnet. Mark the tops of the magnets for a back up because the correct direction of the magnets is necessary. Be careful with all metal parts because these magnets are strong. 
3. Remove the large ring magnet with the modified red handled allen wrench. It may require the use of another screwdriver to remove the magnet.

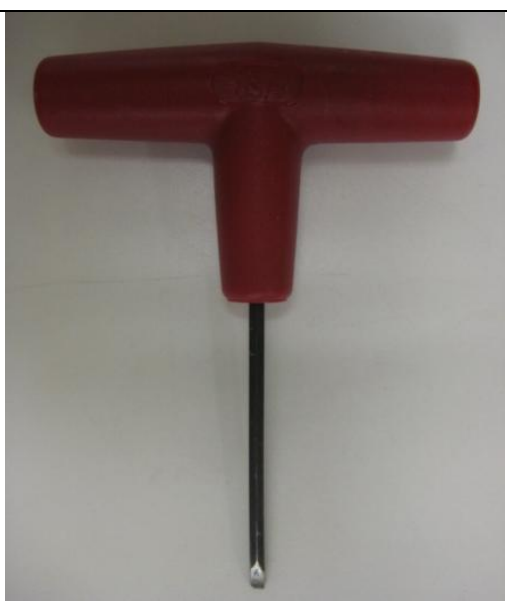

4. To remove the center magnet use the designated plate and place it on the magnet. Insert the red handled tool into the side of the gun to separate the magnet. The magnet is in contact with a ball bearing. The tool is used to move the bearing away from the magnet. Pull the plate off while using the tool and the magnet should come off with the plate.

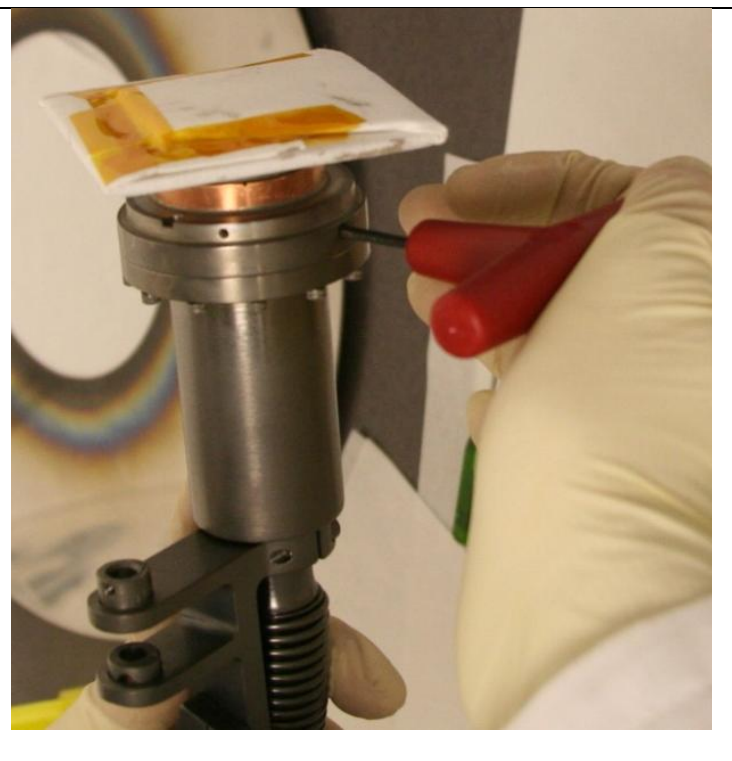


5. At this time it is a good idea to check the condition of the rest of the gun.

Remove the gun sheath. Use a cross pattern to remove and tighten these screws. Don't tighten or loosen any of the screws all at once. These screws are prone to stripping. Check the electrical connection, the condition of the waterlines, and the seal condition.

Reassemble sheath to the gun when done.

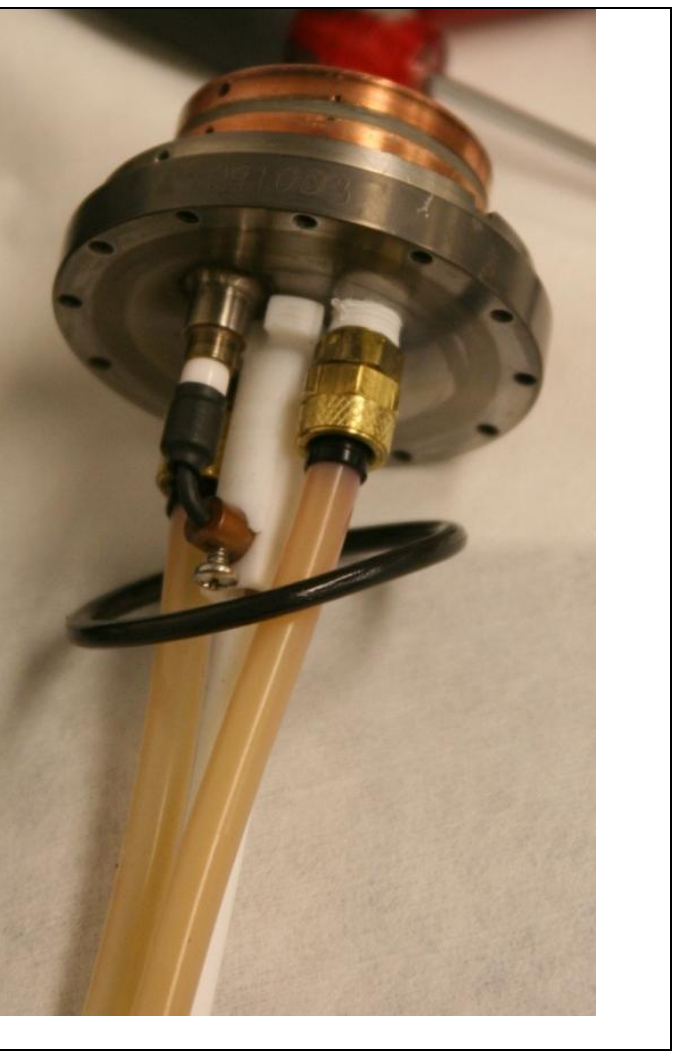

6. Place in the new magnets. Make sure the magnets are in the correct orientation. Use the older magnets to determine the polar direction. Remember opposites attract. Be careful with these magnets, they are very strong. It you get fingers in between them it could hurt.

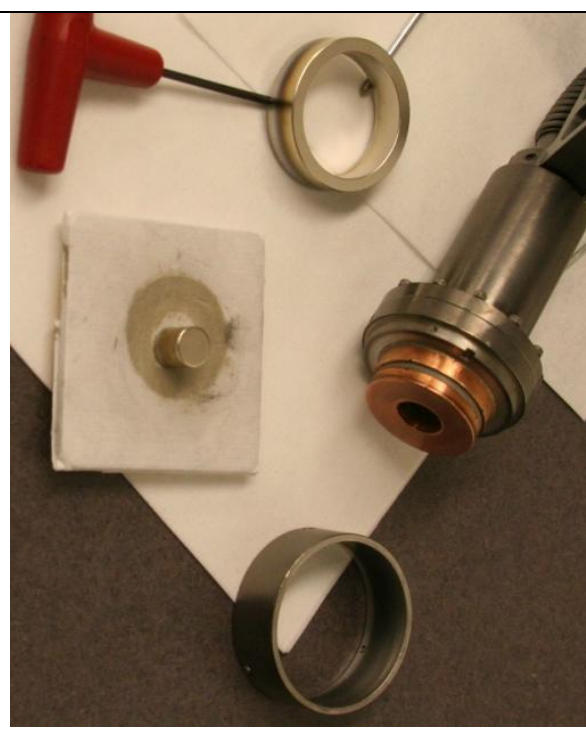

7. Reassemble the guns and put back the guns 


\section{Trouble Shooting}

Chiller flow

Reduced water flow

Flush entire chiller system and clean out lines with high-pressure water from in the chase. Refill the system with distilled water and algaecide.

Heater

Heater will not heat

Possibly blown fuse. Fuse is located in the Black box under the chamber.

Sputtering

Plasma will not ignite

A symptom of a gun component grounding out is the amperage will go up to about 6 and the voltage will be very low. If this happens, turn of guns IMMEDIATELY and find the short.

The DC power connection to the guns may have a bad connection and need to be resoldered.

If backing to the target is not screwed in, the backer can fall off and short the gun. Solution ONLY USE TARGETS WITH SCREWED BACKERS.

Argon flow or pressure drop

Check all argon lines and valves

Master gun power will not turn on

Check all doors are closed

Plasma not stable

Increase the Argon pressure. If this fixes problem the magnets may need to be replaced. 